\title{
Effect of UVB and temperature on the invasive algae Undaria pinnatifida
}

by

Fernanda Piraud Monsalve

\author{
A thesis \\ submitted to the Victoria University of Wellington \\ in fulfilment of the requirements for the degree of \\ Doctor of Philosophy \\ in Marine Biology
}

2015 


\section{Abstract}

The introduction of non-indigenous species and environmental changes are both important threats to marine ecosystems. Environmental changes occur simultaneously and might impact marine organisms synergically or antagonistly. The success of invasive species has been attributed in part to their greater capacity to acclimate to changing conditions. However, the effect of environmental factors on marine invasive species has been little studied. This thesis studied the tolerance of different life stages of the invasive brown seaweed Undaria pinnatifida to UVB and temperature. Also, the possible interactive effect of an increase of temperature and UVB on $U$. pinnatifida was evaluated.

The tolerance of motile zoospores $U$. pinnatifida to increasing UVB irradiances was studied in laboratory experiments, and a strong negative effect of UVB on motile zoospores of $U$. pinnatifida was observed. However, zoospores can recover from UVB stress and the degree of recovery depended on UVB irradiances and exposure time. Their ability to recover could increase the opportunity of zoospores to survive and succeed in the invasion process and shows that $U$. pinnatifida can survive after UVB stress when environmental conditions improve.

The effect of light treatments combined with temperature was also investigated in early life stages of $U$. pinnatifida. Both treatments affected early life stages independently. Early life stages were particularly sensitive to UVB; more so than the other light treatments and temperature. The tolerance of early life stages to a wide range of light and temperature conditions might allow this species to maintain viable populations where they already exist, but also might permit it to invade other areas if predicted environmental changes occur in the future.

The effect of consecutive exposures to PAR and UV treatments at different temperatures on sporophytes of $U$. pinnatifida and the possible photoprotective role of phlorotannins were investigated. There was an interactive effect of light treatments, temperature during the exposure of sporophytes. Sporophytes were highly sensitive to UVB but not to the other light treatments nor to an increase of water temperature. There was no evidence of induction of phlorotannins by UVB and the other light treatments in $U$. pinnatifida. The sensitivity of sporophytes of $U$. pinnatifida to UVB and the lack of photoprotective role of 
phlorotannins suggests this species might have other strategies for success in the intertidal and might direct its energy mainly to growth and reproduction rather than to photoprotection and repair.

The response of the photosynthetic capacity and phlorotannins content to seasonal variations of light and UVB of $U$. pinnatifida was investigated. A clear seasonal trend in the photosynthetic capacity was observed in sporophytes that were correlated to PAR and UVB irradiances measured in the field. Phlorotannins were variable throughout the sampling period where soluble phlorotannins had seasonal and interannual variation, while there was no clear seasonal variation in cell wall phlorotannins concentration. No correlation between both phlorotannins and PAR and UVB was detected. The response of the photosynthetic apparatus to variations of light illustrates the capacity of this species to acclimate to ambient light conditions. Variation of phlorotannins throughout the year could be attributed to a combination of factors such as grazer and wound healing rather than only to the light conditions.

This research contributed to a better understanding of the tolerance of $U$. pinnatifida to environmental factors. This study showed that the tolerance and response to environmental factors is life stage specific. The major factor affecting $U$. pinnatifida negatively was UVB, while temperature had little impact on this species. The capacity of $U$. pinnatifida to inhabit a wide range of light and temperature conditions permits this species to succeed in coastal ecosystems, and these characteristics could permit this species to succeed under future climate change scenarios. 
Dedicated to my daughter Camila, my Ponchis and my parents Maria Teresa and Jorge 


\section{Acknowledgements}

I am using this opportunity to express my gratitude to everyone who supported me throughout my thesis. I am thankful for their aspiring guidance, invaluably constructive criticism and friendly advice during the project work. I am sincerely grateful to them for sharing their truthful and illuminating views on a number of issues related to the project.

Firstly, I would like to thank to my family especially Alfonso or Ponchis for all his support, understanding and patience during this long stressful process. Also I would like to thank my daughter Camila who has been my light, my strength and my inspiration to keep going.

I am very grateful to my supervisor Ken Ryan for his advice, feedback and unlimited support during this process and I would like to thank him for giving me the opportunity to conduct this research. Thanks to my secondary supervisor Nicole Phillips for all the feedback given.

I would like to thank Poncho, my mother Maria Teresa, Alix for helping me with some field work, which many times were unpleasant due to the changing Wellington weather. Also I would like to thank Agnes, Ursula and Shane for helping me with the statistic issues. To Marcela for her infinite advice during my thesis.

Thanks to Ursula, Agnes Henrrieta, Alix, Cesar and to all VUCEL crowd for the support, feedback and happy times.

I would like to thank the technician Daniel (Snout) and John Daniel and John for all their help and make my life easier during my research.

Also I would like to thank my friends who have support me through this process always giving a positive word when I needed it and always being there.

Thanks to the Faculty of Sciences for the possibility to do my research in this University. Thanks for the MAF Biosecurity for the research permits. 


\section{Table of content}

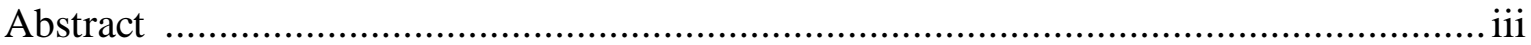

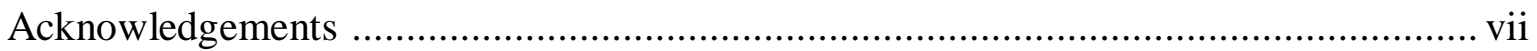

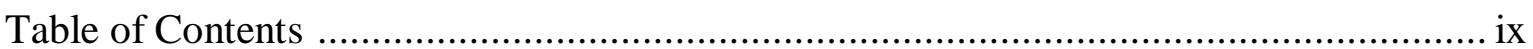

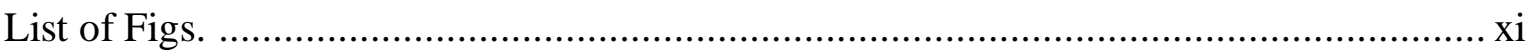

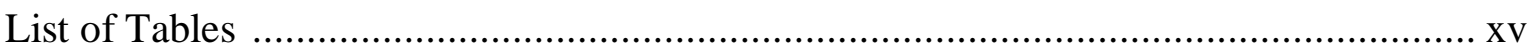

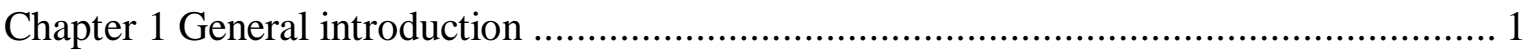

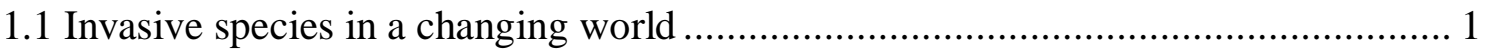

1. 2 Effect of UVB and temperature on macroalgae …............................................ 3

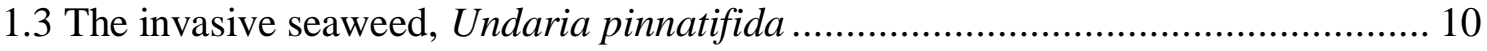

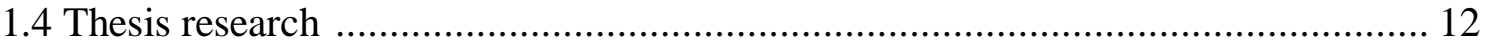

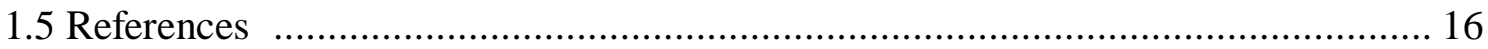

Chapter 2 Effect of UVB on zoospores of $U$. pinnatifida ........................................... 31

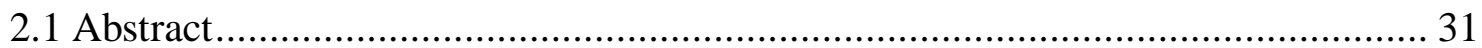

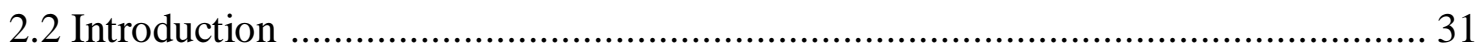

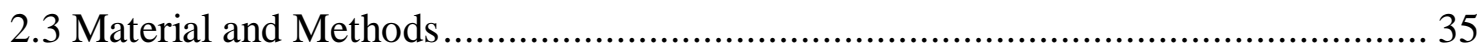

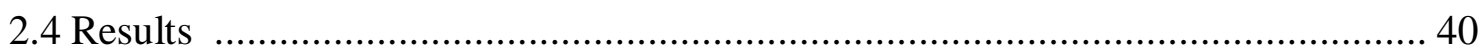

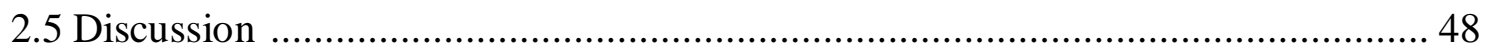

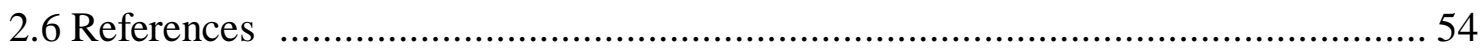

Chapter 3 Effect of UVB and temperature on early life stages of $U$. pinnatifida ............ 61

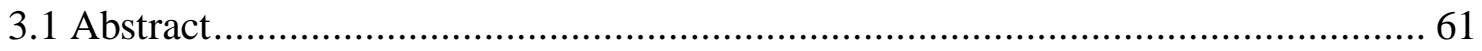

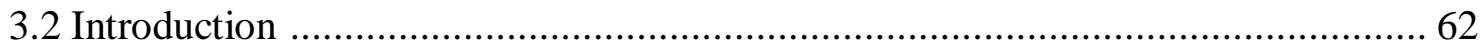

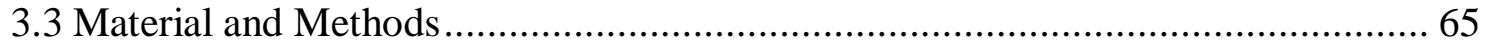

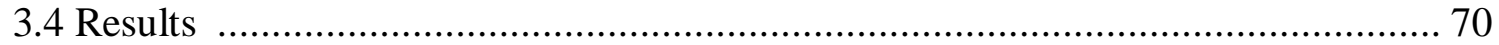

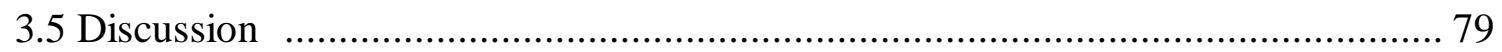

3.6 References 
Chapter 4 Effect of UVB and temperature on sporophytes of the invasive seaweed $U$. pinnatifida.

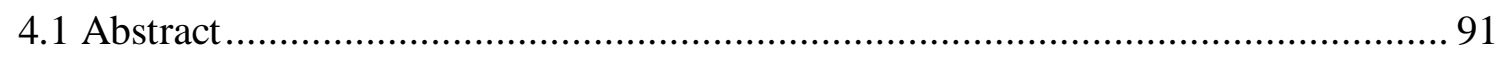

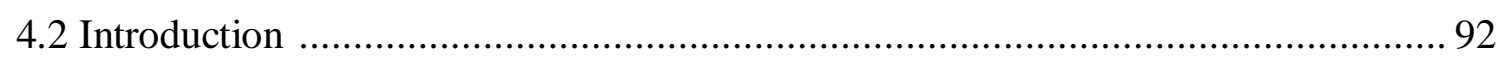

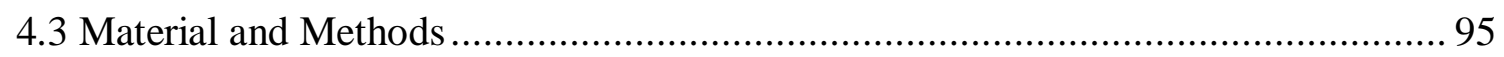

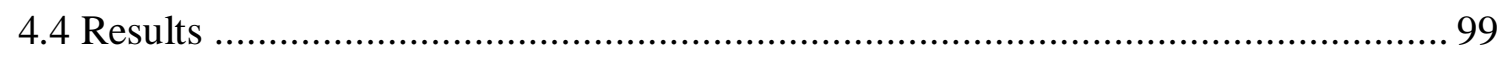

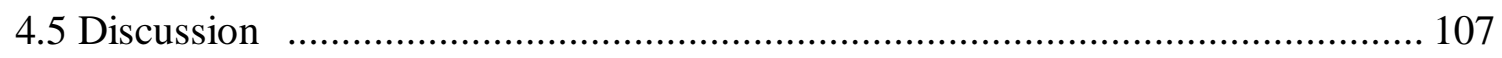

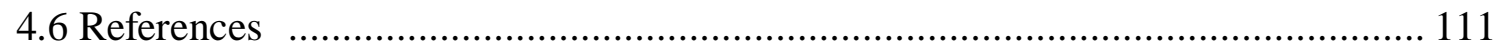

Chapter 5 Seasonal ecophysiology of $U$. pinnatifida ................................................... 119

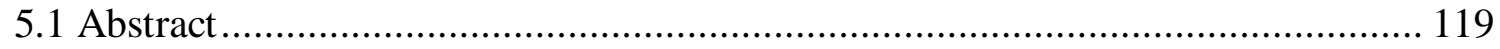

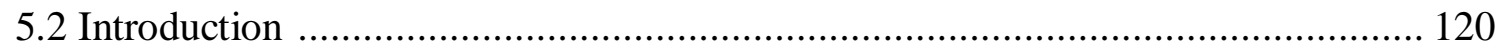

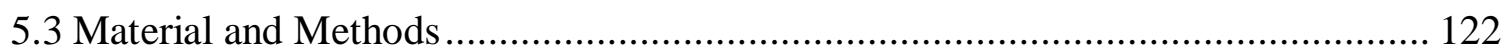

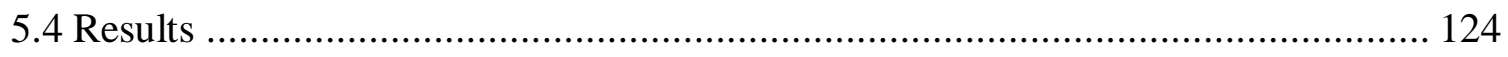

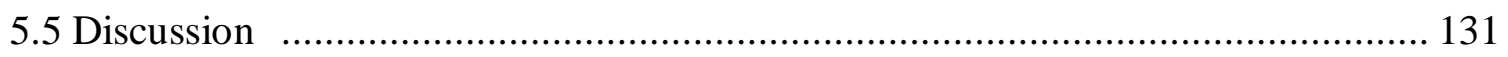

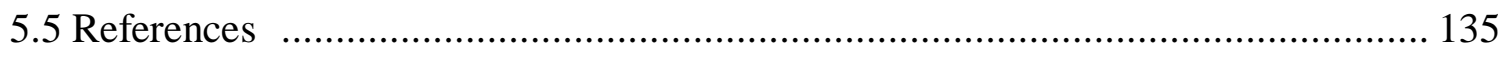

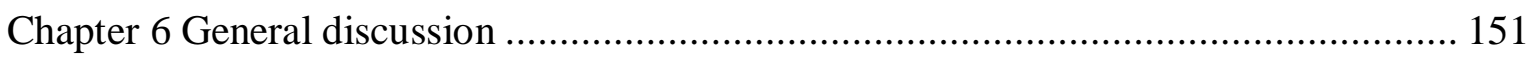

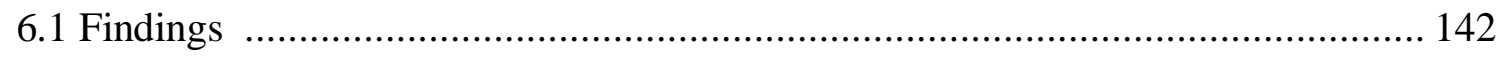

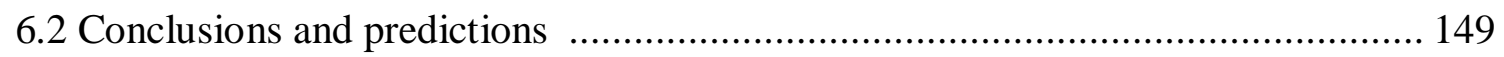

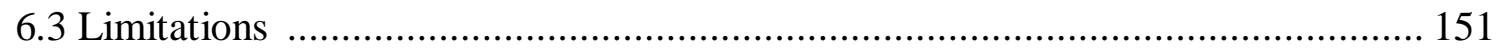

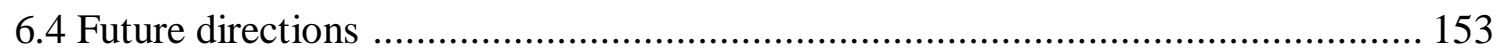

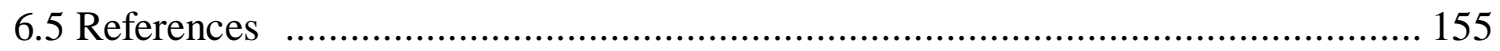




\section{List of figures}

\section{Chapter 1}

Fig. 1.1 Life cycle of Undaria pinnatifida.

\section{Chapter 2}

Fig. 2.1 Experimental set up

Fig. 2.2 Effect of light treatments $(P$ and $P B)$ on maximum quantum yield $\left(F_{v} / F_{m}\right)$ of motile zoospores of $U$. pinnatifida. Zoospores were irradiated for 2 and $4 \mathrm{~h}$ and then left to recover under low light conditions $\left(8 \pm 2 \mu \mathrm{mol}\right.$ photon $\left.\mathrm{m}^{-2} \mathrm{~s}^{-1}\right)$ at $15^{\circ} \mathrm{C}$. PAR was constant in all experiments during exposure $\left(31 \pm 2 \mu \mathrm{mol}\right.$ photon $\left.\mathrm{m}^{-2} \mathrm{~s}^{-1}\right)$ and different UVB irradiances were used. Arrows show the beginning of recovery for each exposure point. Data are means and vertical bars show standard error (SE, $n=4)$

Fig. 2.3 Effect of short term exposure to $P B(a)$ and $P(b)$ on relative quantum yield $\left(\mathrm{rF}_{\mathrm{v}} / \mathrm{F}_{\mathrm{m}}\right)$ of $\mathrm{PB}$ treated zoospores of $U$. pinnatifida exposed for 2 and 4 h to different UVB irradiances. These values are derived from those in Fig 2.1 after normalization to $\mathrm{T}_{0}$ controls. White dots represent the mean of standardized $F_{v} / F_{m}$ of zoospores exposed for $2 h$ to PB and black triangles to zoospores exposed for $4 \mathrm{~h}$. Data are means and vertical bars show standard error (SE, $n=4)$.

Fig. 2.4. Relative quantum yield $\left(\mathrm{rF}_{\mathrm{v}} / \mathrm{F}_{\mathrm{m}}\right)$ of $\mathrm{PB}(\mathrm{a})$ and $\mathrm{P}(\mathrm{b})$ treated zoospores normalised to $\mathrm{T}_{0}$ controls after $4 \mathrm{~h}$ of recovery in zoospores treated with $\mathrm{PB}$ for $2 \mathrm{~h}$ (white dots) and $4 \mathrm{~h}$ (black triangles). Recovery was under low PAR only $\left(8 \pm 2 \mu \mathrm{mol}\right.$ photon $\left.\mathrm{m}^{-2} \mathrm{~s}^{-1}\right)$. Data are the mean and vertical bars show standard errors (SE, $n=4)$

Fig. 2.5 Effect of two different light treatments on germination (\%) of motile zoospores of U. pinnatifida after 2 and 6 days of recovery in dim light conditions $\left(8 \pm 2 \mu \mathrm{mol}\right.$ photon $\mathrm{m}^{-2} \mathrm{~s}^{-}$ $\left.{ }^{1}\right)$ after exposure for 2, 4 and $6 \mathrm{~h}$ to photosynthetically active radiation (P, 35 $22 \mu \mathrm{mol}$ photon $\mathrm{m}^{-2} \mathrm{~s}^{-1}$ ) and UVB irradiances (PB) at $15^{\circ} \mathrm{C}$. UVB irradiances were: $\mathrm{a}-\mathrm{b}, 0.25 \mathrm{Wm}^{-2}$; cd, $0.50 \mathrm{Wm}^{-2}$ and e-f, $0.75 \mathrm{Wm}^{-2}$. Data are mean and vertical bars show standard deviation $(\mathrm{SD}, n=3)$ 
Fig. 2.6 Effect of two different light treatments in length of germination tube of motile zoospores of $U$. pinnatifida in day 2 and 6 of recovery in dim light conditions ( $8 \pm 2 \mu \mathrm{mol}$ photon $\mathrm{m}^{-2} \mathrm{~s}^{-1}$ ) after exposure for 2,4 and $6 \mathrm{~h}$ to photosynthetically active radiation (P, 35 \pm 2 $\mu \mathrm{mol}$ photon $\mathrm{m}^{-2} \mathrm{~s}^{-1}$ ) and UVB irradiances (PB) at $15^{\circ} \mathrm{C}$. UVB irradiances were: $\mathrm{a}-\mathrm{b}$, $0.25 \mathrm{Wm}^{-2}$; c-d, $0.50 \mathrm{Wm}^{-2}$ and e-f $0.75 \mathrm{Wm}^{-2}$. Data are mean and vertical bars show standard deviation $(\mathrm{SD}, n=3)$

Fig 2.7 Effect of different UVB irradiances in DNA content measured as mean fluorescence intensity (MFI) of motile zoospores of $U$. pinnatifida at $15^{\circ} \mathrm{C}$. Data were standardized to controls (0h). Vertical bars show standard error (SE, $n=3$ ). Data from the lowest UVB irradiance $\left(0.25 \mathrm{Wm}^{-2}\right)$ at $2 \mathrm{~h}$ of exposure are missing.

\section{Chapter 3}

Fig. 3.1 Effect of light treatment (P, PA and PAB) at different temperatures (15, 18 and 21 $\left.{ }^{\circ} \mathrm{C}\right)$ on maximum quantum yield $\left(\mathrm{F}_{\mathrm{v}} / \mathrm{F}_{\mathrm{m}}\right)$ of motile zoospores of $U$. pinnatifida. Cell were dark adapted for $10 \mathrm{~min}$. (dark grey background) then they were allowed to acclimate in low light $\left(35 \pm 2 \mu \mathrm{mol}\right.$ photon $\mathrm{m}^{-2} \mathrm{~s}^{-1}$ ) for $3 \mathrm{~h}$ (light grey background) and then exposed to light treatments for $3 \mathrm{~h}$ (white background). Recovery in low light $\left(35 \pm 2 \mu \mathrm{mol}\right.$ photon $\left.\mathrm{m}^{-2} \mathrm{~s}^{-1}\right)$ for 4h (light grey background), and then left in dark conditions for 14h (dark grey background). Vertical bars show standard error (SE, $n=3$ )

Fig. 3.2 Photosynthetic characteristics based on RLCs curves in zoospores of $U$. pinnatifida after a period of temperature acclimation (3h) and after exposure to P, PA and PAB for $6 \mathrm{~h}$ at different temperature $\left(15-18-21^{\circ} \mathrm{C}\right)$. a) $\mathrm{rETR}_{\max }$, maximal electron transport rate ( $\mu \mathrm{mol}$ photons $\left.\mathrm{m}^{-2} \mathrm{~s}^{-1}\right)$; b) alpha $(\alpha)$, c) photosynthetic efficiency measured by the initial slope of the RLCs curve; $E_{k}$, the saturating irradiance for photosynthesis $\left(\mu\right.$ mol photon $\left.{ }^{-2} \mathrm{~s}^{-1}\right)$. Mean values of $\mathrm{rETR}_{\max }, \alpha$ and $\mathrm{E}_{\mathrm{k}} \pm$ standard error (SE, $n=3)$

Fig. 3.3 Effect of light treatments (P, PA and $\mathrm{PAB})$ on the density of settled zoospores of $U$. pinnatifida at different temperatures $\left(15,18,21^{\circ} \mathrm{C}\right)$. Zoospores were left in low light conditions $\left(35 \pm 2 \mu \mathrm{mol}\right.$ photon $\left.\mathrm{m}^{-2} \mathrm{~s}^{-1}\right)$ after exposure to light treatments for $3 \mathrm{~h}$ and then in dark conditions for $14 \mathrm{~h}$. Vertical bars show standard error (SE, $n=4$ ) 
Fig. 3.4 Germination (\%) of zoospores exposed to light treatments (P, PA and PAB) at different temperatures $\left(15,18,21^{\circ} \mathrm{C}\right), 2$ days after exposure. Zoospores were left in recovery with a photoperiod of $10 \mathrm{~h}$ of low light $\left(35 \pm 2 \mu \mathrm{mol}\right.$ photon $\left.\mathrm{m}^{-2} \mathrm{~s}^{-1}\right)$ and $14 \mathrm{~h}$ of dark. Vertical bars show standard error (SE, $n=4)$

Fig. 3.5 Effect of light treatments (P, PA and PAB) at different temperatures $\left(15,18,21^{\circ} \mathrm{C}\right)$ on the mean length $(\mu \mathrm{m})$ of the germination tube of zoospores of $U$. pinnatifida. The germination tube length was measured 2 days after exposure. Zoospores were left in recovery with a photoperiod of $10 \mathrm{~h}$ of low light $\left(35 \pm 2 \mu \mathrm{mol}\right.$ photon $\left.\mathrm{m}^{-2} \mathrm{~s}^{-1}\right)$ and $14 \mathrm{~h}$ of dark. Vertical bars show standard error (SE, $n=4)$.

Fig. 3.6 Effect of light treatments (P, PA and PAB) at different temperatures $\left(15,18,21^{\circ} \mathrm{C}\right)$ on the development of zoospores to gametophyte stage. Zoospores were treated with light treatments daily for $1 \mathrm{~h}$ and then left for $9 \mathrm{~h}$ in low light conditions $\left(35 \pm 2 \mu \mathrm{mol}\right.$ photon $\mathrm{m}^{-2} \mathrm{~s}^{-}$ $\left.{ }^{1}\right)$ followed by $14 \mathrm{~h}$ darkness for 12 days. Vertical bars show standard error (SE, $n=4)$

\section{Chapter 4}

Fig. 4.1 Effect of light treatments $(P, P A$ and $P B)$ on maximum quantum yield $\left(F_{v} / F_{m}\right)$ of sporophytes of $U$. pinnatifida. Discs were left for $2 \mathrm{~h}$ in low light (light grey background) and then exposed to light treatments for $8 \mathrm{~h}$ (white background) followed by $2 \mathrm{~h}$ of low light (light grey background) and $14 \mathrm{~h}$ in dark (dark grey background) at $15^{\circ} \mathrm{C}$. This procedure was repeated three times. Discs were dark adapted to obtain $\mathrm{F}_{\mathrm{v}} / \mathrm{F}_{\mathrm{m}}$. Data are means and vertical bars show standard error (SE, $n=4)$

Fig. 4.2 Effect of light treatments (P, PA and PB) on rETRmax of sporophytes of $U$. pinnatifida. Discs were left for $2 \mathrm{~h}$ in low light (light grey background) and then exposed to light treatments for $8 \mathrm{~h}$ (white background) followed by $2 \mathrm{~h}$ of low light (light grey background) and $14 \mathrm{~h}$ in the dark (dark grey background) at $15^{\circ} \mathrm{C}$. This procedure was repeated three times. Data are means and vertical bars show standard error (SE, $n=4) \ldots$.

Fig. 4.3 Effect of light treatments (P, PA and PB) on non-photochemical quenching (NPQ) of sporophytes of $U$. pinnatifida. Discs were left for $2 \mathrm{~h}$ in low light (light grey background) and then exposed to light treatments for $8 \mathrm{~h}$ (white background) followed by $2 \mathrm{~h}$ of low light (light grey background) and $14 \mathrm{~h}$ in dark (dark grey background) at $15^{\circ} \mathrm{C}$. This procedure was repeated three times. Data are means and vertical bars show standard error (SE, 
$n=4)$.

Fig. 4.4 Effect of light treatments (P, PA and PB) on the concentration of soluble SPs of sporophytes of $U$. pinnatifida. Discs were left for $2 \mathrm{~h}$ in low light and then exposed to light treatments for $8 \mathrm{~h}$ followed by $2 \mathrm{~h}$ of low light and $14 \mathrm{~h}$ in dark at $15^{\circ} \mathrm{C}$. Data are means and vertical bars show standard error (SE, $n=4)$

Fig. 4.5 Effect of light treatments (P, PA and PB) at different temperatures $(18,20$ and 22 $\left.{ }^{\circ} \mathrm{C}\right)$ on the maximum quantum yield $\left(\mathrm{F}_{\mathrm{v}} / \mathrm{F}_{\mathrm{m}}\right)$ of sporophytes of $U$. pinnatifida. Discs were left for temperature acclimation for $3 \mathrm{~h}$ in low light (light grey background) and then exposed to light treatments for $10 \mathrm{~h}$ followed by $14 \mathrm{~h}$ in dark (dark grey background) at $15^{\circ} \mathrm{C}$. Data are means and vertical bars show standard error (SE, $\left.n=4\right)$

Fig. 4.6 SP concentration after exposure to light treatments (P, PA and $\mathrm{PB})$ at different temperatures in sporophytes of $U$. pinnatifida. The initial reading corresponds to the SP concentration after temperature acclimation. Discs were then exposed to light treatments for $10 \mathrm{~h}$ followed by $14 \mathrm{~h}$ in dark; this procedure was repeated two times. Data are means and vertical bars show standard error (SE, $n=4)$

\section{Chapter 5}

Fig. 5.1 Seasonal variation in UVB and PAR irradiances at the intertidal zone of Breaker Bay, Wellington. Superficial irradiances were measured at $10 \mathrm{am}$ every month. Data points represent the mean $\pm \mathrm{SE}(\mathrm{n}=4)$

Fig. 5.2 Seasonal variation in the effective quantum yield $\left(\mathrm{F}_{\mathrm{v}} / \mathrm{F}_{\mathrm{m}}\right)$ of sporophytes of $U$. pinnatifida at Breaker Bay, Wellington. Data points represent the mean of each individual \pm SE ( $n=9$, except June, July and February with 2, 8 and 7 individuals respectively). Dark grey background represents Winter months, clear grey background Autumn and Spring months and background Summer months

Fig. 5.3 Cluster analysis of the effective quantum yield ( $\left.\phi_{\mathrm{PSII}}\right)$ of sporophytes of $U$. pinnatifida between August 2011 and February 2013

Fig. 5.4 Pearson correlations between PAR (a), UVB (b) and the effective quantum yield $\left(\phi_{\mathrm{PII}}\right)$ of sporophytes of $U$. pinnatifida measured as effective quantum yield ( $\left.\phi_{\mathrm{PSII}}\right)$. Data points represent the mean of each individual $(n=9$, except those months with less 
individuals).

Fig. 5.5 Seasonal variation in soluble phlorotannins (SPs), cell wall phlorotannins (CWPs) and total phlorotannins $(\mathrm{Pt})$ of sporophytes of $U$. pinnatifida at Breaker Bay, Wellington. Data points represent the mean $\pm \mathrm{SE}$ ( $\mathrm{n}=5$, except June with 2 individuals).

Fig. 5.6 Cluster analysis of the phlorotannins concentration in sporophytes of $U$. pinnatifida between September 2011 and February 2013. a) represents soluble phlorotannins and b) cell-wall phlorotannins

Fig. 5.7 Pearson correlations between $P A R / U V B$ and total phlorotannins, soluble phlorotannins (SPs) and cell-wall phlorotannins (CWPs) of U. pinnatifida. Data points represent the mean of each individual $(n=5)$

Fig. 5.8 Pearson correlations between soluble phlorotannins (SPs) and cell-wall phlorotannins (CWPs), of U. pinnatifida.

\section{List of tables}

\section{Chapter 2}

Table 2.1 Experimental irradiances in the different experiments

\section{Chapter 3}

Table. 3.1 Experimental irradiances in the experiments

Table 3.2 Multifactorial analysis assessed with Linear mixed effects models, for differences of light treatments, time and temperature on the photosynthetic parameters of zoospores of $U$. pinnatifida. Bold letters shows significance. 
Table 3.3 Two-factor analysis assessed with General Lineal Model (GLM) for differences of light treatments and temperature of zoospores of $U$. pinnatifida on settlement, germination and length of germination tube. Bold letters shows significance. Settlement and gametophytes were analysed with a Poisson distribution, germination with a Binomial distribution and length of germination tube with Gamma distribution

Table 3.4 Summary of the effect of light treatment, temperature and their interactions in the different parameters evaluated

\section{Chapter 4}

Table. 4.1 Experimental irradiances in the experiments

Table 4.2 Permutational multivariate analysis (PERMANOVA) for the photosynthetic variables and phlorotannins concentration comparing the effect of light treatments (three levels) and exposure/recovery (three levels) of sporophytes of $U$. pinnatifida. The analysis was based on similarity matrices calculated using Bray-Curtis coefficients. Bold letters shows significance. NP: Number of permutations.

Table 4.3 Permutational multivariate analysis (PERMANOVA) for $F_{v} / F_{m}$ and soluble phlorotannins comparing the effect of light treatments (three levels), temperature (three levels) and exposure/recovery time (three levels each) of sporophytes of $U$. pinnatifida. The analysis was based on similarity matrices calculated using Bray-Curtis coefficients. Bold letters shows significance. NP: Number of permutations 


\section{Chapter 1 \\ General introduction}

\subsection{Invasive species in a changing world}

The introduction of non-indigenous species is a human-mediated threat for coastal ecosystems (Vitouske et al. 1997, Thornber et al. 2004, Schaffelke et al. 2007a). These often compete with native species (Gurevitch\& Padilla 2004, Thomsen \& McGlathery 2007, Sorte et al. 2010), alter nursery habitat for other organisms and reduce light penetration into the water column (Thomsen \& McGlathery 2007). In addition, non-indigenous species cause important economic losses for countries due primarily to control and eradication costs (Pimentel et al. 2005, Cook et al. 2007). Moreover, the possible impact of introduced species might be exacerbated by other human-mediated disturbances such as global warming, provoking a greater impact (Schaffelke \& Hewitt 2007b).

Compared to terrestrial ecosystems, less is known about the introductions of non-indigenous species in marine ecosystems (Grosholz 2002; Graham \& Bayha 2007) and only in the last two decades has scientific interest focussed on the possible effects of non-indigenous species in coastal areas (Forrest 2007). Introductions of non-indigenous marine species have increased considerably in the last 30 years (Boudouresque \& Verlaque 2002, Schaffelke et al. 2007a) and this has been attributed to increasing trans-oceanic movement of vessels (Waters et al. 2004). Of course, it should also be noted that there has also been an increase of survey effort on species introductions (Hewitt 2003, Schaffelke et al. 2007a), and this may account for some of these apparent increases.

Successful introductions of non-indigenous species are often linked to environmental disturbance (Valentine \& Johnson 2003). Disturbance is being more frequently linked to human interference due to over-harvesting, organic enrichment, pollution, and climate change (Hughes et al. 2005, Occhipinti-Ambrogi \& Savini 2003). Changes in environmental 
conditions (IPCC 2013) might enhance introductions of new invasive species. Temperatures are expected to increase during the 21 st century with a rise in the mean global temperature of 0.2-1.8 ${ }^{\circ} \mathrm{C}$ towards 2050 (IPCC 2013). Other predicted changes include an increase of precipitation in tropical areas but a decrease in the subtropics; and a decrease of snow cover and sea ice, contributing to a rise in sea level that is expected to be $15 \mathrm{~cm}$ by 2050 and $30 \mathrm{~cm}$ by the end of the century. Wind intensities and storm precipitation in future tropical cyclones are both expected to increase (Trenberth 2005, IPCC 2013).

However, there is a lack of knowledge of the effect of climate change on invasive species and opinions are contradictory. Some authors have suggested that climate change might favour introductions (Dukes \& Mooney 1999, Vilà et al. 2007) due to an alteration in population dynamics and in the structure and composition of communities (Walther et al. 2002, Parmesan 2006), while others suggest that the impact of some invasive species might diminish under climate change (Hellmann et al. 2008).

The success of invasive species in a changing world depends on their capacity to acclimate and adapt to environmental changes. The success of invasive species has been attributed in part to their greater acclimation capacity than native species (Baruch \& Goldstein 1999, Yamashita et al. 2000, Yamashita et al. 2002). For example in terrestrial environments, the introduced tree Bischofia javanica in the Bonin Islands has more efficient physiological acclimation to variation in light than native species (Yamashita et al. 2000), and this allows it to proliferate more readily than competing species. For marine invasive organisms there is less knowledge; the success of the invasive green seaweed Caulerpa racemosa var. occidentalis is associated with its high physiological plasticity to different microhabitats and with temporal variation of abiotic factors (Raniello et al. 2004). There are few studies of physiological acclimation and tolerance of invasive species in general to environmental changes even though such studies can help to predict the effect of those changes (Somero 2010). Most of these studies have been done in terrestrial organisms and there is a lack of knowledge in marine organisms. 


\subsection{Effect of UVB and temperature on macroalgae}

\section{UVB and temperature on the Earth}

Solar radiation is essential for life on Earth and its spectrum is composed of infrared radiation, visible light (PAR) and UV radiation. UV radiation is divided in three subgroups: UVA (315400nm), UVB (280-315nm) and UVC (200-280nm). About 7.3\%, 25.5\% and 89.3\% of solar UVB, UVA and PAR respectively, reaches the atmosphere; while UVC is completely absorbed before it reaches the Earth surface (Häder et al. 2007).

UV radiation varies geographically (Häder et al. 2007) and depends on factors such as cloudiness, seasonality, angle, ozone layer thickness, aerosol concentration, altitude and latitude (Adam \& Shazly, 2007, Häder et al. 2007, Cui et al. 2008, Bais et al. 2015). UV levels are highest near the equator (Jablonski \& Chaplin 2010) and generally, decrease as latitude increases as a consequence of the daily noon solar elevation angles and increase in the amount of ozone (Herman, 2010). UV also varies geographically with higher UV irradiances at the same latitude in the south hemisphere than in the north hemisphere (Herman, 2010). Lauder, New Zealand $\left(45^{\circ} \mathrm{S}\right)$ registers $\sim 40 \%$ higher UV irradiances than Hohenpeissenberg, Germany $\left(45^{\circ} \mathrm{N}\right)$ mainly in summer, due to a larger ozone column in Europe than New Zealand and differences in aerosol extinction (McKenzie et al. 2003). Also New Zealand registers higher UV irradiances than in USA at the same latitudes during summer due to Lauder presents lower ozone amounts and is closer between the Earth and Sun (McKenzie et al. 2006). However, similar UV irradiances are registered at similar latitudes between New Zealand and Argentina (Härder et al. 2007) and Chile (Huovinen et al. 2006).

An increase in UVB radiation reaching the Earth's surface was reported in the 1980's as a consequence of ozone depletion (Madronich et al. 1998). This increase of UVB caused great concern for the possible effects on organisms (Vincent \& Neale 2000, Vincent et al. 2000, Cadet et al. 2005), this will be discussed later in this chapter. The observed decline of ozone differed between locations with small changes in the equator and greatest changes toward Polar Regions mainly in the south hemisphere (Weatherhead \& Andersen 2006). Data from 1979 to 2008 shows an increase in UVB up to 1998 due to a decrease in the amount of ozone; but after this period UV irradiances remained more or less constant (Herman, 2010). Although it is projected that UVB will be lower for the $21^{\text {st }}$ century at mid and low latitudes still there is 
uncertainty regarding UVB levels for the future since UVB is not only dependent of ozone but also on other factors such as air pollutants, aerosol and cloud cover(McKenzie et al. 2011, Bais et al. 2015). Thus an increase of UVB is expected to happen in big polluted areas of the North Hemisphere due to improvements in the air quality with a reduction in air pollutants and aerosol concentration; but a decrease in areas with higher cloud cover such as higher latitudes (Bais et al. 2015).

Seawater temperature varies geographically in coastal areas (Barnes et al. 2006, Deser et al. 2010). In tropical areas, seawater temperature fluctuates seasonally about $18-40{ }^{\circ} \mathrm{C}$ (Stuart et al. 2006); in Atlantic waters the median temperatures varies from $7-10{ }^{\circ} \mathrm{C}$ before the entrance to the Nordic seas and at the Arctic Ocean reaches temperature close to $0{ }^{\circ} \mathrm{C}$ (BeszczynskaMöller et al. 2010). In the Peruvian and Chilean coast in the South Pacific Ocean, seawater temperature varies from $6-22{ }^{\circ} \mathrm{C}$ decreasing further south (Kaiser et al. 2005), while in New Zealand sea water temperatures varies from $10-20^{\circ} \mathrm{C}$ (Chiswell 1994).

In the last 50 years the global surface temperature has increased by $\sim 0.7^{\circ} \mathrm{C}$ (IPCC 2013). The sea surface temperature (SST) has increase $\sim 0.59{ }^{\circ} \mathrm{C}$ since 1872 (Roemmich et al. 2012) as a consequence of an increase in the greenhouse gases (Vecchi \& Soden, 2007, Xie et al 2010). Warming is highest in the Equator and there has been a greater increase in the Northern Hemisphere than in the Southern Hemisphere (Vecchi \& Soden, 2007, Roemmich et al. 2012). This difference between hemispheres is due to ice albedo feedback that is the reflection of solar light by ice, snow areas in the North Hemisphere and differences in poleward energy transport between Hemispheres (Xie et al 2010). The expected increase of surface water temperature to the end of the $21^{\text {st }}$ is about 1 to $3{ }^{\circ} \mathrm{C}$ (IPCC 2013). It is expected a faster increase of temperature in Arctic regions $\left(\sim 2-3{ }^{\circ} \mathrm{C}\right)$ than in the South Hemisphere $\left(\sim 1-1.5^{\circ} \mathrm{C}\right)$ (IPPC 2013 Synthesis report). In New Zealand temperature has increase $0.9{ }^{\circ} \mathrm{C}$ since 1900 and is expected to increase another $0.8^{\circ} \mathrm{C}$ above the average temperature of 1986-2005 (IPCC 2013).

\section{Effect of $U V B$ and temperature on seaweeds}

In marine ecosystems, accelerating environmental changes are expected to disturb life (Fredersdorf et al. 2009) by altering the physical and chemical properties of environments 
(Harley et al. 2006). For example, an increase of sea surface temperature might have a negative impact on marine organisms by directly affecting physiological processes (Harley et al.2006; Galbraith et al. 2002), or indirectly impacting ocean dynamics or species interactions (Rilov \& Treves 2010). The thermal expansion of oceans is likely to modify the geography of coastal areas (Scavia et al.2002), change the distribution of species (Harley et al. 2006) and reduce intertidal habitats for some organisms (Galbraith et al. 2002). In addition, changes in atmospheric circulation influencing precipitation patterns and wind events might modify salinity, nutrients and pollutant concentration and increase turbidity in coastal water (Harley et al. 2006). This is likely to affect intertidal and shallow systems that are more vulnerable to hydrodynamic disturbance (Harley et al. 2006) such as reef communities (Gardner et al. 2005). An increase in $\mathrm{CO}_{2}$ storage in oceans produces a reduction of $\mathrm{pH}$ (Feely et al. 2004, Caldeira \& Wickett 2005, Turley et al. 2006, Doney et al. 2009) that might affect physiological processes in marine organisms (Pörtner et al. 2004) such as calcification rates (Feely et al. 2004). Variation in the transmission of UVB to the earth's surface due to ozone depletion (Kerr \& McElroy 1993; Madronich et al. 1998) might also provoke negative effects on ecosystems because UVB radiation negatively affects biological and chemical processes (Caldwell et al. 2007, Zepp et al. 2011).

Macroalgae are ecologically important because they are the most significant primary producers in coastal areas, and provide food resources and shelter for many other marine organisms (Coehlo et al. 2000, Dean \& Hurd 2007). Environmental conditions directly affect the development and growth (Lobban 1994) of macroalgae but also influence physiological processes (Coehlo et al. 2000) and distribution (Lobban 1994). Macroalgae are vulnerable to changes in the physical, chemical and biological properties of the marine environment and therefore, they are vulnerable to climate change (Harley et al. 2012).

UVB varies daily and seasonally (Huovinen et al. 2004). For seaweeds, UVB is an important stress factor and it may play an important role in the pattern of zonation in the water column (Bischof et al. 1998, Wiencke et al. 2000, 2006, Roleda et al. 2005, 2006, Huovinen \& Gomez 2011, 2013). Thus, species inhabiting deeper areas may be more susceptible to UVB than those that inhabit shallower areas where they are exposed to higher levels of solar radiation (Pakker et al.2000, Roleda et al.2005, 2006). 
UVB can negatively affect individuals, and its effect on natural environments varies considerably and depends greatly on the dose (Coelho et al. 2000; Dattilo et al. 2005; Bancroft et al. 2007). The UVB dose depends on the optical characteristics of the water body (Bancroft et al 2007), such as the concentration and characteristics of dissolved organic matter (DOM) and other suspended particles (Hargreaves 2003) and the seasonality of UVB radiation. UVB produces various negative effects on macroalgae at the cellular level, principally affecting DNA and proteins (Vincent et al. 2000). The main photoproducts induced by UVB exposure include cyclobutane-type pyrimidine dimers (CPDs) that cause RNA polymerase to stop during transcription (Wiencke et al. 2000; Vincent et al. 2000, Cadet et al. 2005); photohydrates that have little toxicological effect; and the photoproduct pyrimidine (6-4) pyrimidine that has effects on the genome and cellular function (Vincent et al. 2000).

UVB also affects photosynthetic efficiency (Wiencke et al. 2000; Roleda et al. 2005, Gao \& $\mathrm{Xu}$ 2008) mainly at two levels: firstly, it affects the light dependant reaction of photosynthesis at photosystem II (PSII) and secondly, it affects the light independent reactions of photosynthesis principally degrading Rubisco that is the first enzyme of the reductive pentose phosphate pathway in the Calvin cycle (Vincent et al. 2000, Nishiyama et al. 2006). UVB also induces pigment bleaching (Döhler et al 1995) through direct absorption of UVB. This process occurs through a photosensitizer action where electrons in the pigments are excited to a higher energy level and this energy is transferred to oxygen producing reactive oxygen species (ROS). ROS causes oxidative degradation of pigments and other molecules (Vincent et al. 2000, Lesser 2006).

Temperature is an important factor for macroalgae because it regulates the geographical distribution of seaweeds (Müller et al. 2008) through their individual requirements for reproduction, growth and physiological processes (Lobban 1994, Chohelo et al. 2000). Temperature affects biochemical reactions by affecting molecular structure and activity (Lobban 1994) and it has consequences for photosynthesis, respiration and growth (Lobban 1994). An increase in water temperature is likely to impact organisms directly by affecting these processes (Harley et al. 2006; Galbraith et al. 2002), or indirectly by impacting ocean dynamics and species interactions (Rilov \& Treves 2010) and changing the structure of ecosystems (Stachowicz et al. 2002, Hoegh-Guldberg \& Bruno 2010 ). In addition, an increase of temperature may encourage the spread of warmer adapted species while cold adapted species could decrease in abundance or become extinct (Hellmann et al. 2008). Seaweeds 
living in their upper thermal limit are likely to move to lower latitudes (Steneck et al. 2002). Moreover, an increase of water temperature could facilitate the long-term establishment of non-indigenous species (Rahel \& Olden 2008).

The response of seaweeds to abiotic environmental factors is species-specific and also depends on the life stage (Dring et al. 1996, Roleda et al. 2007). Unicellular stages (spores and gametes) are more susceptible to stressors than multicellular stages (gametophytes and sporophytes), microscopic stages more than macroscopic stages and young stages more than adults (Coelho et al. 2000, Roleda et al. 2005). Environmental stressors at early stages of development may produce lethal and sub-lethal effects that might impact recruitment success and development of communities because they may alter growth rate and the ability to compete with others (Coelho et al. 2000). In juveniles and adults, environmental stressors are in general sub-lethal, and are reflected mainly in a decrease of photosynthetic performance, growth rate, development and reproduction (Coelho et al. 2000).

\section{Mechanism of photoprotection of seaweeds}

Seaweeds are sessile organisms; therefore they cannot avoid environmental stressors. However, these organisms have developed different physiological mechanisms of protection such as acclimation and damage repair (Roy 2000, Zacher et al. 2007), and photochemical and non-photochemical quenching (Vincent et al. 2000, Goss \& Jakob 2010). For example, DNA and proteins are damaged principally by UVB radiation and DNA repair may occur through photoreactivation or nucleotide excision, as well as protein repair (Roy 2000). The excess energy induced in photosystem II by UVB radiation is dissipated by photochemical (photosynthesis) and non-photochemical quenching via fluorescence and heat (Müller et al. 2001, Betterle et al. 2009). Further, the capacity of biosynthesis and accumulation of screening compounds is a clear acclimation process in seaweeds. Thus, the extent of any effects of environmental stressor on seaweeds depends on the ability of each species to acclimate.

Photoprotection refers to mechanisms in plants and algae that prevent photodamage of the photosynthetic apparatus caused by excess light energy (Lavaud et al. 2004, Jahns \& Holzwartg 2012). There are different photoprotective mechanisms in algae such as photoinhibition of photosynthesis (Franklin \& Neale 2002), dissipation of energy via the 
xanthophyll cycle (Goss \& Jakob 2010, Latowski et al. 2011), and production of photoprotective substances (Pavia et al. 1998, Bischof et al. 2007).

Photoinhibition of photosynthesis is the inhibition of photosystem II (PSII) that results in a reduced rate of photosynthesis due an excess of light (Murata et al. 2007, Adams et al. 2013). Under excess light, the photosynthetic quantum yield decreases to protect reaction centres and suppress the production of reactive oxygen species. When the energy pressure decreases the quantum yield recovers rapidly; this process is called dynamic photoinhibition (Hurd et al. 2014). In contrast, when there is photoinactivation of PSII a slower recovery is observed indicating damage; this process is called chronic photoinhibition (Hurd et al. 2014). Chronic photoinhibition occurs mainly when photosynthetic organisms including seaweeds are exposed to the UV component of solar radiation. UVB in particular affects the D1 protein of the PSII (Friso et al. 1994, Babu et al. 1999, Roleda et al. 2004, 2005, 2006, Nishiyam et al. 2011). When D1 is degraded, and its rates of biosynthesis and repair are slower than its degradation, photodamage is produced, and recovery may occur with longer recovery time or may not occur (Melis 1999, Tyystjärvi 2008).

Non-photochemical quenching (NPQ) is the thermal dissipation of excess of energy and it is an important photoprotective mechanism for photosynthetic organisms (Johnson et al. 2009). This process involves the quenching of chlorophyll a (chl a) fluorescence with three components: state transitions (qT), $\Delta \mathrm{pH}$-dependent quenching (qE) and photoinhibition (ql) (Johnson et al. 2009). The major component of NPQ is qE (Maxwell \& Johnson 2000) and requires the formation of $\Delta \mathrm{pH}$, the presence of the PSII antenna subunit and the synthesis of zeaxanthin (Garcia-Mendoza et al. 2012). The synthesis of zeaxanthin occurs during the xanthophyll cycle that is common in vascular plants, green and brown algae (Goss \& Jakob 2010). This cycle protects the photosynthetic apparatus from photodamage due to oxidative stress produced under excess light (Latowski et al. 2011, Jahns \& Holzwarth 2012). The xanthophyll cycle differs with taxonomic groups; although the most common is the violaxanthin cycle, where violaxanthin is converted by de-epoxidation to zeaxanthin with antheraxanthin as intermediate under excess light (Latowski et al. 2011). In brown seaweeds there are two xanthophylls cycles: the violaxanthin cycle and the diadinoxanthin cycle where diadinoxanthin is converted to diatoxanthin when there is an excess of light (Latowski et al. 2011). 
Among the photoprotective substances, the most studied screening compounds in seaweeds are mycosporine-like amino acids (MAAs). These biomolecules absorb in the UVA and UVB range and in macro algae they have been studied principally in Antarctic and cold-temperate Rhodophyta (Bischof et al 2007), but are also found in phytoplankton, dinoflagellates and some cyanobacteria (Carreto \& Carignan 2011). Phaeophyta lack these screening compounds but synthesize phenolic compounds instead (Pavia et al 1998). Phenolic compounds in brown algae are secondary metabolites called phlorotannins (Bischof et al 2007) and are associated with multiple functions such as cell formation, adhesion to surfaces, wound healing, antiherbivory and protection against UVB radiation (Pavia et al 1998; Lüder \& Clayton 2004; Henry \& Van Alstyne 2004).

Phlorotannins absorb mainly in the UVC and part of the UVB ranges and due to this characteristic, they have been catalogued as protective substances against UVB radiation (Pavia et al 1998; Henry \& Van Alstyne, 2004). These macromolecules tend to accumulate principally in the vegetative cells of the cortical layer, suggesting that phlorotannins could respond quickly to stressors such as herbivory, mechanical injury and UVB radiation (Shibata et al. 2004). Bischof et al. (2007) suggested four strategies that qualify these substances as UV-protective substances 1) high tissue concentration of phlorotannins that absorb harmful radiation and prevent cell damage, 2) induction of phlorotannins stimulated by harmful radiation, 3) exudation of phlorotannins into the medium, or 4) inclusion of phlorotannins in cell walls.

The concentration of phlorotannins in tissues is species specific. This is probably due to genetic adaptation to variation in the duration of emersion per tide cycle, which is therefore related to exposure to UVB radiation (Connan et al. 2004). Moreover, phenolic content fluctuates daily in some species, as has been observed in Macrocystis integrifolia after increased solar radiation. Phenolic content also fluctuates with season in this species (Connan et al. 2004) and after exposure to artificial UV radiation (Swanson \& Druehl 2002). While the accumulation of phlorotannins in tissues has been attributed to UVB radiation, Roleda et al. (2006) found that the accumulation of phlorotannins in zoospores is stimulated by UVB, UVA and by photosynthetically active radiation (PAR). Furthermore, these authors observed that phlorotannins are release into the medium, probably as a strategy to minimize the impact of UVB radiation. Recently, Huovinen et al. (2010) found that the concentration of soluble 
phlorotannins decrease in the presence of copper either alone or together with nitrate under both UVA and UVB radiation.

Studies on the effect of environmental changes on organisms have focussed mainly on individual factors and few studies have examined the interactions between several stressors, even though environmental changes occur simultaneously, and they might act in combination or independently (Fredersdorf et al. 2009). The priority for future research now should be to try to understand the interaction of environmental factors in order to understand the real effect on organisms, rather than the study of the effects of individual stressors. Moreover, the few studies that have assessed interactive effects of stressors, have been carried out in native organisms (Alatamirano et al. 2003, Rautenberger \& Bischof. 2006, Sheras \& Ross 2010), and there is a lack of knowledge of their effect on non-indigenous species; even though environmental changes might benefit introduced species (Stachowicz et al. 2002, Walther et al. 2009).

\subsection{The invasive seaweed, Undaria pinnatifida}

Seaweed invasions are an important threat for native ecosystems worldwide (Valentine et al. 2007) because they alter the natural properties of ecosystems and may have negative economic effects for aquaculture (e.g. fouling on nets, ropes, boats, etc.). The establishment and spread of invasive species have both been associated with disturbances of the environment (Valentine \& Johnson 2003), and the success of these species has been related principally to their high growth, and regenerative and dispersal capacity (Rejmánek \& Richardson 1996, Nyberg \& Wallentinus 2005). However, high physiological acclimation capacity of these species to habitat and seasonal variations may play an important role in invasion success (Raniello et al. 2004, 2006, Garcia-Sanchez et al. 2012).

Undaria pinnatifida (Harvey) Suringar is a brown seaweed (Phaeophyceae Laminariales) endemic to Japan, Korea and China that has been introduced to many countries via maritime shipping and aquaculture (Stuart et al. 1999) and now is a common inhabitant of coastal areas of New Zealand, Tasmania, Argentina, Italy, France, England and North America. This 
species has been recognised as one of the most successful marine invaders in the world (Lowe et al. 2000, Williams \& Smith 2007).

U. pinnatifida is an annual species that has a heteromorphic life-cycle (Fig. 1.1). The macroscopic stage is the sporophyte that lasts around 6 months and develops a specialized reproductive tissue called the sporophyll. The sporophyll produces microscopic zoospores that settle, germinate and grow into a dioecious microscopic gametophyte that can last at least 24 months (Stuart 2004). The gametophyte releases sperm and eggs, the sperm fertilise the eggs and the embryo grows into a sporophyte (Saito 1975, Koh \& Shin 1990). The sporophyte is the visible life stage divided in three parts: the holdfast that is the structure to anchor to the substrate, stipe or stem and a blade divided by a midrib (Fig 1.1).

In its natural environments, the sporophytes appear in Winter-Spring and generally die in late Summer (Campbell \& Burridge 1998, Yoshikawa et al. 2001). However, in invaded areas the life cycle characteristics of U. pinnatifida vary (Hay \& Villouta 1990, Campbell \& Burridge 1998, Thornber et al. 2004). Sporophytes of U. pinnatifida can be found at different times of the year depending of the environment (Hay \& Villouta 1990, Campbell \& Burridge 1998, Thornber et al. 2004, Primo et al. 2010). In Tasmania this species presents visible sporophytes in Summer (Schaffelke et al. 2005), while in Argentina there is a constant recruitment throughout the year (Casas et al. 2008). In California, the recruitment occurs mainly during Winter and Spring with few recruits during Summer (Thornber et al. 2004). In New Zealand, sporophytes occur at all times of the year (Hay \& Villouta 1990, Campbell et al. 1998) with overlapping cohorts between years (Schiel \& Thompson 2012); but, maximum abundance occurs in late Winter and spring (Christian 2003).

In New Zealand, U. pinnatifida was recorded for the first time in 1987 in Wellington Harbour (Hay et al. 1993). Since its introduction this species has spread around the North Island from Wellington to Rangaunu Harbour and in the South island from Golden Bay to Stewart Island mainly in the West Coast (Stuart 2004, Russell et al. 2008, James et al. 2014). U. pinnatifida has also been found in remote areas such as the Snares Islands and Fiordland (Cassidy 2009, Henderson 2010). The legal status of this species in New Zealand is "Unwanted Organism" (Biosecurity Act 1993), but the Ministry of Agriculture and Forestry (2010) has announced some geographical areas may be permitted for farming $U$. pinnatifida as a commercial opportunity (Wellington Harbour, The Marlborough Sounds and Lyttelton Harbour). There 
have been efforts to control and eradicate this species principally through regular inspections, manual removal and different methods of sterilisation (THT chlorine, hot water, etc). While the results show a reduction in the abundance of this species, complete eradication has not occurred (Hunt et al. 2009). Only the heat method applied in Chatham Islands in 2001 has been successful, but at a cost of millions of dollars (Wotton et al. 2004). Recently, biocontrol with a sea urchin has had some success in Fiordland National Park, but also with temporal loss of native canopy of macroalgae (Atalah et al. 2013).

U. pinnatifida grows on a wide range of substrates such as rocky reefs, wharf pilings and ship hulls (Wotton et al. 2004). This species also inhabits a variety of depths from the low intertidal zone (Schiel \& Thompson 2012) down to the subtidal zone (Forrest \& Taylor 2002). $U$. pinnatifida can also grow under mild to severe wave exposures (Russell et al. 2008).

The success of $U$. pinnatifida in colonizing new environments is associated with its high physiological and morphological plasticity (Dean \& Hurd 2007) but also its biological characteristics, with fast growth and high reproductive rate, and quick maturation (Stuart 2004, Casas et al. 2004). However, little is known about the tolerance of $U$. pinnatifida to environmental changes, despite the fact that physiological acclimation to environmental stresses could play an important role in its success.

\subsection{Thesis research}

An evaluation of the effect of interactive stresses is necessary to determine the impact of global environmental changes more accurately. Moreover, the few studies on the effect of stressors as single and combined factors have been tested principally in native species, and the effect on invasive species has been ignored even though physiological acclimation might play an important role in invasion process.

My $\mathrm{PhD}$ research was focused on an investigation of the tolerance of the invasive kelp Undaria pinnatifida to UVB as single factor or combined with temperature. Through this research I examined the effect of these two stressors on different life stages of $U$. pinnatifida under laboratory conditions, and I also examined the physiological response to seasonal variation of light in the field. 


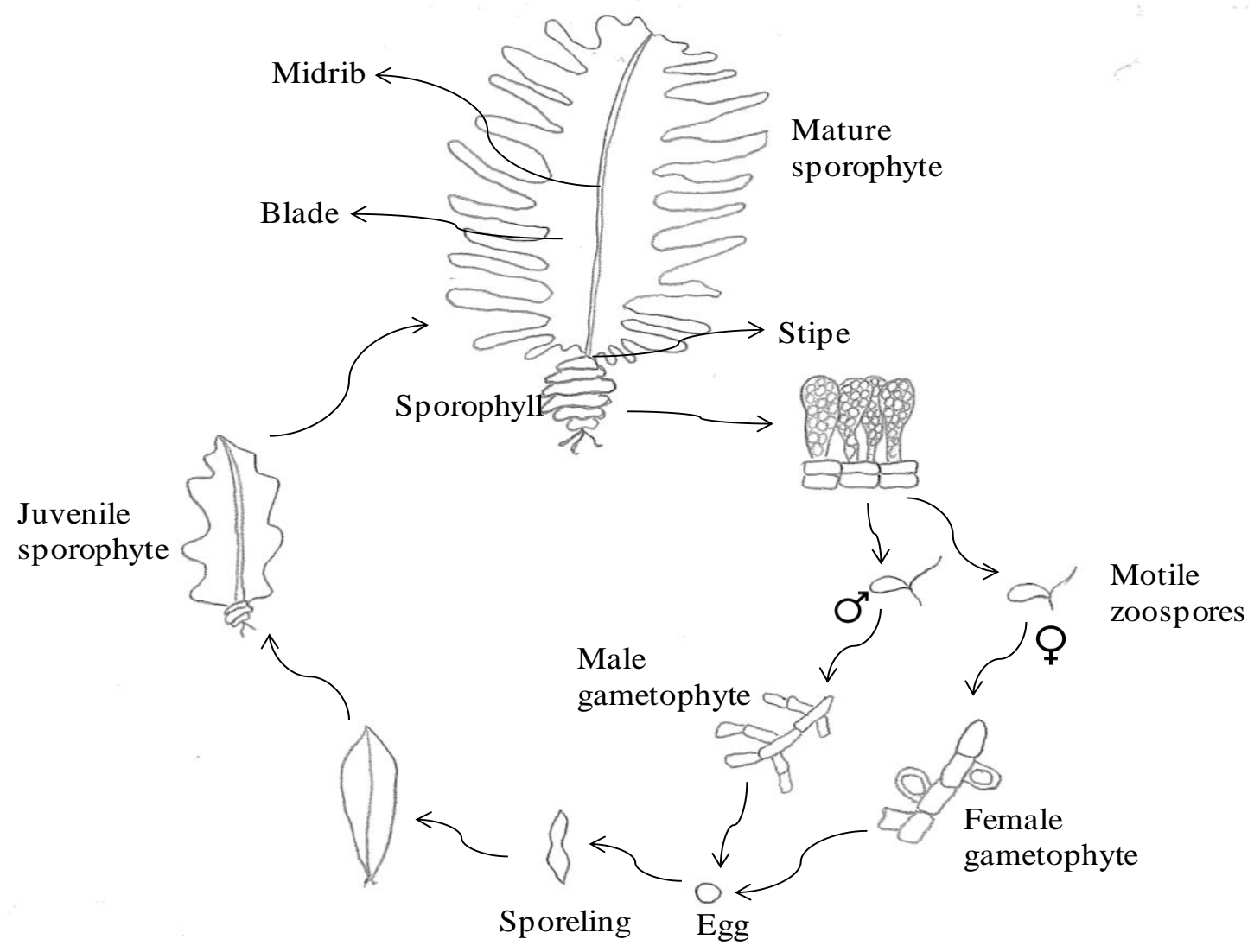

Fig. 1.1 Life cycle of Undaria pinnatifida.

Early developmental stages are critical for establishing benthic populations (Vadas et al. 1992, Burridge et al. 1996) and these stages are most susceptible to environmental factors, often suffering high mortality (Vadas et al. 1992, Coelho et al. 2000). However, U. pinnatifida is an invasive species and high tolerance to environmental conditions is expected, I hypothesised that motile zoospores of $U$. pinnatifida will be tolerant to UVB radiation and direct exposure to UVB will have little impact on this stage. To test this hypothesis in Chapter 2, I exposed motile zoospores to increasing UVB doses and measured its effect on photosynthetic efficiency, germination, growth and DNA damage. 
Since environmental changes occur simultaneously, it is imperative to study the effect of multiple factors on organisms. Temperature has an interactive effect with UVB in early life stages of some seaweeds (Hoffman et al. 2003, Steinhoff et al. 2011) and their effect can be synergic (Alatamirano et al. 2003) or mitigating (Rautenberger \& Bischof 2006). As $U$. pinnatifida has a wide thermotolerance, I hypothesised that an increase of water temperature will ameliorate the effect of UVB in early life stages of this species. To test this hypothesis in Chapter 3 I exposed motile and settled zoospores to UVB at increasing water temperature and measured its effect on photosynthetic efficiency, settlement, germination, growth and development to gametophytes.

Sporophytes are generally the most tolerant life stage to environmental stressors, but they may still show a decrease of photosynthetic performance, growth rate, development, and reproduction (Coelho et al. 2000). UVB produces considerable damage in seaweeds; however many brown seaweeds produce screening compounds such as phlorotannins, to protect the organism against high UVB doses. As sporophytes of $U$. pinnatifida inhabiting the low intertidal are exposed to direct natural light and therefore to UVB during low tide, I hypothesised that sporophyte phlorotannins will increase after exposure to UVB as a mechanism of photoprotection. I also hypothesised that temperature and UVB will have an interactive effect that will reduce the effect of UVB on $U$. pinnatifida. To test this hypothesis in Chapter 4 I exposed sporophytes to UVB at increasing water temperature and measured their effects on photosynthetic efficiency and phlorotannins concentration.

Seasonal acclimation is an important characteristic of seaweeds that allows them to tolerate environmental changes (Raniello et al. 2006). Light is one environmental factors that has considerable seasonal variability in temperate areas. Annual species have faster acclimation to seasonal variations of light and UVB than perennial species (Huovinen et al. 2006). Since $U$. pinnatifida principally inhabits the intertidal zone in temperate areas where it is exposed to high variations of light through the year, I hypothesized that phlorotannins of sporophytes of this species will change seasonally as a mechanism to protect from seasonal changes in UVB doses. Because $U$. pinnatifida is an annual species I also hypothesised that this species will acclimate rapidly to variations of light. To test this in Chapter 5, I examined the effect of seasonal variation of light on the phlorotannins concentration and photosynthetic performance of mature sporophytes of $U$. pinnatifida. 
This thesis has been written as a series of independent chapters with the intention to submit them for publication. Therefore, there is inevitably some repetition of background material. 


\subsection{References}

Adam, M. E. N., \& El Shazly, S. M. (2007). Attenuation of UV-B radiation in the atmosphere: Clouds effect, at Qena (Egypt). Atmospheric Environment, 41(23), 4856-4864

Adams III, W. W., Muller, O., Cohu, C. M., \& Demmig-Adams, B. (2013). May photoinhibition be a consequence, rather than a cause, of limited plant productivity?. Photosynthesis research, $117(1-3), 31-44$.

Altamirano, M., Flores-Moya, A. \& Figueroa, F. (2003) Altamirano, M., Flores-Moya, A., \& Figueroa, F. L. (2003). Effects of UV radiation and temperature on growth of germlings of three species of Fucus (Phaeophyceae). Aquatic Botany. 75(1): 9-20.

Atalah, J., G.A. Hopkins, and B.M. Forrest. 2013. Augmentative biocontrol in natural marine habitats: persistence, spread and non-target effects of the sea urchin Evechinus chloroticus. PloS one 8:e80365.

Babu, T. S., Jansen, M. A., Greenberg, B. M., Gaba, V., Malkin, S., Mattoo, A. K., \& Edelman, M. (1999). Amplified degradation of photosystem II D1 and D2 proteins under a mixture of photosynthetically active radiation and UVB radiation: dependence on redox status of photosystem II. Photochemistry and photobiology, 69(5), 553-559.

Bais, A. F., McKenzie, R. L., Bernhard, G., Aucamp, P. J., Ilyas, M., Madronich, S., \& Tourpali, K. (2015). Ozone depletion and climate change: Impacts on UV radiation. Photochemical \& Photobiological Sciences, 14(1), 19-52.

Bancroft, B. A., Baker, N. J. \& Blaustein, A. R. (2007). Effects of UVB radiation on marine and freshwater organisms: a synthesis through meta-analysis. Ecology Letters. 10(4): 332-345.

Barnes, D. K., Fuentes, V., Clarke, A., Schloss, I. R., \& Wallace, M. I. (2006). Spatial and temporal variation in shallow seawater temperatures around Antarctica. Deep Sea Research Part II: Topical Studies in Oceanography, 53(8), 853-865.

Baruch, Z. \& Goldstein, G. (1999). Leaf construction cost, nutrient concentration, and net CO2 assimilation of native and invasive species in Hawaii. Oecologia. 121(2): 183-192.

Betterle, N., Ballottari, M., Zorzan, S., et al. (2009) Light-induced dissociation of an antenna heterooligomer is needed for non-photochemical quenching induction. Journal of Biological Chemistry. 284(22):15255-15266.

Beszczynska-Möller, A., Fahrbach, E., Schauer, U., \& Hansen, E. (2012). Variability in Atlantic water temperature and transport at the entrance to the Arctic Ocean, 1997-2010. ICES Journal of Marine Science: Journal du Conseil, fss056. 
Bischof, K., Hanelt, D. \& Wiencke, C. (1998). UV-radiation can affect depth-zonation of Antarctic macroalgae. Marine Biology. 131(4): 597-605.

Bischof, K., Gomez, I., Molis, M., Hanelt, D., Karsten, U., Lüder, U., ... \& Wiencke, C. (2007). Ultraviolet radiation shapes seaweed communities. In Life in Extreme Environments (pp. 187212). Springer Netherlands.

Boudouresque, C.F. \& Verlaque, M. 2002. Biological pollution in the Mediterranean Sea: invasive versus introduced macrophytes. Marine Pollution Bulletin 44: 32-38

Burridge, T. R., Portelli, T. \& Ashton, P. (1996). Effect of sewage effluents on germination of three marine brown algal macrophytes. Marine and freshwater research. 47(8): 1009-1014.

Cadet, J., Sage, E. \& Douki, T. (2005). Ultraviolet radiation-mediated damage to cellular DNA. Mutation Research/Fundamental and Molecular Mechanisms of Mutagenesis. 571(1): 3-17.

Caldeira, K. \& Wickett, M. E. (2005). Ocean model predictions of chemistry changes from carbon dioxide emissions to the atmosphere and ocean. Journal of Geophysical Research: Oceans (1978-2012), 110(C9).

Caldwell, M. M., Bornman, J.F., et al. (2007) Terrestrial ecosystems, increased solar ultraviolet radiation, and interactions with other climate change factors. Photochemical \& Photobiological Sciences. 6(3):252-266.

Campbell, S. J. \& Burridge, T. R. (1998). Occurrence of Undaria pinnatifida (Phaeophyta: Laminariales) in Port Phillip Bay, Victoria, Australia. Marine and Freshwater Research. 49(5): 379-381.

Carreto, J. I., \& Carignan, M. O. (2011). Mycosporine-like amino acids: relevant secondary metabolites. Chemical and ecological aspects. Marine drugs, 9(3), 387-446.

Casas, G., Scrosati, R. \& Piriz, M. L. (2004). The invasive kelp Undaria pinnatifida (Phaeophyceae, Laminariales) reduces native seaweed diversity in Nuevo Gulf (Patagonia, Argentina). Biological Invasions. 6(4): 411-416.

Casas, G. N., Piriz, M. L., \& Parodi, E. R. (2008). Population features of the invasive kelp Undaria pinnatifida (Phaeophyceae: Laminariales) in Nuevo Gulf (Patagonia, Argentina). Marine Biological Association of the United Kingdom. Journal of the Marine Biological Association of the United Kingdom, 88(1), 21.

Cassidy, M. 2009. Review of the Undaria commercial harvest policy. MAF Biosecurity New Zealand Discussion Paper No: 2009/02. 
Chiswell, S. M. (1994). Variability in sea surface temperature around New Zealand from AVHRR images. New Zealand journal of marine and freshwater research, 28(2), 179-192.

Christian S.J. (2003) Growth, Longevity and Density of the Adventive Asian Kelp Undaria Pinnatifida from the Intertidal Zone in Wellington Harbour and South Coast. Victoria University of Wellington.

Coelho, S.M., Rijstenbil, J. W. \& Brown, M. T. (2000) Impacts of anthropogenic stresses on the early development stages of seaweeds. Journal of Aquatic Ecosystem Stress and Recovery. 7(4): 317-333.

Connan, S., Goulard, F., Stiger, V., Deslandes, E., \& Ar Gall, E. (2004). Interspecific and temporal variation in phlorotannin levels in an assemblage of brown algae. Botanica Marina, 47(5), 410-416.

Cook, D. C., Thomas, M. B., Cunningham, S. A., Anderson, D. L. \& De Barro, P. J. (2007). Predicting the economic impact of an invasive species on an ecosystem service. Ecological Applications. 17(6): 1832-1840.

Cui, X., Gu, S., Zhao, X., Wu, J., Kato, T., \& Tang, Y. (2008). Diurnal and seasonal variations of UV radiation on the northern edge of the Qinghai-Tibetan Plateau. Agricultural and forest meteorology, 148(1), 144-151.

Dattilo, A. M., Bracchini, L., Carlini, L., Loiselle, S. \& Rossi, C. (2005). Estimate of the effects of ultraviolet radiation on the mortality of Artemia franciscana in naupliar and adult stages. International journal of biometeorology. 49(6): 388-395.

Dean, P. R. \& Hurd, C. L. (2007). Seasonal growth, erosion rates, and nitrogen and photosynthetic ecophysiology of Undaria pinnatifida (Heterokontophyta) in southern New Zealand1. Journal of Phycology. 43(6):1138-1148.

Deser, C., Alexander, M. A., Xie, S. P., \& Phillips, A. S. (2010). Sea surface temperature variability: Patterns and mechanisms. Marine Science, 2.

Döhler, G., Hagmeier, E. \& David, C. (1995). Effects of solar and artificial UV irradiation on pigments and assimilation of $15 \mathrm{~N}$ ammonium and $15 \mathrm{~N}$ nitrate by macroalgae. Journal of Photochemistry and Photobiology B: Biology. 30(2): 179-187.

Doney, S. C., Fabry, V.J., et al. (2009) Ocean acidification: the other CO2 problem. Marine Science. 1.

Dring, M. J., Wagner, A., Boeskov, J. \& Lüning, K. (1996). Sensitivity of intertidal and subtidal red algae to UVA and UVB radiation, as monitored by chlorophyll fluorescence measurements: 
influence of collection depth and season, and length of irradiation. European Journal of Phycology. 31(4): 293-302.

Dukes, J. \& Mooney, H. (1999) Does global change increase the success of biological success. Trends in Ecology and Evolution. 14(4):135-139.

Feely, R. A., Sabine, C. L., Lee, K., Berelson, W., Kleypas, J., Fabry, V. J., \& Millero, F. J. (2004). Impact of anthropogenic $\mathrm{CO} 2$ on the $\mathrm{CaCO} 3$ system in the oceans. Science. 305(5682): 362366.

Forrest, B.M., \& M.D. Taylor. 2002. Assessing invasion impact : survey design considerations and implications for management of an invasive marine plant. Biological Invasions 4:375-386.

Forrest, B.M. 2007. Managing risks from invasive marine species: is post-border management feasible? $\mathrm{PhD}$ Thesis, Victoria University of Wellington.

Franklin, L. A., \& Neale, P. J. (2002). Biological Weighting Functions for the Effect of UV Radiation on Carbon Partitioning in Microalgae. Journal of Phycology, 38(s1), 10-10.

Fredersdorf, J., Müller, R., Becker, S., Wiencke, C. \& Bischof, K. (2009) Interactive effects of radiation, temperature and salinity on different life history stages of the Arctic kelp Alaria esculenta (Phaeophyceae). Oecologia. 160(3):483-492.

Friso, G., Spetea, C., Giacometti, G. M., Vass, I., \& Barbato, R. (1994). Degradation of photosystem II reaction center D1-protein induced by UVB radiation in isolated thylakoids. Identification and characterization of $\mathrm{C}$-and $\mathrm{N}$-terminal breakdown products. Biochimica et Biophysica Acta (BBA)-Bioenergetics, 1184(1), 78-84.

Galbraith, H., Jones, R., Park, R., Clough, J., Herrod-Julius, S., Harrington, B. \& Page, G. (2002). Global climate change and sea level rise: potential losses of intertidal habitat for shorebirds. Waterbirds. 25(2): 173-183.

Gao, K. \& Xu, J. (2008) Effects of solar UV radiation on diurnal photosynthetic performance and growth of Gracilaria lemaneiformis (Rhodophyta). European Journal of Phycology. 43(3): 297-307.

Garcia-Sanchez, M., Korbee, N., et al. (2012) Physiological response and photoacclimation capacity of Caulerpa prolifera (Forsskål) JV Lamouroux and Cymodocea nodosa (Ucria) Ascherson meadows in the Mar Menor lagoon (SE Spain). Marine environmental research. 79: 37-47.

Gardner, T. A., Cote, I. M., Gill, J. A., Grant, A., \& Watkinson, A. R. (2005). Hurricanes and Caribbean coral reefs: impacts, recovery patterns, and role in long-term decline. Ecology 86(1): 174-184. 
Graham, W. M. \& Bayha, K. M. (2007). Biological invasions by marine jellyfish. In Biological invasions (pp. 239-255). Springer Berlin Heidelberg.

Goss, R. \& Jakob. T. (2010) Regulation and function of xanthophyll cycle-dependent photoprotection in algae. Photosynthesis Research. 106(1-2):103-122

Grosholz, E. (2002). Ecological and evolutionary consequences of coastal invasions. Trends in Ecology \& Evolution. 17(1): 22-27.

Gurevitch, J. \& Padilla, D. K. (2004) Are invasive species a major cause of extinctions? Trends in Ecology \& Evolution. 19(9):470-474.

Häder, D. P., Kumar, H. D., Smith, R. C., \& Worrest, R. C. (2007). Effects of solar UV radiation on aquatic ecosystems and interactions with climate change. Photochemical \& Photobiological Sciences. 6(3): 267-285.

Hansen, J., Sato, M., Ruedy, R., Lo, K., Lea, D. W., \& Medina-Elizade, M. (2006). Global temperature change. Proceedings of the National Academy of Sciences, 103(39), 14288-14293.

Harley, C. D., Randall Hughes, A., Hultgren, K. M., Miner, B. G., Sorte, C. J., Thornber, C. S., et al. (2006). The impacts of climate change in coastal marine systems. Ecology letters. 9(2): 228241.

Harley, C. D., Anderson, K. M., Demes, K. W., Jorve, J. P., Kordas, R. L., Coyle, T. A. \& Graham, M. H. (2012). Effects of climate change on global seaweed communities. Journal of Phycology. 48(5): 1064-1078.

Hargreaves, B. R. (2003). Water column optics and penetration of UVR. UV effects in aquatic organisms and ecosystems. 1: 59-108.

Hay, C. H. (1990). The dispersal of sporophytes of Undaria pinnatifida by coastal shipping in New Zealand, and implications for further dispersal of Undaria in France. British phycological journal. 25(4): 301-313.

Hay, C. H. \& Villouta, E. (1993) Seasonality of the adventive Asian kelp Undaria pinnatifida in New Zealand. Botanica marina. 36(5):461-476.

Hellmann, J. J., Byers, J. E., Bierwagen, B. G. \& Dukes, J. S. (2008). Five potential consequences of climate change for invasive species. Conservation Biology, 22(3), 534-543.

Henry, B. E., \& Van Alstyne, K. L. (2004). Effect of UV radiation on growth and phlorotannins in Fucus Gardneri (Phaeophyceae) juveniles and embryios1. Journal of Phycology, 40(3), 527533. 
Herman, J. R. (2010). Global increase in UV irradiance during the past 30 years (1979-2008) estimated from satellite data. Journal of Geophysical Research: Atmospheres (1984-2012), 115(D4).

Hewitt, C. (2003) Marine biosecurity issue: Global in the world oceans: Global activities and Australian directions. Ocean Year book. 17:193-212

Hoegh-Guldberg, O. \& Bruno, J.F. (2010) The impact of climate change on the world's marine ecosystems. Science. 328(5985):1523-1528.

Hoffman, J. R., Hansen, L. J. \& Klinger, T. (2003). Interactions between UV radiation and temperature limit inferences from single-factor experiment1. Journal of Phycology. 39(2):268-272.

Hughes, T. P., Bellwood, D. R., Folke, C., Steneck, R. S. \& Wilson, J. (2005). New paradigms for supporting the resilience of marine ecosystems. Trends in ecology \& evolution. 20(7): 380386.

Huovinen, P., Gomez, I., Figueroa, F., Ulloa, N., Morales, V. \& Lovengreen, C. (2004) Ultravioletabsorbing mycosporine-like amino acids in red macroalgae from Chile. Botanica Marina, 47(1):21-29

Huovinen, P., Gómez, I., \& Lovengreen, C. (2006). A Five-year Study of Solar Ultraviolet Radiation in Southern Chile (39 S): Potential Impact on Physiology of Coastal Marine Algae?. Photochemistry and Photobiology, 82(2), 515-522.

Huovinen, P., Leal, P., \& Gómez, I. (2010). Interacting effects of copper, nitrogen and ultraviolet radiation on the physiology of three south Pacific kelps. Marine and Freshwater Research, 61(3), 330-341.

Huovinen, P. \& Gomez, I. (2011) Spectral attenuation of solar radiation in Patagonian fjord and coastal waters and implications for algal photobiology. Continental Shelf Research,. 31(3):254-259.

Huovinen, P. \& Gomez, I. (2013) Photosynthetic characteristics and UV stress tolerance of Antarctic seaweeds along the depth gradient. Polar biology. 36(9):1319-1332.

Hurd, C. L., Harrison, P. J., Bischof, K., \& Lobban, C. S. (2014). Seaweed ecology and physiology. Cambridge University Press.

Hunt, L., Chadderton, L., Stuart, M., Cooper, S. \& Carruthers, M. (2009) Results of an attempt to control and eradicate Undaria pinnatifida in Southland, New Zealand, April 1997 November 2004. Department of Conservation, Invercargill,New Zealand,.

IPCC, 2013: Climate Change 2013: The Physical Science Basis. Contribution of Working Group I to the Fifth Assessment Report of the Intergovernmental Panel on Climate Change [Stocker, T. F., D. Qin, G.-K. Plattner, M. Tignor, S. K. Allen, J. Boschung, A. Nauels, Y. Xia, V. Bex 
and P. M. Midgley (eds.)]. Cambridge University Press, Cambridge, United Kingdom and New York, NY, USA. http://www.climatechange2013.org/images/report/WG1AR5_TS_FINAL.pdf

Jablonski, N. G., \& Chaplin, G. (2010). Human skin pigmentation as an adaptation to UV radiation. Proceedings of the National Academy of Sciences, 107(Supplement 2), 8962-8968.

Jahns, P., \& Holzwarth, A. R. (2012). The role of the xanthophyll cycle and of lutein in photoprotection of photosystem II. Biochimica et Biophysica Acta (BBA)-Bioenergetics, 1817(1), 182-193.

Johnson, M. P., Pérez-Bueno, M. L., Zia, A., Horton, P., \& Ruban, A. V. (2009). The zeaxanthinindependent and zeaxanthin-dependent $\mathrm{qE}$ components of nonphotochemical quenching involve common conformational changes within the photosystem II antenna in Arabidopsis. Plant Physiology, 149(2), 1061-1075.

Kaiser, J., Lamy, F., \& Hebbeln, D. (2005). A 70-kyr sea surface temperature record off southern Chile (Ocean Drilling Program Site 1233). Paleoceanography, 20(4).

Kerr, J. B. \& McElroy, C. T. (1993). Evidence for large upward trends of ultraviolet-B radiation linked to ozone depletion. Science. 262(5136): 1032-1034.

Koh, C.H., \& H.C. Shin. 1990. Growth and size distribution of some large brown algae in Ohori, east coast of Korea. Hydrobiologia 204:225-231.

Latowski, D., Kuczyńska, P., \& Strzałka, K. (2011). Xanthophyll cycle-a mechanism protecting plants against oxidative stress. Redox Report, 16(2), 78-90.

Lavaud, J., Rousseau, B., \& Etienne, A. L. (2004). General Features of Photoprotection By Energy Dissipation in Planktonic Diatoms (Bacillariophyceae) 1. Journal of Phycology, 40(1), 130137.

Lesser, M. P. (2006) Oxidative stress in marine environments: biochemistry and physiological ecology. Annu. Rev. Physiol. 68: 253-278.

Lobban, C. (1994). Seaweed ecology and physiology. Cambridge University Press.

Lowe, S., Browne, M., Boudjelas, S. \& De Poorter, M. (2000). 100 of the world's worst invasive alien species: a selection from the global invasive species database (p. 12). Species Survival Commission, World Conservation Union (IUCN), Auckland, New Zealand: Invasive Species Specialist Group. 
Lüder, U. H., \& Clayton, M. N. (2004). Induction of phlorotannins in the brown macroalga Ecklonia radiata (Laminariales, Phaeophyta) in response to simulated herbivory - the first microscopic study. Planta, 218(6), 928-937.

Madronich, S., McKenzie, R. L., Björn, L. O. \& Caldwell, M. M. (1998). Changes in biologically active ultraviolet radiation reaching the Earth's surface. Journal of Photochemistry and Photobiology B: Biology. 46(1): 5-19.

Maxwell, K., \& Johnson, G. N. (2000). Chlorophyll fluorescence-a practical guide. Journal of experimental botany, 51(345), 659-668.

McKenzie, R., Smale, D., Bodeker, G., \& Claude, H. (2003). Ozone profile differences between Europe and New Zealand: Effects on surface UV irradiance and its estimation from satellite sensors. Journal of Geophysical Research: Atmospheres (1984-2012), 108(D6).

McKenzie, R., Bodeker, G., Scott, G., Slusser, J., \& Lantz, K. (2006). Geographical differences in erythemally-weighted UV measured at mid-latitude USDA sites. Photochemical \& Photobiological Sciences, 5(3), 343-352.

McKenzie, R. L., Aucamp, P. J., Bais, A. F., Björn, L. O., Ilyas, M., \& Madronich, S. (2011). Ozone depletion and climate change: impacts on UV radiation. Photochemical \& Photobiological Sciences, 10(2), 182-198.

Melis, A. (1999). Photosystem-II damage and repair cycle in chloroplasts: what modulates the rate of photodamage in vivo?. Trends in plant science, 4(4), 130-135.

Murata, N., Takahashi, S., Nishiyama, Y., \& Allakhverdiev, S. I. (2007). Photoinhibition of photosystem II under environmental stress. Biochimica et Biophysica Acta (BBA)Bioenergetics, 1767(6), 414-421.

Müller, P., Li, X. P. \& Niyogi, K. K. (2001). Non-photochemical quenching. A response to excess light energy. Plant Physiology. 125(4): 1558-1566.

Müller, R., Wiencke, C. \& Bischof, K. (2008). Interactive effects of UV radiation and temperature on microstages of Laminariales (Phaeophyceae) from the Arctic and North Sea. Climate Research. 37:203-213.

Nishiyama, Y., Allakhverdiev, S. I. \& Murata, N. (2006) A new paradigm for the action of reactive oxygen species in the photoinhibition of photosystem II. Biochimica et Biophysica Acta (BBA)-Bioenergetics. 1757(7):742. 
Nishiyama, Y., Allakhverdiev, S. I., \& Murata, N. (2011). Protein synthesis is the primary target of reactive oxygen species in the photoinhibition of photosystem II. Physiologia Plantarum, 142(1), 35-46.

Nyberg, C. D., \& Wallentinus, I. (2005). Can species traits be used to predict marine macroalgal introductions?. Biological Invasions, 7(2), 265-279.

Occhipinti-Ambrogi, A. \& Savini, D. (2003). Biological invasions as a component of global change in stressed marine ecosystems. Marine pollution bulletin. 46(5): 542-551.

Pakker, H., Beekman, C. \& Breeman, A. (2000). Efficient photoreactivation of UVBR-induced DNA damage in the sublittoral macroalga Rhodymenia pseudopalmata (Rhodophyta). European Journal of Phycology, 35(2):109-114.

Parmesan, C. (2006). Ecological and evolutionary responses to recent climate change. Annual Review of Ecology, Evolution, and Systematics, 637-669.

Pavia, H., Cervin, G., Lindgren, A., \& Aberg, P. (1998). Effects of UV-B radiation and simulated herbivory on phlorotannins in the brown alga Ascophyllum nodosum. Oceanographic Literature Review, 3(45), 523-524.

Pimentel, D., Zuniga, R. \& Morrison, D. (2005). Update on the environmental and economic costs associated with alien-invasive species in the United States. Ecological economics: 52(3): 273288.

Pörtner, H. O., Langenbuch, M. \& Reipschläger, A. (2004). Biological impact of elevated ocean CO2 concentrations: lessons from animal physiology and earth history. Journal of Oceanography. 60(4): 705-718.

Primo, C., Hewitt, C. L., \& Campbell, M. L. (2010). Reproductive phenology of the introduced kelp Undaria pinnatifida (Phaeophyceae, Laminariales) in Port Phillip Bay (Victoria, Australia). Biological invasions, 12(9), 3081-3092.

Rahel, F. J. \& Olden, J. D. (2008) Assessing the effects of climate change on aquatic invasive species. Conservation Biology. 22(3):521-533.

Raniello, R., Lorenti, M., Brunet, C. \& Buia, M. (2004) Photosynthetic plasticity of an invasive variety of Caulerpa racemosa in a coastal Mediterranean area: light harvesting capacity and seasonal acclimation. Marine Ecology Progress Series, 271:113-120.

Raniello, R., Lorenti, M., Brunet, C., et al. (2006) Photoacclimation of the invasive alga Caulerpa racemosa var. cylindracea to depth and daylight patterns and a putative new role for siphonaxanthin. Marine Ecology, 27 (1): 20-30. 
Rautenberger, R. \& Bischof, K. (2006). Impact of temperature on UV-susceptibility of two Ulva (Chlorophyta) species from Antarctic and Subantarctic regions. Polar Biology. 29(11): 988996.

Rejmánek, M. \& Richardson, D. M. (1996). What attributes make some plant species more invasive?. Ecology. 1655-1661.

Rilov, G. \& Treves, H. (2010). Climate change effects on marine ecological communities. In Seaweeds and their Role in Globally Changing Environments(pp. 51-68). Springer Netherlands.

Roemmich, D., Gould, W. J., \& Gilson, J. (2012). 135 years of global ocean warming between the Challenger expedition and the Argo Programme. Nature Climate Change, 2(6), 425-428.

Roleda, M., van de Poll, W. H., Hanelt, D., \& Wiencke, C. (2004). PAR and UVBR effects on photosynthesis, viability, growth and DNA in different life stages of two coexisting Gigartinales: implications for recruitment and zonation pattern. Marine ecology-progress series, 281, 37-50.

Roleda, M., Wiencke, C., Hanelt, D., van de Poll, W. \& Gruber, A. (2005) Sensitivity of Laminariales zoospores from Helgoland (North Sea) to ultraviolet and photosynthetically active radiation: implications for depth distribution and seasonal reproduction. Plant, Cell \& Environment, 28(4):466-479.

Roleda, M. Wiencke, C. \& Lüder, U. (2006) Impact of ultraviolet radiation on cell structure, compounds, photosynthesis, DNA damage, and germination in zoospores of Arctic Saccorhiza dermatodea. Journal of Experimental Botany, 57(14):3847-3856.

Roleda, M. Y., Wiencke, C. et al. (2007) Sensitivity of the Early Life Stages of Macroalgae from the Northern Hemisphere to Ultraviolet Radiation. Photochemistry and photobiology. 2007, vol. 83, no 4, p. 851-862.

Roy, S. (2000). Strategies for the minimisation of UV-induced damage. The effects of UV radiation in the marine environment. 177-205.

Russell, L. K., Hepburn, C. D., Hurd, C. L., \& Stuart, M. D. (2008). The expanding range of Undaria pinnatifida in southern New Zealand: distribution, dispersal mechanisms and the invasion of wave-exposed environments. Biological invasions, 10(1), 103-115.

Saito, Y. 1975. Undaria. In: Tokida, J., Hirose, H. (Eds.), Advance of Phycology in Japan. Junk, The Hague, pp. 304-320

Scavia, D., Field, J. C., Boesch, D. F., Buddemeier, R. W., et al. (2002). Climate change impacts on US coastal and marine ecosystems. Estuaries. 25(2): 149-164. 
Schaffelke, B., Smith, J. E. \& Hewitt C. L. (2007a) Introduced macroalgae-a growing concern. En Eighteenth International Seaweed Symposium. Springer Netherlands. p. 303-315.

Schaffelke, B. \& Hewitt, C. (2007b). Impacts of introduced seaweeds. Botanica Marina, 50:397-417

Schiel, D. R., \& Thompson, G. A. (2012). Demography and population biology of the invasive kelp Undaria pinnatifida on shallow reefs in southern New Zealand. Journal of Experimental Marine Biology and Ecology, 434, 25-33.

Sheras, N. T. \& Ross, P. M. (2010) Toxic cascades: multiple anthropogenic stressors have complex and unanticipated interactive effects on temperate reefs. Ecology letters. 13: 1149-1159.

Shibata, T., Kawaguchi, S., Hama, Y., Inagaki, M., Yamaguchi, K., \& Nakamura, T. (2004). Local and chemical distribution of phlorotannins in brown algae. Journal of applied phycology, 16(4), 291-296.

Somero, G. N. (2010). The physiology of climate change: how potentials for acclimatization and genetic adaptation will determine 'winners' and 'losers'. The Journal of experimental biology. 213(6): 912-920.

Sorte, C.J.B., Williams, S. L., et al. (2010) Marine range shifts and species introductions: comparative spread rates and community impacts. Global Ecology and Biogeography. 19,(3): 303-316.

Stachowicz, J. J., Terwin, J. R., Whitlatch, R. B. \& Osman, R. W. (2002). Linking climate change and biological invasions: ocean warming facilitates nonindigenous species invasions. Proceedings of the National Academy of Sciences. 99(24):15497-1550.

Steinhoff, F. S., Wiencke, C., Wuttke, S. \& Bischof, K. (2011). Effects of water temperatures, UV radiation and low vs high PAR on phlorotannin content and germination in zoospores of Saccorhiza dermatodea (Tilopteridales, Phaeophyceae). Phycologia. 50(3): 256-263.

Steneck, R. S., Graham, M. H., Bourque, B. J., Corbett, D., Erlandson, J. M., Estes, J. A. \& Tegner, M. J. (2002). Kelp forest ecosystems: biodiversity, stability, resilience and future. Environmental conservation. 29(04):436-459.

Stuart, M. D., Hurd, C. L. \& Brown, M. T. (1999). Effects of seasonal growth rate on morphological variation of Undaria pinnatifida (Alariaceae, Phaeophyceae). In Sixteenth International Seaweed Symposium (pp. 191-199). Springer Netherlands.

Stuart, M. D. (2004). Review of research on Undaria pinnatifida in New Zealand and its potential impacts on the eastern coast of the South Island (p. 40). Wellington, New Zealand: Department of Conservation. 
Swanson, A. K., \& Druehl, L. D. (2002). Induction, exudation and the UV protective role of kelp phlorotannins. Aquatic Botany, 73(3), 241-253.

Thornber, C. S., Kinlan, B. P., Graham, M. H. \& Stachowicz, J. J. (2004). Population ecology of the invasive kelp Undaria pinnatifida in California: environmental and biological controls on demography. Marine Ecology-Progress Series, 268.

Thomsen, M. S. \& McGlathery, K. J. (2007). Stress tolerance of the invasive macroalgae Codium fragile and Gracilaria vermiculophylla in a soft-bottom turbid lagoon. Biological Invasions. 9(5):499-513.

Trenberth, K. (2005). Uncertainty in hurricanes and global warming. Science (Washington). 308(5729): 1753-1754.

Turley, C., Blackford, J. C., Widdicombe, S., Lowe, D., Nightingale, P. D., \& Rees, A. P. (2006). Reviewing the impact of increased atmospheric $\mathrm{CO} 2$ on oceanic $\mathrm{pH}$ and the marine ecosystem. Avoiding dangerous climate change. 8: 65-70.

Tyystjärvi, E. (2008). Photoinhibition of photosystem II and photodamage of the oxygen evolving manganese cluster. Coordination Chemistry Reviews, 252(3), 361-376.

Vadas, R. Johnson, S. \& Norton, T. (1992) Recruitment and mortality of early post-settlement stages of benthic algae. British Phycological Journal, 27(3):331-351.

Valentine, J. \& Johnson, C. (2003) Establishment of the introduced kelp Undaria pinnatifida in Tasmania depends on disturbance to native algal assemblages. Journal of Experimental Marine Biology and Ecology, 295(1):63-90.

Valentine, J. P., Magierowski, R. H. \& Johnson, C. R. (2007). Mechanisms of invasion: establishment, spread and persistence of introduced seaweed populations. Botanica Marina, 50(5/6), 351360.

Vecchi, G. A., \& Soden, B. J. (2007). Effect of remote sea surface temperature change on tropical cyclone potential intensity. Nature, 450(7172), 1066-1070.

Vilà, M., Corbin, J. D., Dukes, J. S., Pino, J., \& Smith, S. D. (2007). Linking plant invasions to global environmental change. In Terrestrial ecosystems in a changing world (pp. 93-102). Springer Berlin Heidelberg.

Vincent, W. F. \& Neale, P. J. (2000). Mechanisms of UV damage to aquatic organisms. The effects of UV radiation in the marine environment. 10: 72-100.

Vitousek, P. M., Mooney, H. A., Lubchenco, J. \& Melillo, J. M. (1997). Human domination of Earth's ecosystems. Science. 277(5325), 494-499. 
Walther, G. R., Roques, A., Hulme, P. E., Sykes, M. T., Pyšek, P., Kühn, I., et al.(2009). Alien species in a warmer world: risks and opportunities. Trends in ecology \& evolution. 24(12):686-693.

Waters, J. M. \& Roy, M. S. (2004). Phylogeography of a high-dispersal New Zealand sea-star: does upwelling block gene-flow?. Molecular Ecology, 13(9). 2797-2806.

Walther, G. R., Post, E., Convey, P., Menzel, A., Parmesan, C., Beebee, T. J., et al.. (2002). Ecological responses to recent climate change. Nature. 416(6879):389-395.

Weatherhead, E. C. \& Andersen, S. B. (2006). The search for signs of recovery of the ozone layer. Nature. 441(7089), 39-45.

Wiencke, C., Gómez, I., Pakker, H., Flores-Moya, A., Altamirano, M., Hanelt, D., Bischof K. \& Figueroa, F. L. (2000). Impact of UV-radiation on viability, photosynthetic characteristics and DNA of brown algal zoospores: implications for depth zonation. Marine ecology. Progress series, 197, 217-229.

Wiencke, C., Roleda, M., Gruber, A., Clayton, M. \& Bischof, K. (2006) Susceptibility of zoospores to UV radiation determines upper depth distribution limit of Arctic kelps: evidence through field experiments. Journal of Ecology, 84:455-463.

Williams, S. L. \& Smith, J. E. (2007) A global review of the distribution, taxonomy, and impacts of introduced seaweeds. Annual Review of Ecology, Evolution, and Systematics. 327-359.

Wotton, D. M., O'Brien, C., Stuart, M. D. \& Fergus, D. J. (2004). Eradication success down under: heat treatment of a sunken trawler to kill the invasive seaweed Undaria pinnatifida. Marine Pollution Bulletin. 49(9): 844-849.

Xie, S. P., Deser, C., Vecchi, G. A., Ma, J., Teng, H., \& Wittenberg, A. T. (2010). Global warming pattern formation: sea surface temperature and rainfall*. Journal of Climate, 23(4), 966-986.

Yamashita, N., Ishida, A., Kushima, H. \& Tanaka, N. (2000) Acclimation to sudden increase in light favoring an invasive over native trees in subtropical islands, Japan. Oecologia. 125(3):412419.

Yamashita, N., Koike, N. \& Ishida, A. (2002). Leaf ontogenetic dependence of light acclimation in invasive and native subtropical trees of different successional status. Plant, Cell \& Environment 25(10): 1341-1356.

Yoshikawa, T., Takeuchi, I. \& Furuya, K. (2001). Active erosion of Undaria pinnatifida. Suringar (Laminariales, Phaeophyceae) mass-cultured in Otsuchi Bay in northeastern Japan. Journal of experimental marine biology and ecology. 266(1): 51-65. 
Zacher, K., Roleda M.Y., et al. (2007) UV effects on photosynthesis and DNA in propagules of three Antarctic seaweeds (Adenocystis utricularis, Monostroma hariotii and Porphyra endiviifolium). Planta. 225(6): 1505-1516.

Zepp, R. G., Erickson D. J., et al. (2011) Effects of solar UV radiation and climate change on biogeochemical cycling: interactions and feedbacks. Photochemical \& photobiological sciences. 10(2): 261-279. 


\section{Chapter 2}

\section{Effect of UVB on}

\section{zoospores of $U$. pinnatifida}

\subsection{Abstract}

The effect of short exposure to UVB irradiances on zoospores of the invasive kelp $U$. pinnatifida was studied in the laboratory for the first time. Spectral irradiance consisted of photosynthetically active radiation (P, 400-700nm) and PAR + UVB (295-320nm) radiation (PB). The optimum quantum yield $\left(\mathrm{F}_{\mathrm{v}} / \mathrm{F}_{\mathrm{m}}\right)$ and DNA damage were measured after exposure to light treatments. Germination capacity and germination tube growth were measured 2 and 6 days after exposure. Photosynthetic capacity was dramatically depressed during exposure to $\mathrm{PB}$; however recovery was observed after $2 \mathrm{~h}$ in low light conditions and the recovery was dose dependent. DNA was negatively affected by the high UVB irradiance and exposure time. Germination and the growth of the germination tube were highly inhibited by PB, but zoospores were eventually able to germinate after recovery; the length of the delay in germination depended on the UVB dose they received. The results show that zoospores of $U$. pinnatifida can recover from UVB stress and the degree of recovery depends on the doses they receive. A fast recovery of the photosynthetic yield and the capacity of zoospores to germinate and grow after exposure to UVB shows $U$. pinnatifida can survive when environmental conditions improve and this could increase the opportunity of zoospores to survive and compete with other species.

\subsection{Introduction}

Seaweeds are an important component of coastal ecosystems because they are primary producers; they provide shelter and are food resources for many other organisms (Lobban 1994, Burkepile \& Hay 2006). The establishment of seaweed populations depends greatly on 
the survival of early life stages and recruitment, which in turn depend on favourable environmental windows (Vadas et al.1992, Coelho et al. 2000). However, in coastal ecosystems, these windows might be rare because of the high variability of physical conditions, such as light intensity, temperature, wave exposure and other factors, resulting in high mortality of early life stages. Even when these stages survive, sub-lethal effects might also impact their development and thereby, the establishment of new populations. This is because sub-lethal effects could alter important aspects of the ecological performance of the species, such as reproductive output and recruitment success (Davison et al. 1993). For example, a reduction of photosynthetic performance or cellular damage as a consequence of environmental stresses could delay subsequent development and growth of early life stages and could affect their ability to compete with other organisms (Coelho et al. 2000).

Abiotic stresses in natural environments vary daily and their effects depend on different factors such as type of stressor, length of exposure and even seasonality of the stressor (Davison et al. 1993, Doblin \& Clyton 1995, Lloret et al. 2001, Alberts et al. 2005; Crain et al. 2008). Stress tolerances also vary with life stage, age and species (Davison et al. 1993, Coelho et al. 2000, Byrne 2012). For instance, unicellular stages (spores and gametes) are more susceptible to stressors than multicellular stages (gametophytes and sporophytes), microscopic stages more than macroscopic stages and young stages more than adults (Davison et al. 1993, Coelho et al. 2000, Roleda et al. 2005). Nevertheless, seaweeds can acclimate, repair and produce protective substances to counteract unfavourable conditions. For example, the production of screening substances protects seaweeds from high solar irradiances and UV radiation and act as antioxidants (Cockell \& Knowland 1999, Huovinen et al. 2004). In addition, DNA damage can be repaired by photoreactivation or excision repair (van de Poll 2002, Pakker et al. 2000, Roleda et al. 2006), and photoinhibition of photosynthesis is an efficient mechanism to dissipate the excess of energy absorbed by photosystem II (PSII) (Hanelt et al. 1997, Roleda et al. 2006).

The effect of light stress and UV radiation on the photosynthetic apparatus has been assessed by chlorophyll fluorescence using Pulse Amplitude Modulation (PAM) fluorometry (Wiencke et al. 2004, Roleda et al. 2005, Baker 2008). This method is widely used to study the physiology and ecophysiology of photosynthetic organisms because it rapid, non-destructive and provides easily interpreted information on the state of photosystem II (PSII) (Baker 2008, Murchie \& Lawson 2013). The light energy absorbed by chlorophyll can be used for 
photosynthesis (photochemistry), re-emitted as fluorescence or re-emitted as heat (Murchie \& Lawson 2013). Thus, the chlorophyll fluorescence is complementary to the alternative pathways of photochemistry, de-excitation, and heat dissipation. The fluorescence signal is higher when the yields of photochemistry and heat dissipation are lowest (Murchie \& Lawson 2013). Different chlorophyll fluorescence parameters can be measured; however one of the most used is the maximum quantum yield of PSII $\left(F_{v} / F_{m}\right)$ (Murchie \& Lawson 2013). The $\mathrm{F}_{\mathrm{v}} / \mathrm{F}_{\mathrm{m}}$ is reached after dark acclimation by closing reaction centres when photochemistry and heat dissipation are inactivated. This parameter gives robust information of the quantum yield of PSII chemistry (Murchie \& Lawson 2013). For unstressed seaweeds the value of $F_{v} / F_{m}$ varies from $~ 0.8$-to 0.4 depending on the species and life stage (Gómez et al. 2001, Roleda et al. 2007, Chaloub et al. 2010). After light or/and UV stress the photosynthetic capacity decreases photoinhibition (Hurd et al. 2014). This is observed as a decrease in $\mathrm{F}_{\mathrm{v}} / \mathrm{F}_{\mathrm{m}}$ ) to protect the reaction centres and suppress the production of reactive oxygen species. When the stress diminishes the $F_{v} / F_{m}$ may recover.

DNA damage after exposure to UVB on algae has been evaluated mainly via the quantification of cyclobutane pyrimidine dimers (CPDs), since these are the most common DNA photolesions induced by UV radiation (Kumari et al. 2008). However, DNA damage can also be quantified by flow cytometry, which is a technique based on the quantitative measurement of the light-scattering and fluorescent properties of fluorescently stained cells (Binet \& Stauber 2006). Analysis of the physiological status of individual cells by flow cytometry has the advantages that it is fast and gives multi-parametric data of a population of cells (Velhuis \& Kraay 2000, Vives-Rego et al. 2000). Flow cytometry has been used in phytoplankton and microalgae for the quantification DNA, apoptosis, and cell viability (Franqueira et al. 2000, Collier 2001, Readman et al. 2004, Haberkorn et al. 2011), but has only been used rarely in the study or unicellular stages of macroalgae. However, flow cytometry is a useful tool to obtain relevant information rapidly about populations of algal spores.

In brown seaweeds, zoospores are a motile transitional stage (Bell 1997). Zoospores of kelp can last $72 \mathrm{~h}$ in this planktonic phase, and their dispersal distances can extend $1 \mathrm{~km}$ from the source through water motion (Reed et al. 1988). The dispersal capacity of zoospores depends on their viability and environmental factors (Hoffmann \& Camus 1989, Reed et al. 1992, Fukuhara et al. 2011). During this planktonic phase, zoospores are exposed to highly variable environmental conditions (Roleda et al. 2005, Roleda et al. 2010).Water motion can suspend 
zoospores in the euphotic zone, where zoospores may be exposed more directly to solar radiation. UVB radiation induces zoospore mortality, photoinhibition of photosynthesis (Wiencke et al. 2004, Roleda et al. 2005), produces DNA damage, and changes in cell structure (Wiencke et al. 2004, Roleda et al. 2006, Karsten et al. 2011) in brown seaweeds. The impact of direct exposure of zoospores to UVB varies depending on the species, their tolerance to this stressor and their vertical distribution (Roleda et al. 2005, 2010; Wiencke et al. 2006).

Seaweed invasions are an important threat to marine ecosystems worldwide (Valentine et al. 2007) because they alter the natural properties of the ecosystem and may have negative economic effects for aquaculture (e.g. fouling on nets, ropes, boats, etc.). Furthermore, the control and eradication of invasive species is costly (Dukes \& Mooney 1999, Valentine \& Johnson 2003, Valentine et al. 2007, Schaffelke et al. 2007). The establishment and spread of invasive species have both been associated with disturbances of the environment (Valentine \& Johnson 2003), and the success of these species has been related principally to their high growth, and regenerative and dispersal capacity (Rejmanek \& Richardson 1996, Nyberg \& Wallentinus 2005). However, high physiological acclimation capacity of these species to habitat and seasonal variations may play an important role in invasion success (Raniello et al. 2004, Lockwood \& Somero 2011). For example, Yamashita et al. (2000) found that the invasive tree Bischofia javanica has faster physiological acclimation and better use of nutrients after high light compared to native species and these characteristics could contribute to its success as an invader. Daehler (2003) compared the performance of native versus invasive plants and suggested that invasive species are more advantaged in areas with high resource availability and high physical disturbance. The success of the invasive green seaweed Caulerpa racemosa var. occidentalis may be due to its high physiological plasticity to different microhabitats and to temporal variation of abiotic factors (Raniello et al. 2004). While physiological acclimation and adaption might play an important role in seaweeds invasions, only a few studies have focused on the physiological responses of invasive seaweeds to environmental changes (Raniello et al. 2004, Henkel et al. \& Hofmann 2008).

The invasive brown seaweed Undaria pinnatifida, native to Asia, has a heteromorphic life cycle with macroscopic sporophytes that release motile zoospores and microscopic gametophytes that produce gametes. As noted earlier, the establishment and persistence of non-indigenous seaweeds depends greatly on the survival of early life stages (Vadas et al. 
1992), thus the survival of zoospores of $U$. pinnatifida is crucial for the dispersal and growth of populations. Adverse environmental conditions during this stage could affect the survival and development of individuals and therefore, could influence the whole community. The sporophyte of $U$. pinnatifida releases zoospores all year around in New Zealand; although release occurs mainly in Winter and early Spring when light conditions are lower (Hay 1990, Campbell et al. 1998). In Wellington, UVB irradiances during Winter and early Spring vary from $\sim 400$ to $1200 \mathrm{mWm}^{-2}$, while in Summer they can reach $\sim 1800 \mathrm{mWm}^{-2}$ (see Chapter 5). Thus, zoospores of $U$. pinnatifida might be exposed to relatively high UVB irradiances under some conditions. However, U. pinnatifida is highly successful in colonizing new environments and this success might be due to their high tolerance to environmental conditions. Nevertheless, the tolerance and susceptibility of zoospores of $U$. pinnatifida to environmental stressors remain unstudied. Some populations of $U$. pinnatifida inhabit the intertidal zone (Schiel \& Thompson 2012), thus during spores release, zoospores might be exposed to harmful UVB irradiances. Because $U$. pinnatifida is a successful invader, I hypothesised that motile zoospores of this species are tolerant to UVB radiation and direct exposure to UVB will have little impact this life stage. The objective of this study was to examine the tolerance of zoospores of $U$. pinnatifida to UVB radiation. For this the effect of changes of UVB irradiances on the photosynthetic performance, germination and growth rate, and DNA content were examined in zoospores of $U$. pinnatifida.

\subsection{Material and Methods}

\section{Zoospores}

Mature sporophytes of $U$. pinnatifida were collected by hand in the intertidal zone of Princess Bay, Wellington, $\left(41^{\circ} 20^{\prime} 39.94^{\prime \prime}\right.$ S, $174^{\circ} 47^{\prime} 17.07^{\prime \prime}$ E) during low tide. Sporophylls of 6-8 individuals for each experiment were separated and cleaned with tap water to remove epiphytes. To induce zoospores release, the sporophylls were immersed in filtered seawater ( $2 \mu \mathrm{m}$ pore size filter) at $\pm 15{ }^{\circ} \mathrm{C}$ and exposed to natural light close to a window for $45 \mathrm{~min}$. Zoospore concentration was counted by using a Neubauer Chamber on a light microscope (Leica,DM LB, Germany). 
Light treatments

Photosynthetically active radiation (PAR, 400-700nm) was provided by white fluorescent tubes (36W/840, Davis, New Zealand) and UVB radiation (295-320nm) was supplied with UVB fluorescent tubes (TL 40W/12RS, Phillip, New Zealand) with an emission peak at 302 $\mathrm{nm}$ and emitting range of 290-390 $\mathrm{nm}$. The experimental design consisted of two treatments, 1) $P A R+U V B(P B)$, where samples were exposed to full radiation from both lamps and 2) PAR (P), where samples were covered with a polycarbonate sheet that cuts radiation from and below 390nm. UVB lamps were cover with PVC filters to cut radiation below 290nm. Radiation was measured with a SpectroSense2+ radiometer (Skye Instrument Ltd. United Kingdom); for PAR measurements a 4-Chanel Sensor SK 1850/SS2 was used and for UVB a UVB sensor SKU 430/SS2. Experimental irradiances are shown in Table 2.1. The UVB and PAR irradiances used in these experiments are similar to light irradiances in the water column and/or intertidal of Wellington coast during Spring and Summer (see Chapter 5).

\section{Chlorophyll fluorometry}

Photosynthetic efficiency was measured using a Pulse Amplitude Modulation (PAM) fluorometer (Water-PAM) connected to a PC with WinControl software (Heinz Walz GmbH, Effeltrich, Germany). Before measurement, samples were dark adapted for $10 \mathrm{~min}$ and the maximum quantum yield was obtained. Dark acclimation permits all reaction centres of PSII to be open (all primary acceptors are oxidized) and heat dissipation to be minimal. Thus, dark adapted samples have a minimal fluorescence yield $\left(\mathrm{F}_{\mathrm{o}}\right)$. After a saturating pulse of actinic light, all reaction centres close and samples reach maximal florescence $\left(\mathrm{F}_{\mathrm{m}}\right)$. The difference between $F_{o}$ and $F_{m}$ gives the variable fluorescence $\left(F_{v}\right)$ that indicates the capacity of the sample for photochemical quenching. The maximum quantum yield of PSII was defined as $\mathrm{F}_{\mathrm{v}} / \mathrm{F}_{\mathrm{m}}$. 
Table 2.1 Experimental irradiances in the different experiments.

\begin{tabular}{|c|c|c|c|c|c|}
\hline \multirow[b]{3}{*}{ Experiment 1} & \multicolumn{5}{|c|}{ Experimental irradiances } \\
\hline & \multirow{2}{*}{$\begin{array}{l}\text { PAR } \\
\left(\mu \mathrm{mol} \text { photon } \mathrm{m}^{-2} \mathrm{~s}^{-1}\right)\end{array}$} & \multirow{2}{*}{$\begin{array}{l}\text { UVB } \\
\left(\mathrm{Wm}^{-2}\right)\end{array}$} & & & \\
\hline & & & & & \\
\hline PB & $33 \pm 1.7$ & $0.5 \pm 0.2$ & $1.0 \pm 0.1$ & $1.5 \pm 0.8$ & $2.0 \pm 0.3$ \\
\hline $\mathrm{P}$ & $31.5 \pm 1.7$ & & & & \\
\hline \multicolumn{6}{|l|}{ Experiment 2} \\
\hline PB & $35 \pm 1.7$ & $0.25 \pm 0.1$ & $0.5 \pm 0.2$ & $0.75 \pm 0.3$ & - \\
\hline $\mathrm{P}$ & $31.5 \pm 1.7$ & & & & \\
\hline Low light & $8 \pm 1.7$ & - & - & - & - \\
\hline
\end{tabular}

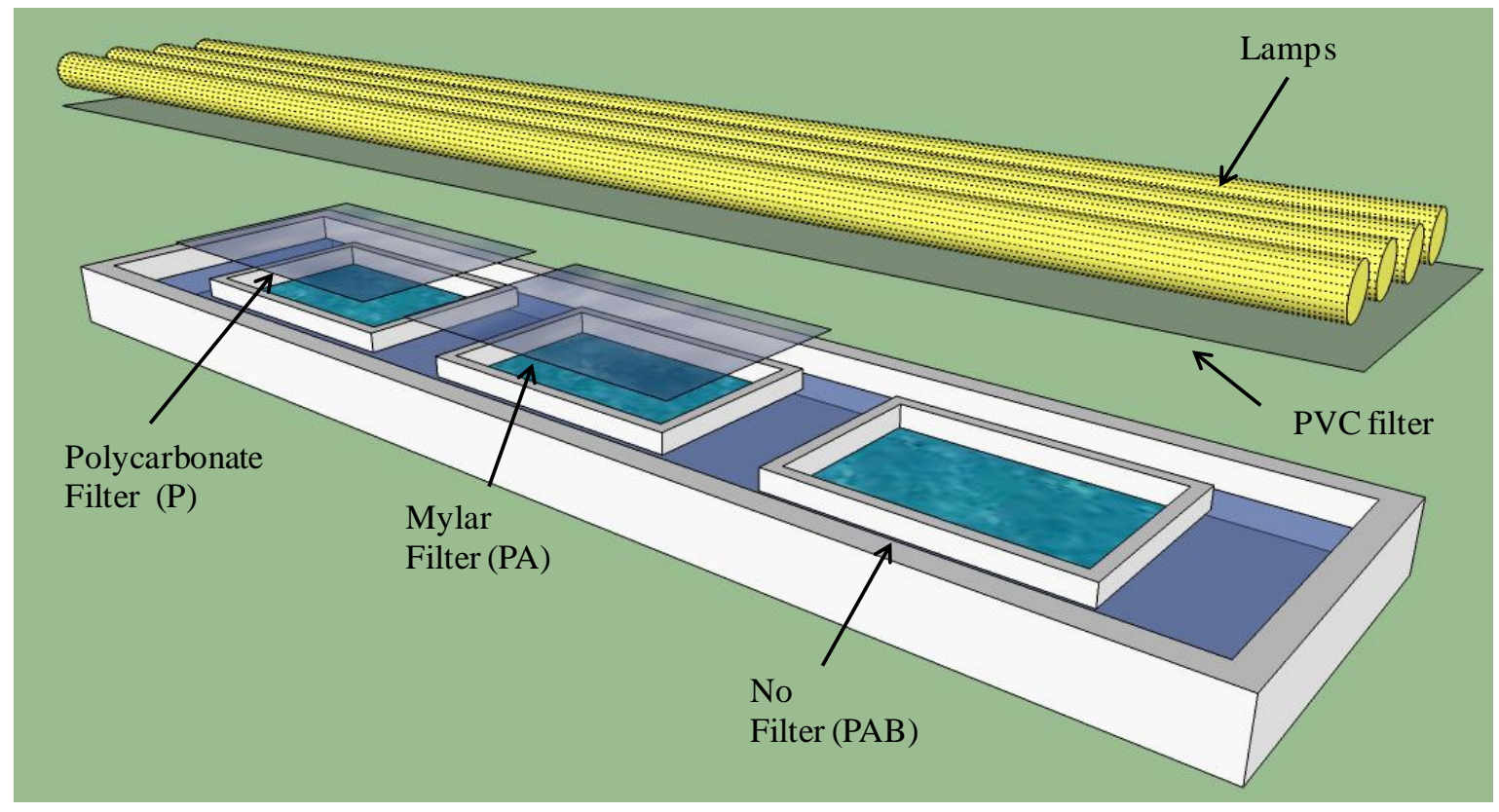

Fig. 2.1 Experimental set up. 
Photosynthesis experiments were performed at four increasing irradiances of UVB $(0.5,1.0$, 1.5 and $2.0 \mathrm{Wm}^{-2}$ ) and stable PAR (table 2.1). For each irradiance, an independent experiment of $8 \mathrm{~h}$ duration was performed at different days with new algal material. After adjustment of zoospore concentration to $3 \times 10^{5}$ spores $\mathrm{ml}^{-1}, 200 \mathrm{ml}$ of zoospores solution was poured into each of 8 plastic chambers $(18 \mathrm{~cm} \times 10 \mathrm{~cm} \times 5.5 \mathrm{~cm} \times 5.5 \mathrm{~cm})$, where 4 of them were covered with the polycarbonate filter ( $\mathrm{P}$ treatment) and 4 exposed directly to lamps (PB treatment) for $2 \mathrm{~h}$ and $4 \mathrm{~h}$ at $15{ }^{\circ} \mathrm{C} \quad(\mathrm{n}=4$ per treatment $)$. The plastic containers were randomly distributed using the software tool "research randomizer" (Urbaniak \& Plous 2013). To obtain different UVB irradiances, the height of UVB lamps above the samples was modified with respect to the samples. Before exposure to light treatments, $\sim 5 \mathrm{ml}$ of the zoospore solution was poured into a quartz cuvette, left for $10 \mathrm{~min}$. in the dark and then $\mathrm{F}_{\mathrm{v}} / \mathrm{F}_{\mathrm{m}}$ was measured at time zero (control) (Roleda et al. 2005). At the end of each exposure time, $5 \mathrm{ml}$ of samples of each replicate were poured in quartz cuvettes, left in darkness for $10 \mathrm{~min}$. and $\mathrm{F}_{\mathrm{v}} / \mathrm{F}_{\mathrm{m}}$ was measured. At the end of each exposure, subsamples $(50 \mathrm{ml})$ were left for recovery under dim light conditions $\left(8 \mu \mathrm{mol}\right.$ photon $\left.\mathrm{m}^{-2} \mathrm{~s}^{-1}, 0 \mathrm{Wm}^{-2} \mathrm{UVB}\right) . \mathrm{F}_{\mathrm{v}} / \mathrm{F}_{\mathrm{m}}$ was measured after $2 \mathrm{~h}$ and $4 \mathrm{~h}$ of recovery of each exposure time.

Experiment 2: Effect of UVB on spore germination, germination tube growth and DNA content

Germination, germination tube growth and DNA content experiments were performed at three UVB irradiances and stable PAR (Table 2.1). As above, the height of UVB lamps were changed with respect the samples to obtain different UVB irradiances. Plastic chambers $(n=6)$ were filled with $200 \mathrm{ml}$ zoospore suspension, three of which were exposed to PAR and UVB radiation (PB treatment) and the rest were covered with polycarbonate filters (P treatment). The zoospore concentration was $4 \times 10^{5}$ cells $\mathrm{ml}^{-1}$. Aliquots $(2 \mathrm{ml})$ of zoospore suspension were taken at the beginning of the experiment, and put into small petri dishes $(40 \mathrm{~mm} \times 12 \mathrm{~mm})$ after every two hours of exposure $(0,2,4,6 \mathrm{~h}$ of exposure). Dishes with zoospores suspension were filled with filtered seawater $(4 \mathrm{ml})$ and sea water was changed twice a day to avoid desiccation and to maintain salinities at normal levels. These dishes were then left under low light conditions without a cover $\left(8 \mu \mathrm{mol}\right.$ photon $\left.\mathrm{m}^{-2} \mathrm{~s}^{-1}, 0 \mathrm{Wm}^{-2} \mathrm{UVB}\right)$ with a photoperiod of $12: 12 \mathrm{~h}$ (day:night) for 6 days to recover. Germination and growth of the germination tube were determined 2 and 6 days after treatment by taking photographs of the bottom of each petri dish 
(QImaging, MicroPublisher 0.5 33 RTV, Canada) attached to a light microscope (Leica DM LB, Germany) at x 20 objective magnification that represented an area of $0.109 \mathrm{~mm}^{-2}$. Images were analyzed with Image Pro-Plus (USA) software. Zoospores were counted as germinated when a visible germination tube had developed. Germination was expressed as a percentage of the total of zoospores per replicate. Growth of the germination tube was determined by measuring the germination tube length $(\mu \mathrm{m})$ from the edge of the zoospore to the end of the tube.

For DNA content analysis, $1 \mathrm{ml}$ samples of zoospores suspension $(\mathrm{n}=3$, pre treatment) were taken at $0,2,4$ and $6 \mathrm{~h}$ exposure from treatments and then fixed in $1 \%$ formaldehyde. To determine DNA content, samples were centrifuged for $5 \mathrm{~min}$. to concentrate the zoospores. Supernatant was removed $(0.5 \mathrm{ml})$ and the zoospore DNA was stained with $0.8 \mathrm{uM} 4,6$ diamidino-2-phenylindole (DAPI) for $30 \mathrm{~min}$. The DNA content was determined with a flow cytometer (Becton Dickson, LSR II) equipped with a $100 \mathrm{~mW} 488 \mathrm{~nm}$ Blue laser and $20 \mathrm{~mW}$ 355 UV laser. 10,000 events were recorded per sample. The data analysis was performed by the Flow Jo (Treestart) software package to measure the mean fluorescence intensity (MFI) in each sample.

\section{Data analysis}

Data of photosynthetic performance measured as maximum quantum yield $\left(\mathrm{F}_{\mathrm{v}} / \mathrm{F}_{\mathrm{m}}\right)$ was analyzed separately for exposure and recovery time. A comparison between PAR (P) and PAR+UVB (PB) treatments was done with a linear mixed model (LME) in SPSS statistical software (corp, USA). Treatment $\mathrm{P}$ was used to discard any negative effect of PAR in the treatment PB. Due to the variability of photosynthetic capacity of zoospores at the beginning of the experiments, data of zoospores exposed to PB and recovery after exposure PB were normalised to the control (0h). Generalized linear mixed models (GLMM) were used to analyze the effect of UVB on photosynthesis of zoospores and their recovery. A binomial distribution was used due to the normalisation step. In these analyses, samples of zoospores suspension for photosynthesis measurements were included as a random factor because these samples represent just a proportion of each replicate exposed to treatments, while time and UVB irradiances were fixed factors. These analyses were conducted using the lme4 statistical package within $\mathrm{R}$ ( $\mathrm{R}$ development Core Team 2009). 
Differences in germination between UVB irradiances and time were assessed with a generalized lineal model (GLM) analysis of deviance (data were normally distributed without equal variance assumption). A Quasi-Binomial distribution was used when data was overdispersed (residual deviance > residual df). The length of the germination tube was analyzed with GLM analysis of deviance with gamma distribution for continuous data. A linear effect model (LME) was used to assess differences in DNA content at different UVB irradiances. Germination, length of germination tube, and DNA fluorescence were standardized among the experiments to enable comparison.

\subsection{Results}

\section{Experiment 1: Effect of UVB on Photosynthesis}

The effect of PAR $(\mathrm{P})$ and PAR+UVB $(\mathrm{PB})$, on maximum quantum yield $\left(\mathrm{F}_{\mathrm{v}} / \mathrm{F}_{\mathrm{m}}\right)$ of zoospores of Undaria pinnatifida is shown in Fig. 2.1. The $\mathrm{F}_{\mathrm{v}} / \mathrm{F}_{\mathrm{m}}$ of zoospores before exposure to treatments $(0 \mathrm{~h})$ was high but variable among treatments (LME, $\mathrm{t}=-3.722, \mathrm{p}=0.002$, Fig. 2.1). The variability at time 0 (controls) among experiments shows that differences in the physiological state of different batches of zoospores exist, due to experiments being performed at different days with different environmental conditions at the time of sporophyte collection. However, similar responses to light treatments was observed among experiments where there was a reduction in $\mathrm{F}_{\mathrm{v}} / \mathrm{F}_{\mathrm{m}}$ after $2 \mathrm{~h}$ exposure to $\mathrm{P}$ and $\mathrm{PB}$ but a greater reduction was observed for the PB treatment. This was true for all 4 UVB irradiances. After $4 \mathrm{~h}$ exposure there was a rise in $F_{v} / F_{m}$ in zoospores exposed to $P$ in all experiments, while a further decrease was observed in zoospores exposed to PB at all 4 UVB irradiances.

After exposure to light treatments (P and PB), chambers with zoospore suspension were left under low light conditions for zoospores to recover from the treatments. The $F_{v} / F_{m}$ of zoospores exposed for $2 \mathrm{~h}$ to $\mathrm{P}$ and $\mathrm{PB}$ recovered after 2 and $4 \mathrm{~h}$ of recovery under low light conditions. $\mathrm{F}_{\mathrm{v}} / \mathrm{F}_{\mathrm{m}}$ after recovery was higher in zoospores exposed to $\mathrm{P}$ alone compared to $\mathrm{PB}$. Moreover, the extent of the recovery in $\mathrm{F}_{\mathrm{v}} / \mathrm{F}_{\mathrm{m}}$ of zoospores exposed to $\mathrm{PB}$ reduced with increasing UVB irradiances (Fig. 2.1). A lower recovery was observed in zoospores exposed for $4 \mathrm{~h}$ to $\mathrm{PB}$ compared to the $2 \mathrm{~h}$ exposure, while recovery in $\mathrm{F}_{\mathrm{v}} / \mathrm{F}_{\mathrm{m}}$ was observed for zoospores 
exposed to $\mathrm{P}$ in the second $2 \mathrm{~h}$ of exposure with values of $\mathrm{F}_{\mathrm{v}} / \mathrm{F}_{\mathrm{m}}$ returning to values similar to those at $\mathrm{Oh}$.

The data of zoospores exposed to PB in Fig 2.1 were normalized to controls $(0 \mathrm{~h})$ so the response to different UVB irradiances and the later recovery could be compared among experiments. Relative $\mathrm{F}_{\mathrm{v}} / \mathrm{F}_{\mathrm{m}}\left(\mathrm{rF}_{\mathrm{v}} / \mathrm{F}_{\mathrm{m}}\right)$ declined dramatically after exposure for $2 \mathrm{~h}$ to $\mathrm{PB}$ at all UVB irradiances and longer exposure time (4h) to $\mathrm{PB}$ produced similar decreases in $\mathrm{rF}_{\mathrm{v}} / \mathrm{F}_{\mathrm{m}}$ (Fig. 2.2). There was no interaction between irradiances and time on $\mathrm{rF}_{\mathrm{v}} / \mathrm{F}_{\mathrm{m}}(\mathrm{GLMM}, \mathrm{z}=-$ 0.730, $\mathrm{p}=0.465)$, neither difference among irradiances $(\mathrm{z}=0.291, \mathrm{p}=0.771)$ nor time (GLMM, $\mathrm{z}=-1.014, \mathrm{p}=0.311)$.

The standardized recovery in $\mathrm{rF}_{\mathrm{v}} / \mathrm{F}_{\mathrm{m}}$ of zoospores exposed to $\mathrm{PB}$ for 2 and $4 \mathrm{~h}$ and then left to recover for $4 \mathrm{~h}$ in low light conditions $\left(8 \mu \mathrm{mol} \mathrm{m} \mathrm{m}^{-2} \mathrm{~s}^{-1}\right)$ is shown in Fig. 2.3. There was no interaction between exposure time in the recovery and irradiances (GLMM, z=-0.351, $\mathrm{p}=0.725)$. The recovery in $\mathrm{rF}_{\mathrm{v}} / \mathrm{F}_{\mathrm{m}}$ of zoospores exposed to $\mathrm{PB}$ was higher in zoospores exposed for $2 \mathrm{~h}$ than for $4 \mathrm{~h}$, except at the highest UVB irradiance $\left(2.0 \mathrm{Wm}^{-2}\right)$ where there was almost no recovery for zoospores exposed to 2 and $4 \mathrm{~h}$ (Fig.2.3). No differences in the recovery $\mathrm{rF}_{\mathrm{v}} / \mathrm{F}_{\mathrm{m}}$ of zoospores exposed for $2 \mathrm{~h}$ to different UVB irradiances was detected (GLMM, $\mathrm{z}=-1.839$, $\mathrm{p}=0.066$ ), although there is steady decline in the recovery capacity as UVB irradiances increases (Fig. 2.3). Zoospores exposed for longer time (4h) had some recovery in $\mathrm{rF}_{\mathrm{v}} / \mathrm{F}_{\mathrm{m}}$ at the lowest UVB irradiances ( 20\%, Fig. 2.3); however no differences among UVB irradiances were detected (GLMM, z=-0.992, $\mathrm{p}=0.321$ ). 

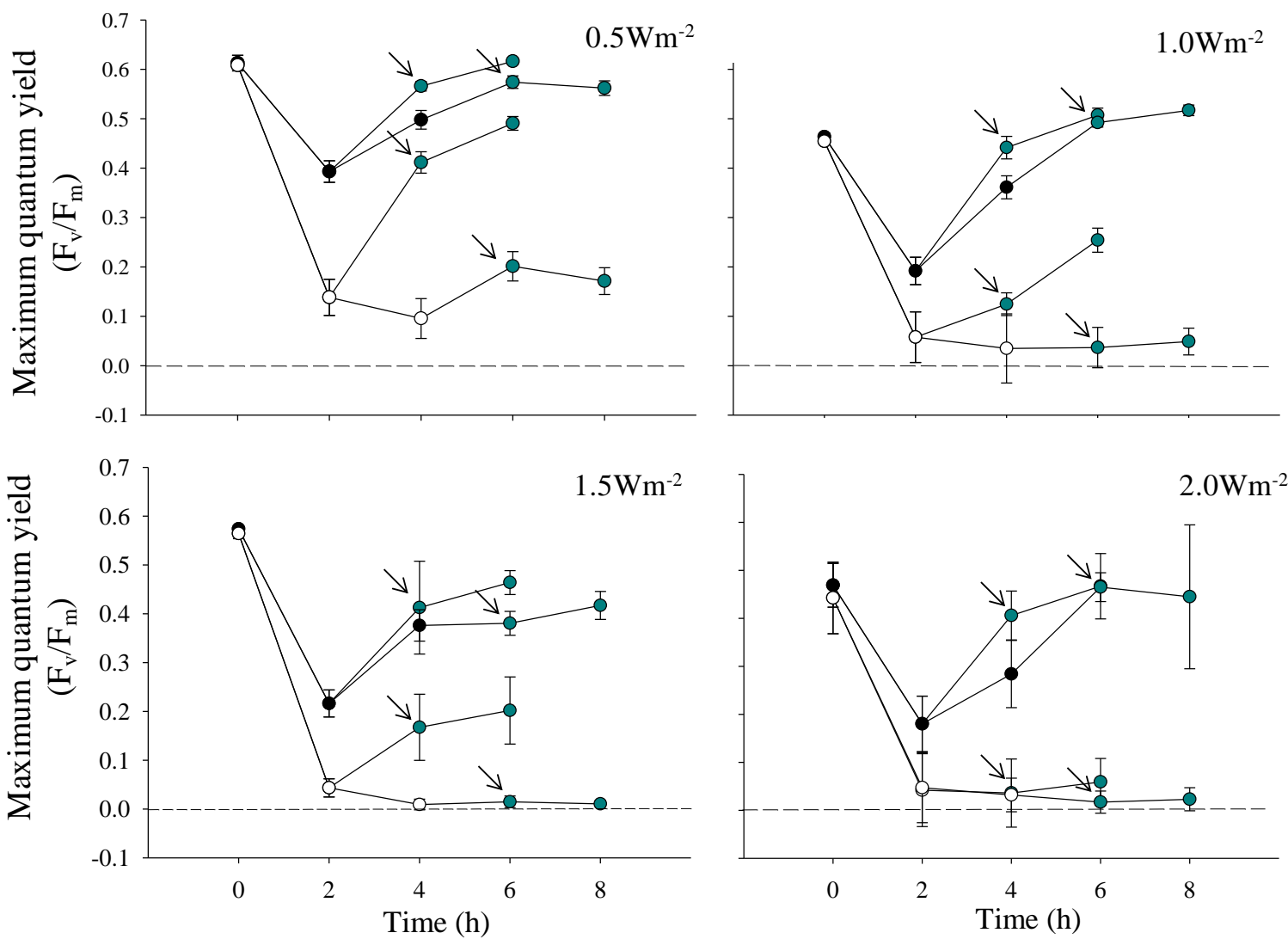

Р $\bigcirc$ Рв $\bigcirc$ Recovery

Fig. 2.2 Effect of light treatments $(P$ and $P B)$ on maximum quantum yield $\left(F_{v} / F_{m}\right)$ of motile zoospores of $U$. pinnatifida. Zoospores were irradiated for 2 and $4 \mathrm{~h}$ and then left to recover under low light conditions $\left(8 \pm 2 \mu \mathrm{mol}\right.$ photon $\left.\mathrm{m}^{-2} \mathrm{~s}^{-1}\right)$ at $15^{\circ} \mathrm{C}$. PAR was constant in all experiments during exposure $\left(31 \pm 2 \mu \mathrm{mol}\right.$ photon $\left.\mathrm{m}^{-2} \mathrm{~s}^{-1}\right)$ and different UVB irradiances were used. Arrows show the beginning of recovery for each exposure point. Data are means and vertical bars show standard error (SE, $n=4)$. 

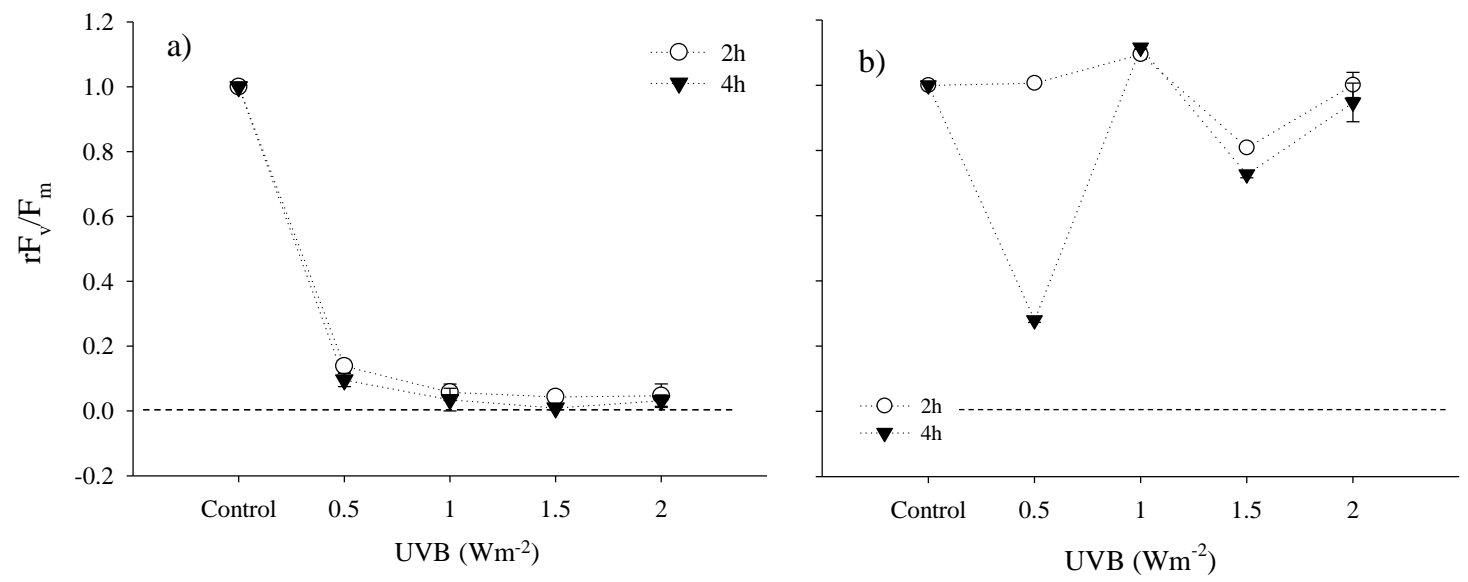

Fig. 2.3 Effect of short term exposure to $\mathrm{PB}(\mathrm{a})$ and $\mathrm{P}(\mathrm{b})$ on relative quantum yield $\left(\mathrm{rF}_{\mathrm{v}} / \mathrm{F}_{\mathrm{m}}\right)$ of $\mathrm{PB}$ treated zoospores of $U$. pinnatifida exposed for 2 and $4 \mathrm{~h}$ to different UVB irradiances. These values are derived from those in Fig 2.1 after normalization to $\mathrm{T}_{0}$ controls. White dots represent the mean of standardized $\mathrm{F}_{\mathrm{v}} / \mathrm{F}_{\mathrm{m}}$ of zoospores exposed for $2 \mathrm{~h}$ to $\mathrm{PB}$ and black triangles to zoospores exposed for $4 \mathrm{~h}$. Data are means and vertical bars show standard error (SE, $n=4)$.
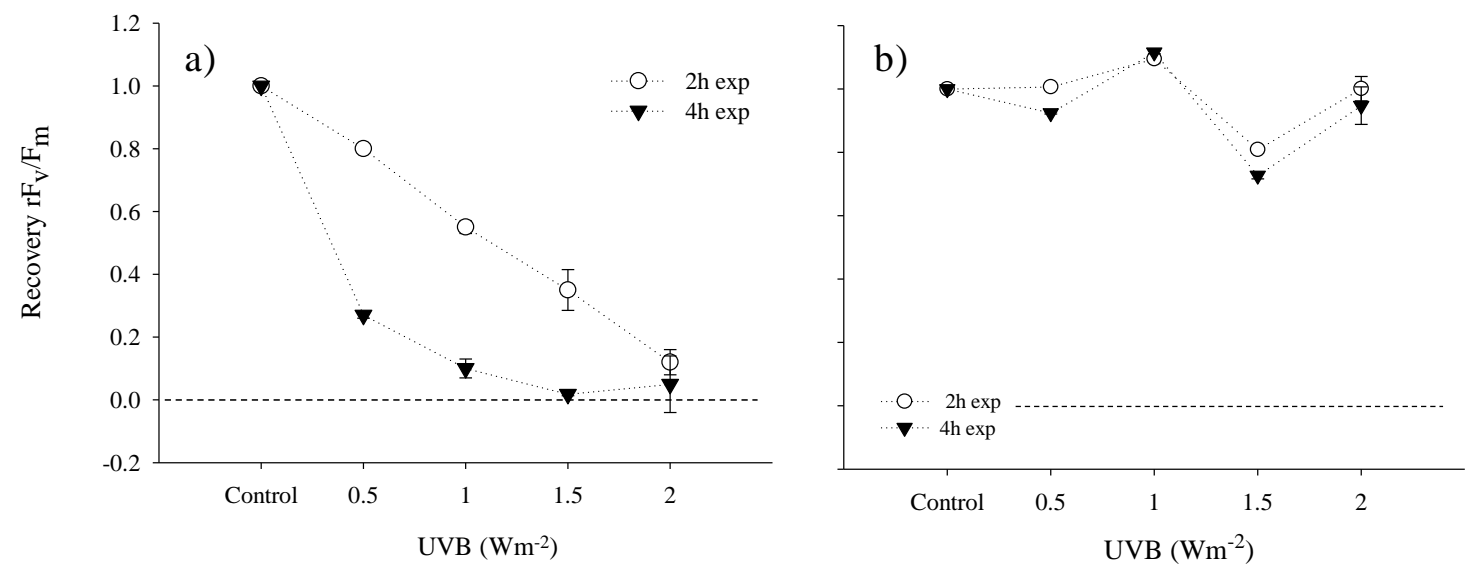

Fig. 2.4. Relative quantum yield $\left(\mathrm{rF}_{\mathrm{v}} / \mathrm{F}_{\mathrm{m}}\right)$ of $\mathrm{PB}$ (a) and $\mathrm{P}$ (b) treated zoospores normalised to $\mathrm{T}_{0}$ controls after $4 \mathrm{~h}$ of recovery in zoospores treated with $\mathrm{PB}$ for $2 \mathrm{~h}$ (white dots) and $4 \mathrm{~h}$ (black triangles). Recovery was under low PAR only $\left(8 \pm 2 \mu \mathrm{mol}\right.$ photon $\left.\mathrm{m}^{-2} \mathrm{~s}^{-1}\right)$. Data are the mean and vertical bars show standard errors (SE, $n=4)$. 


\section{Experiment 2: Effect of UVB on germination, growth and DNA content}

After exposure to $\mathrm{P}$ and $\mathrm{PB}$, dishes with zoospore suspension were left with a photoperiod of 12:12 (low light, $8 \mu \mathrm{mol}$ photons $\mathrm{m}^{-2} \mathrm{~s}^{-1}$ ) for 6 days to allow zoospores to germinate. The effect of exposure to light treatment (P and PB) on zoospores germination is shown in Fig. 2.4. High germination of zoospores exposed to $\mathrm{P}$ and then incubated under low light conditions was observed after 2 and 6 days of recovery regardless of the length of the exposure to high PAR irradiance (Fig. 2.4). Germination of zoospores not exposed to light treatments (0h exposure) was different among experiments (Fig 2.4, a, c, and e), since the experiments were performed on different days (GLM, $\mathrm{z}=5,119, \mathrm{p}=0.000$ ). The addition of UVB highly affected the germination rate in all experiments at all exposure times (Fig.2.4).

For comparison of the effect of different UVB irradiances in germination, data of PB treatment was standardized due to the variability in zoospores germination among the control (0h). There was no interaction between UVB irradiances and exposure time on germination after 2 days of recovery (GLM, $\mathrm{t}=-1.600, \mathrm{p}=0.120)$ nor differences in germination among UVB irradiances (GLM, t=0.361, p=0.721) nor time (GLM, t=0.161, p=873). However, differences among irradiances after $2 \mathrm{~h}$ of exposure were detected (GLM, $\mathrm{t}=-5.479, \mathrm{p}=0.0009 ; 4 \mathrm{~h}, \mathrm{t}=-5.479$, $\mathrm{p}=0.009$ ) where germination decreases as UVB irradiances increases. Higher germination was observed in zoospores exposed for $2 \mathrm{~h}$ at the lower UVB irradiances ( 35\%), while little germination was observed at the two higher irradiances. After 6 days of recovery the percentage of germination was higher in comparison to 2 days of recovery (Fig. 2.4), showing zoospores were able to germinate with longer recovery depending on the UVB dose they received. There was an interaction between UVB irradiances and exposure time in germination after 6 days of recovery (GLM, $\mathrm{t}=-5.718, \mathrm{p}=0.000$ ), thus the effect of different UVB irradiances in germination after 6 day of recovery was variable among exposure time (Fig. 2.4). At the lowest UVB irradiances $\left(0.25 \mathrm{Wm}^{-2}\right)$ germination decreased as exposure time increased, while for the two higher UVB irradiances $\left(0.5\right.$ and $\left.0.75 \mathrm{Wm}^{-2}\right)$ germination dropped significantly after $2 \mathrm{~h}$ of exposure and almost no germination was recorded at longer exposure time (Fig. 2.4). 

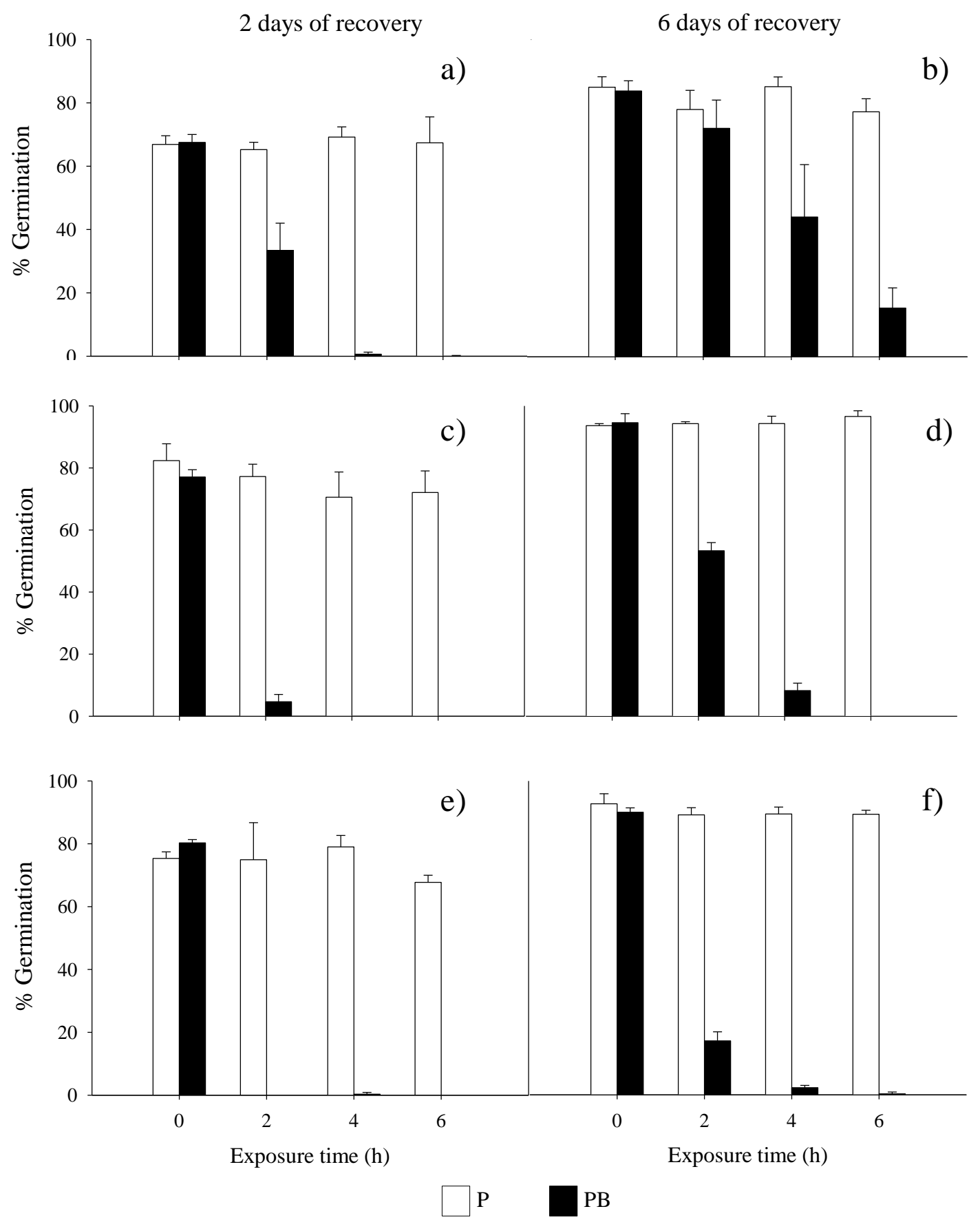

Fig. 2.5 Effect of two different light treatments on germination (\%) of motile zoospores of $U$. pinnatifida after 2 and 6 days of recovery in dim light conditions $\left(8 \pm 2 \mu \mathrm{mol}\right.$ photon $\left.\mathrm{m}^{-2} \mathrm{~s}^{-1}\right)$ after

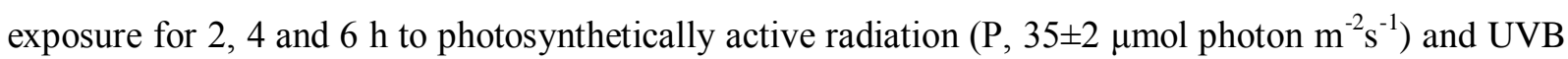
irradiances $(\mathrm{PB})$ at $15^{\circ} \mathrm{C}$. UVB irradiances were: a-b, $0.25 \mathrm{Wm}^{-2}$; c-d, $0.50 \mathrm{Wm}^{-2}$ and e-f, $0.75 \mathrm{Wm}^{-2}$. Data are mean and vertical bars show standard deviation $(\mathrm{SD}, n=3)$. 
Zoospores treated with P developed a long germination tube (over $10 \mu \mathrm{m}$ ) in all experiments, while the addition of UVB slowed the development of the germination tube in all experiments (Fig. 2.5). There was no interaction between UVB irradiances and exposure time in the development of the germination tube (GLM, t=1.947, $\mathrm{p}=0.0604)$ neither among UVB irradiances (GLM, $\mathrm{t}=-0.079, \mathrm{p}=0.937)$ nor among exposure times (GLM, $\mathrm{t}-1.841, \mathrm{p}=0.075)$. After 2 days of recovery only zoospores exposed for $2 \mathrm{~h}$ and $4 \mathrm{~h}$ to the lowest UVB irradiance were able to grow a germination tube (Fig. 2.5) at the lowest UVB irradiance; while no development of a germination tube was observed in zoospores exposed to the other UVB irradiances (0.5 and $0.75 \mathrm{Wm}^{-2}$, Fig. 2.5). After 6 days of recovery there was an interaction between UVB irradiances and exposure time for the mean length of germination tube (GLM, $\mathrm{t}=3.654, \mathrm{p}=0.000$ ), thus the effect of different UVB irradiances on the length of the germination tube was different through exposure time.

The germination tube after 6 days of recovery was longer than after 2 days of recovery in zoospores exposed to the lowest UVB irradiance $\left(0.25 \mathrm{Wm}^{-2}\right)$. Thus at the lowest UVB irradiances the growth of the germination tube decreased with longer exposure time, while for the two highest UVB irradiances little growth was observed in zoospores exposed for $2 \mathrm{~h}$ and almost no growth was observed for those exposed for 4 and 6h (Fig. 2.5).

DNA content was measured as mean fluorescence intensity (MFI). Due to the high variability in DNA fluorescence experiments at time 0 (controls), data from treatment PB was standardized to controls to compare the effect of different UVB irradiances on DNA fluorescence (Fig. 2.6). The effect of different UVB irradiances on DNA fluorescence after $2 \mathrm{~h}$ was compared only between the two highest irradiances because the samples treated with the lowest UVB irradiance $\left(0.25 \mathrm{Wm}^{-2}\right)$ were not well preserved and analysis could not be performed. Differences in the reduction in DNA fluorescence were found between UVB irradiances (LME, $\mathrm{t}=-2.645, \mathrm{p}=0.016$ ), but not among exposure time. After $2 \mathrm{~h}$ exposure, zoospores exposed to the medium irradiance $\left(0.5 \mathrm{Wm}^{-2}\right)$ had a reduction of $\sim 6 \%$ in DNA content, while a $\sim 26 \%$ decrease was observed at the highest UVB irradiance $\left(0.75 \mathrm{Wm}^{-2}\right)$. At $4 \mathrm{~h}$ exposure, the highest reduction in DNA fluorescence was observed at the highest UVB irradiance with $\sim 25 \%\left(0.75 \mathrm{Wm}^{-2}\right)$, while for the medium UVB irradiance was less than $5 \%$ and no reduction at the lower UVB irradiance (Fig. 2.6). At $6 \mathrm{~h}$ of exposure a higher decrease in DNA fluorescence was observed in zoospores irradiated with the medium and high UVB 
irradiances ( $\sim 5$ and 10\%, respectively) in comparison to $4 \mathrm{~h}$ of exposure (Fig.2.6). DNA fluorescence after $6 \mathrm{~h}$ of exposure decreased as UVB irradiances increased (Fig. 2.6).

2 days of recovery 6 days of recovery

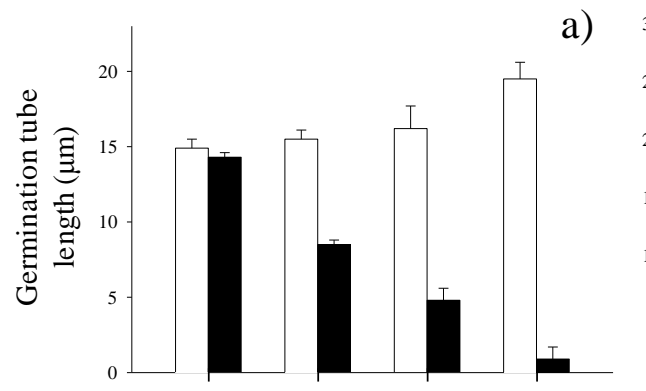

a)
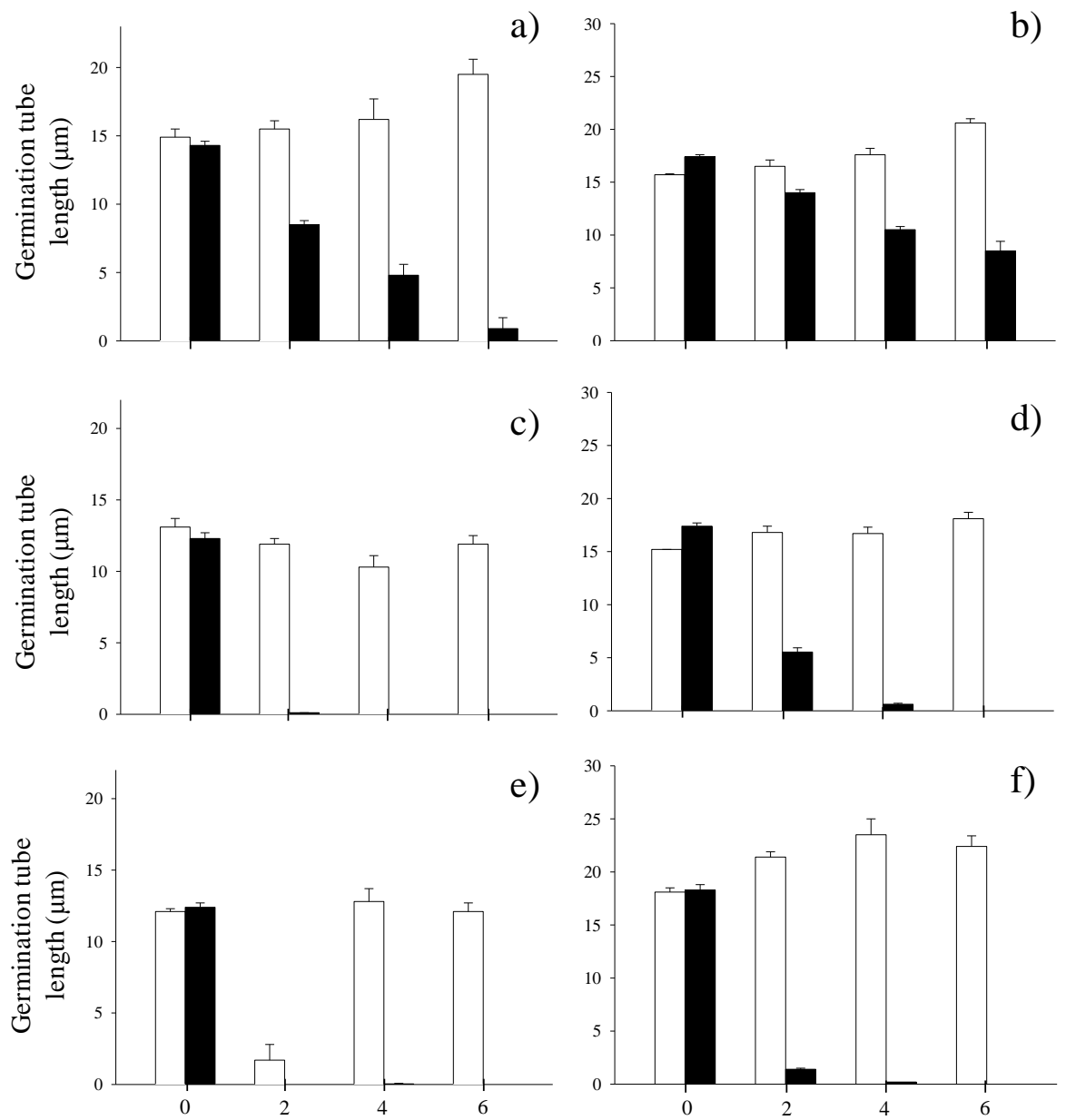

Exposure Time (h)

Exposure Time (h)

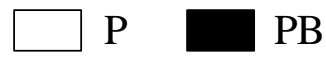

Fig. 2.6 Effect of two different light treatments in length of germination tube of motile zoospores of $U$. pinnatifida in day 2 and 6 of recovery in dim light conditions $\left(8 \pm 2 \mu \mathrm{mol}\right.$ photon $\left.\mathrm{m}^{-2} \mathrm{~s}^{-1}\right)$ after exposure for 2, 4 and $6 \mathrm{~h}$ to photosynthetically active radiation (P, 35 $\pm 2 \mu \mathrm{mol}$ photon $\mathrm{m}^{-2} \mathrm{~s}^{-1}$ ) and UVB irradiances (PB) at $15^{\circ} \mathrm{C}$. UVB irradiances were: a-b, $0.25 \mathrm{Wm}^{-2}$; c-d, $0.50 \mathrm{Wm}^{-2}$ and e-f $0.75 \mathrm{Wm}^{-2}$. Data are mean and vertical bars show standard deviation $(\mathrm{SD}, n=3)$. 


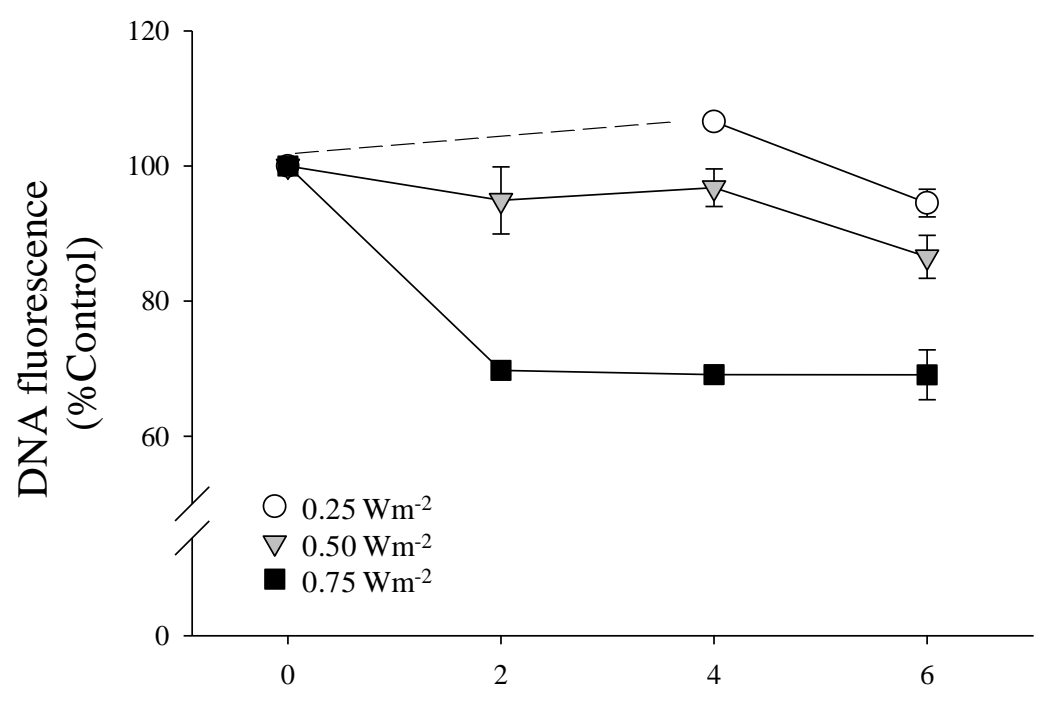

Exposure time (h)

Fig 2.7 Effect of different UVB irradiances in DNA content measured as mean fluorescence intensity (MFI) of motile zoospores of Undaria pinnatifida at $15^{\circ} \mathrm{C}$. Data were standardized to controls (0h). Vertical bars show standard error (SE, $n=3$ ). Data from the lowest UVB irradiance $\left(0.25 \mathrm{Wm}^{-2}\right)$ at $2 \mathrm{~h}$ of exposure are missing.

\subsection{Discussion}

UVB radiation alters physiological processes in seaweeds such as photosynthesis (Wiencke et al. 2000, Roleda et al. 2005, 2006, 2010,), production of screening substances (Swanson \& Druehl 2002, Roleda et al. 2006, Müller et al. 2009) and produces molecular and DNA damage (van de Poll et al. 2001, 2002, Roleda et al. 2010). This study is the first to examine the effect of UVB on zoospores of the invasive kelp U. pinnatifida.

The experiments in this study attempted to simulate the light conditions in the field where zoospores are protected by the thick tissue of the sporophyll prior to their release into the water column. The zoospores were therefore held under low light before introduction to the treatment set up and then exposed to PAR and UVB levels similar to those in the water column. A reduction in $\mathrm{F}_{\mathrm{v}} / \mathrm{F}_{\mathrm{m}}$ occurred during the first two hours of exposure to $\mathrm{P}(33 \pm 2 \mu \mathrm{mol}$ 
photon $\mathrm{m}^{-2} \mathrm{~s}^{-1}$ ) suggesting that zoospores had been acclimated to lower light conditions prior to the beginning of the experiment. The subsequent increase in $F_{v} / F_{m}$ under the same light conditions illustrates that zoospores were able to acclimate rapidly to higher light conditions. This reduction and then increase in $\mathrm{F}_{\mathrm{v}} / \mathrm{F}_{\mathrm{m}}$ by zoospores exposed to $\mathrm{P}$ treatment was observed in all experiments; but there was variability in the initial $F_{v} / F_{m}$ among experiments. Samples were collected on different days over Winter/Summer 2011, and this may have led to variability in the physiological stage among zoospores of the different experiments before exposure to treatments. The $\mathrm{F}_{\mathrm{v}} / \mathrm{F}_{\mathrm{m}}$ of zoospores of three Laminariales species from Helgoland (German Bight) and Spitsbergen (Arctic) also reduced under similar experimental conditions, and reduced further at increasing doses of PAR as a function of exposure time (Roleda et al. 2007). Thus, Laminariales species were photoinhibited after $1 \mathrm{~h}$ exposure to $22 \mu$ mol photon $\mathrm{m}^{-2} \mathrm{~s}^{-1}$ and further depression in $\mathrm{F}_{\mathrm{v}} / \mathrm{F}_{\mathrm{m}}$ was observed at longer exposure at the same conditions (Roleda et al. 2007). The PAR irradiance used during the experiments for U. pinnatifida was higher than those used by Roleda et al. (2007), and this demonstrates that zoospores of $U$. pinnatifida could acclimated to higher light conditions than other species of the same order. $U$. pinnatifida inhabits the intertidal to the subtidal zone of Wellington coastline; therefore, zoospores must be able to tolerate high fluxes of visible and UVB radiation, while the Laminariales species studied by Roleda et al. (2007) inhabit the upper sublitoral to lower sublitoral receiving lower irradiances of light, and were therefore adapted to lower light conditions than $U$. pinnatifida. This data suggests their rapid photoacclimation will allow $U$. pinnatifida zoospores to tolerate the light conditions that exist when they are released and also could allow $U$. pinnatifida to survive in areas with higher light irradiances. The ability to acclimate to a wide range of light irradiances might increase the success of this species to invade.

The addition of UVB produced a significant decrease in $\mathrm{F}_{\mathrm{v}} / \mathrm{F}_{\mathrm{m}}$ in comparison to $\mathrm{P}$ alone. The reduction in $\mathrm{F}_{\mathrm{v}} / \mathrm{F}_{\mathrm{m}}$ of zoospores of $U$. pinnatifida exposed to $\mathrm{PB}$ was similar among UVB irradiances and exposure time, but the recovery in $\mathrm{F}_{\mathrm{v}} / \mathrm{F}_{\mathrm{m}}$ was highly dependent on both the UVB exposure time and the UVB irradiances. Thus, photosynthesis efficiency of zoospores after recovery time was higher in those exposed for $2 \mathrm{~h}$ than $4 \mathrm{~h}$, except at the highest UVB irradiance. Furthermore, the recovery in $\mathrm{F}_{\mathrm{v}} / \mathrm{F}_{\mathrm{m}}$ improved as UVB irradiances decreased. The photosynthetic performance of zoospores of $U$. pinnatifida after exposure to UVB had similar reduction in $\mathrm{F}_{\mathrm{v}} / \mathrm{F}_{\mathrm{m}}(76-84 \%)$ compared to zoospores of other Laminariales species from the 
Northern Hemisphere (85-95\%) after similar UVB treatment (Roleda et al. 2005, 2006). A fast recovery in $\mathrm{F}_{\mathrm{v}} / \mathrm{F}_{\mathrm{m}}$ in zoospores of $U$. pinnatifida exposed to low doses of $\mathrm{UVB}$ was observed after a short period of recovery (4h), while Laminariales spp. had higher recovery but after a longer recovery time (48h). A fast recovery in $\mathrm{F}_{\mathrm{v}} / \mathrm{F}_{\mathrm{m}}$ of $U$. pinnatifida after exposure to UVB could increase the opportunity to survive and succeed in the invasion process.

Zoospores of Laminaria digitata, L. saccharina, L. hyperborea had a low recovery in $\mathrm{F}_{\mathrm{v}} / \mathrm{F}_{\mathrm{m}}$ after $48 \mathrm{~h}$ demonstrating the negative effect of UVB on the photosynthetic apparatus; moreover, photosynthesis of zoospores was depressed in a dose-dependent manner (Roleda et al. 2010). This reduction in $\mathrm{F}_{\mathrm{v}} / \mathrm{F}_{\mathrm{m}}$ is likely due to changes and/or damage to the light harvesting complex, PSII centres and/or the Calvin-Benson Cycle (Franklin et al. 2003). The main target is the D1 protein of PSII (Friso et al. 1994, Babu et al. 1999, Roleda et al. 2004, 2005, 2006, Nishiyam et al. 2011). When D1 is degraded, and its rates of biosynthesis and repair are slower than its degradation, photodamage is produced, and recovery may occur with longer recovery time or may not occur (Melis 1999, Tyystjärvi 2008). Differences among UVB doses in the recovery of zoospores of $U$. pinnatifida might be due to degradation of protein D1. Thus, at lower UVB dose the biosynthesis and repair of protein D1 might be higher than its degradation, and therefore, faster recovery is observed. In contrast, higher UVB dose might produce higher degradation, so the recovery is slower.

Germination and the length of the germination tube of zoospores of $U$. pinnatifida exposed to $\mathrm{P}$ were not affected by exposure to high PAR radiation. According to Roleda et al. (2007), low photon flux densities (PFD) of PAR in the range of 10-20 $\mu \mathrm{mol}$ photon $\mathrm{m}^{-2} \mathrm{~s}^{-1}$ are optimum for germination of zoospores, however, high PAR may decrease germination rate (Wiencke et al. 2004). Morelissen et al. (2013) suggested that the optimum light requirement for germination of zoospores of $U$. pinnatifida is between 28 and $145 \mu \mathrm{mol}$ photon $\mathrm{m}^{-2} \mathrm{~s}^{-1}$, and this observation is supported here. In my study, zoospores of $U$. pinnatifida were exposed to $33 \mu \mathrm{mol}$ photon $\mathrm{m}^{-2} \mathrm{~s}^{-1}$ for no more than $6 \mathrm{~h}$, and then left under low light conditions $(8 \mu \mathrm{mol}$ photon $\mathrm{m}^{-2} \mathrm{~s}^{-1}$ ) for 6 days. This illustrates that zoospores are able to germinate and develop a well formed germination tube at very low light conditions after exposure to higher irradiances.

The addition of UVB reduced the germination rate and delayed the growth of germination tube of zoospores of $U$. pinnatifida and this decrease was dependant on the UVB irradiances and exposure time. A dose-dependent response of germination after exposure to UVB also was 
found in zoospores of Lessonia nigrescens and Lessonia. trabeculata (Tala et al. 2007), where the germination rate of both species decreased as UVB dose increased. After 2 days of recovery the germination rate of zoospores of $U$. pinnatifida exposed for $2 \mathrm{~h}$ at the lowest irradiance (UVB $0.25 \mathrm{Wm}^{-2}$ ) was around $40 \%$, and the mean length of the germination tube was smaller than $5 \mu \mathrm{m}$, and both parameters decreased further after longer UVB exposure times. Almost no germination was observed at the two higher UVB irradiances $(0.5$ and $0.75 \mathrm{Wm}^{-2}$ ). The germination rate increased with longer recovery time in all treatments, showing zoospores can recover from UVB stress, depending on the UVB dose they receive. Germination and tube growth were very sensitivity to UVB stress, although some zoospores were able to germinate and develop a germination tube after long recovery time. After settlement zoospores are exposed to less UVB compared to the water column due to light attenuation through the water column and via algal assemblages and irregular substrates of the rocky intertidal. This suggests that zoospores of $U$. pinnatifida might develop after UVB stress if they settle in areas with low exposure to direct sun light, for example, the subtidal, in low light areas of the rocky intertidal or under the protection of algal assemblages.

The effect of UVB on the DNA content of zoospores was evaluated by flow cytometry. Flow cytometry has been used in phytoplankton and microalgae in many analyses (Franqueira et al. 2000, Collier 2001, Readman et al. 2004, Haberkorn et al. 2011). However, to the best of my knowledge, this is the first time this approach has been used to determine and quantify DNA damage in zoospores of kelps. DNA fluorescence of zoospores of $U$. pinnatifida differed among UVB irradiances and decreased with increased exposure time and UVB irradiance. The decrease in DNA fluorescence has been associated to a disruption of the chromatin resulting in cellular death or apoptosis (Telford et al. 2002, 2004). However, the decrease of DNA fluorescence in these experiments might due to chromatin remodelling during DNA repair (Dinant et al. 2008) where chromatin must change its structure to let this process happen. Chromatin remodelling occurs during photorepair of cyclobutane pyrimidine dimers (CPDs). CPDs are the most common form of DNA damage induced by UV (Wiencke et al. 2000, Pakker et al. 2000, Van de Poll et al. 2001, 2002, Cadet et al. 2005, Pfeifer \& Besaratinia 2011) that inhibit transcription and replication of DNA and, therefore, disrupt cell metabolism and cell division (Buma et al. 1995, 2000, 2003, Ljungman \& Lane 2004). Steinhoff et al. (2008) suggested UVB might induce replication and modify the stereochemical conformation of chromatin in L. hyperborea exposed to treatments with UVB. The impact of UVB in DNA 
fluorescence mainly at the longest exposure time (6h) and the higher UVB irradiance of zoospores of $U$. pinnatifida combined with the effect in their photosynthetic capacity might explain the delay in germination and growth of the germination tube in zoospores observed from day 2 of recovery to day 6. UVB has direct consequences on cell metabolism, cell division, DNA, and, therefore, on growth and development of zoospores (van de Poll et al. 2001, Jian et al. 2007). Moreover, the energetic cost of protection and repair means that less energy is directed to the development and therefore, germination and growth are delayed (Roleda et al. 2005). DNA analysis by flow cytometry in these experiments complements the results of germination and development of zoospores. Thus, this method is a very helpful tool to obtain relevant information rapidly about a population of zoospores.

Zoospores of $U$. pinnatifida in these experiments were exposed to light treatments immediately after zoospore release, to simulate zoospore release in the water column during daylight. The impact of UVR on germination of zoospores of brown seaweeds has been investigated previously (Wiencke et al. 2004, Roleda et al. 2005, 2007, 2010) and their results indicate that zoospores are highly vulnerable to light stress and their susceptibility depends on the vertical distribution of the species (Wiencke et al. 2004, Roleda et al. 2005) and the stage of development (Veliz et al. 2006). Motile zoospores are small and have poorly-developed cell walls in comparison with settled zoospores (Henry \& Cole 1982, Veliz et al. 2006), and as suggested by Altamirano et al. (2003) their structural and cellular simplicity could explain their high susceptibility to UVB. This is further supported by the findings of Veliz et al. (2006), who observed a more detrimental effect in motile zoospores than settled ones. Zoospores of $U$. pinnatifida exposed to short periods of UVB recovered their photosynthetic capacity at all UVB irradiances. Furthermore, the germination findings in U. pinnatifida might help to understand the success of this species as an invader because they show that even the most susceptible life stage can recover from short term exposure to UVB. Motile zoospores are only likely to be exposed to direct light in the water column for short periods due water circulation in the intertidal zone; and are likely to settle and develop despite the initial stress they could suffer after release. In addition, attenuation and scattering of light within the water column reduces ambient irradiances and protection/shading by other algal assemblages might be important for the success of the survival of zoospores of $U$. pinnatifida.

$U$. pinnatifida is one of the most invasive organisms worldwide. Studies have focussed on the possible ecological impact of this species after its introduction, but there has been little focus 
on the physiological tolerance to environmental changes that could make this species a successful invader. As early life stages play an important role maintaining populations, it is important to understand and know their tolerances to adverse environmental factors. Physiological tolerance could also aid the understanding of the mechanisms of invasion that could be favouring invasive species. Moreover, knowing the vulnerable stages could help in decision-making and actions to control and/or eradicate this species. This study shows that zoospores of $U$. pinnatifida are able to recover from the impact of short exposure of UVB depending on the dose they receive. The medium-high UVB irradiances used in these experiments are similar to those found in the intertidal zone of the Wellington coast during spring and summer. Sporophytes of $U$. pinnatifida are fertile mainly at late winter and spring when UVB irradiances are low-medium and very variable due to cloud cover that attenuates incident UVB radiation. Synchronization of zoospores release when light conditions are low decreases the possibility for zoospores to be irreparably damaged by UVB radiation. Therefore, the recovery capacity of zoospores of $U$. pinnatifida combined with settlement of zoospores in attenuated light areas and its life cycle make this species very successful in maintaining viable populations despite the initial stress they might suffer, and could also facilitate invasion success in areas with variable medium-high UVB conditions. 


\subsection{References}

Alberts, S.C., Hollister-Smith, J. A., Mututua, R. S., Sayialel, S. N., et al. (2005). Seasonality and longterm change in a savanna environment. Cambridge studies in biological and evolutionary anthropology. 44: 157.

Altamirano, M., Flores-Moya, A., \& Figueroa, F. (2003) Effects of UV radiation and temperature on growth of germlings of three species of Fucus (Phaeophyceae). Aquatic Botany, 75(1):9-20.

Babu, T. S., Jansen, M.A.K., Greenberg, B.M., Malkin S., Matoo A.K., \& Edelman M. (1999) Amplified degradation of photosystem II D1 and D2 proteins under a mixture of photosynthetically active radiation and UVB radiation : dependence on redox status of photosystem II. Photochemistry and Photobiology, 69:553-559.

Baker, N. R. (2008). Chlorophyll fluorescence: a probe of photosynthesis in vivo. Annu. Rev. Plant Biol., 59, 89-113.

Binet, M. T., \& Stauber, J. L. (2006). Rapid flow cytometric method for the assessment of toxic dinoflagellate cyst viability. Marine environmental research, 62(4), 247-260.

Burkepile, D. E., \& Hay, M. E. (2006). Herbivore vs. nutrient control of marine primary producers: context-dependent effects. Ecology, 87(12), 3128-3139.

Byrne, M. (2012). Global change ecotoxicology: identification of early life history bottlenecks in marine invertebrates, variable species responses and variable experimental approaches. Marine environmental research. 76: 3-15.

Buma, A., Boelen, P., \& Jeffrey, W. (2003). UVR-induced DNA damage in aquatic organisms. UV effects in aquatic organisms and ecosystems. 291-327.

Buma, A. G., Hannen, E. J., Roza, L., Veldhuis, M. J., \& Gieskes, W. W. (1995). Monitoring Ultraviolet-B-induced DNA damage in individual diatom cells by immnofluorescent Thymine dimer detection1. Journal of Phycology, 31(2): 314-321

Buma, A., Van Oijen, T., van De Poll, W., Veldhuis, M., \& Gieskes, W. (2000). The sensitivity of Emiliania huxleyi (Prymnesiophyceae) to ultraviolet-b radiation. Journal of Phycology, 36(2), 296-303.

Cadet, J., Sage, E., \& Douki, T. (2005). Ultraviolet radiation-mediated damage to cellular DNA. Mutation Research/Fundamental and Molecular Mechanisms of Mutagenesis. 571(1): 3-17. 
Campbell, S. J., \& Burridge, T. R. (1998). Occurrence of Undaria pinnatifida (Phaeophyta: Laminariales) in Port Phillip Bay, Victoria, Australia. Marine and Freshwater Research, 49(5), 379-381.

Chaloub, R. M., Reinert, F., Nassar, C. A., Fleury, B. G., Mantuano, D. G., \& Larkum, A. W. (2010). Photosynthetic properties of three Brazilian seaweeds. Brazilian Journal of Botany, 33(2), 371-374.

Cockel, C. \& Knowland, J. (1999) Ultraviolet radiation screening compounds. Biological Reviews, 94(3): 311-345.

Coelho, S.M., Rijstenbil, J. W. \& Brown, M. T. (2000) Impacts of anthropogenic stresses on the early development stages of seaweeds. Journal of Aquatic Ecosystem Stress and Recovery, 7(4): 317-333.

Collier J.L (2001). Review flow cytometry and the single cell in phycology. Journal of phycology, 36(4): 628-644.

Crain, C. M., Kroeker, K., \& Halpern, B. S. (2008). Interactive and cumulative effects of multiple human stressors in marine systems. Ecology letters. 11(12): 1304-1315.

Daehler, C. (2003). Performance comparisons of co-occurring native and alien invasive plants: implications for conservation and restoration. Annual Review of Ecology, Evolution, and Systematics. 183-211.

Davison, I., Johnson, L. \& Brawley, S. (1993). Sublethal stress in the intertidal zone: tidal emersion inhibits photosynthesis and retards development in embryos of the brown alga Pelvetia fastigiata. Oecologia, 96(4), 483-492.

Dinant, C, Houtsmuller, A. B., \& Vermeulen, W. (2008) Chromatin structure and DNA damage repair. Epigenetics \& Chromatin, 1(1): 9.

Doblin, C. \& Clyton, M. (1995) Effects of secondarily-treated sewage effluent on the early life-history stages of two species of brown macroalgae : Hormosira banks and Durvillaea potatorum. Marine Biology. 122: 689-698.

Dukes, J. \& Mooney, H. (1999) Does global change increase the success of biological success. Trends in Ecology and Evolution. 14(4): 135-139.

Gómez, I., Figueroa, F. L., Sousa-Pinto, I., Viñegla, B., Pérez-Rodríguez, E., Maestre, C., ... \& Pereira, R. (2001). Effects of UV radiation and temperature on photosynthesis as measured by PAM fluorescence in the red alga Gelidium pulchellum (Turner) Kützing. Botanica Marina, 44(1), 9-16. 
Franklin, L., Osmond, C., \& Larkum, A. (2003). Photoinhibition, UV-B and algal photosynthesis. In Photosynthesis in Algae (pp. 351-384). Springer Netherlands.

Franqueira, D., Orosa, M., Torres, E., Herrero, C. \& Cid, A. (2000) Potential use of flow cytometry in toxicity studies with microalgae. The Science of the Total Environment, 247: 119-126.

Friso, G., Spetea, C., Giacometti, G., Vass, I. \& Barbato, R. (1994) Degradation of Photosystem II reaction center D1-protein induced by UVB radiation in isolated thylakoids. Identification and characterization of $\mathrm{C}$ - and N-terminal breakdown products. Biochimica et Biophysica Acta (BBA) Bioenergetics, 1184(1): 78-84.

Fukuhara, Y., Mizuta, H., \& Yasui, H. (2002). Swimming activities of zoospores in Laminaria japonica (Phaeophyceae). Fisheries Science. 68(6): 1173-1181.

Haberkorn, H., Hégaret, H., Marie, D., Lambert, C., \& Soudant, P. (2011). Flow cytometric measurements of cellular responses in a toxic dinoflagellate Alexandrium minutum upon exposure to thermal, chemical and mechanical stresses. Harmful Algae. 10(5): 463-471.

Hanlet, D., Wiencke, C. \& Nultsch, W. (1997) Influence of UV radiation on the photosynthesis of arctic macroalgae in the field. Journal of Photochemistry and Photobiology, 38:40-47.

Hay, C. H. (1990). The dispersal of sporophytes of Undaria pinnatifida by coastal shipping in New Zealand, and implications for further dispersal of Undaria in France. British phycological journal, 25(4), 301-313.

Henkel, S. \& Hofmann, G. (2008) Thermal ecophysiology of gametophytes cultured from invasive Undaria pinnatifida (Harvey) Suringar in coastal California harbours. Journal of Experimental Marine Biology and Ecology. 367(2): 164-173.

Henry, E. C. \& Cole, K. M. (1982) Ultrastructure of Swarmers in the Laminariales (phaeophyceae). I. Zoospores1 . Journal of Phycology. 18(4):550-569.

Hoffmann, A. \& Camus, P. (1989) Sinking rates and viability of spores from benthic algae in central Chile. Journal of Experimental Marine Biology and Ecology. 126(3):281-291.

Hurd, C. L., Harrison, P. J., Bischof, K., \& Lobban, C. S. (2014). Seaweed ecology and physiology. Cambridge University Press.

Huovinen, P., Gomez, I., Figueroa, F., Ulloa, N., Morales, V. \& Lovengreen, C. (2004) Ultravioletabsorbing mycosporine-like amino acids in red macroalgae from Chile. Botanica Marina. 47(1):21-29. 
Jiang, H., Gao, K. \& Helbling, W. (2007) Effects of solar UV radiation on germination of conchospores and morphogenesis of sporelings in Porphyra haitanensis (Rhodophyta). Marine Biology. 15:1751-1759.

Karsten, U., Wulff, A., Roleda, M. Y., Müller, R., Steinhoff, F. S., Fredersdorf, J., \& Wiencke, C. (2009). Physiological responses of polar benthic algae to ultraviolet radiation. Botanica Marina. 52(6): 639-654.

Kumari, S., Rastogi, R. P., Singh, K. L., Singh, S. P., \& Sinha, R. P. (2008). DNA damage: detection strategies. Excli Journal, 7, 44-62.

Ljungman, M., \& Lane, D. P. (2004). Transcription—guarding the genome by sensing DNA damage. Nature Reviews Cancer. 4(9): 727-737.

Lockwood, B. L., \& Somero, G. N. (2011). Invasive and native blue mussels genus Mytilus on the California coast: The role of physiology in a biological invasion. Journal of Experimental Marine Biology and Ecology. 400(1): 167-174.

Lloret, J., Lleonart, J., Solé, I., \& Fromentin, J. M. (2001). Fluctuations of landings and environmental conditions in the north-western Mediterranean Sea. Fisheries Oceanography. 10(1): 33-50.

Lobban, C. (1994). Seaweed ecology and physiology. Cambridge University Press.

Melis, A. (1999). Photosystem-II damage and repair cycle in chloroplasts : what modulates the rate of photodamage in vivo ? Trend in plant sciences reviews, 1360-1385.

Morelissen, B., Dudley, B. D., Geange, S. W., \& Phillips, N. E. (2013). Gametophyte reproduction and development of Undaria pinnatifida under varied nutrient and irradiance conditions. Journal of Experimental Marine Biology and Ecology. 448:197-206.

Müller, R., Laepple, T., Bartsch, I. \& Wiencke C. (2009) Impact of oceanic warming on the distribution of seaweeds in polar and cold-temperate waters. Botanica Marina 52: 617-638.

Murchie, E. H., \& Lawson, T. (2013). Chlorophyll fluorescence analysis: a guide to good practice and understanding some new applications. Journal of experimental botany, ert208.

Nishiyama, Y., Allakhverdiev, S. I., \& Murata, N. (2011). Protein synthesis is the primary target of reactive oxygen species in the photoinhibition of photosystem II. Physiologia plantarum. 142(1): $35-46$

Nyberg, C. \& Wallentinus. I. (2005) Can species traits be used to predict marine macroalgal introductions?. Biological Invasions. 7(2): 265-679 
Pakker, H., Beekman, C., \& Breeman, A. (2000). Efficient photoreactivation of UVBR-induced DNA damage in the sublittoral macroalga Rhodymenia pseudopalmata (Rhodophyta). European Journal of Phycology, 35(2):109-114.

Pfeifer, G. P., \& Besaratinia, A. (2011). UV wavelength-dependent DNA damage and human nonmelanoma and melanoma skin cancer. Photochem. Photobiol. Sci. 11(1), 90-97.

Raniello, R., Lorenti, M., Brunet, C. \& Buia, M. (2004) Photosynthetic plasticity of an invasive variety of Caulerpa racemosa in a coastal Mediterranean area: light harvesting capacity and seasonal acclimation. Marine Ecology Progress Series. 271:113-120.Readman, J., Devilla, R., Tarran, T., Llewellyn, C., Fileman, T., Easton, A., Burkill, P. \& Mantoura, R. (2004) Flow cytometry and pigment analyses as tools to investigate the toxicity of herbicides to natural phytoplankton communities. Marine Environmental Research. 58:353-358.

Reed, D., Laur, D. \& Ebeling, A. (1988). Variation in algal dispersal and recruitment: the importance of episodic events. Ecological Monographs. 58(4): 321-335.

Reed, D. C., Amsler, C. D., \& Ebeling, A. W. (1992). Dispersal in kelps: factors affecting spore swimming and competency. Ecology. 1577-1585.

Rejmanek, M. \& Richardson, D. (1996) What Attributes Make Some Plant Species More Invasive?. Ecology. 77(6):1655-1661.

Roleda, M., van de Poll, W., Hanelt, D., \& Wiencke, C. (2004) PAR and UVBR effects on photosynthesis, viability, growth and DNA in different life stages of two coexisting Gigartinales: implications for recruitment and zonation pattern. Marine Ecology Progress series. 281:37-50.

Roleda, M., Wiencke, C., Hanelt, D., van de Poll, W. \& Gruber, A. (2005) Sensitivity of Laminariales zoospores from Helgoland (North Sea) to ultraviolet and photosynthetically active radiation: implications for depth distribution and seasonal reproduction. Plant, Cell \& Environment. 28(4):466-479.

Roleda, M. Wiencke, C. \& Lüder, U. (2006a) Impact of ultraviolet radiation on cell structure, compounds, photosynthesis, DNA damage, and germination in zoospores of Arctic Saccorhiza dermatodea. Journal of Experimental Botany. 57(14):3847-3856.

Roleda, M. Y., Hanelt, D., \& Wiencke, C. (2006b). Exposure to ultraviolet radiation delays photosynthetic recovery in Arctic kelp zoospores. Photosynthesis research. 88(3): 311-322.

Roleda, M., Wiencke, C., Hanelt, D. \&Bischof, K. (2007) Sensitivity of the Early Life Stages of Macroalgae from the Northern Hemisphere to Ultraviolet Radiation. Photochemistry and Photobiology. 83:851-862. 
Roleda, M., Lüder, U. \& Wiencke, C. (2010) UV-susceptibility of zoospores of the brown macroalga Laminaria digitata from Spitsbergen. Polar Biology. 33:577-588.

Schaffelke, B., \& Hewitt, C. L. (2007). Impacts of introduced seaweeds. Botanica Marina, 50(5/6), 397-417.

Schiel, D. R., \& Thompson, G. A. (2012). Demography and population biology of the invasive kelp Undaria pinnatifida on shallow reefs in southern New Zealand. Journal of Experimental Marine Biology and Ecology, 434, 25-33.

Steinhoff, F., Wiencke, C., Müller, R. \& Bischof, K. (2008) Effects of ultraviolet radiation and temperature on the ultrastructure of zoospores of the brown macroalga Laminaria hyperborea. Plant Biology. 10(3):388-397.

Swanson, A. \& Druehl, L. (2002) Induction, exudation and the UV protective role of kelp phlorotannins. Aquatic Botany. 73(3):241-253.

Tala, F., Veliz K., Gomez, I. \& Edding, M. (2007) Early life stages of the South Pacific kelps Lessonia nigrescens and Lessonia trabeculata (Laminariales, Phaeophyceae) show recovery capacity following exposure to UV radiation. Phycologia. 46(4): 467-470.

Telford, W., Komoriya, A. \& Packard, B. (2002) Detection of localized caspase activity in early apoptotic cells by laser scanning cytometry. Cytometry. 47(2):81-88.

Telford, W. G., Komoriya, A. \& Packard, B. Z. (2004) Multiparametric analysis of apoptosis by flow and image cytometry. Methods in molecular biology. 263:141-160.

Urbaniak, G. C., \& Plous, S. (2013). Research Randomizer (Version 4.0)[Computer software]. Retrieved on June 22, 2013.

Tyystjärvi, E. (2008). Photoinhibition of photosystem II and photodamage of the oxygen evolving manganese cluster. Coordination Chemistry Reviews. 252(3): 361-376.

Vadas, R. Johnson, S. \& Norton, T. (1992) Recruitment and mortality of early post-settlement stages of benthic algae. British Phycological Journal. 27(3):331-351.

Valentine, J. \& Johnson, C. (2003) Establishment of the introduced kelp Undaria pinnatifida in Tasmania depends on disturbance to native algal assemblages. Journal of Experimental Marine Biology and Ecology. 295(1): 63-90.

Valentine, J. P., Magierowski, R. H., \& Johnson, C. R. (2007). Mechanisms of invasion: establishment, spread and persistence of introduced seaweed populations. Botanica Marina. 50(5/6): 351360. 
van de Poll Poll, W., Eggert, A., Buma, A. \& Breeman, A. (2001). Effects of UV-B indiced DNA damage and photoinhibition on growth of temperate marine red macrophytes: habitat-relates differences in UV-B tolerance. Journal of Phycology. 37:30-37.

van de Poll, W., Hanelt, D., Hoyer, K., Buma, A. \& Breeman, A. (2002) Ultraviolet-B-induced cyclobutame pyrimidine dimer formation and repair in arctic marine macrophytes. Photochemistry and Photobiology. 76(5): 493-500.

Veldhuis, M. \& Kraay, G. (2000). Application of flow cytometry in marine phytoplankton research: current applications and future perspectives. Scientia Marina. 64(2): 121-134.

Veliz, K., Edding, M., Tala, F. \& Gomez, I. (2006) Effects of ultraviolet radiation on different life cycle stages of the south Pacific kelps, Lessonia nigrescens and Lessonia trabeculata (Laminariales, Phaeophyceae). Marine Biology. 149(5): 1015-1024.

Vives-Rego, J., Lebaron, P. \& Nebe-von Caron, G. (2000) Current and future applications of flow cytometry in aquatic microbiology. FEMS microbiology reviews. 24(4):249-248.

Wiencke, C., Gómez, I., Pakker, H., Flores-Moya, A., Altamirano, M., Hanelt, D., Bischof K. \& Figueroa, F. L. (2000). Impact of UV-radiation on viability, photosynthetic characteristics and DNA of brown algal zoospores: implications for depth zonation. Marine ecology. Progress series. 197: 217-229.

Wiencke, C., Clayton, M. \& Schoenwaelder, M. (2004) Sensitivity and acclimation to UV radiation of zoospores from five species of Laminariales from the Arctic. Marine Biology. 145(1): 31-39.

Wiencke, C., Roleda, M., Gruber, A., Clayton, M. \& Bischof, K. (2006) Susceptibility of zoospores to UV radiation determines upper depth distribution limit of Arctic kelps: evidence through field experiments. Journal of Ecology. 84: 455-463.

Yamashita, N., Ishida, A., Kushima, H. \& Tanaka, N. (2000) Acclimation to sudden increase in light favoring an invasive over native trees in subtropical islands, Japan. Oecologia. 125(3):412419. 


\title{
Chapter 3
}

\section{Effect of UVB and temperature on}

\author{
early life stages of $U$. pinnatifida
}

\subsection{Abstract}

The effect of light treatments combined with temperature on early life stages of $U$. pinnatifida was investigated for the first time. Zoospores and gametophytes of $U$. pinnatifida were exposed to photosynthetically active radiation $(\mathrm{P}, 400-700 \mathrm{~nm}), \mathrm{PAR}+\mathrm{UVA}$ radiation (PA, 320-400nm) and PAR+UVA+UVB radiation (PAB, 285-320nm), and incubated at temperatures between 15 and $21{ }^{\circ} \mathrm{C}$. The photosynthetic capacity, zoospore settlement, germination success, growth of the germination tube and development to gametophyte were studied. Light treatments and temperature affected early life stages independently. $\mathrm{F}_{\mathrm{v}} / \mathrm{F}_{\mathrm{m}}$ was highly depressed by $\mathrm{PAB}$ treatment during exposure, but it recovered after incubation in the dark. Higher temperature resulted in a faster recovery in $\mathrm{F}_{\mathrm{v}} / \mathrm{F}_{\mathrm{m}}$ in the short term but a full recovery was always observed at the end of the experiment regardless of the temperature. Settlement of zoospores decreased as temperature increased when exposed to PA and PAB but not to $\mathrm{P}$ treatment. Germination rate and the growth of the germination tube were both very low in zoospores exposed to $\mathrm{PAB}$ and also less gametophytes formation was observed in zoospores exposed to this treatment at the two highest temperatures. Early life stages were affected mainly by UVB, while temperature had minor effects. The capacity of $U$. pinnatifida to develop in a wide range of light and temperatures might allow this species to maintain viable populations where they already exist in a scenario of environmental changes but also might permit this invasive seaweed to spread to higher latitudes. 


\subsection{Introduction}

Global environmental changes observed in the last few decades have led to concern over the possible effect on ecosystems. The Fifth Assessment Report of the United Nations Intergovernmental Panel on Climate Change (IPCC 2013) predicts large changes in environmental conditions in the future. These changes are expected to disturb marine organisms (Fredersford et al. 2009) due to physical and chemical changes in the water (Harley et al. 2006). For example, an increase in water temperature is likely to impact organisms directly by affecting physiological processes (Galbraith et al. 2002, Harley et al. 2006), or indirectly impacting ocean dynamics and species interactions (Rilov \& Treves 2010) and, therefore, changing the structure of ecosystems (Stachowicz et al. 2002, Doney et al. 2012).

For seaweeds, temperature regulates their geographic distribution, and controls their survival, reproduction (Lobban 1994) and physiological processes such as photosynthesis (Coelho et al. 2000). For example, an increase in the temperature of coastal waters due to global warming might permit the spread of warm-adapted species to higher latitudes, while cold-adapted species could decrease in abundance or become extinct (Rahel \& Olden 2008), and it could enable invasive species to expand their geographical distribution to areas where they could not previously survive or reproduce (Walther et al. 2009). Invasion success has been associated mainly with disturbance of the environment where ecosystems become more susceptible to an introduction of non-indigenous species (Williams \& Smith 2007) through altered community structure and organism interaction (e.g. competition).

Another environmental factor affecting coastal environments is the variation in the amount of UVB radiation reaching the surface of the earth due to ozone depletion. UVB negatively impacts organisms by damaging physiological processes (Rousseaux et al. 1999, Saito \& Taguchi 2003, Obermuller et al. 2005, Rocarati et al. 2008). In seaweeds, the effect of UVB has been well studied in macroscopic stages. UVB can produce considerable damage to the photosynthetic apparatus by decreasing the photosynthetic rate or inhibiting it (Roleda et al. 2004), damaging macro-molecules such as DNA and proteins (Roleda et al. 2005, 2006a, 2006b) and inhibiting growth (Roleda et al. 2006a ). In addition, UVB delays growth in early (microscopic) life stages and can cause high mortality (Coelho et al. 2000, Wiencke et al. 2000 ), produce photoinhibition of photosynthesis (Wiencke et al. 2000, 2004, Roleda et al. 2004, 2005), damage DNA, and change cell structure (Roleda et al. 2006a, Steinhoff et al. 
2008). The susceptibility of seaweed to UVB is species-specific and is related to their vertical distribution; thus deep-water species are more susceptible to UVB than those that inhabit upper areas more exposed to solar radiation (Pakker et al. 2000, Roleda et al. 2005,2006a). Also, their susceptibility depends on the development stage; in general, unicellular stages are more susceptible than multicellular (spores vs. gametophytes and sporophytes) and juveniles more than adults ( Coelho et al. 2000).

The fluorescence of the chlorophyll is measured by using Pulse Amplitude Modulation fluorometer (PAM) (Wiencke et al. 2004, Roleda et al. 2005, Baker 2008). As has been described in the previous chapter, this method is widely used to study the physiology and ecophysiology of photosynthetic organisms because it is non destructive, easy to use and provides useful information on the state of the photosystem II (PSII) (Baker 2008, Murchie \& Lawson 2013). One of the most used parameters is the maximum quantum yield of PSII $\left(F_{v} / F_{m}\right)$ (Murchie \& Lawson 2013). $F_{v} / F_{m}$ is measured after dark acclimation, which closes reaction centres when photochemistry and heat dissipation are inactivated. Additionally, rapid light curves (RLCs) give information on the saturation characteristics of electron transport and the overall photosynthetic performance of the organism (Ralph \& Gademann 2005). Electron transport rate (ETR) is a relative measure shows the relation between the effective quantum yield ( $\left.\phi_{\text {PSII }}\right)$ and the incident light (PAR) (Schreiber et al. 2012, Szabó et al. 2014). RLCs also give additional information such as the initial slope of the non-saturated photosynthetic rate $(\alpha)$, the maximum relative electron transport rate $\left(\mathrm{rETR}_{\max }\right)$, and saturating irradiance of photosynthesis $\left(\mathrm{E}_{\mathrm{k}}\right)$ (Schreiber et al. 2012).

The effect of abiotic conditions on the physiology of seaweeds has usually been assessed through single factor analysis. However, environmental changes occur simultaneously, and they might act in combination or independently (Fredersford et al. 2009). An evaluation of the effect of interactive stresses is necessary to determine more accurately the impact of global environmental changes. In seaweeds, the few studies on the combined effect of UV and temperature that have been done show an interactive effect of factors (Hoffman et al. 2003). For example, the harmful effect of UVB on growth of Fucus species increased at higher temperatures (Alatamirano et al. 2003), in contrast, an increase of temperature ameliorated photoinhibition induced by UVB in Ulva sp. (Rautenberger \& Bischof 2006). The impact of combined factors on seaweeds is species and stage specific at various temperatures (Müller $e t$ 
al. 2008); thus some species could be favoured with environmental changes; while others won't be affected.

The effect of UVB and temperature as single and/or combined factors has been tested principally in native species, while the effect on introduced species has not been studied, even though environmental changes might benefit introduced species (Stacowicz et al. 2002, Walther et al. 2009). The introduction of new species is a major threat to coastal ecosystems (Thornber et al. 2004) because they often compete with native species (Thomsen \& McGlathery 2007), alter nursery habitat for other organisms and reduce light penetration into the water column (Thomsen \& McGlathery 2007). Studies on the tolerance to environmental changes of invasive species are limited; however, invasive species often present high plasticity that leads to success in new environments. For example, the success of the invasive Caulerpa racemosa var. occidentalis in the Mediterranean is attributed to its high physiological plasticity to different habitats and environmental variations (Raniello et al. 2004), and the high stress tolerance of Gracilaria vermiculophylla has allowed this species to spread throughout Europe and North America (Thomsen \& McGlathery 2007).

Undaria pinnatifida is a brown seaweed ranked as one of the most successful invasive seaweeds in the world (Lyons \& Scheibling 2009). The success of this species has been linked to its high dispersal ability and its capacity to establish in varied environments (Dean \& Hurd 2007). However, its ability to establish and maintain viable populations in new environments depends greatly on the ability of each life stage to acclimate to habitat and seasonal variation (Raniello et al. 2004). Additionally, its success relies on the survival of unicellular stages (Vadas et al. 1992), which in seaweeds have high mortality due to high vulnerability to environmental conditions (Davison et al. 1993, Coelho et al. 2000). In New Zealand, this species was first found in Wellington Harbour in 1987, and since then has spread around the North Island from Wellington to Rangaunu Harbour, Aupouri Peninsula and in the South island from Golden Bay to Stewart Island mainly on the west coast (Stuart 2004, Russell et al. 2008, James et al. 2014). U. pinnatifida has an alternation of generations (gametophytes and sporophytes) that is regulated principally by temperature. Thus, in its native environment $U$. pinnatifida has an annual cycle where gametophytes are produced in Autumn, and the sporophytes appear in Winter-Spring and die in late Summer (Yoshikawa et al. 2001). In New Zealand, in contrast, sporophytes of this species can be found throughout the year (Hay \& Villouta 1993, Morelissen 2012). 
$U$. pinnatifida is as a very plastic species because it can survive and develop in a wide range of conditions, and this might explain its success colonizing new environments. Moreover, this characteristic could allow this species to become more successful under predicted global changes. However, there is a lack of studies on the effect of environmental changes of invasive species. Since environmental changes occur simultaneously, it is imperative to study the effect of multiple factors on organisms. As U. pinnatifida has a wide thermotolerance, I hypothesised that an increase of water temperature will ameliorate the effect of UVB in early life stages of this species as shown in other macroalgae (Rautenberger \& Bischof 2006). Thus, I exposed motile and settled zoospores to UVB at increasing water temperature and measured its effect on photosynthetic efficiency, settlement, germination, growth and development to gametophytes. This chapter extends the findings in Chapter 2.

\subsection{Materials and Methods}

\section{Zoospores}

Mature sporophytes of $U$. pinnatifida were collected by hand in the intertidal zone of Princess Bay, Wellington, $\left(41^{\circ} 20^{\prime} 39.94^{\prime \prime} \mathrm{S}, 174^{\circ} 47^{\prime} 17.07^{\prime \prime}\right.$ E) during low tide in July 2013. Mature sporophylls of 6-8 algae were separated and cleaned with fresh water to eliminate epiphytes. To induce zoospores release, the sporophylls were dried with paper towels and then immersed in filtered seawater ( $2 \mu \mathrm{m}$ pore size filter) at $\pm 15{ }^{\circ} \mathrm{C}$ and exposed to natural light close to a window for $45 \mathrm{~min}$. Zoospore concentration was counted by using a Neubauer Chamber (haemocytometer) on a light microscope (Leica,DM LB, Germany).

\section{Light treatments}

Photosynthetically active radiation (PAR) was provided by white fluorescent tubes (36W/840, Davis, New Zealand), ultraviolet radiation A was supplied with UVA fluorescent tubes (TL 40W/03RS, Philips, New Zealand) with an emission peak at $375 \mathrm{~nm}$ and emitting range of 320 to $410 \mathrm{~nm}$ and ultraviolet radiation B with UVB fluorescents tubes (TL 40W/12RS, Philips, New Zealand) with an emission peak at $302 \mathrm{~nm}$ and emitting range of 290-390 nm. The experimental design consisted of three treatments, 1) PAR+UVA+UVB (PAB), where samples were exposed to full radiation from lamps, 2) PAR+UVA (PA), samples covered with a mylar 
sheet that cuts radiation below $320 \mathrm{~nm}$ and 3) PAR (P), samples covered with a polycarbonate sheet that cuts radiation below $390 \mathrm{~nm}$. UVB lamps were covered with PVC filters to cut radiation below 290nm. Radiation was measured with a SpectroSense2 + radiometer (Skye Instrument Ltd. United Kingdom); for PAR measurements a 4-Chanel Sensor SK 1850/SS2 was used, for UVA, a UVA sensor SKU 421, and for UVB a UVB sensor SKU 430/SS2 were used (as Fig. 2.1, Chapter2). Experimental irradiances are shown in Table 3.1. The light treatments attempt to approximate natural light levels during a $10 \mathrm{hr}$ day. Samples were collected in late Winter/early Spring when the typical day length was approximately $10 \mathrm{hr}$. and light irradiances were low. The UVB and PAR irradiances used in these experiments are similar to light irradiances in the water column and/or intertidal of Wellington coast during Winter (see Chapter 5).

\section{PAM fluorometry}

Photosynthetic efficiency was measured as the variable fluorescence of PSII using a Pulse Amplitude Modulation fluorometer (Water-PAM) connected to a PC with WinControl software (Heinz Walz GmbH, Effeltrich, Germany). Before measurement, samples were dark adapted for 10 min. and the maximum quantum yield $\left(\mathrm{F}_{\mathrm{v}} / \mathrm{F}_{\mathrm{m}}\right)$ was obtained. Dark acclimation permits all reaction centres of PSII to be open (all primary acceptors are oxidized) and heat dissipation is minimal. Thus, dark adapted samples have a minimal fluorescence yield $\left(\mathrm{F}_{\mathrm{o}}\right)$. After a saturating pulse of actinic light, all reaction centres close and samples reach the maximal variable florescence $\left(F_{m}\right)$. The difference between $F_{o}$ and $F_{m}$ gives the variable fluorescence $\left(F_{v}\right)$ that indicates the capacity of the sample for photochemical quenching. The maximum quantum yield of PSII was defined as $\mathrm{F}_{\mathrm{v}} / \mathrm{F}_{\mathrm{m}}$.

The relative electron transport rate (rETR) was measured from rapid light curves (RLCs) that measure the effective quantum yield over a range of increasing actinic light intensities ( up to $700 \mu \mathrm{mol}$ photon $\mathrm{m}^{-2} \mathrm{~s}^{-1}$ ) (Schreiber et al. 1994). The rETR was calculated as:

$\operatorname{ETR}\left(\mu \mathrm{mol}\right.$ electrons $\left.\mathrm{m}^{-2} \mathrm{~s}^{-1}\right)=\phi_{\text {PSII }} * \mathrm{E}$

Where $\phi_{\text {PSII }}$ is the PSII effective quantum yield, determinate as $\left(F^{\prime} m-F\right) / F^{\prime} m=\Delta F / F^{\prime} m$, where $F^{\prime} m$ and $F$ are the maximum and minimum fluorescence respectively, in presence of actinic light and $\mathrm{E}$ is the incident irradiance of PAR. The following photosynthetic parameters were derived from the RLCs: the maximum relative electron transport rate $\left(\mathrm{rETR}_{\max }\right)$, the initial 
slope of the non-saturated photosynthetic rate $(\alpha)$ and saturating irradiance of photosynthesis $\left(\mathrm{E}_{\mathrm{k}}\right)$.

\section{Experiments:}

In this study, three different experiments were performed. The objective of the first experiment was to determine the effect of different PAR and UV treatments under different temperatures on the photosynthetic performance of the zoospores. The second set of experiments examined their effect on zoospore germination, settlement and length of germination tube. The third experiment aimed to determine the effect of PAR and UV treatments under different temperatures on the development of zoospores to gametophytes.

Table. 3.1 Experimental irradiances in the experiments.

\begin{tabular}{llcc}
\hline & \multicolumn{2}{l}{ Experimental irradiances } & \\
\cline { 2 - 4 } & PAR & UVA & UVB \\
& $\left(\mu \mathrm{mol}\right.$ photons $\left.\mathrm{m}^{-2} \mathrm{~s}^{-1}\right)$ & $\left(\mathrm{Wm}^{-2}\right)$ & 0 \\
\hline Low light & $35 \pm 1.7$ & 0 & \\
Experiment 1 \& 2 & & & $0.3 \pm 0.07$ \\
\hline PAB & $57 \pm 2$ & $2.5 \pm 0.4$ & $0.1 \pm 0.07$ \\
PA & $54.1 \pm 2$ & $2.15 \pm 0.4$ & $0.02 \pm 0.07$ \\
P & $54.0 \pm 2$ & $0.025 \pm 0.4$ & \\
Experiment 3 & & & $0.3 \pm 0.4$ \\
\hline PAB & $67 \pm 2$ & $3.4 \pm 0.5$ & $0.1 \pm 0.4$ \\
PA & $63.5 \pm 2$ & $2.9 \pm 0.5$ & $0.02 \pm 0.4$ \\
P & $63.4 \pm 2$ & $0.02 \pm 0.5$ & \\
\hline
\end{tabular}


Photosynthesis experiments were performed with three different light treatments (P, PA and $\mathrm{PAB})$ at three different temperatures $\left(15,18,21{ }^{\circ} \mathrm{C}\right)$ with 4 replicates in each treatment. Temperature conditions were chosen to approximate the temperature during Summer in the intertidal of Wellington coast (lower temperature) and the possible increase in temperature as a consequence of global warming. After adjustment of zoospores concentration to $2.7 \times 10^{-5}$ cell $\mathrm{ml}^{-1}$, the zoospore solution was divided into different plastic chambers (total=36) $(18 \mathrm{~cm} \mathrm{x}$ $10 \mathrm{~cm} \times 5.5 \mathrm{~cm}$ ), where 12 containers were covered with polycarbonate filters, 12 with mylar filters and 12 were left without filters (as described earlier).

The samples were maintained at constant temperature using 3 water baths, while the light was provided by a set of UVB, UVA and PAR lamps hung above the water baths. After zoospore release, a small aliquot of zoospore solution was poured into $5 \mathrm{ml}$ quartz cuvettes and left for $10 \mathrm{~min}$. in the dark to measure $\mathrm{F}_{\mathrm{v}} / \mathrm{F}_{\mathrm{m}}$ and rETR before experiments (0h). All cultures were maintained at their experimental temperature under low light conditions $\left(35 \mu\right.$ mol photon $\mathrm{m}^{-2}$ $\mathrm{s}^{-1}$ PAR only) for $3 \mathrm{~h}$. After temperature acclimation, zoospores were exposed to their respective light treatment for $3 \mathrm{~h}$ (Table 3.1), then left under the lower light condition for $4 \mathrm{~h}$ $\left(35 \mu \mathrm{mol}\right.$ photon $\left.\mathrm{m}^{-2} \mathrm{~s}^{-1}\right)$ and finally in darkness for $14 \mathrm{~h}$. This light regime attempts to reflect changing light conditions during a $10 \mathrm{~h}$ day and $14 \mathrm{~h}$ darkness. $\mathrm{F}_{\mathrm{v}} / \mathrm{F}_{\mathrm{m}}$ and $\mathrm{rETR}$ were also measured after $3 \mathrm{~h}$ temperature acclimation time and then after exposure for $3 \mathrm{~h}$ to light treatments. $F_{v} / F_{m}$ was also measured after $4 \mathrm{~h}$ of recovery under low light and after $14 \mathrm{~h}$ of recovery in dark conditions. The zoospores samples were returned to the corresponding petri dish after measurements were performed.

Experiment 2: Effect of light treatments and temperature on settlement, germination and growth

Petri dishes $(\mathrm{n}=3$ per treatment, total=27) $(100 \mathrm{~mm} \times 15 \mathrm{~mm})$ were filled with $6 \mathrm{ml}$ zoospore solution $\left(4 \times 10^{5}\right.$ cells $\left.\mathrm{ml}^{-1}\right)$ and then left in water baths at $15,18,21{ }^{\circ} \mathrm{C}$ for $3 \mathrm{~h}$ for temperature acclimation under low light (Table 3.1). Samples were covered with the filters to provide $\mathrm{P}$ and PA irradiances and another set of samples were left without filters to obtain PAB treatment as in Experiment 1. After the temperature acclimation period, the zoospores were exposed to light treatment (P, PA, PAB) for $3 \mathrm{~h}$ and then left under low light conditions (Table 3.1) for $4 \mathrm{~h}$, followed by dark conditions for $14 \mathrm{~h}$. $24 \mathrm{~h}$ after zoospores release, the zoospore 
solutions in the petri dishes were changed with filtered sea water, thus only zoospores attached to the bottom of the dish remained. Sea water from the petri dishes were changed filled two times per day to avoid desiccation after the first day of the experiment. The zoospores were exposed to low light (Table 3.1) for 2 days with a photoperiod of 10:14h (day:night). Zoospores settlement, germination and growth of the germination tube were measured 2 days after zoospore release by taking three photographs of the bottom of each petri dish with a QImaging (MicroPublisher $0.5 \& 33 \mathrm{RTV}$, Canada) camera attached to a Leica DM LB (Germany) light microscope at x20 objective magnification representing an area of $0.109 \mathrm{~mm}^{-}$ ${ }^{2}$. Images were analyzed with Image Pro-Plus (USA) software. Zoospores were counted as germinated when a visible germination tube was developed. Germination was expressed as a percentage of the total zoospores per replicate. Growth of the germination tube was determined by measuring the germination tube length $(\mu \mathrm{m})$ from the edge of the zoospore to the end of the tube and settlement was assessed by counting the zoospores that remain attached to the bottom of the petri dishes.

\section{Experiment 3: Effect of temperature and light treatments on gametogenesis}

Petri dishes $(\mathrm{n}=4$, total $=36)$ were filled with $6 \mathrm{ml}$ zoospore solution $\left(3 \times 10^{5}\right.$ cells $\left.\mathrm{ml}^{-1}\right)$ enriched with F/2 medium (Morelissen et al. 2013) and then left in different water baths at 15, 18, 21 ${ }^{\circ} \mathrm{C}$ for $3 \mathrm{~h}$ at low light as above for temperature acclimation. Samples were covered with the corresponding filters to provide the $\mathrm{P}$ and PA treatments and another set without filter to provide $\mathrm{PAB}$ as in previous experiments. After the temperature acclimation period, the zoospores were exposed to light treatments $(\mathrm{P}, \mathrm{PA}, \mathrm{PAB})$ for $1 \mathrm{~h}$ and then left under low light conditions for 9h (Table 3.1), followed by dark conditions for 14h. The zoospores were incubated under a photoperiod of 10:14h (day:night) for 12 days and zoospores were exposed daily for $1 \mathrm{~h}$ to the light treatments (P, PA, and PAB) after $3 \mathrm{~h}$ of light to simulate the possible exposure of zoospores after settlement, hypothesizing zoospores might settle in areas protected from the direct sun light with short exposure period. After $24 \mathrm{~h}$ the zoospores solutions in the petri dishes were changed with filtered sea water and added F2, thus only zoospores attached to the bottom of the dish remained. Petri dishes were refilled with filtered sea water two times per day to avoid desiccation from the beginning of the experiment. Zoospores development to gametophytes was observed 12 days after zoospore release by taking three photos of the bottom of each petri dish with the light microscope at x20 objective magnification. Images were analyzed with the Image Pro-Plus (USA) software. 
Data analysis

All statistical analyses were carried out with R software (version 2.13.2, Core Team 2009). The effect of factors (light treatments, temperature and time) on $\mathrm{F}_{\mathrm{v}} / \mathrm{F}_{\mathrm{m}}$ was analyzed separately for exposure and recovery time. A linear mixed model (LME) (function "lme" in package "nlme"; Pinheiro et al. 2014) was used to detect interaction between light treatment and temperature on photosynthetic performance of zoospores measured as $F_{v} / F_{m}$ and $E R_{\max }$. Akaike information criterion (AIC) was used to compare models, for $F_{v} / F_{m}$ exposure and $\mathrm{ETR}_{\max }$ a full model was used (interaction of all factors), while a reduced model excluding time was used for $F_{v} / F_{m}$ in recovery. Light treatments, temperature and/or time were fixed variables, while samples were taken as the random variable.

Differences in germination between irradiances and time were assessed with a generalized lineal model (GLM) analysis of deviance (data were normally distributed but no equal variance assumption). Quasi-Binomial distribution was used when overdispersion of data (residual deviance > residual df) was observed. Growth of germination tube was analyzed with GLM analysis of deviance with gamma distribution for continuous data and settlement and gametophytes with poisson distribution for count data or quasipoisson when overdispersion of data (residual deviance > residual df) was observed. The effect of each light treatment at different temperatures in growth of germination tube was assessed with ANOVA one-way after normality (quantile-quantile plots) and homogeneity (Bartlett test) of variance were checked.

\subsection{Results}

\section{Experiment 1: Effect of $U V$ and temperature on photosynthesis}

The effect of $\mathrm{P}, \mathrm{PA}$ and $\mathrm{PAB}$ treatments at different temperatures $\left(15,18\right.$ and $\left.21{ }^{\circ} \mathrm{C}\right)$ in $\mathrm{F}_{\mathrm{v}} / \mathrm{F}_{\mathrm{m}}$ of zoospores of Undaria pinnatifida is shown in Fig. 3.1 Zoospores had high $\mathrm{F}_{\mathrm{v}} / \mathrm{F}_{\mathrm{m}}$ values after release and after 3 hours of temperature acclimation in low light, before exposure to the full light treatments. There was a reduction in $\mathrm{F}_{\mathrm{v}} / \mathrm{F}_{\mathrm{m}}$ during this acclimation period and this reduction was different among temperatures (LME, $\mathrm{t}=1.78, \mathrm{p}<0.0001$ ), with a larger reduction in $F_{v} / F_{m}$ as temperature decreased (Fig. 3.1). There was interaction between light 
treatments and time (LME, $\mathrm{t}=2.17, \mathrm{p}=0.04)$ for $\mathrm{F}_{\mathrm{v}} / \mathrm{F}_{\mathrm{m}}$ in exposure, but no other interactions were detected (Table 3.2). Differences among light treatments were detected after $3 \mathrm{~h}$ of full exposure at all temperatures $\left(\mathrm{LME}, 15^{\circ} \mathrm{C}, \mathrm{t}=-4.62, \mathrm{p}=0.002 ; 18^{\circ} \mathrm{C}, \mathrm{t}=-3.98, \mathrm{p}=0.005 ; 21^{\circ} \mathrm{C}, \mathrm{t}=-\right.$ 4.91, $\mathrm{p}=0.001$ ). A decrease in $\mathrm{F}_{\mathrm{v}} / \mathrm{F}_{\mathrm{m}}$ was observed in all light treatments, with a greater decrease in zoospores treated with PAB (Fig. 3.1). Furthermore, the decrease in $F_{v} / F_{m}$ in zoospores exposed to $\mathrm{P}$ and PA was different among temperatures (LME, $\mathrm{t}=4.75, \mathrm{p}=0.0002$ and $\mathrm{t}=2.88, \mathrm{p}=0.01$, respectively), where the decrease was more pronounced at $15^{\circ} \mathrm{C}$ (Fig $3.1 \mathrm{a}$ and b). The Fv/Fm of zoospores exposed to PAB decreased to a similar amount at all temperatures (Fig 3.1). There was no interaction between factors in $F_{v} / F_{m}$ recovery, neither the main effect light treatment nor the temperature treatment (Table 3.2). Differences in the recovery among temperatures of zoospores exposed to $\mathrm{P}$ and $\mathrm{PA}(\mathrm{LME}, \mathrm{t}=3.47, \mathrm{p}=0.01 ; \mathrm{t}=$ $4.36, \mathrm{p}=0.003$; respectively) were detected after $4 \mathrm{~h}$ of recovery in low light conditions. A lower recovery in $\mathrm{F}_{\mathrm{v}} / \mathrm{F}_{\mathrm{m}}$ for zoospores treated with $\mathrm{PA}$ and $\mathrm{PAB}$ at the lowest temperature $\left(15^{\circ} \mathrm{C}\right)$ was observed, while that of zoospores exposed to $\mathrm{P}$ was at 15 and $18^{\circ} \mathrm{C}$ (Fig 3.1). The maximum quantum yield of zoospores left for $14 \mathrm{~h}$ in dark conditions recovered to initial values in all light treatments and the recovery was similar among temperatures (Fig.3.1), no statistical differences were detected.

The photosynthetic parameters $\mathrm{rETR}_{\max }, \mathrm{E}_{\mathrm{k}}$ and $\alpha$ derived from RLCs are presented in (Fig. 2.2). After a period of temperature acclimation (3h), all parameters increased in magnitude compared to initial values or remain similar to initial values (Fig. 3.2). In general, $\mathrm{rETR}_{\max }, \mathrm{E}_{\mathrm{k}}$ and $\alpha$ increased as temperature increased (Fig. 3.2). After exposure to light treatments (P, PA and $\mathrm{PAB}$ ) the response of $\mathrm{E}_{\mathrm{k}}$ and $\alpha$ was variable, while $\mathrm{rETR}_{\max }$ decreased in zoospores exposed to all light treatments at all temperatures. There was no interaction between factors in $\mathrm{rETR}_{\max }$ recovery (Table 3.2). The $\mathrm{rETR}_{\max }$ increased after the temperature acclimation compared to initial treatments (Fig. 3.2a). After exposure to light treatments, a significant reduction $(\mathrm{LME}, \mathrm{P}, \mathrm{t}=-4.08, \mathrm{p}=0.001 ; \mathrm{PA}, \mathrm{t}=-2.24, \mathrm{p}=0.03 ; \mathrm{PAB}, \mathrm{t}=-8.14, \mathrm{p}=0.000)$ in $\mathrm{rETR}_{\max }$ compared to values at $\mathrm{Oh}$ was observed at all temperatures. 

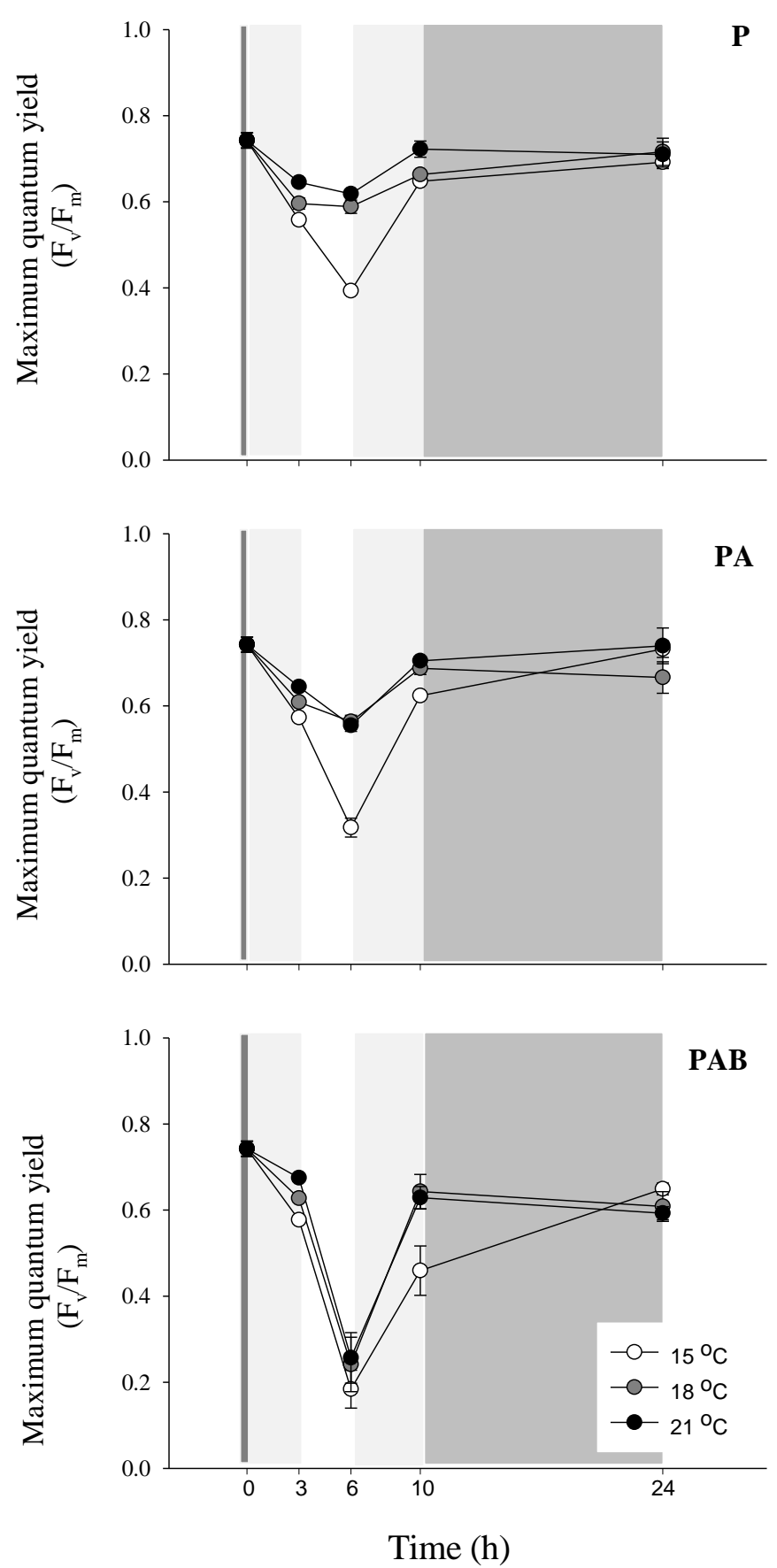

Fig. 3.1 Effect of light treatment (P, PA and $\mathrm{PAB})$ at different temperatures $\left(15,18\right.$ and $\left.21{ }^{\circ} \mathrm{C}\right)$ on maximum quantum yield $\left(\mathrm{F}_{\mathrm{v}} / \mathrm{F}_{\mathrm{m}}\right)$ of motile zoospores of $U$. pinnatifida. Cell were dark adapted for 10 min. (dark grey background) then they were allowed to acclimate in low light ( $35 \pm 2 \mu$ mol photon $\mathrm{m}^{-2}$ $\mathrm{s}^{-1}$ ) for $3 \mathrm{~h}$ (light grey background) and then exposed to light treatments for $3 \mathrm{~h}$ (white background). Recovery in low light ( $35 \pm 2 \mu$ mol photon $\mathrm{m}^{-2} \mathrm{~s}^{-1}$ ) for $4 \mathrm{~h}$ (light grey background), and then left in dark conditions for $14 \mathrm{~h}$ (dark grey background). Vertical bars show standard error (SE, $n=3$ ). 

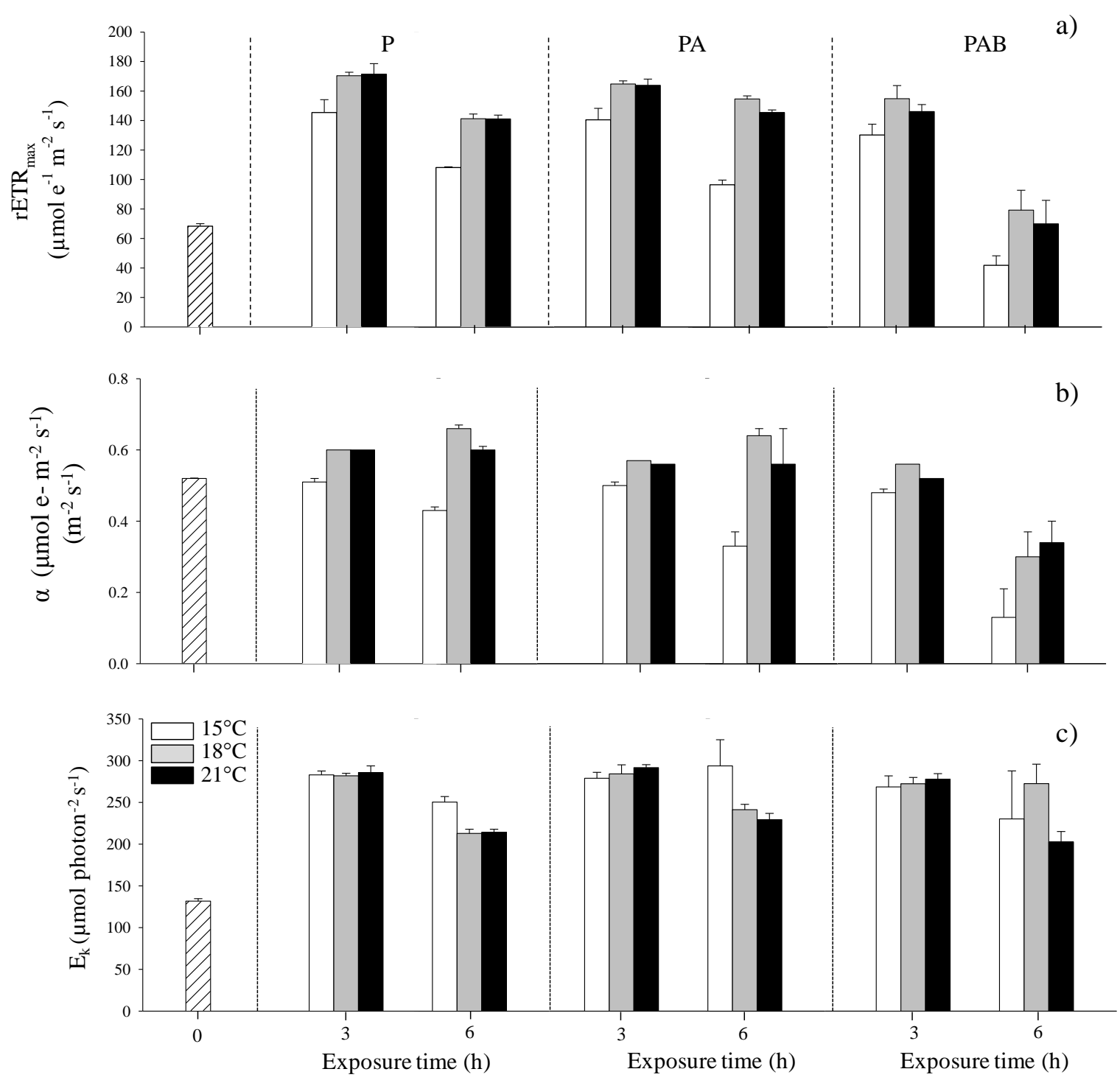

Fig. 3.2 Photosynthetic characteristics based on RLCs curves in zoospores of U. pinnatifida after a period of temperature acclimation (3h) and after exposure to P, PA and PAB for $6 \mathrm{~h}$ at different temperature $\left(15-18-21^{\circ} \mathrm{C}\right)$. a) $\mathrm{rETR}_{\max }$, maximal electron transport rate ( $\mu \mathrm{mol}$ photons $\left.\mathrm{m}^{-2} \mathrm{~s}^{-1}\right)$; b) alpha $(\alpha)$, c) photosynthetic efficiency measured by the initial slope of the RLCs curve; $E_{k}$, the saturating irradiance for photosynthesis $\left(\mu \mathrm{mol}\right.$ photon ${ }^{-2} \mathrm{~s}^{-1}$ ). Mean values of $\mathrm{rETR}_{\max }, \alpha$ and $\mathrm{E}_{\mathrm{k}} \pm$ standard error (SE, $n=3)$. 
The highest drop in $\mathrm{rETR}_{\max }$ for all light treatments was observed at $15^{\circ} \mathrm{C}$ (Fig. 3.2a) with $\sim 21,30$ and $60 \%$ reductions in zoospores treated with $\mathrm{P}, \mathrm{PA}$ and $\mathrm{PAB}$ respectively, while at 18 and $21{ }^{\circ} \mathrm{C}$ the decreases were $\sim 13$ and $11 \%$ for P, $\sim 5$ and $9 \%$ for PA and $\sim 51$ and $56 \%$ for $\mathrm{PAB}$, respectively. Differences among light treatments were detected at all temperatures after exposure (LME, $\left.15^{\circ} \mathrm{C} \mathrm{t}=-11.32, \mathrm{p}<0.0005 ; 18^{\circ} \mathrm{C} \mathrm{t}=-5.45, \mathrm{p}<0.005 ; 21^{\circ} \mathrm{C}, \mathrm{t}=-5.45, \mathrm{p}=<0.005\right)$, thus after exposure, $\mathrm{rETR}_{\max }$ varied among light treatments, with the lowest $\mathrm{rETR}_{\max }$ in zoospores exposed to PAB (Fig. 3.2a). In addition, differences among temperatures were detected for $\mathrm{P}$ and PA treatments (LME, P, t=4.34, $\mathrm{p}=0.003$; PA, $\mathrm{t}=3.25, \mathrm{p}=0.01$ ) after exposure.

Table 3.2 Multifactorial analysis assessed with Linear mixed effects models, for differences of light treatments, time and temperature on the photosynthetic parameters of zoospores of $U$. pinnatifida. Bold letters shows significance.

\begin{tabular}{|c|c|c|c|c|}
\hline Variable & Factor & DF & t value & P-value \\
\hline \multirow[t]{7}{*}{$\mathrm{F}_{\mathrm{v}} / \mathrm{F}_{\mathrm{m}}$ exposure } & Temperature (A) & 23 & 1.084 & 0.287 \\
\hline & Light Treatment (B) & 23 & -1.280 & 0.213 \\
\hline & Time $(\mathrm{C})$ & 23 & 0.403 & 0.690 \\
\hline & $A * B$ & 23 & 1.216 & 0.235 \\
\hline & $\mathrm{A} * \mathrm{C}$ & 23 & -1.569 & 0.130 \\
\hline & $\mathrm{B} * \mathrm{C}$ & 23 & 2.173 & 0.040 \\
\hline & $A * B * C$ & 23 & -1.803 & 0.084 \\
\hline \multirow[t]{3}{*}{$\mathrm{F}_{\mathrm{v}} / \mathrm{F}_{\mathrm{m}}$ recovery } & Temp (A) & 77 & 1.210 & 0.229 \\
\hline & Treat (B) & 77 & -0.566 & 0.572 \\
\hline & $\mathrm{A} * \mathrm{~B}$ & 77 & 0.190 & 0.849 \\
\hline \multirow[t]{7}{*}{$\mathrm{ETR}_{\max }$} & Temperature (A) & 46 & 0.389 & 0.699 \\
\hline & Light treatment (B) & 46 & 0.444 & 0.658 \\
\hline & Time $(\mathrm{C})$ & 46 & -0.315 & 0.753 \\
\hline & $\mathrm{A} * \mathrm{~B}$ & 46 & -0.282 & 0.779 \\
\hline & $\mathrm{A} * \mathrm{C}$ & 46 & 0.339 & 0.735 \\
\hline & $\mathrm{B} * \mathrm{C}$ & 46 & -0.574 & 0.568 \\
\hline & $A * B * C$ & 46 & 0149 & 0.881 \\
\hline
\end{tabular}


The effect of light treatments and temperature on zoospores settlement is shown in Fig 3.3. A low density of settled zoospores was observed in the experiments (Fig 3.3). There was no interaction between factors for zoospores settlement, neither the main effect of light treatment nor temperature (Table 3.3); although there is a trend for decreasing density at increasing temperature. Zoospores density was different among temperatures in zoospores exposed to PA and PAB (PA, t=-3.876, p=0.003; PAB, $\mathrm{t}=-4.181, \mathrm{p}=0.001$ ), where settlement decreases as temperature increase (Fig. 3.3). Differences in the effect of light treatments in zoospores settlement was detected only at $18{ }^{\circ} \mathrm{C}(\mathrm{GLM}, \mathrm{t}=-2.966, \mathrm{p}=0.01)$.

The effect of exposure to light treatments and temperature on germination of zoospores is shown in Fig. 3.4. There was no interaction between factors for zoospores germination, neither the main effect light treatment nor temperature (Table 3.3). Germination rate was very low 2 days after exposure to light treatments with a maximum germination of $\sim 40 \%$ for zoospores treated with $\mathrm{P}$ (Fig 3.4). The effect of light treatments on germination of zoospores of $U$. pinnatifida was similar among temperatures. Differences among light treatments were detected at all temperatures $\left(\mathrm{GLM}, 15^{\circ} \mathrm{C}, \mathrm{t}=-5.647, \mathrm{p}=0.0001 ; 18^{\circ} \mathrm{C}, \mathrm{t}=-4.545, \mathrm{p}=0.0001 ; 21^{\circ} \mathrm{C}, \mathrm{t}=-\right.$ 4.268, $\mathrm{p}=0.0001$ ), where the lowest germination was observed in zoospores exposed to PAB treatment with a maximum germination rate of $25 \%$, while zoospores exposed to P and PA had a higher germination rate with over $35 \%$ (Fig. 3.4). 


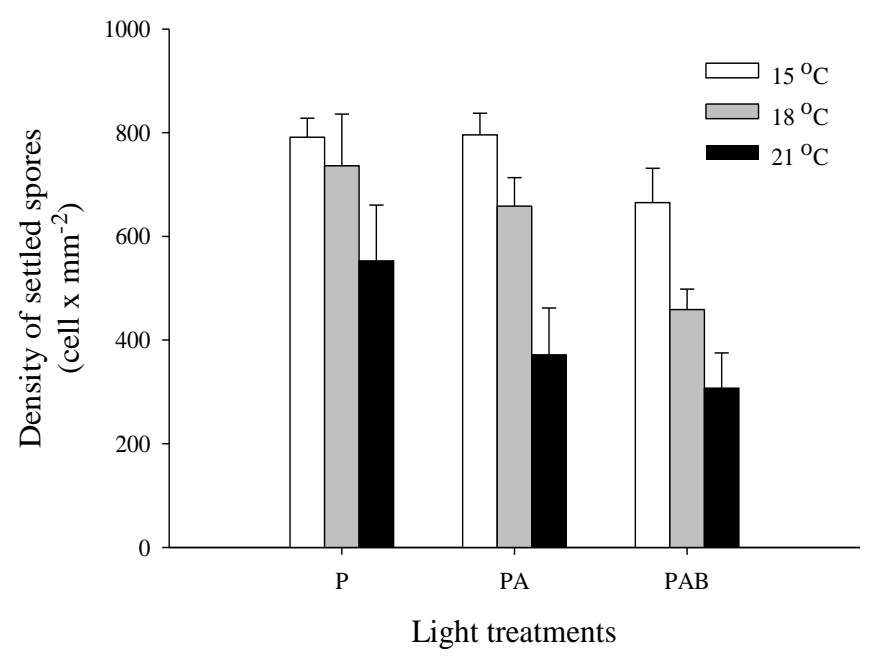

Fig. 3.3 Effect of light treatments (P, PA and PAB) on the density of settled zoospores of $U$. pinnatifida at different temperatures $\left(15,18,21^{\circ} \mathrm{C}\right)$. Zoospores were left in low light conditions $(35 \pm 2$ $\mu \mathrm{mol}$ photon $\mathrm{m}^{-2} \mathrm{~s}^{-1}$ ) after exposure to light treatments for $3 \mathrm{~h}$ and then in dark conditions for $14 \mathrm{~h}$. Vertical bars show standard error (SE, $n=4)$.

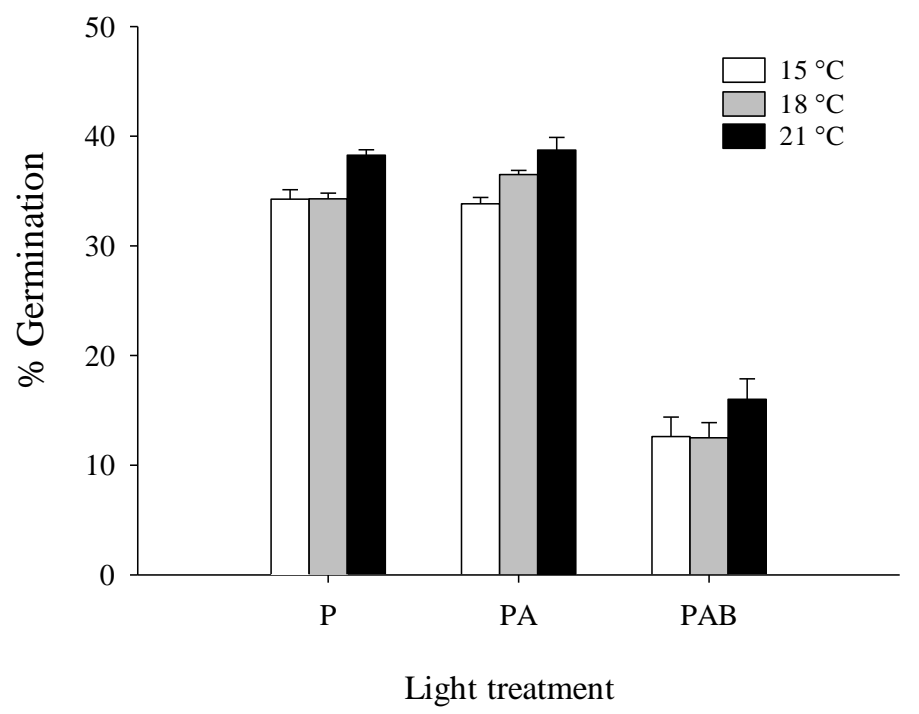

Fig. 3.4 Germination (\%) of zoospores exposed to light treatments (P, PA and PAB) at different temperatures $\left(15,18,21^{\circ} \mathrm{C}\right), 2$ days after exposure. Zoospores were left in recovery with a photoperiod of $10 \mathrm{~h}$ of low light $\left(35 \pm 2 \mu \mathrm{mol}\right.$ photon $\left.\mathrm{m}^{-2} \mathrm{~s}^{-1}\right)$ and $14 \mathrm{~h}$ of dark. Vertical bars show standard error (SE, $n=4)$. 
Table 3.3 Two-factor analysis assessed with General Lineal Model (GLM) for differences of light treatments and temperature of zoospores of $U$. pinnatifida on settlement, germination and length of germination tube. Bold letters shows significance. Settlement and gametophytes were analysed with a Poisson distribution, germination with a Binomial distribution and length of germination tube with Gamma distribution.

\begin{tabular}{llll}
\hline Variable & Factor & t value & P-value \\
\hline Settlement & Temperature (A) & 1.198 & 0.239 \\
& Light Treatment (B) & -0.668 & 0.509 \\
& $\mathrm{~A} * \mathrm{~B}$ & -1.700 & 0.098 \\
Germination & Temperature (A) & -1.236 & 0.216 \\
& Light treatments (B) & 0.410 & 0.682 \\
& $\mathrm{~A} * \mathrm{~B}$ & 0.102 & 0.918 \\
Length & & & \\
germination & Temperature (A) & 0.680 & 0.501 \\
tube & Light treatment (B) & 0.132 & 0.896 \\
& $\mathrm{~A} * \mathrm{~B}$ & -0.176 & 0.861 \\
Gametophytes & Temperature (A) & 0.510 & 0.613 \\
Female & Light treatments (B) & 0.438 & 0.664 \\
& $\mathrm{~A} * \mathrm{~B}$ & -1.036 & 0.308 \\
Gametophytes & Temperature (A) & 0.410 & 0.685 \\
Male & Light treatments (B) & 0.613 & 0.544 \\
& $\mathrm{~A}$ B & -1.258 & 0.218 \\
\hline
\end{tabular}

The mean lengths of zoospore germination tubes after 2 days exposure to light and temperatures are shown in Fig. 3.5. There was no interaction between factors for growth of zoospores germination tube (Table 3.3). The effect of light treatments on the length of the germination tube differed at all temperatures (ANOVA, $15{ }^{\circ} \mathrm{C}, \mathrm{f}=28.104, \mathrm{p}<0.0001,18{ }^{\circ} \mathrm{C}$, $\left.\mathrm{f}=13, \mathrm{p}<0.005 ; 21^{\circ} \mathrm{C}, \mathrm{f}=18.744, \mathrm{p}<0.005\right)$. The germination tube length was not affected by temperature at all light treatments. The length of the germination tube was similar in zoospores treated with $\mathrm{P}$ and $\mathrm{PA}$ at about $10 \mu \mathrm{m}$, however PAB treatment highly affected the growth of the germination tube, which were smaller than $8 \mu \mathrm{m}$ (Fig. 3.5). 
The densities of female and male gametophytes after 12 days at different light and temperature treatments are shown in Fig. 3.6. There was no interaction between factors for female and male gametophytes (Table 3.3). The number of female gametophytes in general may have been slightly higher than male gametophytes for all light treatments and temperatures (Fig.3.6) although no statistical differences were found. The number of females was lower in zoospores treated with $\mathrm{PAB}$ at the highest temperatures $\left(18\right.$ and $21^{\circ} \mathrm{C}$, Fig. 3.6), however, statistical differences among light treatments were detected only at $18{ }^{\circ} \mathrm{C}$ (GLM, female, $\mathrm{t}=-8.22$, $\mathrm{p}<0.005$ ). The same pattern was observed for male gametophytes and differences among light treatments were also detected only at $18{ }^{\circ} \mathrm{C}(\mathrm{GLM}$, male, $\mathrm{t}=-7.51, \mathrm{p}<0.005)$.

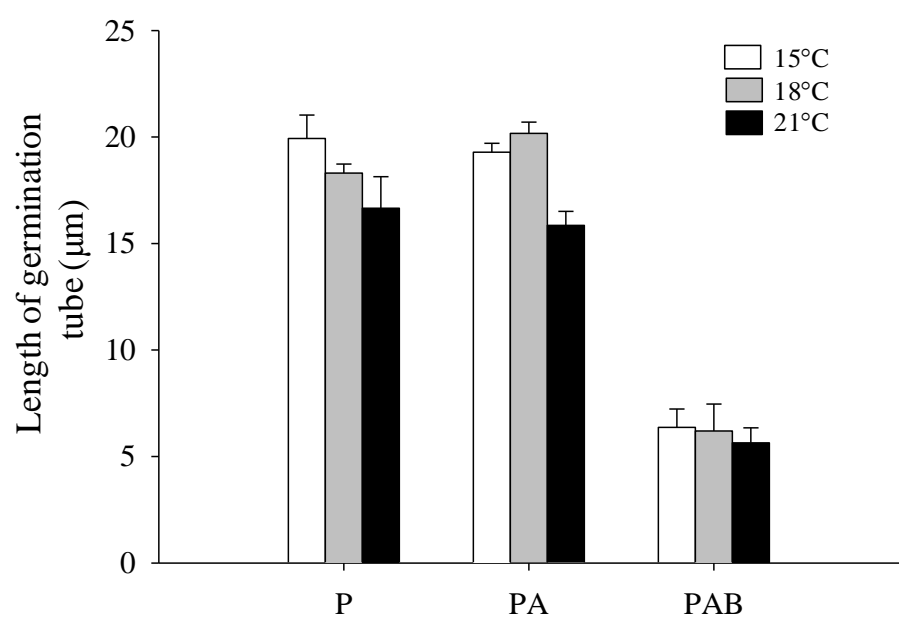

Light treatments

Fig. 3.5 Effect of light treatments $(\mathrm{P}, \mathrm{PA}$ and $\mathrm{PAB})$ at different temperatures $\left(15,18,21^{\circ} \mathrm{C}\right)$ on the mean length $(\mu \mathrm{m})$ of the germination tube of zoospores of $U$. pinnatifida. The germination tube length was measured 2 days after exposure. Zoospores were left in recovery with a photoperiod of $10 \mathrm{~h}$ of low light $\left(35 \pm 2 \mu \mathrm{mol}\right.$ photon $\left.\mathrm{m}^{-2} \mathrm{~s}^{-1}\right)$ and $14 \mathrm{~h}$ of dark. Vertical bars show standard error (SE, $\left.n=4\right)$.

The number of female and male gametophytes was variable among temperatures in zoospores exposed to light treatments (Fig.3.6); however, no statistical differences were detected (GLM, $\mathrm{t}=0.510, \mathrm{p}=0.613 ; \mathrm{t}=0.410, \mathrm{p}=0.685$, respectively). The effect of temperature on the number of 
gametophytes varied among light treatments. Thus, zoospores treated with $\mathrm{P}$ produced fewer female gametophytes at $21^{\circ} \mathrm{C}$, while zoospores exposed to PAB produced fewer female and male gametophytes at $18^{\circ} \mathrm{C}$. The development of zoospores treated with $\mathrm{PAB}$ into gametophytes was most affected at the two higher temperatures $\left(18\right.$ and $\left.21^{\circ} \mathrm{C}\right)$.

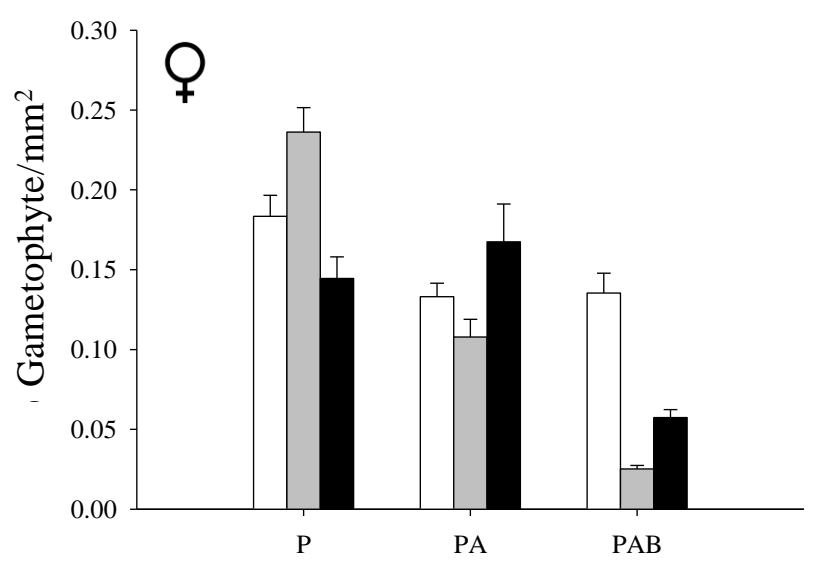

Light treatments

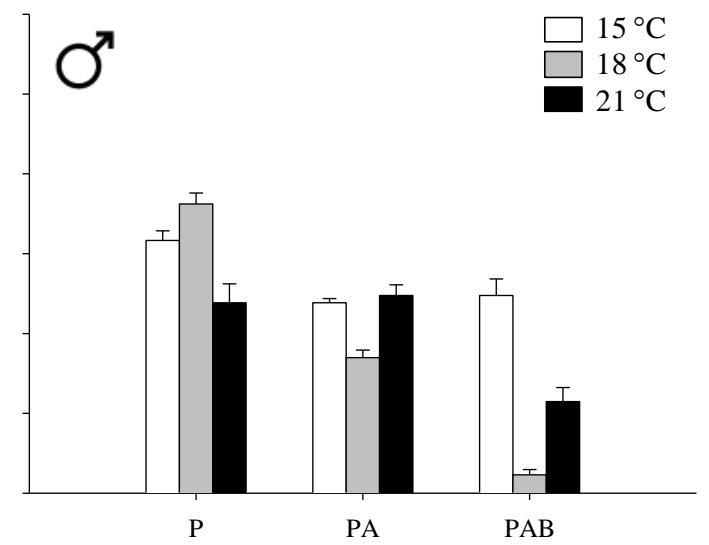

Light treatments

Fig. 3.6 Effect of light treatments $(\mathrm{P}, \mathrm{PA}$ and $\mathrm{PAB})$ at different temperatures $\left(15,18,21^{\circ} \mathrm{C}\right)$ on the development of zoospores to gametophyte stage. Zoospores were treated with light treatments daily for $1 \mathrm{~h}$ and then left for $9 \mathrm{~h}$ in low light conditions $\left(35 \pm 2 \mu \mathrm{mol}\right.$ photon $\left.\mathrm{m}^{-2} \mathrm{~s}^{-1}\right)$ followed by $14 \mathrm{~h}$ darkness for 12 days. Vertical bars show standard error (SE, $n=4)$.

\section{5 Discussion}

This study confirms that zoospores of Undaria pinnatifida can tolerate and develop well at a range of temperatures. Furthermore, temperature and light treatments affect microscopic life stages of the invasive kelp $U$. pinnatifida independently. The effect of light treatments, temperature and their interactions in the different parameters evaluated is summarized in Table 3.4. For example, photosynthesis after exposure to light treatments, germination and growth are mainly affected by light treatments, while settlement was highly affected by temperature. 
Table 3.4 Summary of the effect of light treatment, temperature and their interactions in the different parameters evaluated.

\begin{tabular}{llll}
\hline & Factors & \\
\cline { 2 - 3 } Parameter & Light treatments (LT) & Temperature (T) & LT * T \\
\hline $\mathrm{F}_{\mathrm{v}} / \mathrm{F}_{\mathrm{m} \text { (exposure) }}$ & ++ & ++ & - \\
$\mathrm{F}_{\mathrm{v}} / \mathrm{F}_{\mathrm{m} \text { (recovery) }}$ & - & - & - \\
ETR (exposure) & ++ & + & - \\
Settlement & + & ++ & - \\
Germination & +++ & - & - \\
Germination tube length & ++ & - & - \\
Gametophytes & ++ & - & -
\end{tabular}

The effect of factor was designated as follows: strong effect when $\mathrm{p}$ vales were lower than $0.0005(+++)$; medium effect $\mathrm{p}$ vales were lower than $0.005(++)$; low effect when $\mathrm{p}$ vales were lower than $0.05(+)$ and no effect when $\mathrm{p}$ vales were higher than $0.05(-)$ when at least one treatment was significant.

After exposure to light treatments, a reduction in $\mathrm{F}_{\mathrm{v}} / \mathrm{F}_{\mathrm{m}}$ was observed. The decrease in $\mathrm{F}_{\mathrm{v}} / \mathrm{F}_{\mathrm{m}}$ varied among temperatures in zoospores treated with P and PA with a higher decrease at the lower temperature. In contrast, $\mathrm{F}_{\mathrm{v}} / \mathrm{F}_{\mathrm{m}}$ reduced to a very low level under PAB regardless of the culture temperature. The lowest $\mathrm{rETR}_{\max }$ value was also observed in zoospores exposed to $\mathrm{PAB}$ regardless of temperature, suggesting that the main factor negatively affecting photosystem II was UVB. During the recovery phase, higher temperatures allowed faster recovery in $F_{v} / F_{m}$ for zoospores exposed to $P A B$, and after longer recovery $F_{v} / F_{m}$ reached values similar to initials regardless of temperature. A decrease in $F_{v} / F_{m}$ and $r E T R_{\max }$ under UVB has been associated with damage to the photosystem II (PSII), where the main target is the D1 protein within the reaction center; when protein D1 is degraded, its rates of biosynthesis and repair are slower than its degradation (Kato \& Sakamoto 2009, Che et al. 
2013). Zoospores of $U$. pinnatifida reached over $80 \%$ of the initial $\mathrm{F}_{\mathrm{v}} / \mathrm{F}_{\mathrm{m}}$ and $\mathrm{rETR} \mathrm{R}_{\max }$ values after $18 \mathrm{~h}$ of recovery compared to $70-80 \%$ observed in Laminaria digitata, L. saccharina, and L. hyperborea, after $48 \mathrm{~h}$ of recovery (Roleda et al. 2005). The high and relatively fast recovery of $F_{v} / F_{m}$ in zoospores exposed to PAB suggests that the UVB dose used in this experiment did not produce permanent damage in the photosynthetic apparatus. A fast zoospores settlement might be beneficial to survival and a fast recovery capacity in the photosynthetic capacity of $U$. pinnatifida after exposure to UVB could increase the opportunity to survive and might increase success in the invasion process.

Increasing temperature ameliorated the effect of UV on photosynthesis in Ulva bulbosa and Ulva clathrata (Rautenberger \& Bischof 2006). For U. pinnatifida, temperature compensates only the effect of $\mathrm{P}$ and PA treatments in photosynthesis $\left(\mathrm{F}_{\mathrm{v}} / \mathrm{F}_{\mathrm{m}}\right.$ and $\left.\mathrm{rETR}_{\max }\right)$ during exposure. Gómez et al. (2001) and Cruces et al. (2012) suggested that high temperature is less damaging for the photochemistry than lower temperatures and the turnover of D1, synthesis of pigments and enzymatic processes are stimulated by increasing temperatures in repair and photoprotective processes. These could explain the fast recovery capacity in $\mathrm{F}_{\mathrm{v}} / \mathrm{F}_{\mathrm{m}}$ of $U$. pinnatifida at higher temperatures. Higher temperature might increase the opportunity of survival of zoospores after light stress.

The influence of UV on zoospore settlement has not been studied previously in brown seaweeds and neither has the effect of UV combined with temperature to the best of my knowledge. A lower settlement was observed in zoospores exposed to PA and PAB, however differences among light treatments were only detected at $18^{\circ} \mathrm{C}$. Veliz et al. (2006) observed motile zoospores of Lessonia nigrescens and Lessonia trabeculata were more susceptible to UV than settled spores and suggested that UV might affect the settlement process by decreasing spore viability. Tolerance to light of $U$. pinnatifida during settlement might increase the potential of this species to grow viable populations, mainly in the intertidal where there is high variability of the light conditions. In contrast, temperature influenced zoospores settlement, decreasing settlement as temperature increased in zoospores exposed to PA and PAB. These findings agree with Thornber et al. (2004) who found a higher number of recruits of $U$. pinnatifida in field studies when water temperature was below $15{ }^{\circ} \mathrm{C}$, and also the survival rate of recruits decreased as temperature increased in laboratory experiments. The susceptibility of zoospores during settlement to high temperatures could be a barrier for $U$. 
pinnatifida to spread to warmer areas in the intertidal where they are exposed to UV radiation, but no deeper in the water column.

Germination and the length of the germination tube of zoospores were affected more by light treatments than temperature. Higher germination and growth was observed in zoospores exposed to $\mathrm{P}$ and PA than in zoospores exposed to PAB. These results illustrates that zoospores are able to germinate and growth at very low light conditions and that zoospores tolerate short exposure and low doses of UVA. The impact of UV on germination and growth has been previously assessed in zoospores of other Laminaria species (Wiencke et al. 2004, Roleda et al. 2005, 2007, 2010), and their results indicate germination is also highly sensitive to UV in those species. The viability of zoospores depends greatly on the effective repair mechanism and photoprotection of these stages and the susceptibility of zoospores to UVR determines their viability and germination success (Roleda et al. 2005, 2010). For example, the reduction in growth rate of young sporophytes of Saccorhiza by UVB radiation was attributed to DNA damage and lower concentrations of UV absorbing compounds (Roleda et al. 2005), and efficient DNA repair and recovery of PSII damage contributed to the germination success of L. digitata (Roleda et al. 2007). Hoffman et al. (2003) suggested that a rise of water temperature could ameliorate the effect of $\mathrm{UV}$ on germination. For $U$. pinnatifida, temperature showed no additional or mitigating effect on light treatments. This finding suggest that zoospores of $U$. pinnatifida might develop well in areas with low exposure to direct sunlight, for example the subtidal, areas of the rocky intertidal with low light or under the protection of algal assemblages and also, this might explain the capacity of $U$. pinnatifida to inhabit the intertidal zone where variations of water temperature exist.

The last experiment simulated possible light conditions after settlement of zoospores, and therefore, zoospores were exposed to low doses of UVA and UVB assuming settlement might be in shadowed areas with low exposure to direct sun light. An interactive effect of light treatments and temperature was not detected for $U$. pinnatifida, in contrast to Müller et al. (2008) who found a species-specific interactive effect of these factors in the gametogenesis of Laminaria species. Gametophyte formation was different among light treatments only at $18^{\circ} \mathrm{C}$, although there were lower gametophytes under PAB treatment especially at the two highest temperatures. These findings suggest that settlement of zoospores of $U$. pinnatifida in areas protected from the direct light might increase the capacity of zoospores to develop to gametophytes regardless of the temperature condition, so long as that is within the 
thermotolerance of this species. Microscopic life stages of $U$. pinnatifida are able to develop in a wide range of temperatures (Morita et al. 2003, Henkel \& Hofmann 2008). Furthermore, for gametophyte formation, the results of this experiment suggest the optimum temperature for growth might depended on the light treatment, thus zoospores exposed to $\mathrm{P}$ grew better at $18^{\circ} \mathrm{C}$, while zoospores exposed to PA grew best at $21^{\circ} \mathrm{C}$ and zoospores exposed to PAB favoured $15^{\circ} \mathrm{C}$. Therefore, an increase of water temperature might affect the development of zoospores of $U$. pinnatifida depending on their vertical distribution and the local UVR environment. For example, the development of zoospores inhabiting the subtidal exposed to low or no UVR exposure might be enhanced by an increase of temperature, while development of zoospore inhabiting areas more exposed to UVB such as intertidal might be delayed or inhibited by an increase of temperature.

The results of this experiment extend the result from the previous chapter in which the effect of increasing UVB irradiances was studied. In this chapter as well in Chapter 2 shows that UVB is an important stressor for early life stages. This chapter adds the effect of temperature in early life stages and shows temperature had little effects on $U$. pinnatifida. This chapter also demonstrate that UVA has minor effect on early life stages and shows that the lack of UVA in the experiments from Chapter 2 had minor repercussions for the results. The difference in the germination rate between Chapter 2 (late Winter and Spring) and this Chapter (early Winter) are likely due to seasonal variation. Differences in the germinations of Alaria esculenta between experiments also has been observed and this difference is related this variation to different collection times (Wiencke et al. 2004, 2007).

The effect of global environmental change is expected to modify the diversity of coastal communities provoking extinction of some species and a shift in the geographical distribution of others (Brook et al.2008). Introduced seaweeds, mainly those with invasive characteristics, could be more favoured by environmental changes than native species, due to their greater plasticity (Schiel ., \& Thompson 2012). Although controversial opinion exists where some authors have suggested that climate change might favour introductions (Dukes \& Mooney 1999, Vilà et al. 2007) due to an alteration in population dynamics and the structure and composition of communities (Walther et al. 2002, Parmesan 2006), others suggest that the impact of some invasive species might diminish under climate change (Hellmann et al 2008). My results show that light treatments and temperature affect microscopic stages of the invasive $U$. pinnatifida independently, where UVB is the strongest factor negatively influencing 
microscopic stages. Zoospores are highly vulnerable to UVR stress and their susceptibility depends on the dose of UVB, the vertical distribution of the species, (Roleda et al. 2005, Wiencke et al. 2004) and the stage of development (Veliz et al. 2006).

The capacity of $U$. pinnatifida to inhabit deeper zones and settle in protected areas from the direct light could be an advantage for maintaining viable populations in areas with high fluctuations of light conditions and UVB. In addition, synchronization of the life cycle with seasonal variation of PAR and UVB is also an advantageous feature of this species, where zoospores that are the most sensitive stages to UVB are released mainly in late Winter when light and UVB levels are low. Settlement of $U$. pinnatifida was negatively affected by an increase of temperature in zoospores exposed to PA and PAB. This suggests that an increase of oceanic water temperature might decrease the abundance of $U$. pinnatifida and also might slow the ability of this species to invade lower latitudes in the intertidal but could increase the ability to invade higher latitudes in both north and south hemispheres. Therefore, the capacity of $U$. pinnatifida to develop in a wide range of temperatures, and also in a wide range of light conditions and the life cycle might allow this species to maintain viable populations where they already exist in a scenario of environmental changes but also might permit invasion of higher latitudes. 


\subsection{References}

Altamirano, M., Flores-Moya, A. \& Figueroa, F. (2003) Altamirano, M., Flores-Moya, A., \& Figueroa, F. L. (2003). Effects of UV radiation and temperature on growth of germlings of three species of Fucus (Phaeophyceae). Aquatic Botany. 75(1): 9-20.

Baker, N. R. (2008). Chlorophyll fluorescence: a probe of photosynthesis in vivo. Annu. Rev. Plant Biol., 59, 89-113.

Brook, B. W., Sodhi, N. S., \& Bradshaw, C. J. (2008). Synergies among extinction drivers under global change. Trends in ecology \& evolution, 23(8), 453-460.

Che, Y., Fu, A., Hou, X., McDonald, K., Buchanan, B. B., Huang, W., \& Luan, S. (2013). C-terminal processing of reaction center protein D1 is essential for the function and assembly of photosystem II in Arabidopsis. Proceedings of the National Academy of Sciences, 110(40), $16247-16252$.

Coelho, S.M., Rijstenbil, J. W. \& Brown, M. T. (2000) Impacts of anthropogenic stresses on the early development stages of seaweeds. Journal of Aquatic Ecosystem Stress and Recovery. 7(4): 317-333.

Cruces, E., Huovinen, P., \& Gómez, I. (2012). Phlorotannin and Antioxidant Responses Upon Short-term Exposure to UV Radiation and Elevated Temperature in Three South Pacific Kelps. Photochemistry and photobiology, 88(1), 58-66.

Davison, I., Johnson, L. \& Brawley, S. (1993). Sublethal stress in the intertidal zone: tidal emersion inhibits photosynthesis and retards development in embryos of the brown alga Pelvetia fastigiata. Oecologia, 96(4), 483-492.

Dean, P. R. \& Hurd, C. L. (2007). Seasonal growth, erosion rates, and nitrogen and photosynthetic ecophysiology of Undaria pinnatifida (Heterokontophyta) in southern New Zealand1. Journal of Phycology. 43(6):1138-1148.

Doney, S. C., Ruckelshaus, M., Duffy, J. E., Barry, J. P., Chan, F., English, C. A., ... \& Talley, L. D. (2012). Climate change impacts on marine ecosystems. Marine Science, 4.

Dukes, J. \& Mooney, H. (1999) Does global change increase the success of biological success. Trends in Ecology and Evolution. 14(4):135-139.

Fredersdorf, J., Müller, R., Becker, S., Wiencke, C. \& Bischof, K. (2009) Interactive effects of radiation, temperature and salinity on different life history stages of the Arctic kelp Alaria esculenta (Phaeophyceae). Oecologia. 160(3):483-492. 
Galbraith, H., Jones, R., Park, R., Clough, J., Herrod-Julius, S., Harrington, B. \& Page, G. (2002). Global climate change and sea level rise: potential losses of intertidal habitat for shorebirds. Waterbirds. 25(2): 173-183.

Gómez, I., Figueroa, F. L., Sousa-Pinto, I., Viñegla, B., Pérez-Rodríguez, E., Maestre, C., ... \& Pereira, R. (2001). Effects of UV radiation and temperature on photosynthesis as measured by PAM fluorescence in the red alga Gelidium pulchellum (Turner) Kützing. Botanica Marina, 44(1), $9-16$.

Harley, C. D., Randall Hughes, A., Hultgren, K. M., Miner, B. G., Sorte, C. J., Thornber, C. S., et al. (2006). The impacts of climate change in coastal marine systems. Ecology letters. 9(2): 228241.

Hay, C. H. \& Villouta, E. (1993) Seasonality of the adventive Asian kelp Undaria pinnatifida in New Zealand. Botanica marina. 36(5):461-476.

Henkel, S. K., \& Hofmann, G. E. (2009, January). Differing patterns of hsp70 gene expression in invasive and native kelp species: evidence for acclimation-induced variation. In Nineteenth International Seaweed Symposium (pp. 465-474). Springer Netherlands.

Hellmann, J. J., Byers, J. E., Bierwagen, B. G., \& Dukes, J. S. (2008). Five potential consequences of climate change for invasive species. Conservation biology, 22(3), 534-543.

Hoffman, J. R., Hansen, L. J., \& Klinger, T. (2003). INTERACTIONS BETWEEN UV RADIATION AND TEMPERATURE LIMIT INFERENCES FROM SINGLE-FACTOR EXPERIMENTS1. Journal of Phycology, 39(2), 268-272. IPCC 2013

James, K., Middleton, I., Middleton, C., \& Shears, N. T. (2014). Discovery of Undaria pinnatifida (Harvey) Suringar, 1873 in northern New Zealand indicates increased invasion threat in subtropical regions. BioInvasions Records, 3(1), 21-24.

Kato, Y., \& Sakamoto, W. (2009). Protein quality control in chloroplasts: a current model of D1 protein degradation in the photosystem II repair cycle. Journal of biochemistry, 146(4), 463469.

Lobban, C. (1994). Seaweed ecology and physiology. Cambridge University Press.

Lyons, D. A., \& Scheibling, R. E. (2009). Range expansion by invasive marine algae: rates and patterns of spread at a regional scale. Diversity and Distributions, 15(5), 762-775.

Morelissen, B. (2012). Ecological effects of Undaria pinnatifida (Harvey) Suringar and nutrientenrichment on intertidal assemblages in the Wellington region of New Zealand. 
Morita, T., Kurashima, A., \& Maegawa, M. (2003). Temperature requirements for the growth and maturation of the gametophytes of Undaria pinnatifida and U. undarioides (Laminariales, Phaeophyceae). Phycological Research, 51(3), 154-160.

Murchie, E. H., \& Lawson, T. (2013). Chlorophyll fluorescence analysis: a guide to good practice and understanding some new applications. Journal of experimental botany, ert208.

Müller, R., Wiencke, C. \& Bischof, K. (2008). Interactive effects of UV radiation and temperature on microstages of Laminariales (Phaeophyceae) from the Arctic and North Sea. Climate Research. 37:203-213.

Obermüller, B., Karsten, U. L. F., \& Abele, D. (2005). Response of oxidative stress parameters and sunscreening compounds in Arctic amphipods during experimental exposure to maximal natural UVB radiation. Journal of Experimental Marine Biology and Ecology, 323(2), 100117.

Pakker, H., Martins, R. S., Boelen, P., Buma, A. G., Nikaido, O., \& Breeman, A. M. (2000). Effects of temperature on the photoreactivation of ultraviolet-b-induced dna damage in Palmaria palmata (Rhodophyta). Journal of Phycology, 36(2), 334-341.

Parmesan, C. (2006). Ecological and evolutionary responses to recent climate change. Annual Review of Ecology, Evolution, and Systematics, 637-669.

Rahel, F. J. \& Olden, J. D. (2008) Assessing the effects of climate change on aquatic invasive species. Conservation Biology. 22(3):521-533.

Ralph, P. J., \& Gademann, R. (2005). Rapid light curves: a powerful tool to assess photosynthetic activity. Aquatic botany, 82(3), 222-237.

Raniello, R., Lorenti, M., Brunet, C. \& Buia, M. (2004) Photosynthetic plasticity of an invasive variety of Caulerpa racemosa in a coastal Mediterranean area: light harvesting capacity and seasonal acclimation. Marine Ecology Progress Series, 271:113-120.

Rautenberger, R. \& Bischof, K. (2006). Impact of temperature on UV-susceptibility of two Ulva (Chlorophyta) species from Antarctic and Subantarctic regions. Polar Biology. 29(11): 988996.

Rilov, G. \& Treves, H. (2010). Climate change effects on marine ecological communities. In Seaweeds and their Role in Globally Changing Environments(pp. 51-68). Springer Netherlands.

Roncarati, F., Rijstenbil, J. W., \& Pistocchi, R. (2008). Photosynthetic performance, oxidative damage and antioxidants in Cylindrotheca closterium in response to high irradiance, UVB radiation and salinity. Marine Biology, 153(5), 965-973. 
Roleda, M., van de Poll, W. H., Hanelt, D., \& Wiencke, C. (2004). PAR and UVBR effects on photosynthesis, viability, growth and DNA in different life stages of two coexisting Gigartinales: implications for recruitment and zonation pattern. Marine ecology-progress series, 281, 37-50.

Roleda, M. Y., Wiencke, C., Hanelt, D., van de Poll, W. H., \& Gruber, A. (2005). Sensitivity of Laminariales zoospores from Helgoland (North Sea) to ultraviolet and photosynthetically active radiation: implications for depth distribution and seasonal reproduction. Plant, Cell \& Environment, 28(4), 466-479. Roleda et al. 2006b

Roleda, M. Y., Wiencke, C., \& Lüder, U. H. (2006). Impact of ultraviolet radiation on cell structure, UV-absorbing compounds, photosynthesis, DNA damage, and germination in zoospores of Arctic Saccorhiza dermatodea. Journal of experimental botany, 57(14), 3847-3856.

Roleda, M. Y., Wiencke, C., \& Hanelt, D. (2006). Thallus morphology and optical characteristics affect growth and DNA damage by UV radiation in juvenile Arctic Laminaria sporophytes. Planta, 223(3), 407-417.

Roleda, M. Y., Wiencke, C., Hanelt, D., \& Bischof, K. (2007). Sensitivity of the Early Life Stages of Macroalgae from the Northern Hemisphere to Ultraviolet Radiation $\uparrow$. Photochemistry and photobiology, 83(4), 851-862.

Roleda, M. Y., Lüder, U. H., \& Wiencke, C. (2010). UV-susceptibility of zoospores of the brown macroalga Laminaria digitata from Spitsbergen. Polar biology, 33(5), 577-588.

Rousseaux, M. C., Ballaré, C. L., Giordano, C. V., Scopel, A. L., Zima, A. M., Szwarcberg-Bracchitta, M., ... \& Díaz, S. B. (1999). Ozone depletion and UVB radiation: Impact on plant DNA damage in southern South America. Proceedings of the National Academy of Sciences, 96(26), 15310-15315.

Russell, L. K., Hepburn, C. D., Hurd, C. L., \& Stuart, M. D. (2008). The expanding range of Undaria pinnatifida in southern New Zealand: distribution, dispersal mechanisms and the invasion of wave-exposed environments. Biological invasions, 10(1), 103-115.

Saito, H., \& Taguchi, S. (2003). Influence of UVB radiation on hatching success of marine copepod Paracalanus parvus sl. Journal of experimental marine biology and ecology, 282(1), 135-147.

Schiel, D. R., \& Thompson, G. A. (2012). Demography and population biology of the invasive kelp Undaria pinnatifida on shallow reefs in southern New Zealand. Journal of Experimental Marine Biology and Ecology, 434, 25-33. 
Schreiber, U., Klughammer, C., \& Kolbowski, J. (2012). Assessment of wavelength-dependent parameters of photosynthetic electron transport with a new type of multi-color PAM chlorophyll fluorometer. Photosynthesis research, 113(1-3), 127-144.

Schreiber, U., Bilger, W. \& Neubauer, C. (1994) Chlorophyll fluorescence as a non intrusive indicator for rapid assessment of in vivo photosynthesis. Ecological Studies. 100:49-70.

Stachowicz, J. J., Terwin, J. R., Whitlatch, R. B. \& Osman, R. W. (2002). Linking climate change and biological invasions: ocean warming facilitates nonindigenous species invasions. Proceedings of the National Academy of Sciences. 99(24):15497-1550.

Steinhoff, F., Wiencke, C., Müller, R. \& Bischof, K. (2008) Effects of ultraviolet radiation and temperature on the ultrastructure of zoospores of the brown macroalga Laminaria hyperborea. Plant Biology. 10(3):388-397.

Stuart, M. D. (2004). Review of research on Undaria pinnatifida in New Zealand and its potential impacts on the eastern coast of the South Island (p. 40). Wellington, New Zealand: Department of Conservation.

Szabó, M., Wangpraseurt, D., Tamburic, B., Larkum, A. W., Schreiber, U., Suggett, D. J., ... \& Ralph, P. J. (2014). Effective light absorption and absolute electron transport rates in the coral Pocillopora damicornis. Plant Physiology and Biochemistry, 83, 159-167.

Thomsen, M. S. \& McGlathery, K. J. (2007). Stress tolerance of the invasive macroalgae Codium fragile and Gracilaria vermiculophylla in a soft-bottom turbid lagoon. Biological Invasions. 9(5):499-513.

Thornber, C. S., Kinlan, B. P., Graham, M. H. \& Stachowicz, J. J. (2004). Population ecology of the invasive kelp Undaria pinnatifida in California: environmental and biological controls on demography. Marine Ecology-Progress Series, 268.

Vadas, R. Johnson, S. \& Norton, T. (1992) Recruitment and mortality of early post-settlement stages of benthic algae. British Phycological Journal, 27(3):331-351.

Veliz, K., Edding, M., Tala, F. \& Gomez, I. (2006) Effects of ultraviolet radiation on different life cycle stages of the south Pacific kelps, Lessonia nigrescens and Lessonia trabeculata (Laminariales, Phaeophyceae). Marine Biology. 149(5): 1015-1024.

Vilà, M., Corbin, J. D., Dukes, J. S., Pino, J., \& Smith, S. D. (2007). Linking plant invasions to global environmental change. In Terrestrial ecosystems in a changing world (pp. 93-102). Springer Berlin Heidelberg. 
Walther, G. R., Roques, A., Hulme, P. E., Sykes, M. T., Pyšek, P., Kühn, I., et al.(2009). Alien species in a warmer world: risks and opportunities. Trends in ecology \& evolution. 24(12):686-693.

Walther, G. R., Post, E., Convey, P., Menzel, A., Parmesan, C., Beebee, T. J., ... \& Bairlein, F. (2002). Ecological responses to recent climate change. Nature, 416(6879), 389-395.

Williams, S. L., \& Smith, J. E. (2007). A global review of the distribution, taxonomy, and impacts of introduced seaweeds. Annual Review of Ecology, Evolution, and Systematics, 327-359.

Wiencke, C., Gómez, I., Pakker, H., Flores-Moya, A., Altamirano, M., Hanelt, D., Bischof K. \& Figueroa, F. L. (2000). Impact of UV-radiation on viability, photosynthetic characteristics and DNA of brown algal zoospores: implications for depth zonation. Marine ecology. Progress series, 197, 217-229.

Wiencke, C., Clayton, M. N., \& Schoenwaelder, M. (2004). Sensitivity and acclimation to UV radiation of zoospores from five species of Laminariales from the Arctic. Marine Biology, 145(1), 31-39.

Wiencke, C., Lüder, U. H., \& Roleda, M. Y. (2007). Impact of ultraviolet radiation on physiology and development of zoospores of the brown alga Alaria esculenta from Spitsbergen. Physiologia Plantarum, 130(4), 601-612.

Yoshikawa, T., Takeuchi, I., \& Furuya, K. (2001). Active erosion of Undaria pinnatifida Suringar (Laminariales, Phaeophyceae) mass-cultured in Otsuchi Bay in northeastern Japan. Journal of experimental marine biology and ecology, 266(1), 51-65. 


\title{
Chapter 4
}

\section{Effect of UVB and temperature on sporophytes of the}

\author{
invasive seaweed $U$. pinnatifida
}

\subsection{Abstract}

Sporophytes of the invasive $U$. pinnatifida were exposed to light treatments in combination with temperature to evaluate the interactive effect of both environmental variables on quantum yield $\left(\mathrm{F}_{\mathrm{v}} / \mathrm{F}_{\mathrm{m}}\right)$, electron transport rate $(\mathrm{ETR})$, non-photochemical quenching (NPQ) and phlorotannins content. Spectral irradiance consisted of photosynthetically active radiation $(\mathrm{P}$, 400-700nm) and PAR+UVA (PA, 320-400nm) and PAR+UVB radiation (PAB, 285-320nm) combined with temperature between 15 and $21{ }^{\circ} \mathrm{C}$. At $15{ }^{\circ} \mathrm{C}$, all photosynthetic parameters were highly depressed by PAB. Moreover, phlorotannins content decreased through the experiments under $\mathrm{PAB}$ treatments. The effect of light treatments varied with temperature throughout the experiment in $\mathrm{F}_{\mathrm{v}} / \mathrm{F}_{\mathrm{m}}$ and in the phlorotannins content. $\mathrm{F}_{\mathrm{v}} / \mathrm{F}_{\mathrm{m}}$ of sporophytes of $U$. pinnatifida was sensitive to $\mathrm{PAB}$ treatment regardless of the temperature and phlorotannins content was higher at the higher temperature. The sensitivity of sporophytes of $U$. pinnatifida to UVB and the lack of photoprotective role of phlorotannins suggests this species might have other strategies for success in the intertidal, for example it may direct its energy to growth and reproduction rather than photoprotection and repair. 


\subsection{Introduction}

Organisms inhabiting the intertidal zone are exposed to potentially stressful conditions due to the high variability in environmental conditions (Vernery et al. 2006, 2007, Helmuth et al. 2006, Collén et al. 2007, Schneider 2008, Coelho et al. 2009). Organisms may be exposed to high light and temperature, desiccation, osmotic shock and nutrient limitation during tidal emersion (Davison \& Pearson 1996, Kummar et al. 2014). Stress occurs when there is a limitation or excess of resources available (Davison \& Pearson 1996), and the frequency of stress events and their duration depends on the tidal elevation (Collén \& Davison 1999). These stresses may be lethal or sublethal depending on the dose (Davison et al. 1993, Somero 2002) and the organism's capacity to cope with these stresses. Moreover, climate change brings additional stresses to organisms for example an increase of water temperature is expected over the next $50-100$ years (IPCC 2013).

An important factor influencing the zonation pattern of intertidal seaweeds is UVB radiation (Bischof et al. 1998, 2007, Wiencke et al. 2000, 2007, Roleda et al. 2005, 2006a, 2010). Species inhabiting deeper areas may be more susceptible to UVB than those that inhabit shallower areas where they are more exposed to this type of radiation (Roleda et al. 2005, 2006a, Huovinen \& Gómez 2013). On the other hand, the geographical distribution of seaweeds is regulated mainly by temperature (Müller et al.2009), through their individual requirements for reproduction, growth and physiological processes (Lobban 1994, Coehlo et al.2000).

UVB radiation has diverse effects on seaweeds, including damage to the photosynthetic apparatus (Roleda et al. 2004), degradation of pigments such as chl $\alpha$ and carotenoids (Roleda et al. 2004), damage to macro-molecules such as DNA and proteins (Roleda et al. 2005, 2006a, 2006b) and inhibition of growth (Henry \& Van Alstyne 2004, Zheng \& Gao 2009). For intertidal seaweeds, although they cannot completely avoid exposure to direct sun light, the overlying algal canopy might mitigate this exposure (Henry \& Van Alstyne 2004). Therefore, for these species, repair and screening processes might play an important role in their protection against UVB. For example, seaweeds can repair DNA damaged by UVB through photoreactivation and nucleotide excision (Pakker et al. 2000, Buma et al. 2003). 
Photosynthetic organisms dissipate excess energy as fluorescence and heat (Krause \& Jahns 2004, Ruban et al, 2007) or repair the D1 protein that is the main target of UVB in the photosynthetic apparatus (Bischof et al. 2000). Moreover, algae produce screening compounds such as mycosporine-like-amino acids (Karsten et al. 2003, Ryan et al. 2002, Sinha et al.2007), and phenolics compounds (Pavia et al.1997) that may protect against photodamage. Phlorotannins are phenolic compounds that are produced as secondary metabolites in brown macroalgae (Koivikko et al.2005) and might play multiple ecological roles such as chemical defence against herbivores, antibacterial action, and screening of UV-B (Arnold \& Targett 1998, 2002, Lüder \& Clayton 2004, Halm et al. 2011). Because they are located in vesicles in the cytoplasm and also in the cell wall (Halm et al. 2011), phlorotannins have been linked to intracellular protection against UVB, but they might also provide extracellular protection as exudates or during tissue erosion (Jennings \& Steinberg 1994, Swanson \& Druehl 2002) creating a layer of "gelbstoff” (CDOM) that absorbs UVB (Sieburth 1969).

Intertidal seaweeds in general have a wide thermo-tolerance; therefore the effect of variation in temperature on seaweeds is minor compared to other stressors. However, temperature modifies biochemical reactions by affecting molecular structure and activity (Lobban 1994). For example, temperature regulates enzymatic process that affects the metabolism of seaweeds (Davison 1991) and has consequences on the light independent reactions of photosynthesis, respiration and growth of seaweeds (Lobban1994). In the last decade increased effort has concentrated on the interaction of temperature with other environmental variables, especially the effect of light and temperature on early life stages (Altamirano et al. 2003, Müller et al. 2009, Steinhoff et al. 2011). The response is species-specific (Müller et al. 2008) and also depends on the process (Fredersdorf et al. 2009). For example, in the brown seaweed Alaria esculeta the photosynthetic capacity was affected by temperature and light treatments individually; while germination of zoospores was additionally affected by the interaction of both light and temperature (Fredersdorf et al. 2009).

The fluorescence of the chlorophyll is measured by using Pulse Amplitude Modulation fluorometer (PAM) (Wiencke et al. 2004, Roleda et al. 2005, Baker 2008). The fluorescence of the chlorophyll is widely used because it is non destructive, easy to use and provides useful information on the state of the photosystem II (PSII) (Baker 2008, Murchie \& Lawson 2013). Parameters widely used are the maximum quantum yield of PSII $\left(\mathrm{F}_{\mathrm{v}} / \mathrm{F}_{\mathrm{m}}\right)$, the electron transport rate (ETR) obtained from rapid light curves (RLCs), as described in the previous chapters, and 
the non-photochemical quenching (NPQ). Non-photochemical quenching (NPQ) is the thermal dissipation of excess of energy and it is an important photoprotective mechanism for photosynthetic organisms (Johnson et al. 2009). This process involves the quenching of chlorophyll a (chl a) fluorescence with three components: state transitions (qT), $\Delta \mathrm{pH}-$ dependent quenching (qE) and photoinhibition (q1) (Johnson et al. 2009).

The success of the invasive Undaria pinnatifida has been linked to its high dispersal ability and its capacity to establish in varied environments (Dean \& Hurd 2007). U. pinnatifida has an alternation of generations (gametophytes and sporophytes) that is regulated principally by temperature. Thus, in its native environment, $U$. pinnatifida has an annual cycle where gametophytes are produced in Autumn, and the sporophytes appear in Winter-Spring and die in late Summer (Yoshikawa et al. 2001). In New Zealand, in contrast, sporophytes of this species can be found throughout the year (Hay \& Villouta 1993, Morelissen 2012).

The sporophyte of $U$. pinnatifida is the most visible stage of the life cycle and is common in the intertidal of the Wellington coast. The capacity of sporophytes to tolerate fluctuations in environmental conditions could allow this species to become more successful under predicted global changes. Also this species might be favoured by an increase of temperature due to climate change as suggested for invasive species (Dukes \& Mooney 1999, Dukes et al. 2009, Vilà et al. 2007, Sorte et al. 2010). However, the effect of environmental stressors, both singly and in combination, on invasive seaweed species, and their physiological response are presently unknown. Thus, this study was undertaken to determine the effect of UVB in combination with temperature on sporophytes of $U$. pinnatifida. I hypothesised that sporophyte phlorotannins will increase after exposure to UVB as a mechanism of photoprotection. I also hypothesised that temperature and UVB will have an interactive effect that will reduce the effect of UVB on $U$. pinnatifida. Thus, my goal was to evaluate the interactive effect of UVB and temperature on the photosynthetic performance of sporophytes of $U$. pinnatifida and also to evaluate the photoprotective capacity of soluble phlorotannins (SPs) in this species during exposure to light treatments. 


\subsection{Materials and Methods}

\section{Algal material}

Mature sporophytes of $U$. pinnatifida were collected by hand in the intertidal zone of Princess Bay, Wellington, (41 $\left.20^{\prime} 39.94^{\prime \prime} \mathrm{S}, 174^{\circ} 47^{\prime} 17.07^{\prime \prime} \mathrm{E}\right)$ during low tide. Discs (1.2cm diameter) were cut from thalli of sporophytes of $U$. pinnatifida and then placed in plastic containers $(5 \times 11 \times 15 \mathrm{~cm})$ filled with $200 \mathrm{ml}$ of seawater with a continuous air supply using a small aquarium bubbler (Jebo Aquarium Air Pump 9903) and left to recover for 20h before the experiment. Water was changed two times daily throughout the experiments.

\section{Light treatments}

Photosynthetically active radiation (PAR) was provided by white fluorescent tubes (36W/840, Davis, New Zealand), ultraviolet A (UVA) radiation was supplied with TL 40W/03RS fluorescent tubes (Philips, New Zealand) with an emission peak at $375 \mathrm{~nm}$ and emitting range of 320 to $410 \mathrm{~nm}$, and UVB with TL 40W/12RS fluorescent tubes (Phillips, New Zealand) with an emission peak at $302 \mathrm{~nm}$ and emitting range of 290-390 $\mathrm{nm}$. The experimental design consisted of three treatments, 1) PAR+UVA+UVB (PAB), where samples were exposed to full radiation from lamps, 2) PAR+UVA (PA), where samples were covered with a mylar sheet that cuts radiation below $320 \mathrm{~nm}$ and 3) PAR (P), where samples were covered with a polycarbonate sheet that cuts radiation below $390 \mathrm{~nm}$. UVB lamps were covered with PVC filters to cut damaging radiation below 290nm (as in Fig. 2.1, Chapter2). Radiation was measured with a SpectroSense2 + radiometer (Skye Instrument Ltd. United Kingdom); with a 4-Channel SK 1850/SS2 sensor for PAR; a SKU 421 for UVA and a SKU 430/SS2 for UVB. Two different experiments were performed. In Experiment 1, sporophytes were exposed to different light treatments at constant temperature, and in Experiment 2, sporophytes were exposed to the same light treatments but at increasing temperature conditions. Experimental irradiances are shown in Table 4.1. 
Table. 4.1 Experimental irradiances in the experiments.

\begin{tabular}{llcc}
\hline & \multicolumn{2}{l}{ Experimental irradiances } & \\
\cline { 2 - 4 } & PAR & UVA & UVB \\
& $\left(\mu\right.$ mol photons $\left.\mathrm{m}^{-2} \mathrm{~s}^{-1}\right)$ & $\left(\mathrm{Wm}^{-2}\right)$ & 0 \\
\hline Low light & $57 \pm 1.7$ & 0 & \\
Experiment 1 \&2 & & & $1.0 \pm 0.2$ \\
\hline PAB & $64.6 \pm 1.0$ & $5.1 \pm 0.1$ & $0.3 \pm 0.2$ \\
PA & $61.36 \pm 1.0$ & $4.3 \pm 0.1$ & $0.06 \pm 0.2$ \\
P & $61.16 \pm 1.0$ & $0.04 \pm 0.1$ & \\
\hline
\end{tabular}

\section{Chlorophyll fluorometry}

Photosynthetic efficiency was measured as the variable fluorescence of photosystem II (PSII) using a Pulse Amplitude Modulation fluorometer (Water-PAM) connected to a PC with WinControl software (Heinz Walz GmbH, Effeltrich, Germany). Before each measurement, samples were dark adapted for $30 \mathrm{~min}$. and the maximum quantum yield $\left(\mathrm{F}_{\mathrm{v}} / \mathrm{F}_{\mathrm{m}}\right)$ was obtained. Dark acclimation permits all reaction centres of PSII to be open (all primary acceptors are oxidized) and heat dissipation to be minimal. Thus, dark adapted samples have a minimal fluorescence yield $\left(\mathrm{F}_{\mathrm{o}}\right)$. After a saturating pulse of actinic light, all reaction centres close and samples reach the maximal florescence $\left(F_{m}\right)$. The difference between $F_{o}$ and $F_{m}$ gives the variable fluorescence $\left(\mathrm{F}_{\mathrm{v}}\right)$ that indicates the capacity of the sample for photochemical quenching. The maximum quantum yield of PSII was defined as $F_{v} / F_{m}$.

The relative electron transport rate (rETR) was measured from rapid light curves (RLCs) that measures the effective quantum yield over a range of increasing actinic light intensities (up to $700 \mu \mathrm{mol}$ photon $\mathrm{m}^{-2} \mathrm{~s}^{-1}$ ) provided by a LED lamp (Schreiber et al. 1997). The rETR was calculated as:

ETR $\left(\mu \mathrm{mol}\right.$ electrons $\left.\mathrm{m}^{-2} \mathrm{~s}^{-1}\right)=\phi_{\text {PSII }} * \mathrm{E}$ 
Where $\phi_{\text {PSII }}$ is the PSII effective quantum yield, determined as $\left(F^{\prime} m-F\right) / F^{\prime} m=\Delta F / F^{\prime} m$, where $F^{\prime} m$ and $F$ are the maximum and minimum fluorescence, respectively, in presence of actinic light and $\mathrm{E}$ is the incident irradiance of PAR. The photosynthetic parameters: the maximum relative electron transport rate $\left(\mathrm{rETR}_{\max }\right)$, the initial slope of the non-saturated photosynthetic rate $(\alpha)$ and saturating light of photosynthesis $\left(E_{k}\right)$ were derived from RLCs.

Non Photochemical Quenching (NPQ) of the chlorophyll fluorescence was calculated as follows:

$\mathrm{NPQ}=\left(\mathrm{F}_{\mathrm{m}}-\mathrm{F}_{\mathrm{m}}^{\prime}\right) / \mathrm{F}_{\mathrm{m}}^{\prime}$

\section{Soluble phlorotannins content}

Four discs of $U$. pinnatifida were taken during the experiment and then frozen at $-20^{\circ} \mathrm{C}$. Phenolic content was determined by the colorimetric method Folin-Ciocalteu modified by Koivikko et al. (2005). Samples of seaweed were dried in a freeze drier and $\sim 0.02 \mathrm{~g}$ of each sample was used for the determination of soluble phlorotannins (SPs). Dried algal powder was left in $10 \mathrm{ml}$ of $70 \%$ acetone overnight at $4^{\circ} \mathrm{C}$; the liquid was removed and the procedure was repeated. The acetone extracts were then combined to obtain maximum concentrations of SPs (Koivikko et al. 2005). The algal solution was centrifuged for $10 \mathrm{~min}$ at 2,200g; $500 \mu 1$ of supernatant was mixed with $2.5 \mathrm{ml}$ distilled water and $1 \mathrm{ml}$ Folin-Ciocalteu reagent, and left to stand for $3 \mathrm{~min}$ before $2 \mathrm{ml} 20 \% \mathrm{NaCO}_{3}$ was added. Samples were incubated in the dark at room temperature for $45 \mathrm{~min}$ and then centrifuged for $2,200 \mathrm{~g}$ for $5 \mathrm{~min}$. The absorbance of the supernatants was measured with a spectrophotometer (Evolution 300, Thermo Scientific) at $730 \mathrm{~nm}$.

\section{Experiment 1: Effect of UVB on photosynthesis and SP concentration}

Sporophytes for Experiment 1 were collected during Winter. Photosynthesis experiments were performed with three different light treatments (P, PA and PAB) at $15{ }^{\circ} \mathrm{C}$ in a controlled temperature room. Discs ( $\mathrm{n}=\sim 300)$ from 6-8 thalli (27-50 discs per individual) were combined in a container filled with seawater and then divided randomly into 12 different plastic containers, where 4 containers provided the $\mathrm{P}$ treatment, 4 provided PA treatment and 4 provided PAB treatment as described earlier (25 per container). One disc for each replicate was left for $30 \mathrm{~min}$. in dark conditions and then the $\mathrm{F}_{\mathrm{v}} / \mathrm{F}_{\mathrm{m}}$, rETR and NPQ were measured 
before the experiment began at time $0 \mathrm{~h}$. Discs were exposed to low light for $2 \mathrm{~h}$, then to light treatments for $8 \mathrm{~h}$. After exposure to treatments, discs were left in recovery in low light for $2 \mathrm{~h}$ and then in dark conditions for $12 \mathrm{~h}$. This photoperiod was repeated for two days. The light treatments were chosen in an attempt to approximate natural light levels in cycles of $24 \mathrm{hr}$ during spring for two days. $\mathrm{F}_{\mathrm{v}} / \mathrm{F}_{\mathrm{m}}, \mathrm{rETR}$ and NPQ were measured after exposure to light treatments (and dark adaption) and after recovery during the two days of the experiment. Four discs from each chamber were collected before and after exposure to treatments every day and frozen at $-20{ }^{\circ} \mathrm{C}$ for phenolic analysis.

\section{Experiment 2: Effect of UVB and temperature on photosynthesis and SP concentration}

Sporophytes for Experiment 2 were collected during Summer. Photosynthesis experiments were performed with three different light treatments (P, PA and PAB) in water baths held at three different temperatures $\left(18,20,22{ }^{\circ} \mathrm{C}\right)$. The experiment was performed two times to provide sufficient replicates thus two replicates of each light treatment were used in each part of the experiment. Discs ( $\mathrm{n}=\sim 600)$ of 6-8 thalli (100-75 discs per individual) were combined in a container filled with seawater and then divided into 12 different plastic containers, where 4 chambers provided the $\mathrm{P}$ treatment, 4 provided $\mathrm{PA}$ treatment and 4 provided $\mathrm{PAB}$ treatment as described earlier for each temperature. Samples were left for $3 \mathrm{~h}$ to acclimate to the new temperature in low light conditions. Discs were then dark adapted for $30 \mathrm{~min}$. and then $\mathrm{F}_{\mathrm{v}} / \mathrm{F}_{\mathrm{m}}$ and rETR were measured before temperature acclimation (initial) and before exposure to light treatments at time $0 \mathrm{~h}$ (controls). After the temperature acclimation period, the discs were exposed to light treatment (P, PA. PAB) for $10 \mathrm{~h}$ and then left under dark conditions for $14 \mathrm{~h}$. This photoperiod was repeated for 2 days. Seawater was change daily for each chamber. Also, $\mathrm{F}_{\mathrm{v}} / \mathrm{F}_{\mathrm{m}}$ was measured after light treatment at the end of each day after 30 min dark adaption, and again immediately prior to light treatment the next morning. Four disc from each chamber were collected after exposure to light treatments and frozen at $-20{ }^{\circ} \mathrm{C}$ for phenolic analysis after dark conditions each day (0, 24 and 48h).

Data analysis

The photosynthesis and SP data from both experiments were analysed with a permutational multivariate analysis of variance (PERMANOVA) as the data did not meet the assumption of normality and equal variance. The analyses were based on similarity matrices using BrayCurtis coefficients. Experiment 1 light treatments and exposure/recovery time were included 
as independent factors for photosynthetic parameters and soluble phlorotannins (SPs). For Experiment 2, temperature was added to the model. A pair-wise comparison in PERMANOVA was used when permutations were higher than 999. The tests were run using PRIMER-E v6 software (Plymouth Routines in Multivariate Ecological Research).

\subsection{Results}

\section{Experiment 1: Effect of UVB on photosynthesis and SP concentration}

The effect of light treatments $(\mathrm{P}, \mathrm{PA}$ and $\mathrm{PAB})$ on the maximum quantum yield $\left(\mathrm{F}_{\mathrm{v}} / \mathrm{F}_{\mathrm{m}}\right)$ of sporophytes of $U$. pinnatifida is shown in Fig. 4.1. An interactive effect of light treatments and exposures was detected for both exposure and recovery (Table 4.2), thus the effect of light treatments varied among exposure/recoveries. Sporophytes had high $F_{v} / F_{m}$ values before exposure (0h) (Fig. 4.1). After the first exposure to light treatments $(8 \mathrm{~h})$, the $\mathrm{F}_{\mathrm{v}} / \mathrm{F}_{\mathrm{m}}$ of sporophytes was reduced by PAB (Table 4.2). At the second (32h) exposure (56h) a further decrease in $F_{v} / F_{m}$ was observed in sporophytes exposed to PAB. In contrast, in sporophytes exposed to $\mathrm{P}$ and $\mathrm{PA}, \mathrm{F}_{\mathrm{v}} / \mathrm{F}_{\mathrm{m}}$ remained high throughout the experiment with little variation (Fig.4.1). During the first recovery period (24h) in sporophytes exposed to PAB, there was a slight increase of $F_{v} / F_{m}$. This trend continued in the subsequent recovery period (Fig. 4.1).

There was an interactive effect between light treatments and exposures for ETRmax (Table. 4.2). In general, $\mathrm{rETR}_{\max }$ was lower than initial values after $48 \mathrm{~h}$. $\mathrm{rETR}_{\max }$ of sporophytes exposed to $\mathrm{P}$ and PA remained approximately stable throughout the experiment at $\sim 30 \mu \mathrm{mol}$ photons $\mathrm{m}^{-2} \mathrm{~s}^{-1}$ (Fig 4.2). Lower $\mathrm{rETR}_{\max }$ values were observed in sporophytes exposed to $\mathrm{PAB}$ after exposures and recoveries (Fig. 4.2). rETRmax in sporophytes exposed to PAB declined steeply after the first exposure and remained very low for $32 \mathrm{~h}$; however there was an apparent increase in rETR after the second recovery (48h).

The NPQ of sporophytes exposed to P and PA remained approximately stable throughout the experiments (Fig. 4.3). The NPQ in sporophytes exposed to PAB remained stable after the first exposure and there was a slight decrease after the second exposure. NPQ decreased after the first recovery, but increased after the second after exposure to PAB. There was no interaction 
between light treatments and exposure/recoveries for non-photochemical quenching (NPQ); however differences among light treatments were detected for exposures and recoveries (Fig 4.3 and Table 4.2). Thus, the NPQ of sporophytes exposed to PAB differed from sporophytes exposed to $\mathrm{P}$ (Pair-wise, $\mathrm{t}=2.722, \mathrm{p}=0.0046$ ) and PA (Pair-wise, $\mathrm{t}=2.0654, \mathrm{p}=0.028$ ), while no differences in the NPQ between sporophytes exposed to P and PA were detected. After recovery, the NPQ of sporophytes exposed to PAB differed from sporophytes exposed to $\mathrm{P}$ (Pair-wise, $\mathrm{t}=3.153, \mathrm{p}=0.002$ ) and PA (Pair-wise, $\mathrm{t}=2.44, \mathrm{p}=0.005$ ).

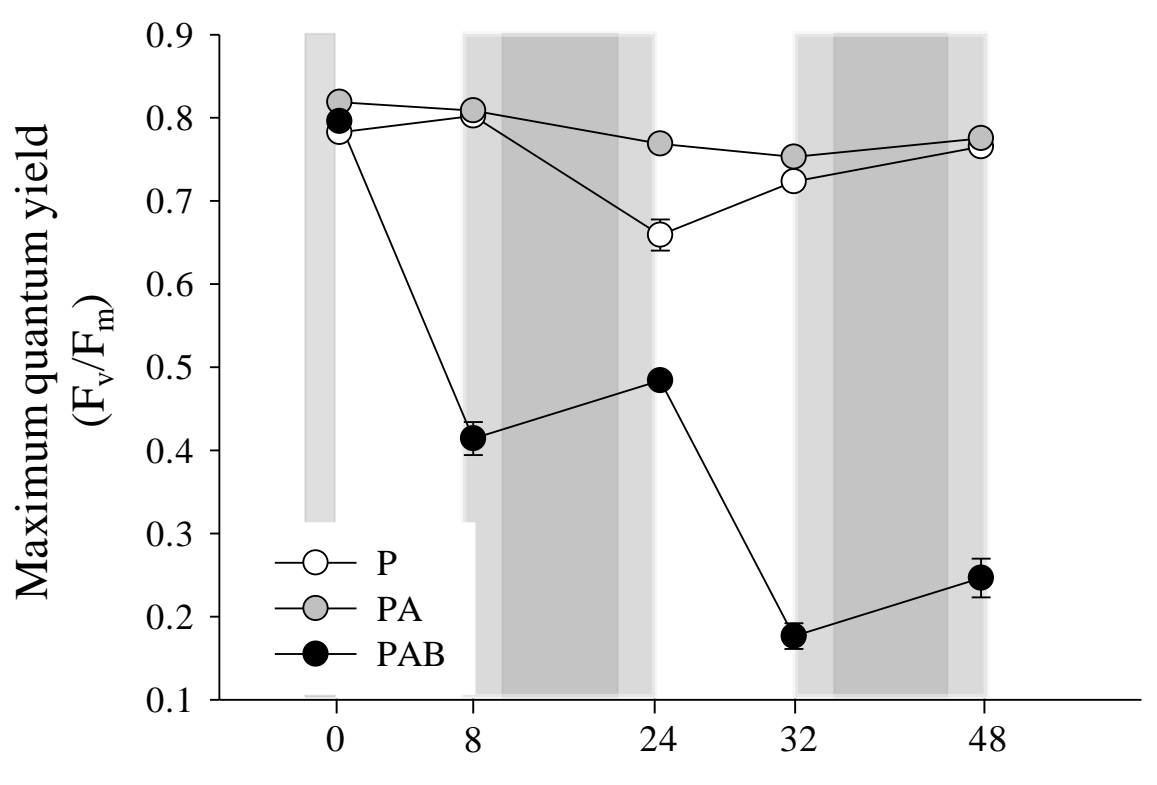

Time (h)

Fig. 4.1 Effect of light treatments $(\mathrm{P}, \mathrm{PA}$ and $\mathrm{PB})$ on maximum quantum yield $\left(\mathrm{F}_{\mathrm{v}} / \mathrm{F}_{\mathrm{m}}\right)$ of sporophytes of $U$. pinnatifida. Discs were left for $2 \mathrm{~h}$ in low light (light grey background) and then exposed to light treatments for $8 \mathrm{~h}$ (white background) followed by $2 \mathrm{~h}$ of low light (light grey background) and $14 \mathrm{~h}$ in dark (dark grey background) at $15^{\circ} \mathrm{C}$. This procedure was repeated three times. Discs were dark adapted to obtain $\mathrm{F}_{\mathrm{v}} / \mathrm{F}_{\mathrm{m}}$. Data are means and vertical bars show standard error (SE, $\left.n=4\right)$. 


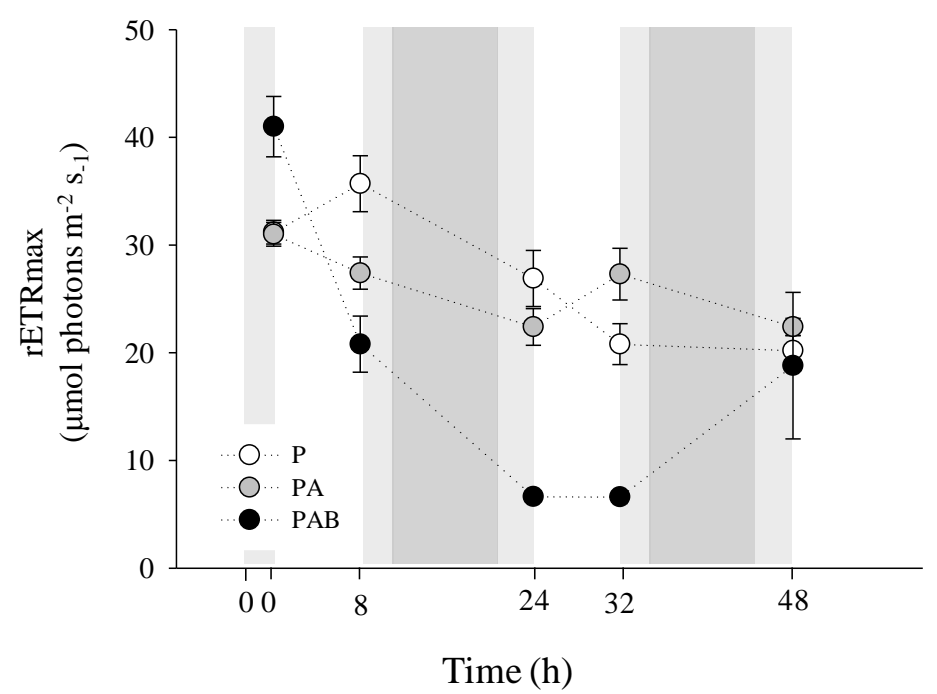

Fig. 4.2 Effect of light treatments (P, PA and PB) on rETRmax of sporophytes of $U$. pinnatifida. Discs were left for $2 \mathrm{~h}$ in low light (light grey background) and then exposed to light treatments for $8 \mathrm{~h}$ (white background) followed by $2 \mathrm{~h}$ of low light (light grey background) and $14 \mathrm{~h}$ in the dark (dark grey background) at $15^{\circ} \mathrm{C}$. This procedure was repeated three times. Data are means and vertical bars show standard error (SE, $n=4)$.

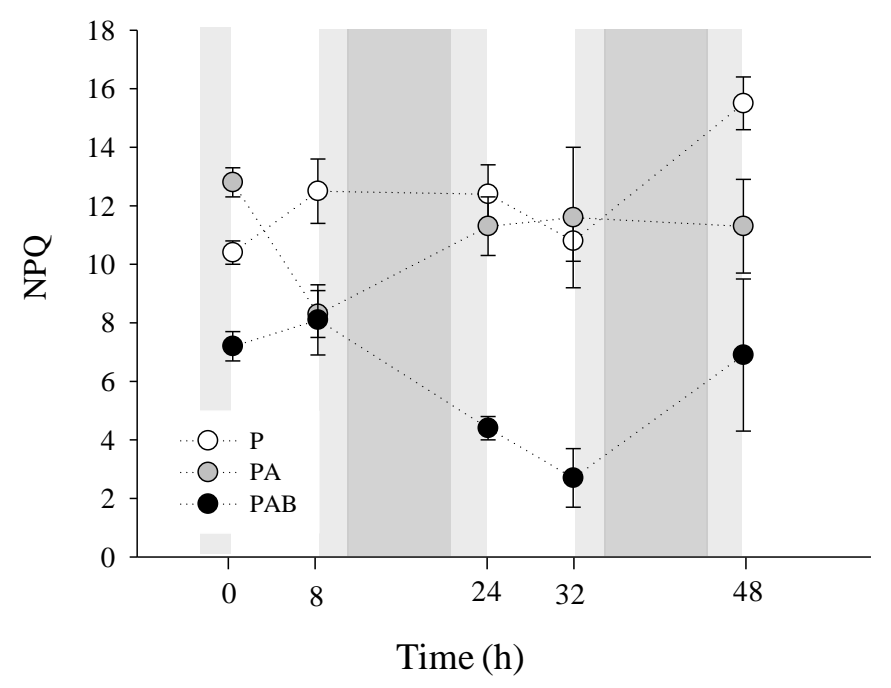

Fig. 4.3 Effect of light treatments (P, PA and PB) on non-photochemical quenching (NPQ) of sporophytes of $U$. pinnatifida. Discs were left for $2 \mathrm{~h}$ in low light (light grey background) and then exposed to light treatments for $8 \mathrm{~h}$ (white background) followed by $2 \mathrm{~h}$ of low light (light grey background) and $14 \mathrm{~h}$ in dark (dark grey background) at $15^{\circ} \mathrm{C}$. This procedure was repeated three times. Data are means and vertical bars show standard error (SE, $n=4)$. 
The effect of light treatments (P, PA and PAB) on the soluble SP concentration of sporophytes of $U$. pinnatifida after exposure and recovery is shown in Fig. 4.4. An interaction of light treatments and exposure time was detected for SP concentration (Table 4.2), where the SP of sporophytes exposed to light treatments varied among exposures. After the first exposure, an increase of SPs was observed at all light treatments (Fig. 4.4); while there was a decrease after the second exposure. SP remain low for the remainder of the experiment in sporophytes exposed to $\mathrm{P}$ and $\mathrm{PA}$ but decreased further in sporophytes exposed to $\mathrm{PAB}$ at the $48 \mathrm{~h}$ reading. No interactive effect of light treatments and recovery time was detected for SPs, but differences among light treatments and time were detected (Table 4.2). The SP concentration decrease after the first recovery in sporophytes exposed to $\mathrm{PAB}$, while increase in sporophytes exposed to P and PA (Fig. 4.4). After the second recovery, marginal changes in SPs were observed at all light treatments. SPs of sporophytes exposed to PAB differed from sporophytes exposed to $\mathrm{P}$ (Pair-wise, $\mathrm{t}=3.064, \mathrm{p}=0.004$ ) and PA (Pair-wise, $\mathrm{t}=2.16, \mathrm{p}=0.035$ ).

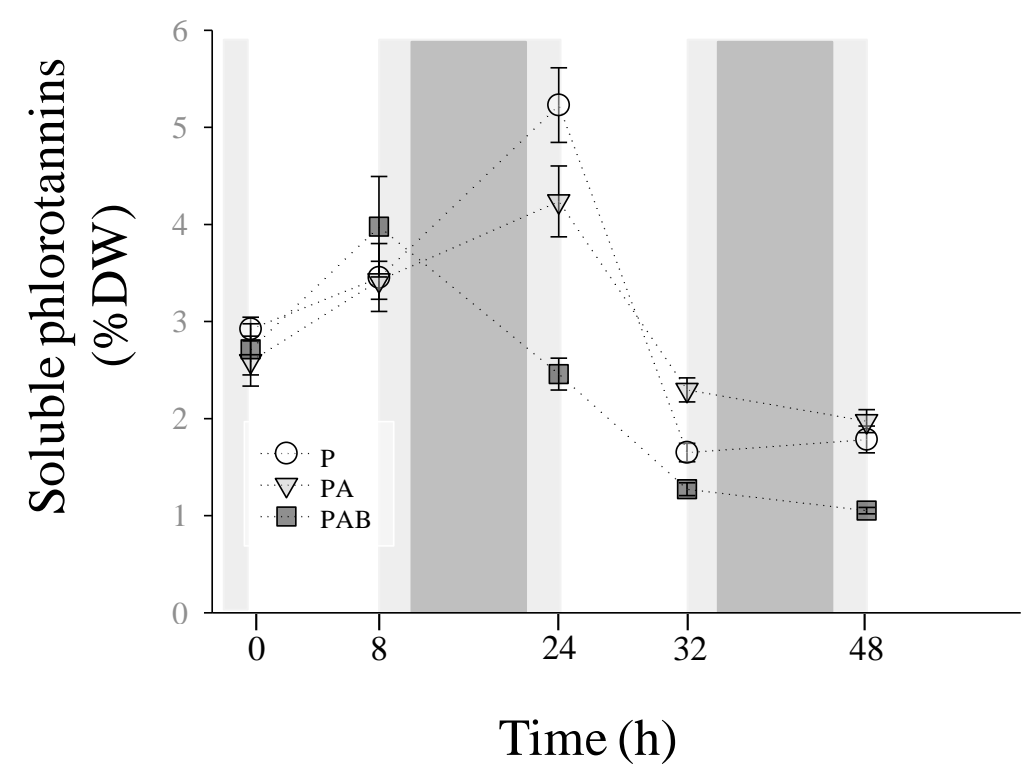

Fig. 4.4 Effect of light treatments (P, PA and PB) on the concentration of soluble SPs of sporophytes of $U$. pinnatifida. Discs were left for $2 \mathrm{~h}$ in low light and then exposed to light treatments for $8 \mathrm{~h}$ followed by $2 \mathrm{~h}$ of low light and $14 \mathrm{~h}$ in dark at $15^{\circ} \mathrm{C}$. Data are means and vertical bars show standard error (SE, $n=4)$. 
Table 4.2 Permutational multivariate analysis (PERMANOVA) for the photosynthetic variables and phlorotannins concentration comparing the effect of light treatments (three levels) and exposure/recovery (three levels) of sporophytes of $U$. pinnatifida. The analysis was based on similarity matrices calculated using Bray-Curtis coefficients. Bold letters shows significance. NP: Number of permutations.

\begin{tabular}{|c|c|c|c|c|c|c|}
\hline Variable & & $\begin{array}{l}\text { Source of } \\
\text { variation }\end{array}$ & $\mathrm{df}$ & Pseudo-F & $\mathrm{P}$ & $\mathrm{NP}$ \\
\hline \multirow{3}{*}{$\overline{F_{v} / F_{m}} \exp }$. & \multirow{3}{*}{ Exposure } & Time (A) & 3 & 3.593 & 0.0001 & 9917 \\
\hline & & Treatments (B) & 2 & 7.497 & 0.0001 & 9920 \\
\hline & & $\mathrm{A} * \mathrm{~B}$ & 6 & 2.965 & 0.0002 & 9887 \\
\hline \multirow[t]{3}{*}{$\mathrm{F}_{\mathrm{v}} / \mathrm{F}_{\mathrm{m}} \mathrm{rec}$} & \multirow[t]{3}{*}{ Recovery } & Time (A) & 3 & 5.978 & 0.0001 & 9950 \\
\hline & & Treatments (B) & 2 & 9.582 & 0.0001 & 9944 \\
\hline & & $\mathrm{A} * \mathrm{~B}$ & 6 & 5.140 & 0.0001 & 9921 \\
\hline \multirow[t]{3}{*}{$\mathrm{ETR}_{\max }$ exp. } & \multirow[t]{3}{*}{ Exposure } & Time (A) & 2 & 11.7 & 0.0002 & 9951 \\
\hline & & Treatments (B) & 2 & 7.082 & 0.001 & 9942 \\
\hline & & $\mathrm{A} * \mathrm{~B}$ & 4 & 4.608 & 0.002 & 9949 \\
\hline \multirow[t]{3}{*}{$\mathrm{ETR}_{\max }$ rec. } & \multirow[t]{3}{*}{ Recovery } & Time (A) & 2 & 19.588 & 0.0001 & 9940 \\
\hline & & Treatments (B) & 2 & 23.463 & 0.0001 & 9956 \\
\hline & & $\mathrm{A} * \mathrm{~B}$ & 4 & 7.601 & 0.0003 & 9948 \\
\hline \multirow[t]{3}{*}{ NPQ exp. } & \multirow[t]{3}{*}{ Exposure } & Time (A) & 2 & 1.298 & 0.273 & 9940 \\
\hline & & Treatments (B) & 2 & 4.355 & 0.008 & 9950 \\
\hline & & $\mathrm{A} * \mathrm{~B}$ & 4 & 1.162 & 0.321 & 9957 \\
\hline \multirow{3}{*}{ NPQ rec. } & \multirow{3}{*}{ Recovery } & Time (A) & 2 & 1.467 & 0.208 & 9937 \\
\hline & & Treatments (B) & 2 & 6.311 & 0.001 & 9941 \\
\hline & & $\mathrm{A} * \mathrm{~B}$ & 4 & 0.929 & 0.484 & 9943 \\
\hline \multirow[t]{3}{*}{ SPs exp. } & \multirow[t]{3}{*}{ Exposure } & Treatment (A) & 2 & 4.616 & 0.002 & 9927 \\
\hline & & Time (B) & 3 & 7.638 & 0.0001 & 9936 \\
\hline & & $\mathrm{A} * \mathrm{~B}$ & 6 & 2.036 & 0.032 & 9916 \\
\hline \multirow[t]{3}{*}{ SPs rec. } & \multirow[t]{3}{*}{ Recovery } & Treatment (A) & 2 & 4.588 & 0.013 & 9951 \\
\hline & & Time (B) & 3 & 17.225 & 0.0001 & 9942 \\
\hline & & $\mathrm{A} * \mathrm{~B}$ & 4 & 2.1412 & 0.076 & 9943 \\
\hline
\end{tabular}


The effect of light treatments (P, PA and PAB) at different temperatures $\left(18,20\right.$, and $\left.22{ }^{\circ} \mathrm{C}\right)$ on the maximum quantum yield $\left(\mathrm{F}_{\mathrm{v}} / \mathrm{F}_{\mathrm{m}}\right)$ of sporophytes of $U$. pinnatifida is shown in Fig. 4.5. Sporophytes had high $\mathrm{F}_{\mathrm{v}} / \mathrm{F}_{\mathrm{m}}$ values before and after temperature acclimation in low light (Fig $4.5,0-3 \mathrm{hrs})$. An interaction among exposure time, light treatments and temperature was detected in $F_{v} / F_{m}$ and an interaction of light treatments and recoveries (Table 4.3). The $F_{v} / F_{m}$ of sporophytes exposed to $\mathrm{P}$ and PA remain approximately stable throughout the experiment at all temperatures (Fig. 4.5). In contrast, $\mathrm{F}_{\mathrm{v}} / \mathrm{F}_{\mathrm{m}}$ of sporophytes exposed to PAB steadily declined throughout the experiment at all temperatures (Fig. 4.5). After the first exposure $F_{v} / F_{m}$ declined rapidly at the highest temperature; while a similar decline was also observed at the other temperatures but the decline was delayed until the dark period (Fig. 4.5). The largest decreases in $\mathrm{F}_{\mathrm{v}} / \mathrm{F}_{\mathrm{m}}$ of sporophytes exposed to $\mathrm{PAB}$ were at 18 and $22^{\circ} \mathrm{C}$.

The effect of light treatments (P, PA and PAB) on SP concentration in sporophytes of $U$. pinnatifida at different temperatures is shown in Fig. 4.6. There was interaction among light treatments, temperature and exposures in the concentration of SP (Table 4.3). Overall, the SPs of sporophytes steadily decreased throughout the experiment after exposure to all light treatments at all temperatures. Only sporophytes exposed to PA at $22^{\circ} \mathrm{C}$ had no change in SPs after the first exposure but declined rapidly after the second, while sporophytes exposed to $\mathrm{PAB}$ at $18^{\circ} \mathrm{C}$ had an increase in SPs after the second exposure (Fig. 4.6). SPs were higher at $22^{\circ} \mathrm{C}$ that the other temperatures after temperature acclimation and the first exposure to light treatments (Fig. 4.6). The initial SPs content in U. pinnatifida was higher in this experiment (3-4.5\%) than experiment 1 (3.0\%). 

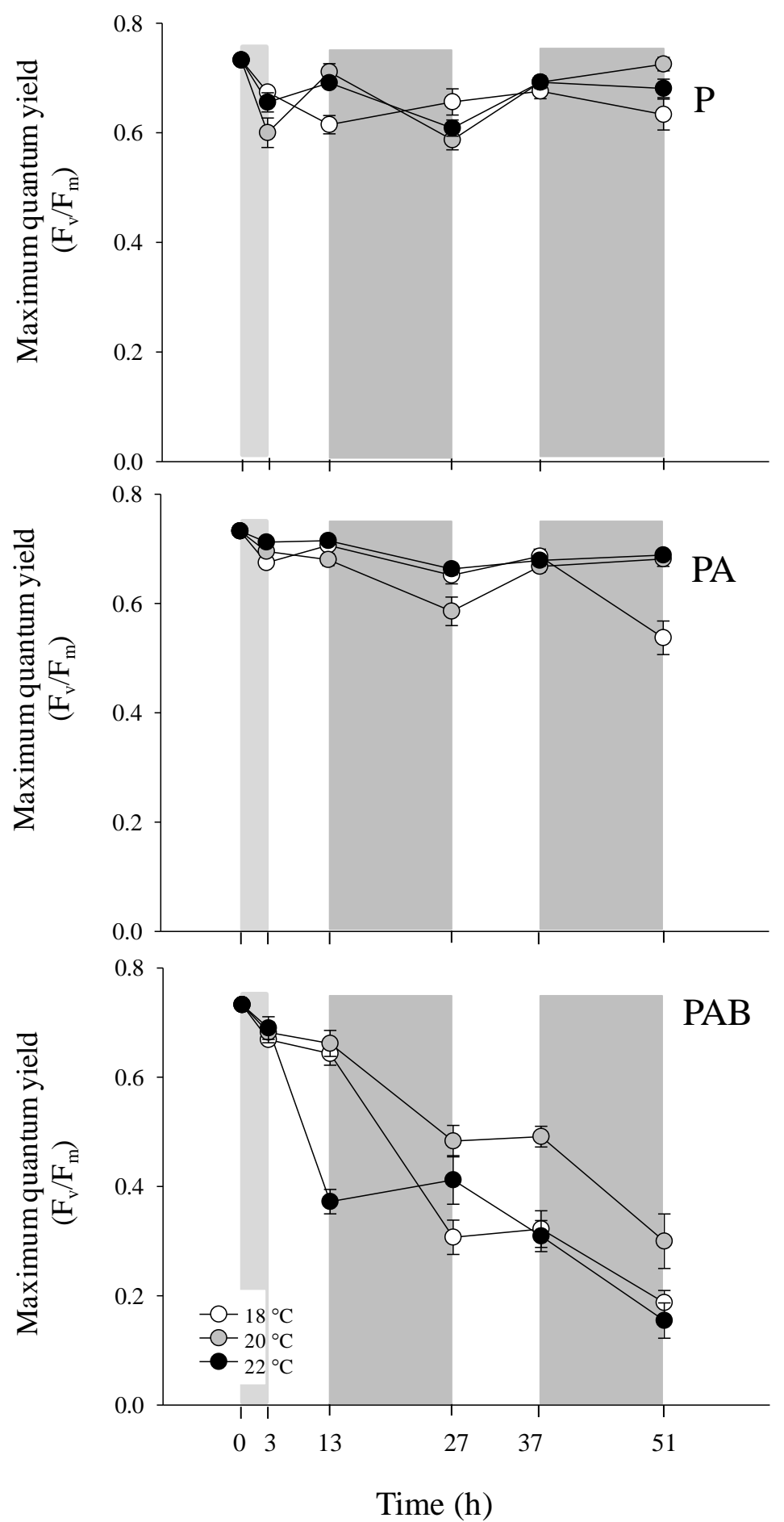

Fig. 4.5 Effect of light treatments (P, PA and PB) at different temperatures $\left(18,20\right.$ and $\left.22{ }^{\circ} \mathrm{C}\right)$ on the maximum quantum yield $\left(\mathrm{F}_{\mathrm{v}} / \mathrm{F}_{\mathrm{m}}\right)$ of sporophytes of $U$. pinnatifida. Discs were left for temperature acclimation for $3 \mathrm{~h}$ in low light (light grey background) and then exposed to light treatments for $10 \mathrm{~h}$ followed by $14 \mathrm{~h}$ in dark (dark grey background) at $15^{\circ} \mathrm{C}$. Data are means and vertical bars show standard error (SE, $n=4)$. 

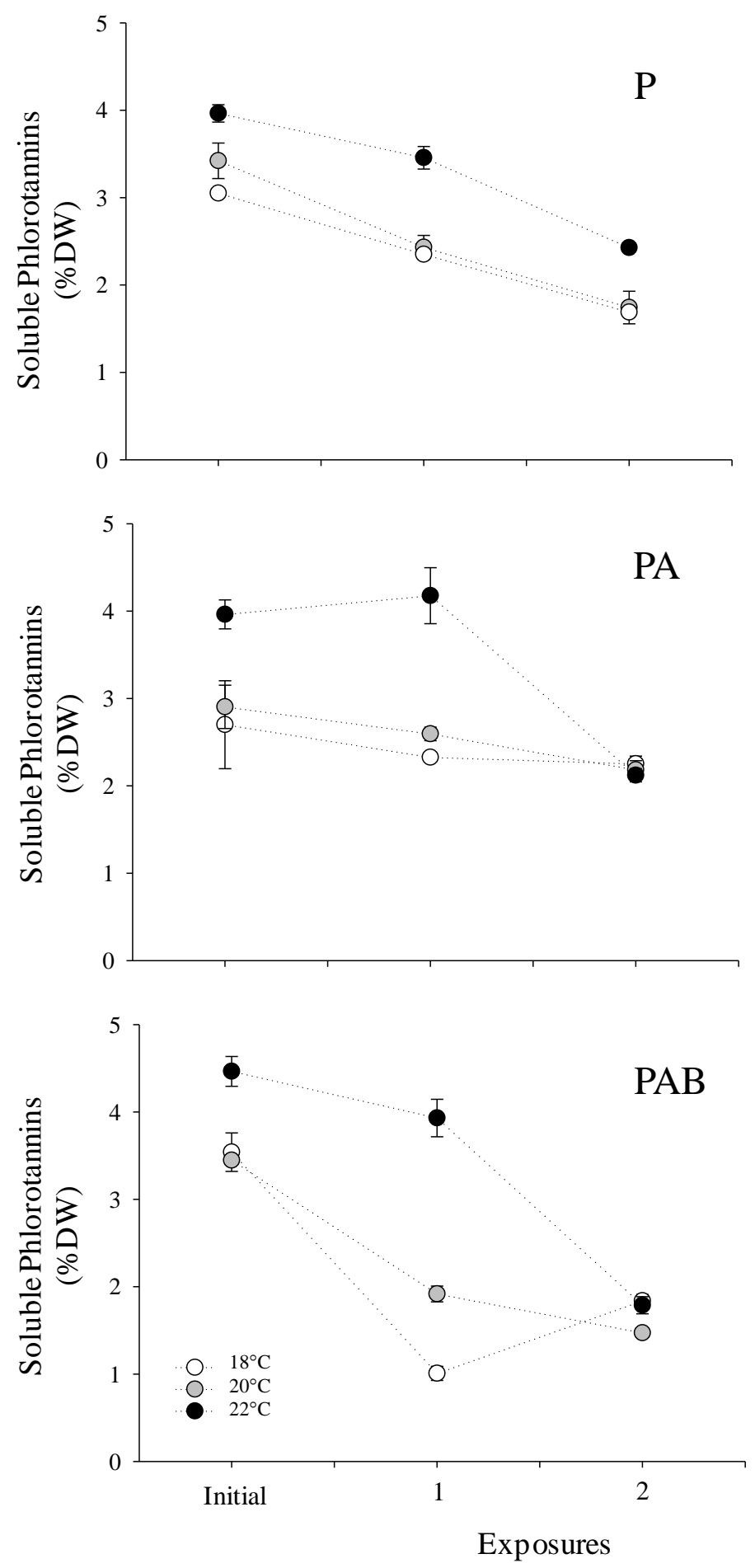

Fig. 4.6 SP concentration after exposure to light treatments (P, PA and PB) at different temperatures in sporophytes of $U$. pinnatifida. The initial reading corresponds to the SP concentration after temperature acclimation. Discs were then exposed to light treatments for $10 \mathrm{~h}$ followed by $14 \mathrm{~h}$ in dark, this procedure was repeated two times. Data are means and vertical bars show standard error (SE, $n=4)$. 
Table 4.3 Permutational multivariate analysis (PERMANOVA) for $F_{v} / F_{m}$ and soluble phlorotannins comparing the effect of light treatments (three levels), temperature (three levels) and exposure/recovery time (three levels each) of sporophytes of $U$. pinnatifida. The analysis was based on similarity matrices calculated using Bray-Curtis coefficients. Bold letters shows significance. NP: Number of permutations.

\begin{tabular}{|c|c|c|c|c|c|}
\hline & Factor & $\mathrm{df}$ & Pseudo-F & $\mathrm{P}($ perm $)$ & NP \\
\hline \multirow[t]{7}{*}{$\mathrm{F}_{\mathrm{v}} / \mathrm{F}_{\mathrm{m}} \exp$} & Light Treatment (A) & 2 & 29.399 & 0.0001 & 9948 \\
\hline & Temperature (B) & 2 & 3.758 & 0.009 & 9950 \\
\hline & Time $(\mathrm{C})$ & 2 & 10.708 & 0.0001 & 9943 \\
\hline & $\mathrm{A} * \mathrm{~B}$ & 4 & 3.5618 & 0.001 & 9938 \\
\hline & $\mathrm{A}^{*} \mathrm{C}$ & 4 & 11.698 & 0.0001 & 9935 \\
\hline & $B * C$ & 4 & 1.534 & 0.158 & 9953 \\
\hline & $A * B * C$ & 8 & 2.194 & 0.010 & 9927 \\
\hline \multirow[t]{7}{*}{$\mathrm{F}_{\mathrm{v}} / \mathrm{F}_{\mathrm{m}}$ rec. } & Light Treatment (A) & 2 & 18.609 & 0.0001 & 9945 \\
\hline & Temperature (B) & 2 & 1.4103 & 0.222 & 9956 \\
\hline & Time $(\mathrm{C})$ & 2 & 8.9518 & 0.0001 & 9946 \\
\hline & $\mathrm{A} * \mathrm{~B}$ & 4 & 1.173 & 0.3078 & 9931 \\
\hline & $\mathrm{A}^{*} \mathrm{C}$ & 4 & 7.426 & 0.0001 & 9928 \\
\hline & $\mathrm{B}^{*} \mathrm{C}$ & 4 & 0.843 & 0.588 & 9922 \\
\hline & $\mathrm{A} * \mathrm{~B} * \mathrm{C}$ & 8 & 0.475 & 0.980 & 9922 \\
\hline \multirow[t]{7}{*}{ SPs rec. } & Light Treatment (A) & 2 & 3.007 & 0.0216 & 9954 \\
\hline & Temperature (B) & 2 & 17.602 & 0.0001 & 9949 \\
\hline & Exposure (C) & 2 & 36.541 & 0.0001 & 9946 \\
\hline & $\mathrm{A} * \mathrm{~B}$ & 4 & 0.550 & 0.8241 & 9948 \\
\hline & $\mathrm{A}^{*} \mathrm{C}$ & 4 & 4.507 & 0.0003 & 9943 \\
\hline & $\mathrm{B}^{*} \mathrm{C}$ & 4 & 4.08 & 0.0003 & 9937 \\
\hline & $A * B * C$ & 8 & 2.548 & 0.0022 & 9933 \\
\hline
\end{tabular}

\subsection{Discussion}

This study is the first to address the effect of light and temperature on sporophytes of the invasive alga $U$. pinnatifida. These results suggest a complex interaction among factors, where time is particularly important. There was a minimal effect of P and PA on all chlorophyll fluorescence parameters of sporophytes in all experiments. These results suggest that sporophytes tolerate $\mathrm{P}$ and $\mathrm{PA}$ irradiances and that UVA radiation is not damaging to this species. U. pinnatifida may even tolerate higher P and PA irradiances that those used in these 
experiments, as some population of this species grows in the intertidal zone of Wellington coast (Schiel \& Thompson 2012) where there may be high irradiances especially during sunny days (data in Chapter 5). In contrast, the decrease in $F_{v} / F_{m}$ and $r E T R_{\max }$ in sporophytes exposed to PAB shows a negative impact. The effect of UVB on the photosynthetic efficiency of seaweeds has been studied previously (Roleda et al. 2004, Hanelt et al. 2009); however, this is the first time the impact of UVB on the invasive $U$. pinnatifida has been observed. The likely target of UVB damage in macroalgae is the D1 protein in the photosynthetic apparatus (Hanlet et al.1997, Bischof et al. 1998, Roleda et al. 2004, 2006). When the rate of degradation of D1 is faster than its biosynthesis and repair, damage occurs (Melis 1999, Kato \& Sakamoto 2009) and recovery of photosynthetic capacity may be delayed or may not occur. The lack of recovery in $\mathrm{F}_{\mathrm{v}} / \mathrm{F}_{\mathrm{m}}$ and $\mathrm{rETR}_{\max }$ of sporophytes after exposure to $\mathrm{UVB}$, in comparison to initial values, suggest UVB produced damage or chronic photoinhibition to the photosynthetic apparatus of sporophytes of $U$. pinnatifida. Values in NPQ for this species were in general high; high values in NPQ also have been observed on other species of brown seaweeds as Macrocystis pyrifera (Colombo-Patolla e al. 2006). Colombo-Pallotta et al. (2006) suggested that NPQ allows seaweeds to have a faster and higher recovery after light stress, as a strategy to reduce the photoinhibition and maintain higher photosynthetic rate. However, sporophytes of $U$. pinnatifida exposed to PAB did not show an efficient mechanism of dissipation of energy, and in fact, NPQ was lower compared to initial values during the experiment. The low capacity of energy dissipation by $U$. pinnatifida after exposure to UVB might be due to damage to the PsbS protein (Johnson et al. 2009). The PsbS protein senses the membrane proton gradient that triggers the $\mathrm{qE}$, damage in the protein would affect this gradient and therefore $\mathrm{qE}$ that is an important component for NQP (Johnson et al. 2009). Also UVB might affect enzymatic processes involved the xanthophylls cycle altering the capacity to convert violaxanthin to zeaxanthin and, thus inhibiting NPQ (Havaux et al. 2000).

An increase of temperature might compensate for the effect of UVB on the photosynthetic capacity of seaweeds because the turnover of the D1 protein, synthesis of pigments and other enzymatic reactions, are all stimulated by increasing temperatures in repair and photoprotective processes (Gómez et al. 2001, Cruces et al. 2012a). However, for sporophytes of $U$. pinnatifida exposed to $\mathrm{P}$ and $\mathrm{PA}$, temperature had no effect on the photosynthetic capacity, illustrating that at least without the stress of UVB radiation, $U$. pinnatifida sporophytes may tolerate temperatures as high as $22^{\circ} \mathrm{C}$. Temperate kelps are the least heat 
resistant among temperate seaweeds, normally with a maximum tolerance of $18^{\circ} \mathrm{C}$, in comparison to over $25^{\circ} \mathrm{C}$ in other algae (Lobban 1994). U. pinnatifida it is an exception among kelps with a broad temperature tolerance from $0-27^{\circ} \mathrm{C}$ in the field (Skriptsova et al. 2004). This characteristic permits $U$. pinnatifida to grow in a wide geographic and depth distribution (Henckel \& Hofmann 2008). The results of experiment 2 confirm the tolerance of $U$. pinnatifida to temperatures in the range $18-22^{\circ} \mathrm{C}$, which could lead this species to be successful under future global warming conditions, and this tolerance may allow it to spread to warmer areas.

Although the UVB irradiances used in these experiments are similar to those measured in Wellington coastal waters during late winter/early spring, 8 and $10 \mathrm{~h}$ of continuous exposure to this irradiance are unlikely in the field, because UVB irradiances vary with solar zenith angle, reaching a maximum irradiance around mid-day. Also, UVB is highly variable during this period of the year due to periods of cloudiness and to changes in water depth due to tidal action (CliFlo, NIWA). Surprisingly the results of this study suggest that sporophytes of $U$. pinnatifida are sensitive to UVB.

Pavia et al. (1997) suggested that the absorption spectra of phlorotannins can be in the range of UVB, since phlorotannins contribute to the reductions of intracellular exposures of UVB (280320) in the brown seaweed Ascophyllum nodosum. Later Swanson \& Druehl (2002) observed that phlorotannins absorbs also in the UVB range (280-320nm). In the last two decades, the photoprotective capacity of SPs against UVB has been documented for different species of brown seaweeds (Pavia et al. 1997, Halm et al. 2011, Henry \& Van Alstyne 2004, Swanson \& Druehl 2002, Halm et al. 2011,). The photoprotective role of phlorotannins in U. pinnatifida is uncertain since the overall trend was a decrease of the concentration throughout the experiments. SPs did increase after the first exposure in the first experiment, but this increase was similar among treatments. Fairhead et al. (2006) observed an increase of phlorotannins concentration after exposure to light treatments in two Antarctic species (Phaeophyceae), but found no differences among treatments, suggesting that PAR availability is the major driver of SP production. For $U$. pinnatifida, it is unlikely that PAR could be the driver for the phlorotannins production since the PAR irradiances of the experiments were much lower than those from the intertidal (see data in Chapter 5) and probably too low to produce stress in this species. Phlorotannins are secondary metabolites that respond to different environmental conditions such as salinity, herbivory intensity, nutrients, etc (Swanson \& Druehl 2002, 
Koivikko et al. 2005), and therefore changes in SPs in U. pinnatifida in these experiments might be a consequence of other factors rather exposure to UVB. It is also possible that resource availability might impact the production of secondary metabolites (Koivikko et al. 2005). Therefore, the decrease in SPs throughout both experiments might due to a limitation of nitrogen or carbon although in these experiments water was changed two times daily to avoid this possibility.

Initial SPs content was lower in experiment $1(2.8-3.0 \%)$ than in experiment $2(3-4.5 \%)$. This difference might be due to the different physiological state of sporophytes due to seasonality. Phlorotannins are higher when plant maturation occurs and growth stops (Pavia et al. 1999). Thus, the sporophytes of experiment 2 were collected in Summer when sporophytes were completely mature, while those from experiment 1 were collected in Winter when they were in an early growing stage. Sporophytes of $U$. pinnatifida incubated in higher water temperatures had higher concentration of SPs. This contrast with Cruces et al. (2012b) who found lower SP content at higher temperature conditions in Lessonia nigrescens and Durvillaea antarctica and suggested that elevated temperature might affect the Golgi-ER membrane complex, which is likely to be responsible for the biosynthesis of SPs (Cruces et al. 2012b). U. pinnatifida has a wider thermotolerance in comparison to other kelps. Therefore, in $U$. pinnatifida physiological processes and organelles might be less affected by an increase of temperature than other kelps.

U. pinnatifida is a very plastic species that tolerates different environmental conditions and can inhabit a wide range of environments. In this study, sporophytes of $U$. pinnatifida were negatively affected by UVB, and the role of phlorotannins could not be determined for this species. This suggests sporophytes of $U$. pinnatifida might have other strategies for success in the intertidal. For example, the maximum growth of this species occurs in late Winter and Spring when UVB irradiances are low, decreasing the possibility to be damaged. $U$. pinnatifida has a rapid growth rate and reaches maturity fast. The strategy of sporophytes might be to direct energy mainly to growth and reproduction rather than to photoprotection and repair. This species can tolerate a range of temperature conditions, and this was reflected in the minimal effect of increasing temperatures on photosynthetic capacity (Pavia et al. 1997, Henry \& Van Alstyne 2004, Halm et al. 2010). The capacity of this species to adapt its life history to the environmental conditions suggests $U$. pinnatifida might be little affected by changes such as increase of UVB and temperature. 


\subsection{References}

Altamirano, M., Flores-Moya, A. \& Figueroa, F. (2003) Effects of UV radiation and temperature on growth of germlings of three species of Fucus (Phaeophyceae). Aquatic Botany. 75(1):9-20.

Arnold, T. M. \& Targett, N. M. (1998). Quantifying in situ rates of phlorotannin synthesis and polymerization in marine brown algae. Journal of Chemical Ecology. 24(3): 577-595.

Arnold, T. M. \& Targett, N. M. (2002). Marine tannins: the importance of a mechanistic framework for predicting ecological roles. Journal of chemical ecology. 28(10): 1919-1934.

Baker, N. R. (2008). Chlorophyll fluorescence: a probe of photosynthesis in vivo. Annu. Rev. Plant Biol., 59, 89-113.

Bischof, K., Hanelt, D. \& Wiencke, C. (1998). UV-radiation can affect depth-zonation of Antarctic macroalgae. Marine Biology. 131(4): 597-605.

Bischof, K., Hanelt, D. \& Wiencke, C. (2000) Effects of ultraviolet radiation on photosynthesis and related enzyme reactions of marine macroalgae. Planta. 211:555-562.

Bischof, K., Gomez, I., Molis, M., Hanelt, D., Karsten, U., Lüder, U. et al. (2007). Ultraviolet radiation shapes seaweed communities. In Life in Extreme Environments (pp. 187-212). Springer Netherlands.

Buma, A. G., Boelen, P., \& Jeffrey, W. H. (2003). UVR-induced DNA damage in aquatic organisms. UV effects in aquatic organisms and ecosystems, 291-327.

CliFlo, National Institute of Water and Atmospheric Sciences (NIWA) National Climate Databasehttp:// cliflo.niwa.co.nz)

Coelho, H., Vieira, S. \& Serôdio, J. (2009). Effects of desiccation on the photosynthetic activity of intertidal microphytobenthos biofilms as studied by optical methods. Journal of Experimental Marine Biology and Ecology. 381(2): 98-104.

Coelho, S.M., Rijstenbil, J. W. \& Brown, M. T. (2000) Impacts of anthropogenic stresses on the early development stages of seaweeds. Journal of Aquatic Ecosystem Stress and Recovery. 7(4):317-333.

Collén, J., Guisle-Marsollier, I., Léger, J. J. \& Boyen, C. (2007). Response of the transcriptome of the intertidal red seaweed Chondrus crispus to controlled and natural stresses. New Phytologist. 176(1): 45-55.

Collén, J. \& Davison, I. R. (1999). Stress tolerance and reactive oxygen metabolism in the intertidal red seaweeds Mastocarpus stellatus and Chondrus crispus. Plant, Cell \& Environment. 22(9): 1143-1151. 
Colombo-Pallotta, M. F., García-Mendoza, E. \& Ladah, L. B. (2006). Photosynthetic performance, light absorption, and pigments composition of Macrocystis pyrifera (Laminariales, Phaeophyceae) blades from different depths. Journal of Phycology. 42(6): 1225-1234.

Colombo-Pallotta, M. F., García-Mendoza, E. \& Ladah, L. B. (2006a). Photosynthetic performance, light absorption, and pigments composition of Macrocystis pyrifera (Laminariales, Phaeophyceae) blades from different depths. Journal of Phycology. 42(6): 1225-1234.

Cruces, E., Huovinen, P. \& Gomez, I. (2012b) Interactive effects of UV radiation and enhanced temperature on photosynthesis, phlorotannin induction and antioxidant activities of two subAntarctic brown algae. Marine Biology. 160(1): 1-13.

Davison, I. R. (1991). Environmental effects on algal photosynthesis: temperature. Journal of Phycology. 27(1): 2-8.

Davison, I., Johnson, L. \& Brawley, S. (1993). Sublethal stress in the intertidal zone: tidal emersion inhibits photosynthesis and retards development in embryos of the brown alga Pelvetia fastigiata. Oecologia. 96(4): 483-492.

Davison, I. R. \& Pearson, G. A. (1996). Stress tolerance in intertidal seaweeds. Journal of Phycology. 32(2): 197-211.

Dean, P. R. \& Hurd, C. L. (2007). Seasonal growth, erosion rates, and nitrogen and photosynthetic ecophysiology of Undaria pinnatifida (Heterokontophyta) in southern New Zealand1. Journal of Phycology. 43(6):1138-1148.

Dukes, J. S. \& Mooney, H. A. (1999). Does global change increase the success of biological invaders?. Trends in Ecology \& Evolution. 14(4): 135-139.

Dukes, J. S., Pontius, J., Orwig, D., Garnas, J. R., Rodgers, V. L., Brazee, Net al. (2009). Responses of insect pests, pathogens, and invasive plant species to climate change in the forests of northeastern North America: What can we predict? This article is one of a selection of papers from NE Forests 2100: A Synthesis of Climate Change Impacts on Forests of the Northeastern US and Eastern Canada. Canadian Journal of Forest Research. 39(2): 231-248.

Fairhead, V. A., Amsler, C. D., McClintock, J. B. \& Baker, B. J. (2006). Lack of defence or phlorotannins induction by UV radiation or mesograzers in Demarestia anceps and D. meziesii (Phaeophyceae) 1. Journal of Phycology. 42(6): 1174-1183.

Fredersdorf, J., Müller, R., Becker, S., Wiencke, C. \& Bischof, K. (2009). Interactive effects of radiation, temperature and salinity on different life history stages of the Arctic kelp Alaria esculenta (Phaeophyceae). Oecologia. 160(3):483-492. 
Gómez, I., Figueroa, F. L., Sousa-Pinto, I., Viñegla, B., Pérez-Rodríguez, E., Maestre, C., et al. (2001). Effects of UV radiation and temperature on photosynthesis as measured by PAM fluorescence in the red alga Gelidium pulchellum (Turner) Kützing. Botanica Marina. 44(1): $9-16$.

Halm, H., Lüder, U. H. \& Wiencke, C. (2011). Induction of phlorotannins through mechanical wounding and radiation conditions in the brown macroalga Laminaria hyperborea. European Journal of Phycology. 46(1):16-26.

Hanlet, D., Wiencke, C. \& Nultsch, W. (1997) Influence of UV radiation on the photosynthesis of arctic macroalgae in the field. Journal of Photochemistry and Photobiology. 38:40-47.

Hanelt, D. \& Roleda, M. Y. (2009). UVB radiation may ameliorate photoinhibition in specific shallowwater tropical marine macrophytes. Aquatic Botany. 91(1): 6-12.

Havaux, M., Bonfils, J. P., Lütz, C. \& Niyogi, K. K. (2000). Photodamage of the photosynthetic apparatus and its dependence on the leaf developmental stage in the npq1 Arabidopsis mutant deficient in the xanthophyll cycle enzyme violaxanthin de-epoxidase. Plant Physiology. 124(1): 273-284.

Hay, C. H. \& Villouta, E. (1993). Seasonality of the adventive Asian kelp Undaria pinnatifida in New Zealand.. Botanica marina. 36(5): 461-476.

Helmuth, B., Broitman, B. R., Blanchette, C. A., Gilman, S., Halpin, P., Harley, C. D. et al. (2006). Mosaic patterns of thermal stress in the rocky intertidal zone: implications for climate change. Ecological Monographs. 76(4): 461-479.

Henkel, S. K. \& Hofmann, G. E. (2008). Thermal ecophysiology of gametophytes cultured from invasive Undaria pinnatifida (Harvey) Suringar in coastal California harbors. Journal of Experimental Marine Biology and Ecology. 367(2): 164-173.

Henry, B. E. \& Van Alstyne, K. L. (2004). Effects of UV radiation on growth and phlorotannins in Fucus gardneri (Phaeophyceae) juveniles and embryos 1. Journal of Phycology. 40(3):527533.

Huovinen, P., \& Gómez, I. (2013). Photosynthetic characteristics and UV stress tolerance of Antarctic seaweeds along the depth gradient. Polar biology, 36(9), 1319-1332.

IPCC 2013 IPCC, 2013: Climate Change 2013: The Physical Science Basis. Contribution of Working Group I to the Fifth Assessment Report of the Intergovernmental Panel on Climate Change [Stocker, T. F., D. Qin, G.-K. Plattner, M. Tignor, S. K. Allen, J. Boschung, A. Nauels, Y. Xia, V. Bex and P. M. Midgley (eds.)]. Cambridge University Press, Cambridge, United 
$\begin{array}{lllll}\text { Kingdom } & \text { and } & \text { New } & \text { York, }\end{array}$ http://www.climatechange2013.org/images/report/WG1AR5_TS_FINAL.pdf

Jennings, J. G. \& Steinberg, P. D. (1994). In situ exudation of phlorotannins by the sublittoral kelp Ecklonia radiata. Marine Biology. 121(2): 349-354.

Johnson, M. P., Pérez-Bueno, M. L., Zia, A., Horton, P. \& Ruban, A. V. (2009). The zeaxanthinindependent and zeaxanthin-dependent $\mathrm{qE}$ components of nonphotochemical quenching involve common conformational changes within the photosystem II antenna in Arabidopsis. Plant Physiology. 149(2): 1061-1075.

Karsten, U., Dummermuth, A., Hoyer, K. \& Wiencke, C. (2003). Interactive effects of ultraviolet radiation and salinity on the ecophysiology of two Arctic red algae from shallow waters. Polar Biology. 26(4): 249-258.

Kato, Y. \& Sakamoto, W. (2009). Protein quality control in chloroplasts: a current model of D1 protein degradation in the photosystem II repair cycle. Journal of biochemistry. 146(4): 463-469.

Koivikko, R., Loponen, J., Honkanen, T. \& Jormalainen, V. (2005). Contents of soluble, cell-wallbound and exuded phlorotannins in the brown alga Fucus vesiculosus, with implications on their ecological functions. Journal of chemical ecology. 31(1):195-212.

Krause, G. H. \& Jahns, P. (2004). Non-photochemical energy dissipation determined by chlorophyll fluorescence quenching: characterization and function. In Chlorophyll a Fluorescence (pp. 463-495). Springer Netherlands.

Kumar, M., Kumari, P., Reddy, C. R. K. \& Jha, B. (2014). Salinity and Desiccation Induced Oxidative Stress Acclimation in Seaweeds. Sea plants, 91.

Lobban, C. (1994). Seaweed ecology and physiology. Cambridge University Press.

Lüder, U. H. \& Clayton, M. N. (2004). Induction of phlorotannins in the brown macroalga Ecklonia radiata (Laminariales, Phaeophyta) in response to simulated herbivory - the first microscopic study. Planta. 218(6): 928-937.

Melis A (1999). Photosystem-II damage and repair cycle in chloroplasts : what modulates the rate of photodamage in vivo? Trend in plant sciences reviews. 1360-1385.

Morelissen, B. (2012). Ecological effects of Undaria pinnatifida (Harvey) Suringar and nutrientenrichment on intertidal assemblages in the Wellington region of New Zealand. Victoria University of Wellington.

Müller, R., Laepple, T., Bartsch, I. \& Wiencke, C. (2009). Impact of oceanic warming on the distribution of seaweeds in polar and cold-temperate waters. Botanica Marina 52(6): 617-638. 
Murchie, E. H., \& Lawson, T. (2013). Chlorophyll fluorescence analysis: a guide to good practice and understanding some new applications. Journal of experimental botany, ert208.

Pakker, H., Beekman, C. \& Breeman, A. (2000). Efficient photoreactivation of UVBR-induced DNA damage in the sublittoral macroalga Rhodymenia pseudopalmata (Rhodophyta). European Journal of Phycology. 35(2):109-114.

Pavia, H., Cervin, G., Lindgren, A. \& Åberg, P. (1997). Effects of UV-B radiation and simulated herbivory on phlorotannins in the brown alga Ascophyllum nodosum. Marine Ecology Progress Series. 157:139-146.

Pavia, H., Toth, G. \& Åberg, P. (1999). Trade-offs between phlorotannin production and annual growth in natural populations of the brown seaweed Ascophyllum nodosum. Journal of Ecology. 87(5): 761-771.

Roleda, M. Y., Hanelt, D., Kräbs, G. \& Wiencke, C. (2004). Morphology, growth, photosynthesis and pigments in Laminaria ochroleuca (Laminariales, Phaeophyta) under ultraviolet radiation. Phycologia. 43(5): 603-613.

Roleda, M. Y., Wiencke, C., Hanelt, D., van de Poll, W. H. \& Gruber, A. (2005). Sensitivity of Laminariales zoospores from Helgoland (North Sea) to ultraviolet and photosynthetically active radiation: implications for depth distribution and seasonal reproduction. Plant, Cell \& Environment. 28(4): 466-479.

Roleda, M. Y., Hanelt, D. \& Wiencke, C. (2006a). Growth and DNA damage in young Laminaria sporophytes exposed to ultraviolet radiation: implication for depth zonation of kelps on Helgoland (North Sea). Marine Biology. 148(6): 1201-1211.

Roleda, M. Y., Wiencke, C. \& Hanelt, D. (2006b). Thallus morphology and optical characteristics affect growth and DNA damage by UV radiation in juvenile Arctic Laminaria sporophytes. Planta. 223(3): 407-417.

Roleda, M. Y., Lüder, U. H., \& Wiencke, C. (2010). UV-susceptibility of zoospores of the brown macroalga Laminaria digitata from Spitsbergen. Polar biology, 33(5), 577-588.

Ruban, A. V., Berera, R., Ilioaia, C., Van Stokkum, I. H., Kennis, J. T., Pascal, A. A., et al. (2007). Identification of a mechanism of photoprotective energy dissipation in higher plants. Nature. 450(7169): 575-578.

Ryan, K. G., McMinn, A., Mitchell, K. A. \& Trenerry, L. (2002). Mycosporine-like amino acids in Antarctic sea ice algae, and their response to UVB radiation. Zeitschrift fur Naturforschung C, 57(5/6), 471-477. 
Schneider, K. R. (2008). Heat stress in the intertidal: comparing survival and growth of an invasive and native mussel under a variety of thermal conditions. The Biological Bulletin, 215(3), 253-264.

Schiel, D. R., \& Thompson, G. A. (2012). Demography and population biology of the invasive kelp Undaria pinnatifida on shallow reefs in southern New Zealand. Journal of Experimental Marine Biology and Ecology, 434, 25-33.

Sieburth, J. M. (1969). Studies on algal substances in the sea. III. The production of extracellular organic matter by littoral marine algae. Journal of Experimental Marine Biology and Ecology. 3(3):290-309.

Sinha, R. P., Singh, S. P. \& Häder, D. P. (2007). Database on mycosporines and mycosporine-like amino acids (MAAs) in fungi, cyanobacteria, macroalgae, phytoplankton and animals. Journal of Photochemistry and Photobiology B: Biology. 89(1): 29-35.

Skriptsova, A., Khomenko, V. \& Isakov, V. (2004). Seasonal changes in growth rate, morphology and alginate content in Undaria pinnatifida at the northern limit in the Sea of Japan (Russia). Journal of applied phycology. 16(1): 17-21.

Somero, G. N. (2002). Thermal physiology and vertical zonation of intertidal animals: optima, limits, and costs of living. Integrative and Comparative Biology. 42(4): 780-789.

Sorte, C. J., Williams, S. L. \& Zerebecki, R. A. (2010). Ocean warming increases threat of invasive species in a marine fouling community. Ecology. 91(8): 2198-2204.

Steinhoff, F. S., Wiencke, C., Wuttke, S. \& Bischof, K. (2011). Effects of water temperatures, UV radiation and low vs high PAR on phlorotannin content and germination in zoospores of Saccorhiza dermatodea (Tilopteridales, Phaeophyceae). Phycologia. 50(3): 256-263.

Swanson, A. \& Druehl, L. (2002) Induction, exudation and the UV protective role of kelp phlorotannins. Aquatic Botany. 73(3):241-253.

Verney, R., Brun-Cottan, J. C., Lafite, R., Deloffre, J. \& Taylor, J. A. (2006). Tidally-induced shear stress variability above intertidal mudflats in the macrotidal Seine estuary. Estuaries and coasts. 29(4): 653-664.

Verney, R., Deloffre, J., Brun-Cottan, J. C. \& Lafite, R. (2007). The effect of wave-induced turbulence on intertidal mudflats: impact of boat traffic and wind. Continental Shelf Research. 27(5): 594-612.

Vilà, M., Corbin, J. D., Dukes, J. S., Pino, J. \& Smith, S. D. (2007). Linking plant invasions to global environmental change. In Terrestrial ecosystems in a changing world (pp. 93-102). Springer Berlin Heidelberg. Wiencke et al. 2000, 2007, 
Wiencke, C., Gómez, I., Pakker, H., Flores-Moya, A., Altamirano, M., Hanelt, D., et al. (2000). Impact of UV-radiation on viability, photosynthetic characteristics and DNA of brown algal zoospores: implications for depth zonation. Marine ecology. Progress series. 197:217-229.

Wiencke, C., Clayton, M. \& Schoenwaelder, M. (2004) Sensitivity and acclimation to UV radiation of zoospores from five species of Laminariales from the Arctic. Marine Biology. 145(1): 31-39.

Wiencke, C., Clayton, M. N., Gómez, I., Iken, K., Lüder, U. H., Amsler, C. D., et al. (2007). Life strategy, ecophysiology and ecology of seaweeds in polar waters. In Life in Extreme Environments (pp. 213-244). Springer Netherlands.

Yoshikawa, T., Takeuchi, I. \& Furuya, K. (2001). Active erosion of Undaria pinnatifida. Suringar (Laminariales, Phaeophyceae) mass-cultured in Otsuchi Bay in northeastern Japan. Journal of experimental marine biology and ecology. 266(1): 51-65.

Zheng, Y., \& Gao, K. (2009). Impacts of solar UV radiation on the photosynthesis, growth, and UVabsorbing compounds in Gracillaria Lemaneiformis (Rhodophyta) grown at different nitrate concentrations. Journal of Phycology. 45(2): 314-323. 


\section{Chapter 5}

\section{Seasonal ecophysiology of $U$. pinnatifida}

\subsection{Abstract}

The aim of this study was to evaluate the response of the effective quantum yield and phlorotannins content of mature sporophytes of $U$. pinnatifida to seasonal variation of light conditions in the field. The effective quantum yield ( $\left.\phi_{\text {PSII }}\right)$ and phlorotannins content measured as soluble phlorotannins (SPs) and cell-wall phlorotannins (CWPs) were investigated over a period of 19 months and correlated to PAR and UVB irradiances measured during the sampling days. A clear seasonal trend in $\phi_{\text {PSII }}$ was observed with higher $\phi_{\text {PSII }}$ values during Winter months and that decreased as light conditions increased (Spring and Summer). Moreover, $\phi_{\text {PSII }}$ was negatively correlated to PAR and UVB irradiances measured in the field. The seasonal trend and negative correlation of $\phi_{\mathrm{PII}}$ of sporophytes and PAR/UVB irradiances suggested a response of the photosynthetic apparatus to variations of light and shows the capacity of this species to acclimate to the light conditions. Seasonal variation of SPs was observed but not in CWPs during the sampling period. SPs had a low negative correlation with PAR but not with UVB. No correlation between CWPs and PAR/UVB was detected, and therefore a photoprotective role of phlorotannins could not demonstrated. The variation of SPs and CWPs in $U$. pinnatifida are likely to be due to a combination of factors more than only the light conditions of the field. 


\subsection{Introduction}

Seasonal variation in the physiological performance of seaweeds is linked to variation of environmental conditions (Lüning 1989, Gévaert et al. 2002, Huovinen et al. 2006). Factors such as light intensity, nutrients availability and temperature control the physiology, reproduction, growth and life history of seaweeds (Lüning. 1989, 1993, Altamirano et al. 2000, Kim et al. 2007). For example the photosynthetic rate of seaweeds increases when light levels are lower and decreases as light increases (Huovinen et al. 2006, Dean \& Hurd 2007), pigment concentration is higher when light intensities are lower (Campbell et a.1999, Gevaert et al. 2002) and screening substances also tend to increase as light intensities increases (Connan et al.2004, 2007). Growth rates in members of the order Laminariales are usually higher during Spring or early Summer (Tala \& Edding 2005, Dean \& Hurd 2007) followed by a rapid decline during summer (Conolly \& Drew 1985, Miller et al.2011). Compared to subtidal species, intertidal seaweeds are more exposed to fluctuations of environmental conditions that are potentially stressful (Davison \& Pearson 1996), including both diurnal variability in temperature, light and desiccation, and also seasonal variation in nutrients and light. Environmental conditions can induce physiological stress in these organisms (Kain 1989, Davison \& Pearson 1996). Generally, seaweeds inhabiting the high tide zone are more tolerant to environmental fluctuations than those inhabiting lower areas (Sampath-Wiley et al 2008) due to morphological (Johnson \& Koehl 1994, Fog 2001, Batala et al. 2011), physiological and/or biochemical differences (Lüning 1993, Gómez et al. 2004), which result in different mechanisms to cope with the extreme conditions (Sampath-Wiley et al. 2008). For example, those exposed to daily desiccation can equilibrate their water potential with the environment (Alpert, 2000). Seaweeds exposed directly to high solar irradiances and UV radiation produce screening substances that also act as antioxidants (Cockell \& Knowland 1999, Huovinen et al. 2004) and they may reduce or inhibit photosynthesis as a mechanism of photoprotection (van de Poll et all 2002, Pakker et al 2000, Roleda eta 2006).

Brown seaweeds produce phenolic compounds called phlorotannins. These secondary metabolites play multiple ecological roles such as chemical defence against herbivores, protection against pathogens and also inhibit the development of epiphytes (Arnold \& Targett 1998, Koivikko et al.2005, Connan et al. 2004, Halm et al. 2011). A photoprotective role of phlorotannins against UVB in brown seaweeds also has been observed (Pavia et al. 1997, 
Henry \& Van Alstyne 2004, Halm et al. 2011). Both soluble (SPs) and cell-wall phlorotannins (CWP) are observed in brown seaweeds (Koivikko et al. 2005). SPs are stored in physodes in the cytoplasm and a portion of these phlorotannins are transformed to cell-wall phlorotannins when they fuse in the cell wall of brown seaweeds (Arnold \& Targett 2003, Koivikko et al. 2005). SPs can provide extracellular protection against UVB as exudates or during tissue erosion (Jennings \& Steinberg 1994, Swanson et al.2002) creating a layer of "gelbstoff" (CDOM) that absorbs UVB (Sieburth \& Jensen 1969). CWPs on the other hand are structural components of brown algae cell walls (Shoenwaelder \& Clayton 1998) and their function is unknown although they might bound the cell wall during sporophyte maturation (Koivikko et al. 2005). The phlorotannins content depends on life stage, age and reproductive status (Connan et al. 2004) and present diurnal and seasonal variations (Connan et al. 2004, AbdalaDiaz et al.2006). The most common method to quantify phenolic compounds in brown seaweeds is the colorimetric method Folin-Ciocalteu. This method is useful and reliable to obtain the total quantification of phlorotannins (Koivikko 2005). Phloroglucinol is used as standard since they contain only phlorotannins (Stern et al. 1996, Koivikko 2005). This method is more sensitive to reduction by phenolic compounds and less prone to precipitate and to interference by non-phenolic compounds (Koivikko 2005).

The brown seaweed $U$. pinnatifida is one of the most invasive seaweeds in the world due its high dispersal potential and its capacity to establish in a wide range of environments (Nyberg \& Wallentinus 2005; Dean \& Hurd 2007). This species is endemic to Asia (Korea, China and Japan) but has spread to several areas worldwide (Floc'h et al 1991, Hay \& Luckens 1987, Campbell \& Burridge 1998, Cecere et al. 2000, Silva et al. 2002) included New Zealand (Hay \& Luckens 1987). This Asian kelp is the only annual species of the order Laminariales, and its maximal growth occurs in Winter and early Spring when light conditions are low (Dean \& Hurd 2007). It has haploid microscopic gametophytes that are produced in Autumn and diploid macroscopic sporophytes appear in Winter-Spring and normally die off in late Summer (Yoshikawa et al. 2001). In New Zealand this species produces sporophytes year round (Hay 1990); however, its maximum abundance occurs in late winter and spring (Christian 2003).

Seasonal acclimation is an important characteristic of seaweeds that allows them to tolerate environmental changes (Raniello et al. 2006, Cebrian \& Ballesteros 2009). In temperate areas, light intensity is one environmental factor that has seasonal variability and intertidal seaweeds 
are more exposed to this variation. Populations of $U$. pinnatifida around the Wellington coast are common on artificial structures inside the harbour but are also well established along the rocky shore of the south coast where they principally inhabit the low intertidal zone. The ecophysiological characteristics of $U$. pinnatifida have not been studied in Wellington even though they may play an important role in its invasive success (Dean \& Hurd 2007). The capacity of this species to acclimate to variation in light intensities and the possible photoprotective capacity of phlorotannins might explain its success in the intertidal zone. Thus, I hypothesized that phlorotannins of sporophytes of this species will change seasonally as a mechanism to protect from seasonal changes in UVB doses. Because $U$. pinnatifida is an annual species I also hypothesised that this species will acclimate rapidly to variations of light. The aim of this study was: (1) to examine the photosynthetic performance of mature sporophytes of $U$. pinnatifida throughout a year, (2) to determine changes in the phlorotannins concentration throughout the year, (3) correlate both the photosynthetic performance and phlorotannins concentration with PAR and UVB irradiances measurements. Populations of $U$. pinnatifida were monitored for 21 months in the intertidal zone of the South Wellington coast.

\subsection{Materials and methods}

\section{Algal material}

Mature sporophytes of $U$. pinnatifida were collected by hand in the intertidal zone of Breaker

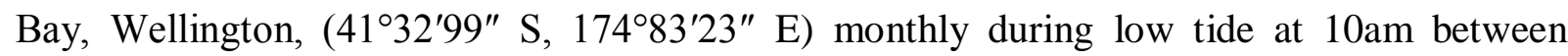
August 2011 to February 2013 for phlorotannins analysis. Healthy sporophytes were selected to eliminate the effect of abiotic factors such as grazing and epiphyte cover that could cause variability in the phlorotannins content. UVB and PAR irradiances were measured after sampling at $11 \mathrm{am}$ with a SpectroSense2+ radiometer (Skye Instrument Ltd. United Kingdom); for PAR measurements a 4-Chanel Sensor SK 1850/SS2 was used, and for UVB a UVB sensor SKU 430/SS2. Irradiances from January 2012 and March 2012 were particularly low due to cloudy conditions during the sampling day. 


\section{Chlorophyll fluorometry}

Photosynthetic efficiency was measured in situ to mature sporophytes as the variable fluorescence of PII using a Pulse Amplitude Modulation fluorometer (Diving-PAM, Walz etc) and quantified as the effective quantum yield $\left(\phi_{\text {PSII }}\right)$. Nine mature sporophytes were sampled per month, with 10 measurements taken from each individual from different healthy areas of the blade (central are close to the midrib). The effective quantum yield is defined according to the expression $\left(\mathrm{F}_{\mathrm{m}^{\prime}}-\mathrm{F}\right) / \mathrm{F}_{\mathrm{m}}=\Delta \mathrm{F} / \mathrm{F}_{\mathrm{m}^{\prime}}$, where $\mathrm{F}_{\mathrm{m}^{\prime}}$ is the maximum fluorescence of a light adapted algae and $F_{t}$ is the basal fluorescence before a saturating pulse (Genty et al. 1989). June and July of 2012 were characterized by a low abundance of mature sporophytes; therefore the $\phi_{\text {PSII }}$ was measured in 2 and 7 individuals, respectively.

\section{Soluble and cell-wall bound phlorotannins content}

Healthy sporophytes $(n=5)$ were chosen that had no evidence of grazing activity and epiphyte cover. For phlorotannins analysis, 4 discs from each sporophyte were taken each sampling day and then frozen at $-20^{\circ} \mathrm{C}$. Phenolic content was determined by the colorimetric FolinCiocalteu method modified by Koivikko et al (2005). Samples of seaweed were dried in a freeze drier and $\sim 0.02 \mathrm{~g}$ of the dried samples were used for the determination of soluble phlorotannins (SPs). Dried algal powder was left in $10 \mathrm{ml}$ of $70 \%$ acetone overnight at $4{ }^{\circ} \mathrm{C}$, this procedure was done twice to obtain $>90 \%$ of phlorotannins (Koivikko et al. 2005). The algal solution was centrifuged for $10 \mathrm{~min}$ at $2200 \mathrm{~g}$; $500 \mu \mathrm{l}$ of supernatant was mixed with 2.5 distilled water and $1 \mathrm{ml}$ Floin-Ciocalteu reagent and left to stand for $3 \mathrm{~min}$ before adding $2 \mathrm{ml}$ of $20 \% \mathrm{NaCO}_{3}$. Samples were incubated in the dark at room temperature for $45 \mathrm{~min}$ and then centrifuged for $2200 \mathrm{~g}$ for $5 \mathrm{~min}$. The absorbance of the supernatants was measure with a spectrophotometer at $730 \mathrm{~nm}$.

Cell-wall phlorotannins (CWP) were determined from residues left in the extraction of soluble phlorotannins using a modified alkaline method (Strack et al. 1989; Koivikko et al. 2005). The algal material was washed using a sequence of solvents for 5 min.: methanol (95\%), water, methanol (98\%), acetone (95\%) and finally diethylether (95\%). Residues were oven dried for $1 \mathrm{~h}$ at $60^{\circ} \mathrm{C}$ and the insoluble residues were first suspended in $8 \mathrm{ml}$ of $1 \mathrm{M}$ sodium hydroxide $(\mathrm{NaOH})$ solution and left for $2.5 \mathrm{~h}$ at room temperature. Then the samples were centrifuged for $5 \mathrm{~min}$. at $2200 \mathrm{~g}$ and a $1 \mathrm{ml}$ aliquot was neutralized with $100 \mu \mathrm{l}$ of phosphoric acid $\left(\mathrm{H}_{3} \mathrm{PO}_{4}\right)$. The 
aliquot was treated with the same methodology as for soluble phlorotannins. Due to the low abundance of sporophytes in June, phlorotannins content was measured only in two specimens. The total phlorotannins $\left(\mathrm{P}_{\mathrm{t}}\right)$ is the sum of SPs and CWPs.

Data analysis

A cluster analysis was performed in PRIMER-E v6 (Plymouth Routines in Multivariate Ecological Research) with effective quantum yield ( $\left.\phi_{\text {PSII }}\right)$, SP and CWP as variables. A Student's t-test was performed to determine differences between groups of the cluster at $95 \%$ confidence intervals for the $\phi_{\text {PSII }}$. Data were normally distributed (qqnorm) with equal variance. A Pearson correlation was used to examine the relationship between the photosynthetic performance of the seaweeds and the PAR and UVB irradiance of the field data assuming normality. For CWP and $\mathrm{P}_{\mathrm{t}}$ a logarithmic transformation was used to obtain a normal distribution of the data; while PSs were normally distributed. A one-way ANOVA was performed to determine differences between groups of the cluster at $95 \%$ confidence intervals for the SPs and CWPs. A Pearson correlation was used to determine the relationship between phlorotannins concentration of sporophytes and the PAR and UVB irradiance in the field.

\subsection{Results}

The UVB and PAR irradiances measured between August 2011 to February 2013 in Breaker Bay, Wellington followed a seasonal trend (Fig. 5.1). Maximal PAR and UVB irradiances occurred during Spring and Summer (more than $1200 \mu \mathrm{mol}$ photon $\mathrm{m}^{-2} \mathrm{~s}^{-1}$ and $1200 \mathrm{~mW} \mathrm{~m}^{-2}$ respectively), while the lowest readings were observed in Autumn and Winter $(<600 \mu \mathrm{mol}$ photon $\mathrm{m}^{-2} \mathrm{~s}^{-1}$ and $<700 \mathrm{~mW} \mathrm{~m} \mathrm{~m}^{-2}$ respectively, Fig 5.1).

PAR and UVB were highly variable during Spring/Summer of 2012, due to higher climatic instability, thus March, May and August 2012 were characterized by very low UVB and PAR irradiances (Fig 5.1). In contrast, sampling was able to be performed on clear sunny days during the second year (2013, Fig 5.1). 


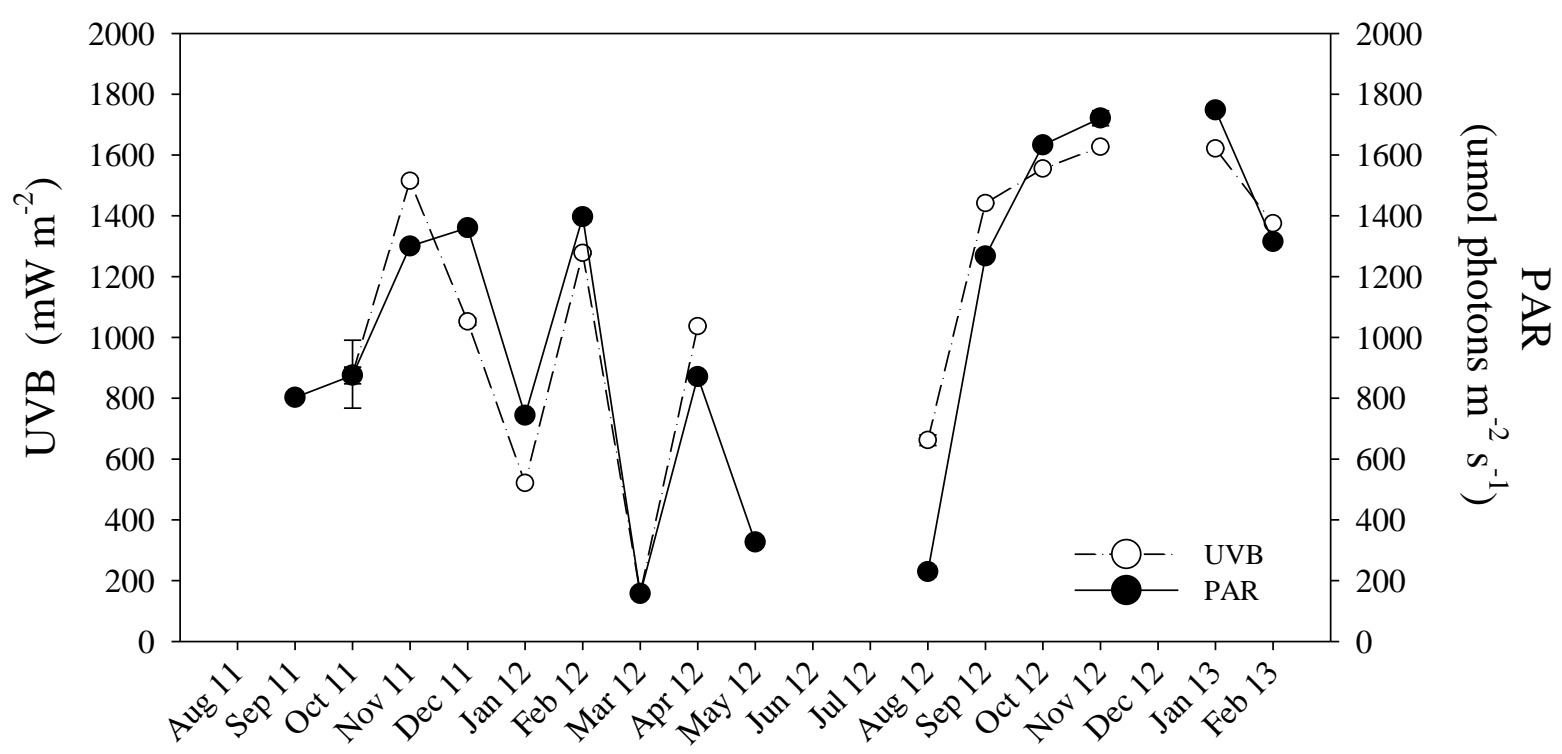

Months

Fig. 5.1 Seasonal variation in UVB and PAR irradiances at the intertidal zone of Breaker Bay, Wellington. Superficial irradiances were measured at 10am every month. Data points represent the mean $\pm \operatorname{SE}(n=4)$.

The effective quantum yield ( $\phi_{\text {PSII }}$ ) of sporophytes of $U$. pinnatifida followed a seasonal trend with higher values between March and August, and lower values between September and February (Fig. 5.2). The $\phi_{\text {PSII }}$ was $~ 90 \%$ similar among months; however, two groups can be observed. The first group was over 97\% similar and included the Autumn and Winter months and September 2011. The second group with over 92\% similarity was represented by the Spring and Summer months, except for August 2011 (Fig. 5.3). Difference between these two groups was detected ( $\mathrm{t}$-test, $\mathrm{p}<0.05$ ), where the $\phi_{\text {PSII }}$ was lower and more variable in Spring/Summer months (between 0.45 and 0.7) than in Autumn/Winter (0.65 and 0.7). 


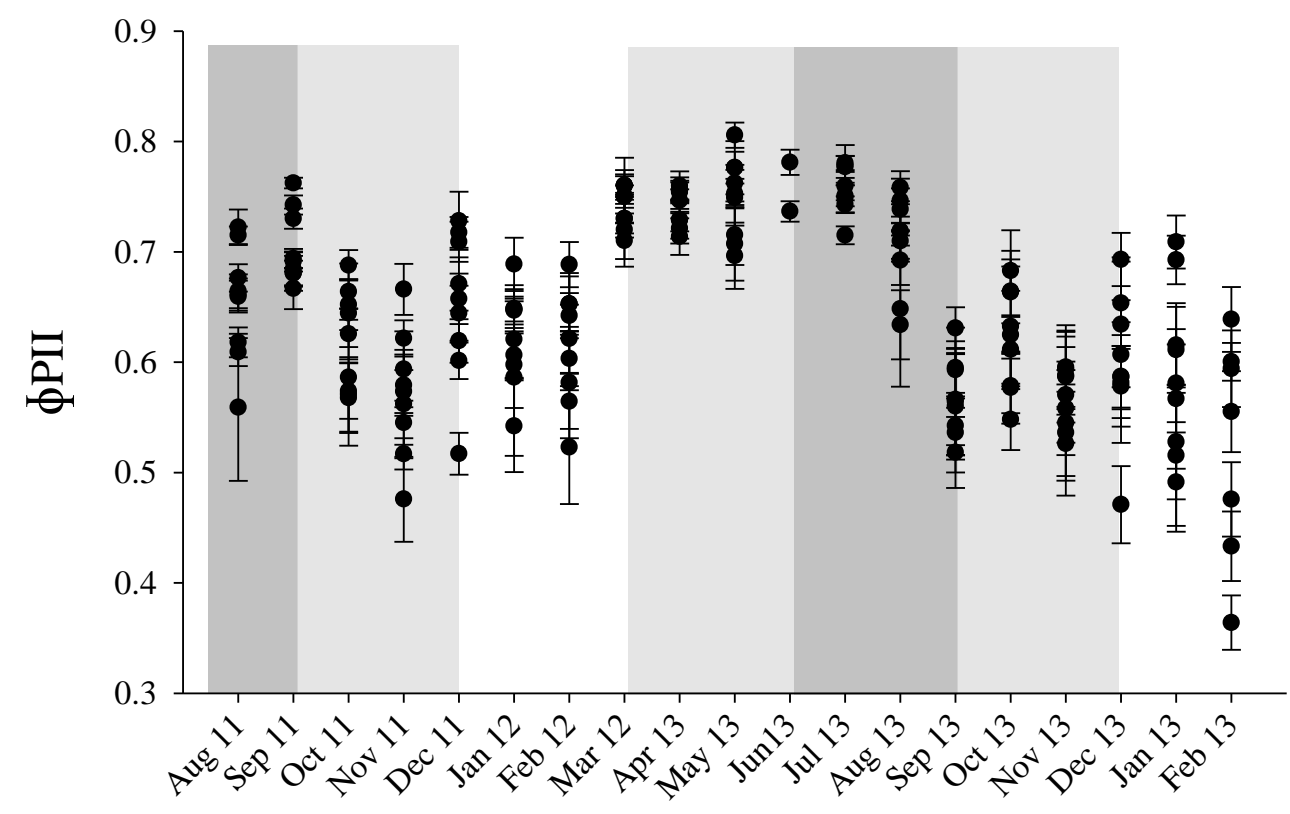

Months

Fig. 5.2 Seasonal variation in the effective quantum yield $\left(\mathrm{F}_{\mathrm{v}} / \mathrm{F}_{\mathrm{m}}\right)$ of sporophytes of $U$. pinnatifida at Breaker Bay, Wellington. Data points represent the mean of each individual \pm SE ( $n=9$, except June, July and February with 2, 8 and 7 individuals respectively). Dark grey background represents Winter months, clear grey background Autumn and Spring months and background Summer months.

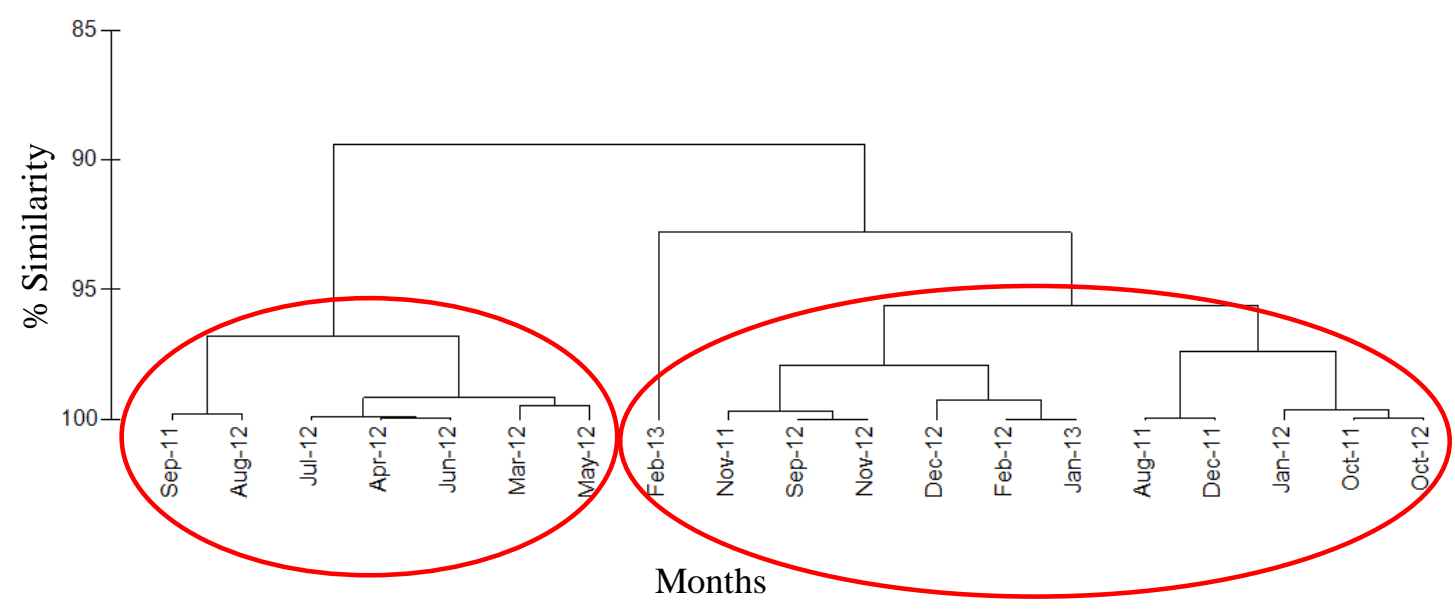

Fig. 5.3 Cluster analysis of the effective quantum yield ( $\left.\phi_{\text {PSII }}\right)$ of sporophytes of $U$. pinnatifida between August 2011 and February 2013. 
A moderate negative correlation between $\phi_{\text {PSII }}$ and PAR $(r=-0.55, p<0.05)$ and $\phi_{\text {PSII }}$ UVB $(r=-$ $0.65, \mathrm{p}<0.05)$ were detected. Thus, at increasing PAR and UVB irradiances the photosynthetic performance of the sporophytes decreased (Fig. 5.4a and b).
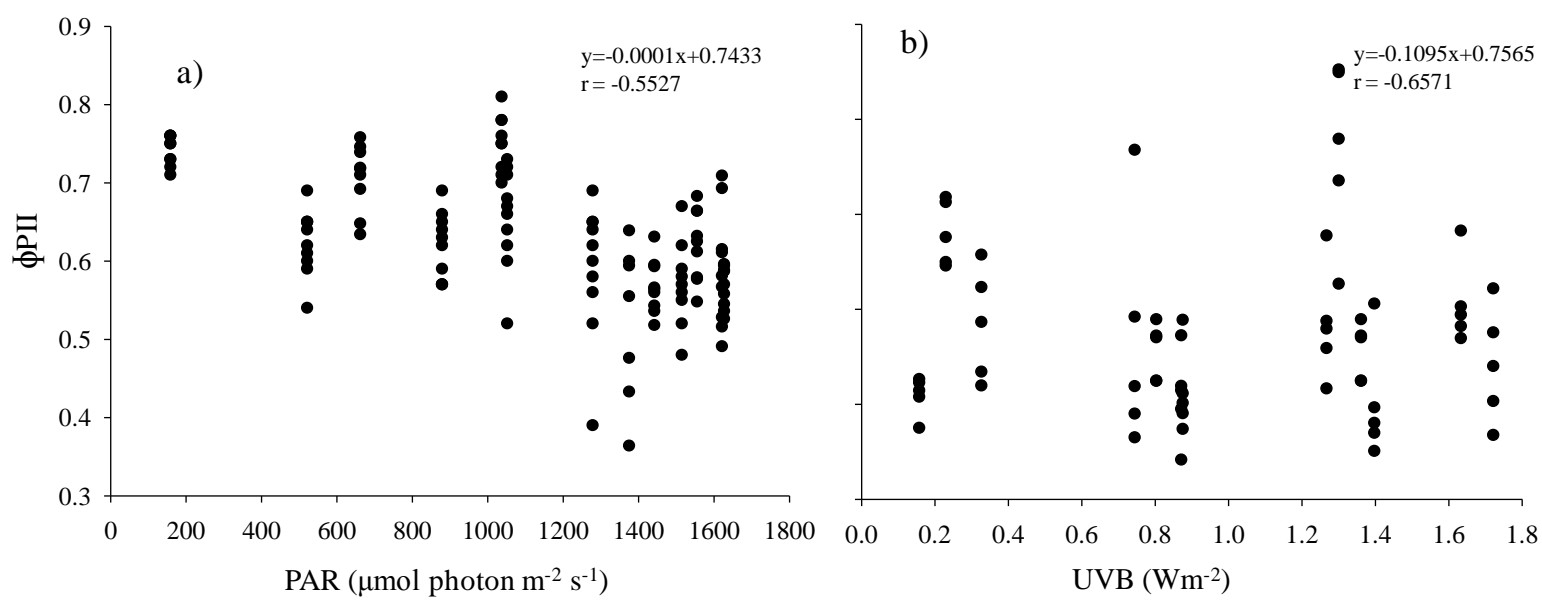

Fig. 5.4 Pearson correlations between PAR (a), UVB (b) and the effective quantum yield ( $\left.\phi_{\text {PII }}\right)$ of sporophytes of $U$. pinnatifida measured as effective quantum yield ( $\left.\phi_{\mathrm{PSII}}\right)$. Data points represent the mean of each individual ( $n=9$, except those months with less individuals).

Higher SPs and Pt concentration was observed during summer 2011-2012 than summer 20122013 (Fig. 5.5). SPs were variable throughout the years of study and the content in sporophytes of $U$. pinnatifida was higher during Summer 2011 than other months (Fig. 5.5). SPs presented over $80 \%$ similarity among months and a cluster analysis identified three groups with similarities of $\sim 92 \%, \sim 95$ and $\sim 93$ (Fig. 5.6a). The first group included mainly Summer months (November 2011 to January 2012) with the exception of April 2012, the second group was more variable and included Spring, Summer and Autumn months; while the third group comprised mainly Winter and Spring months (June 2012 to November 1012, Fig. 5.6a). 
Differences among these three groups were detected (ANOVA, $\mathrm{p}<0.0001$ ). The CWPs were also variable throughout the year with a higher CWPs observed mainly during Winter/Spring (Fig. 5.5). CWPs were more variable than SPs with $\sim 60 \%$ similarity among months and a cluster analysis identified four groups with over $\sim 85 \%$ similarity (Fig. 5.6b). Differences among these groups were detected (ANOVA, $\mathrm{p}<0.0001$ ); however no clear seasonal pattern was observed among groups (Fig. 5.6b).

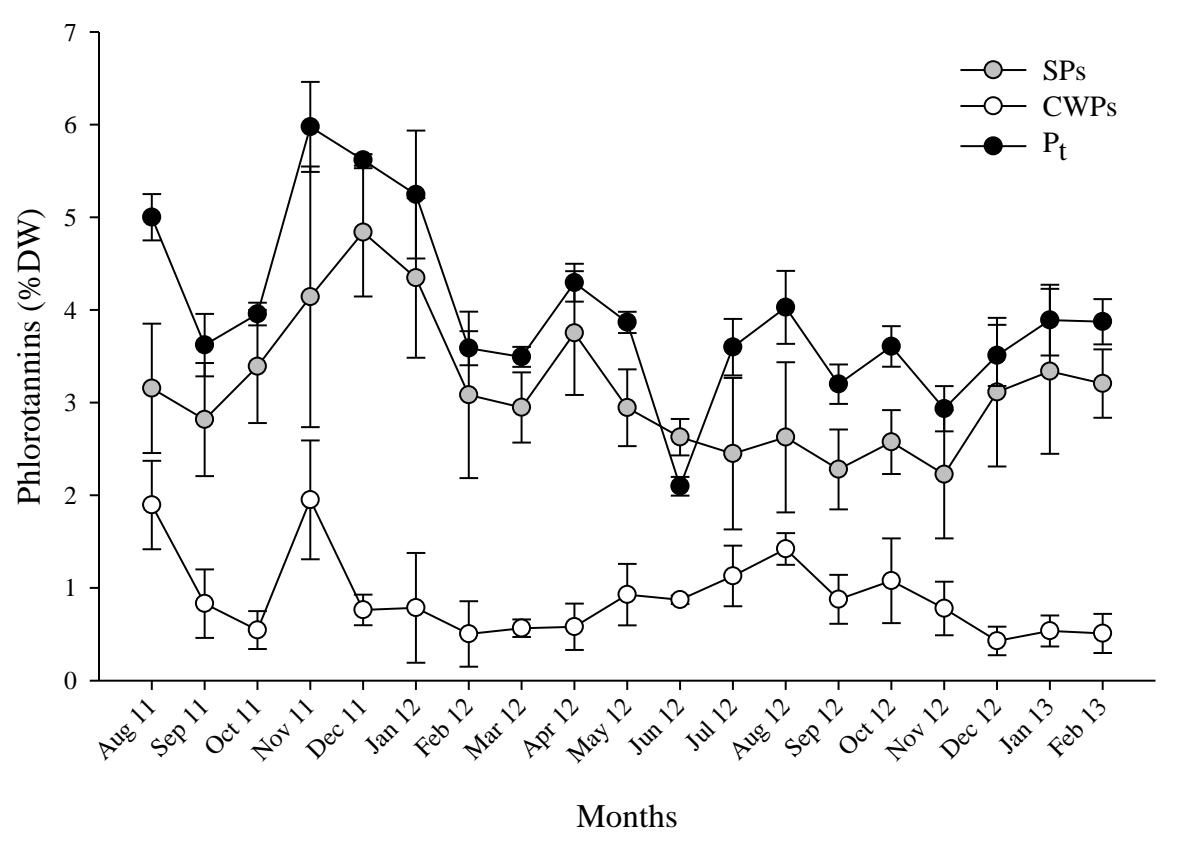

Fig. 5.5 Seasonal variation in soluble phlorotannins (SPs), cell wall phlorotannins (CWPs) and total phlorotannins $(\mathrm{Pt})$ of sporophytes of $U$. pinnatifida at Breaker Bay, Wellington. Data points represent the mean $\pm \mathrm{SE}$ ( $\mathrm{n}=5$, except June with 2 individuals). 

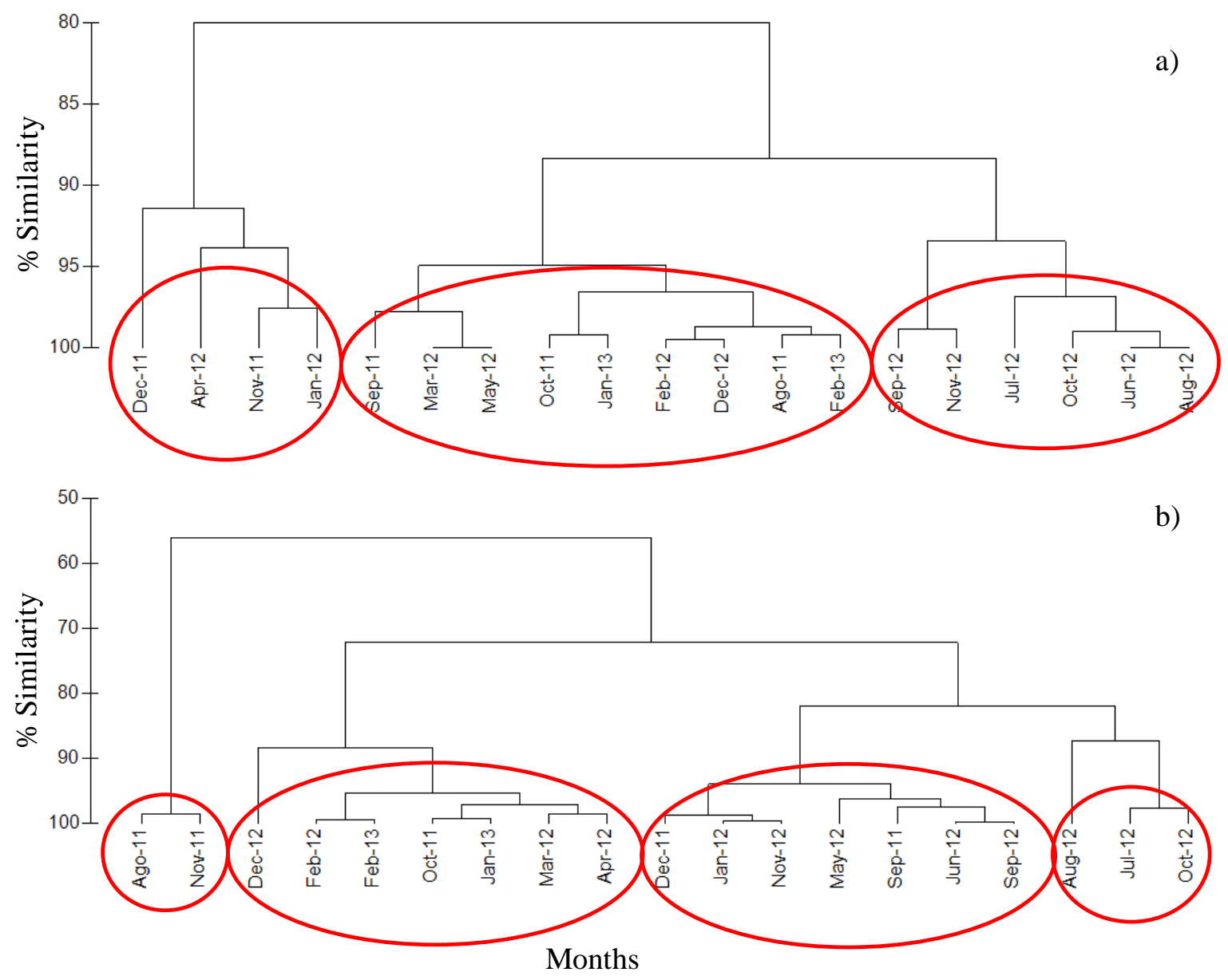

Fig. 5.6 Cluster analysis of the phlorotannins concentration in sporophytes of $U$. pinnatifida between September 2011 and February 2013. a) represents soluble phlorotannins and b) cell-wall phlorotannins.

$\mathrm{P}_{\mathrm{t}}$ and SPs had a low negative correlation with PAR ( $\mathrm{r}=-0.275, \mathrm{p}<0.05, \mathrm{r}=-0.293, \mathrm{p}<0.05$, respectively), but no correlation with UVB ( $\mathrm{r}=-0.145, \mathrm{p}>0.05, \mathrm{r}=-0.0984, \mathrm{p}>0.05)$. Thus, at increasing PAR, the SPS and $\mathrm{P}_{\mathrm{t}}$ tended to decrease (Fig. 5.7). No correlation between CWPs and PAR ( $r=-0.105, p>0.05)$ and UVB was observed ( $r=0.004, p>0.05$; Fig. 5.7). Also no correlation between SPs and CWPs was detected ( $r=0.087$, p>0.05; Fig. 5.8). 

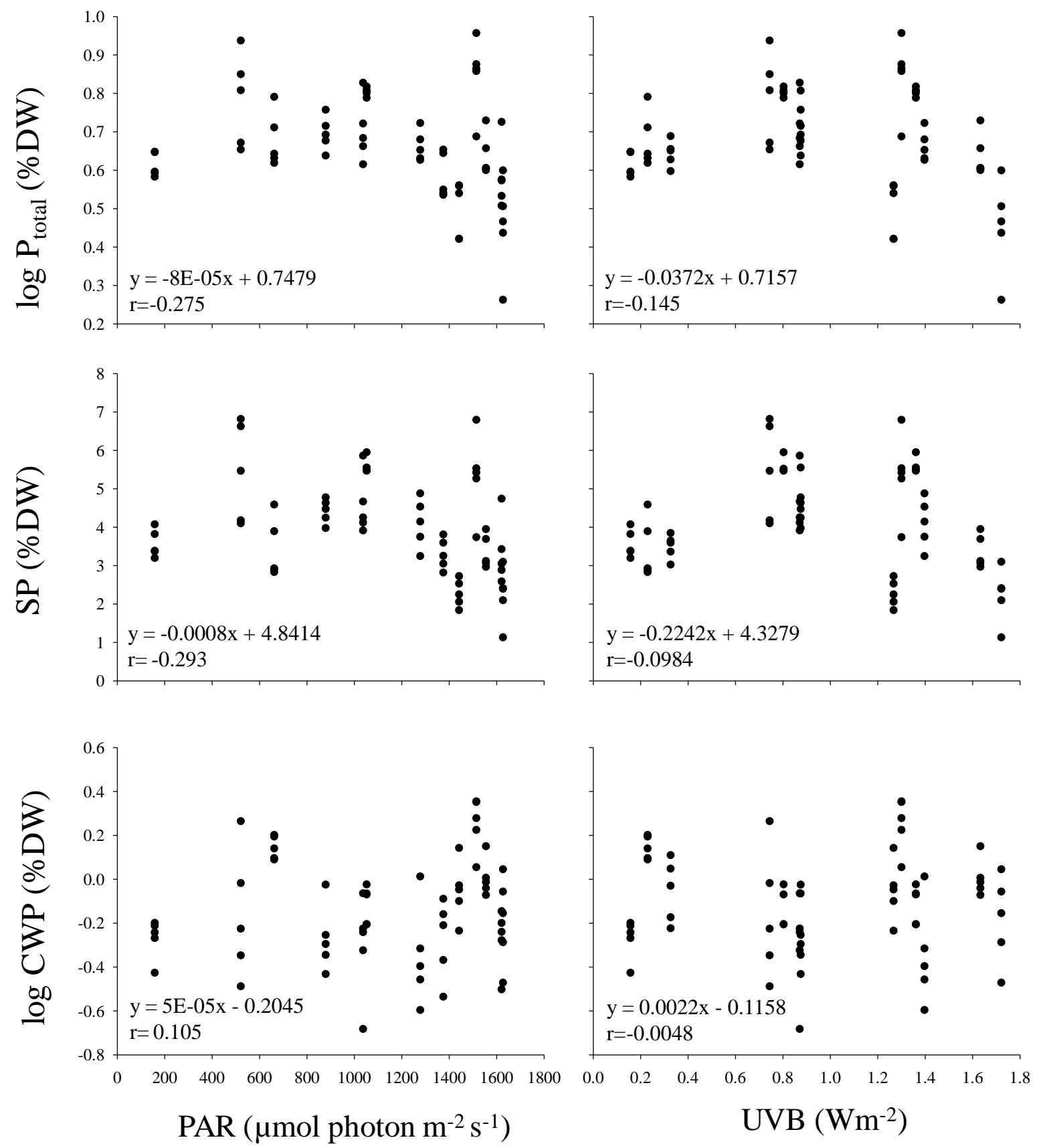

Fig. 5.7 Pearson correlations between PAR/UVB and total phlorotannins, soluble phlorotannins (SPs) and cell-wall phlorotannins (CWPs) of $U$. pinnatifida. Data points represent the mean of each individual $(\mathrm{n}=5)$. 


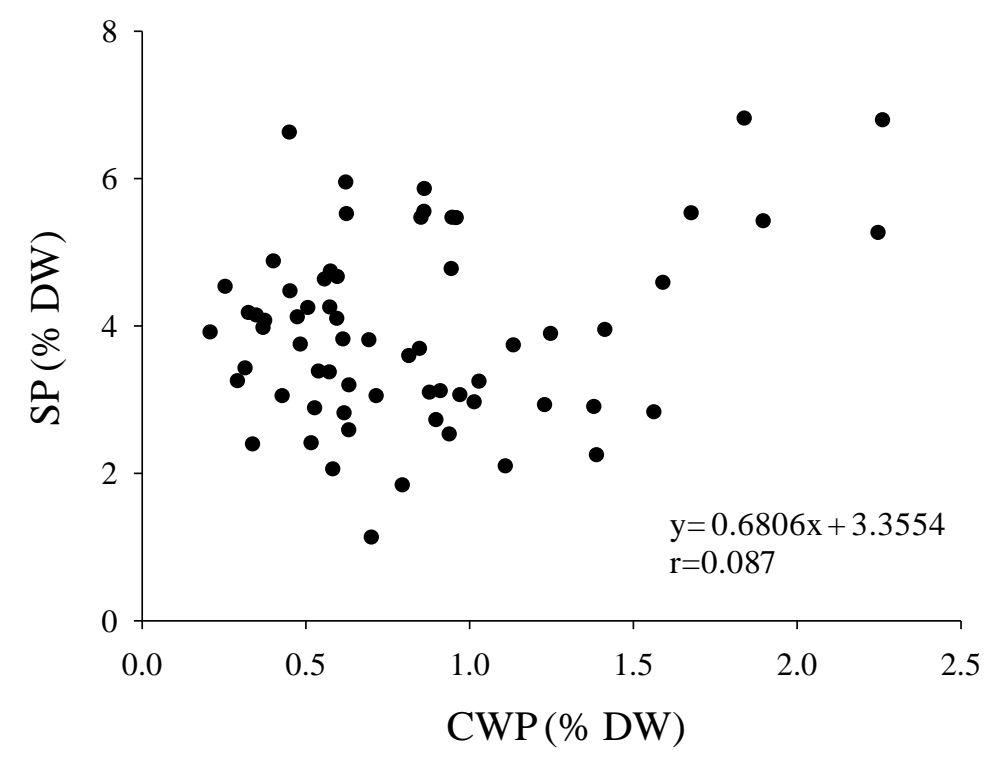

Fig. 5.8 Pearson correlations between soluble phlorotannins (SPs) and cell-wall phlorotannins (CWPs), of $U$. pinnatifida.

\subsection{Discussion}

Seasonal variability in light conditions was observed in Breaker Bay, Wellington between August 2011 and February 2013 that was characterized by high irradiances of PAR and UVB during late Spring/Summer and decreasing towards Winter. The low PAR and UVB irradiances recorded during January 2012 and March 2012 were due to cloudy conditions during the sampling day. It was not possible to select a sampling day that combined clear weather with an appropriate tide. Seasonality in the light conditions was accompanied by a seasonal trend in the effective quantum yield ( $\left.\phi_{\mathrm{PII}}\right)$ and SPs concentration in sporophytes of $U$. pinnatifida.

The variation in $\phi_{\mathrm{PII}}$ throughout the sampling period indicates differences in the photosynthetic performance of $U$. pinnatifida between seasons. The $\phi_{\mathrm{PII}}$ of sporophytes of $U$. pinnatifida was 
higher when PAR and UVB were low and decreased as irradiances increased, characterized mainly by two groups with higher $\phi_{P I I}$ between Autumn/Winter than Spring/Summer. The negative correlation of sporophytes $\phi_{\mathrm{PII}}$ with PAR/UVB irradiances suggested a response of the photosynthetic apparatus to increasing solar radiation and shows the capacity of this species to acclimate to the light conditions. Thus, more reaction centres of the photosynthetic apparatus are closed when light conditions are higher (Spring/Summer) than under lower light conditions. Huovinen et al. (2006) observed that the perennial species Lessonia nigrescens had a stronger seasonal response to UVR than the annual Enteromorpha intestinalis. They also observed that the sensitivity of the perennial species to UVR during Winter was higher than the annual species (Huovinen et al. 2006). Thus, Huovinen et al. (2006) suggested that perennial species have physiological adaptations to seasonal variations as part of their development with a more gradual response to the light changes than annual species that have a faster acclimation to seasonal variations of UVR. U. pinnatifida is an annual species that responds rapidly to seasonal variations in light conditions.

Dynamic photoinhibition with a decrease in the photosynthetic capacity in Summer and increase in Autumn/Winter is well known in seaweeds (Gevart et al. 2002, Abdala-Dias et al. 2006, Huovinen et al. 2006). Lower photosynthetic capacity is a consequence of photoinhibition of photosynthesis and is a mechanism of acclimation and resistance to high light (Abdala-Diaz et al. 2006). The seasonality of photosynthesis has been linked to periods of growth and reproduction of some seaweeds (Haroun et al. 1992) including U. pinnatifida (Oh \& Koh 1996, Campbell et al. 1999). A higher photosynthetic rate in winter for $U$. pinnatifida is associated with an increase of photosynthetic pigments content and increase in tissue $\mathrm{N}$ content to maintain a maximal growth rate (Campbell et al. 1999, Dean \& Hurd 2007) that occurs in late Winter and early Spring when light conditions are low. This is consistent with the differences in the abundance of sporophytes that I observed in the field throughout the year (data not shown) with a lower number of mature individuals during early Winter (JuneJuly), and increasing abundance towards Spring. This trend suggests a rapid growth of sporophytes in Winter during periods of higher photosynthetic capacity. This observation is supported by that of Christian (2003) who found seasonal variation in the abundance of $U$. pinnatifida in the south coast of Wellington with higher density during Spring. 
The photoprotective capacity of phlorotannins against UVB has been documented for different species of brown seaweeds (Pavia et al. 1997, Henry \& Van Alstyne 2004, Halm et al. 2011). In U. pinnatifida, SPs tend to increased towards Spring and Summer where light conditions are increasing. For U. pinnatifida, a photoprotective role of phlorotannins could not demonstrated due to the lack of correlation of the SPs and CWPs and UVB in this species. Moreover, $U$. pinnatifida presented low negative correlation of SPs and PAR and this suggests that phenolic compounds might be stimulated by PAR more than UV as suggested by Fairhead et al. 2006. Thus, the variations of phenolic compounds in U. pinnatifida throughout the year might be stimulated by other factors including wound healing processes as has been observed for Laminaria hyperborea (Halm et al. 2011) or a protection against herbivores as has been documented for Ecklonia radiate (Lüder \& Clayton 2004) .

The concentration of SPs in sporophytes of $U$. pinnatifida was greater than CWP. Koivikko et al. (2005) suggested the differences in concentration of both phlorotannins might be because they bind into the cell wall in small amounts, or that they transform to other compounds and/or some of soluble phlorotannins are exuded into the water. Both phlorotannins (SP and CWP) in $U$. pinnatifida varied throughout the year. Nevertheless the trend between phlorotannins was different with higher SPs in Spring/Summer and higher CWPs occurred in Winter/Spring. The lower difference between phlorotannins in Winter in comparison to Summer may due to SPs bound to the cell wall in period of growth. U. pinnatifida grows faster in Winter reaching maturity in 40 days (Stuart et al. 1999, Christian 2003). The high CWPs concentration in Winter/Spring might allow the cell wall to thicken during growth (Arnold \& Targett 2000) as a mechanism of protection from grazers, and their decrease in summer might be due to turnover to other cell wall compounds or degradation (Koivikko et al. 2005). In contrast, higher SPs and lower CWP during Summer might due to high rate of production of SPs during this period. Correlation of SPs and CWPs has been found in non-growing individuals of Fucus vesiculosus (Koivikko et al. 2005). Mature sporophytes of $U$. pinnatifida had a lack of correlation between SPs and CWPs contrasting with Koivikko et al. 2005. This may indicate that there is an active production of both phlorotannins in $U$. pinnatifida even after maturity.

This study showed seasonal changes in the ecophysiology of mature sporophytes of $U$. pinnatifida. The seasonal development of seaweeds is related mainly to light, temperature and nutrients (Lüning 1980, 1989, Wiencke et al. 2007). For $U$. pinnatifida, maximum growth of sporophytes occurs in winter when light conditions are low and high nutrients concentrations 
exist (Yoshikawa et al. 2001, Dean \& Hurd 2007). This pattern of growth is unusual for Laminariales that often have a maximal growth when light conditions are increasing (Tala \& Edding 2005). Campbell et al (1999) suggested that the growth of juvenile sporophytes during winter and physiological adaptation to low light is an effective strategy of this species to compete with other macroalgae. Seasonal variation of SPs was observed but no CWPs. Since phlorotannins are secondary metabolites linked to multiple ecological roles such as chemical defence against herbivores, antibacterial action and photoprotection (Arnold \& Targett 1998, Halm et al. 2011), the variation of SPs and CWPs in U. pinnatifida could be attributed to the combination of these factors. Changes in the $\phi_{\mathrm{PII}}$ and phlorotannins concentration throughout the year shows $U$. pinnatifida can acclimate and respond to environmental changes and this could explain, in part, the success of this species in temperate regions. 


\subsection{References}

Abdala-Díaz, R. T., Cabello-Pasini, A., Pérez-Rodríguez, E., Alvarez, R. C. \& Figueroa, F. L. (2006). Daily and seasonal variations of optimum quantum yield and phenolic compounds in Cystoseira tamariscifolia (Phaeophyta). Marine Biology. 148(3): 459-465.

Alpert, P. (2000). The discovery, scope, and puzzle of desiccation tolerance in plants. Plant Ecology. 151(1): 5-17.

Abdala-Díaz, R. T., Cabello-Pasini, A., Pérez-Rodríguez, E., Alvarez, R. C. \& Figueroa, F. L. (2006). Daily and seasonal variations of optimum quantum yield and phenolic compounds in Cystoseira tamariscifolia (Phaeophyta). Marine Biology. 148(3): 459-465.

Arnold, T. M. \& Targett, N. M. (2003). To grow and defend: lack of tradeoffs for brown algal phlorotannins. Oikos. 100(2): 406-408.

Arnold, T. M. \& Targett, N. M. (1998). Quantifying in situ rates of phlorotannin synthesis and polymerization in marine brown algae. Journal of Chemical Ecology. 24(3): 577-595.

Arnold, T. M. \& Targett, N. M. (2000). Evidence for metabolic turnover of polyphenolics in tropical brown algae. Journal of chemical ecology. 26(6): 1393-1410.

Balata, D., Piazzi, L. \& Rindi, F. (2011). Testing a new classification of morphological functional groups of marine macroalgae for the detection of responses to stress. Marine biology. 158(11): 2459-2469.

Campbell, S. J., Bite, J. S. \& Burridge, T. R. (1999). Seasonal patterns in the photosynthetic capacity, tissue pigment and nutrient content of different developmental stages of Undaria pinnatifida (Phaeophyta: Laminariales) in Port Phillip Bay, South-Eastern Australia. Botanica Marina. 42(3): 231-242.

Campbell, S. J. \& Burridge, T. R. (1998). Occurrence of Undaria pinnatifida (Phaeophyta: Laminariales) in Port Phillip Bay, Victoria, Australia. Marine and Freshwater Research. 49(5): 379-381.

Cebrian, E. \& Ballesteros, E. (2009). Temporal and spatial variability in shallow-and deep-water populations of the invasive Caulerpa racemosa var. cylindracea in the Western Mediterranean. Estuarine, Coastal and Shelf Science. 83(4): 469-474.

Cecere, E., Petrocelli, A. \& Daniela Saracino, O. (2000). Undaria pinnatifida (Fucophyceae, Laminariales) spread in the central Mediterranean: its occurrence in the Mar Piccolo of Taranto (Ionian Sea, southern Italy). Cryptogamie Algologie. 21(3): 305-309. 
Christian S.J. (2003) Growth, Longevity and Density of the Adventive Asian Kelp Undaria pinnatifida from the Intertidal Zone in Wellington Harbour and South Coast. Victoria University of Wellington.

Cockel, C. \& Knowland, J. (1999) Ultraviolet radiation screening compounds. Biological Reviews, 94(3): 311-345.

Connan, S., Deslandes, E. \& Gall, E. A. (2007). Influence of day-night and tidal cycles on phenol content and antioxidant capacity in three temperate intertidal brown seaweeds. Journal of experimental marine biology and ecology. 349(2): 359-369.

Connan, S., Goulard, F., Stiger, V., Deslandes, E. \& Ar Gall, E. (2004). Interspecific and temporal variation in phlorotannin levels in an assemblage of brown algae. Botanica Marina. 47(5): 410-416.

Conolly, N. J. \& Drew, E. A. (1985). Physiology of Laminaria. Marine Ecology. 6(4): 299-320.

Davison, I. R. \& Pearson, G. A. (1996). Stress tolerance in intertidal seaweeds. Journal of Phycology. 32(2): 197-211.

Dean, P. R. \& Hurd, C. L. (2007). Seasonal growth, erosion rates, and nitrogen and photosynthetic ecophysiology of Undaria pinnatifida (Heterokontophyta) in southern New Zealand1. Journal of Phycology. 43(6):1138-1148.

Floc'h, J. Y., Pajot, R. \& Wallentinus, I. (1991). The Japanese brown alga Undaria pinnatifida on the coast of France and its possible establishment in European waters. Journal du Conseil: ICES Journal of Marine Science. 47(3): 379-390.

Fogg, G. E. (2001). Algal adaptation to stress-some general remarks. In Algal Adaptation to Environmental Stresses (pp. 1-19). Springer Berlin Heidelberg.

Gévaert, F., Creach, A., Davoult, D., Holl, A. C., Seuront, L. \& Lemoine, Y. (2002). Photo-inhibition and seasonal photosynthetic performance of the seaweed Laminaria saccharina during a simulated tidal cycle: chlorophyll fluorescence measurements and pigment analysis. Plant, Cell \& Environment. 25(7): 859-872.

Gómez, I., López-Figueroa, F., Ulloa, N., Morales, V., Lovengreen, C., Huovinen, P. \& Hess, S. (2004). Patterns of photosynthesis in 18 species of intertidal macroalgae from southern Chile. Marine Ecology Progress Series. 270: 103-116.

Halm, H., Lüder, U. H. \& Wiencke, C. (2011). Induction of phlorotannins through mechanical wounding and radiation conditions in the brown macroalga Laminaria hyperborea. European Journal of Phycology. 46(1):16-26. 
Haroun, R., Aruga, Y. \& Yokohama, Y. (1992). Seasonal variation of photosynthetic properties of Ecklonia cava (Laminariales, Phaeophyta) in Nabeta Bay, central Japan. La mer. 30: 339-48.

Hay, C. H. \& Luckens, P. A. (1987). The Asian kelp Undaria pinnatifida (Phaeophyta: Laminariales) found in a New Zealand harbour. New Zealand journal of Botany. 25(2): 329-332.

Hay, C. H. (1990). The dispersal of sporophytes of Undaria pinnatifida by coastal shipping in New Zealand, and implications for further dispersal of Undaria in France. British phycological journal. 25(4): 301-313.

Henry, B. E. \& Van Alstyne, K. L. (2004). Effects of UV radiation on growth and phlorotannins in Fucus Gardneri (Phaeophyceae) juveniles and embryos 1. Journal of Phycology. 40(3): 527533.

Huovinen, P., Gomez, I., Figueroa, F., Ulloa, N., Morales, V. \& Lovengreen, C. (2004) Ultravioletabsorbing mycosporine-like amino acids in red macroalgae from Chile. Botanica Marina, 47(1):21-29.

Huovinen, P., Gómez, I. \& Lovengreen, C. (2006). A Five-year Study of Solar Ultraviolet Radiation in Southern Chile (39 $\mathrm{S}$ ): Potential Impact on Physiology of Coastal Marine Algae?. Photochemistry and Photobiology. 82(2): 515-522.

Jennings, J. G. \& Steinberg, P. D. (1994). In situ exudation of phlorotannins by the sublittoral kelp Ecklonia radiata. Marine Biology. 121(2): 349-354.

Johnson, A. \& Koehl, M. (1994). Maintenance of dynamic strain similarity and environmental stress factor in different flow habitats: thallus allometry and material properties of a giant kelp. Journal of Experimental Biology. 195(1): 381-410.

Kain, J.M. (1989) The seasons in the subtidal Br. Phycol, J. 24:203-215.

Kim, J. K., Kraemer, G. P., Neefus, C. D., Chung, I. K. \& Yarish, C. (2007). Effects of temperature and ammonium on growth, pigment production and nitrogen uptake by four species of Porphyra (Bangiales, Rhodophyta) native to the New England coast. Journal of Applied Phycology. 19(5): 431-440.

Koivikko, R., Loponen, J., Honkanen, T. \& Jormalainen, V. (2005). Contents of soluble, cell-wallbound and exuded phlorotannins in the brown alga Fucus vesiculosus, with implications on their ecological functions. Journal of chemical ecology. 31(1):195-212.

Koivikko, R. (2008). Brown algal phlorotannins: improving and applying chemical methods. 
Lüder, U. H., \& Clayton, M. N. (2004). Induction of phlorotannins in the brown macroalga Ecklonia radiata (Laminariales, Phaeophyta) in response to simulated herbivory-the first microscopic study. Planta. 218(6): 928-937.

Lüning, K. (1980). 15 Control of algal life-history by day length and temperature. In: Price JH, Irvine DEG, Farnham WF (eds) The shore environments, vol. 2, Ecosystems. Academic Press, New York, pp 915-945.

Lüning, K. (1989). Environmental triggers in algal seasonality. Botanica marina. 32(5): 389-398.

Lüning, K. (1993). Environmental and internal control of seasonal growth in seaweeds. In Fourteenth International Seaweed Symposium (pp. 1-14). Springer Netherlands.

Nyberg, C. D. \& Wallentinus, I. (2005). Can species traits be used to predict marine macroalgal introductions?. Biological Invasions. 7(2). 265-279.

Miller, S. M., Hurd, C. L. \& Wing, S. R (2011)Variations in growth, erosion, productivity, and morphology of Ecklonia radiata (Alariaceae; Laminariales) along a fiord in the southern New Zealand. Journal of Phycology. 47(3): 505-516.

Oh, S. H. \& Koh, C. H. (1996). Growth and photosynthesis of Undaria pinnatifida (Laminariales, Phaeophyta) on a cultivation ground in Korea. Botanica Marina. 39(1-6): 389-394.

Pakker, H., Beekman, C. \& Breeman, A. (2000). Efficient photoreactivation of UVBR-induced DNA damage in the sublittoral macroalga Rhodymenia pseudopalmata (Rhodophyta). European Journal of Phycology. 35(2):109-114.

Pavia, H., Cervin, G., Lindgren, A. \& Åberg, P. (1997). Effects of UV-B radiation and simulated herbivory on phlorotannins in the brown alga Ascophyllum nodosum. Marine Ecology Progress Series. 157:139-146.

Raniello, R., Lorenti, M., Brunet, C. \& Buia, M. C. (2006). Photoacclimation of the invasive alga Caulerpa racemosa var. cylindracea to depth and daylight patterns and a putative new role for siphonaxanthin. Marine Ecology. 27(1), 20-30.

Roleda, M. Y., Hanelt, D. \& Wiencke, C. (2006). Growth and DNA damage in young Laminaria sporophytes exposed to ultraviolet radiation: implication for depth zonation of kelps on Helgoland (North Sea). Marine Biology. 148(6): 1201-1211.

Sampath-Wiley, P., Neefus, C. D. \& Jahnke, L. S. (2008). Seasonal effects of sun exposure and emersion on intertidal seaweed physiology: Fluctuations in antioxidant contents, photosynthetic pigments and photosynthetic efficiency in the red alga Porphyra umbilicalis 
Kützing (Rhodophyta, Bangiales). Journal of experimental marine biology and ecology. 361(2): 83-91.

Schoenwaelder, M. E. \& Clayton, M. N. (1998). Secretion of phenolic substances into the zygote wall and cell plate in embryos of Hormosira and Acrocarpia (Fucales, Phaeophyceae). Journal of Phycology. 34(6): 969-980.

Sieburth, J. M. \& Jensen, A. (1969). Studies on algal substances in the sea. II. The formation of Gelbstoff (humic material) by exudates of Phaeophyta. Journal of Experimental Marine Biology and Ecology. 3(3): 275-289.

Silva, P. C., Woodfield, R. A., Cohen, A. N., Harris, L. H. \& Goddard, J. H. (2002). First report of the Asian kelp Undaria pinnatifida in the northeastern Pacific Ocean. Biological Invasions. 4(3): 333-338.

Swanson, A. \& Druehl, L. (2002) Induction, exudation and the UV protective role of kelp phlorotannins. Aquatic Botany. 73(3):241-253.

Tala, F. \& Edding, M. (2005). Growth and loss of distal tissue in blades of Lessonia nigrescensand Lessonia trabeculata (Laminariales). Aquatic Botany. 82(1): 39-54.

Stern, J. L., Hagerman, A. E., Steinberg, P. D., Winter, F. C., \& Estes, J. A. (1996). A new assay for quantifying brown algal phlorotannins and comparisons to previous methods. Journal of Chemical Ecology, 22(7), 1273-1293.

Stuart, M. D., Hurd, C. L., \& Brown, M. T. (1999, January). Effects of seasonal growth rate on morphological variation of Undaria pinnatifida (Alariaceae, Phaeophyceae). In Sixteenth International Seaweed Symposium (pp. 191-199). Springer Netherlands.

van de Poll, W., Hanelt, D., Hoyer, K., Buma, A. \& Breeman, A. (2002) Ultraviolet-B-induced cyclobutame pyrimidine dimer formation and repair in arctic marine macrophytes. Photochemistry and Photobiology. 76(5):493-500.

Wiencke, C., Clayton, M. N., Gómez, I., Iken, K., Lüder, U. H., Amsler, C. D., et al. (2007). Life strategy, ecophysiology and ecology of seaweeds in polar waters. In Life in Extreme Environments (pp. 213-244). Springer Netherlands.

Yoshikawa, T., Takeuchi, I. \& Furuya, K. (2001). Active erosion of Undaria pinnatifida. Suringar (Laminariales, Phaeophyceae) mass-cultured in Otsuchi Bay in northeastern Japan. Journal of experimental marine biology and ecology. 266(1): 51-65. 


\section{Chapter 6}

\section{General discussion}

Environmental changes are accelerating due to anthropogenic activity (Occhipinti \& Savini 2003, Hughes et al. 2005, Kampa \& Castanas 2008, Rockström et al. 2009). These changes are likely to affect organisms and consequently ecosystems. Most studies on the effect of environmental changes on organisms have focussed on native species leaving aside the possible effect on invasive species. Climate change is likely to increase the rate of disturbance of the environment by altering population dynamics and the structure and composition of communities (Walther et.al 2002, Parmesan 2006, Hoegh-Guldberg et al. 2007, Alongi 2008), and this may allow organisms with high physiological plasticity, characteristic of many invasive species, to proliferate. Controversial opinion exist where some authors have suggested that climate change might favour introductions (Dukes \& Mooney 1999, Vilà, et al. 2007), while others suggest that the impact of some invasive species might diminish under climate change (Hellmann et al. 2008). However, there is a lack of knowledge of the tolerance of invasive species to environmental change, even though this could also in part explain their success in colonizing new environments.

This is the first study to analyse the tolerance of early life stages and macroscopic stages of the invasive $U$. pinnatifida to UVB and the combination of UVB with temperature. These results give the first insight into the possible effects of environmental changes on this invasive species. In this discussion I firstly outline the new insights of my study, secondly I describe some conclusions and limitations of this study and finally suggest some recommendations for future research. 


\subsection{Findings}

\section{Effect of light treatments}

It is well known that UVB has various negative effects on macroalgae (Wiencke et al. 2000, Roleda et al. 2005, Bischof \& Steinhoff 2012, Häder et al. 2007, 2015). In this research, the effect of UVB on an invasive brown seaweed was assessed for the first time. I expected that early life stages of $U$. pinnatifida would be tolerant to UVB as this is an invasive species. However, early life stages of zoospores of $U$. pinnatifida were sensitive to UVB (Chapters 2 and 3), which was reflected in a reduction of the photosynthetic performance and lower germination rate of zoospores. Furthermore, the effect of UVB on early life stages was dose dependent (Chapter 2). These findings are consistent with others studies in Laminariales species that also show a dose dependent effect of UVB (Tala et al. 2007, Roleda et al. 2010). The sensitivity of early life stages of seaweeds to UVB is associated with their cellular simplicity (cellular size and cell wall) that permits UVB to reach cellular macromolecules easier than in macroscopic stages (Altamirano et al. 2003, Veliz et al. 2006, Navarro et al. 2010). Susceptibility to UVB of marine unicellular organism is known (Harada et al. 2009, Kottuparambil et al. 2012). Cellular size in marine organism is important trait to compensate variations of the environmental conditions, for example small diatoms are more susceptible to photoinactivation but presents a faster metabolic repair mechanism than larger diatoms to variations of light (Key et al. 2010). Thus, early life stages of $U$. pinnatifida might have faster repair mechanism in comparison to more developed stages to cope with UVB stress.

Although UVB had a negative effect on early life stages, they can recover from the initial stress. In brown seaweeds, the recovery of early life stages occurs several days after exposure to UVB (Roleda et al. 2010). By contrast, zoospores of $U$. pinnatifida recovered within hours of exposure to UVB when environmental conditions improved. Additionally, the decrease of DNA fluorescence in Chapter 2 might due to chromatin remodelling during DNA repair (Dinant et al. 2008) of cyclobutane pyrimidine dimers (CPDs) that are the main DNA damage induced by UV (Cadet et al. 2005, Pfeifer \& Besaratinia 2011). Thus, the capacity for recovery and even repair of zoospores of $U$. pinnatifida under more favourable conditions is an important finding because the capacity of zoospores to recover quickly might allow zoospores to develop and maintain viable populations. 
Moreover, motile zoospores are unlikely to be exposed to direct light for long periods of time because they are constantly moved by water circulation, and may sink or ascend in the water column. Other factors such as attenuation and scattering of light within the water column reduce ambient irradiances and protection/shading by other algal assemblages might reduce the direct exposure. Furthermore, although $U$. pinnatifida grows all year around in $\mathrm{New}$ Zealand (Hay \& Villouta 1993) the peak growth occurs mainly in Winter and Spring and therefore it is likely that zoospores are released mainly in Spring. If this is the case, zoospores would be released in the intertidal of Wellington coast when relative low UVB irradiances exist. Therefore, zoospores of $U$. pinnatifida are very likely to settle and develop despite the initial stress they could suffer after release. After settlement, zoospores are likely to develop in areas protected from direct light such as under other algae canopies or in rock fissures (Morelissen 2012).

As sporophytes of $U$. pinnatifida inhabit mainly the intertidal of Wellington coast I expected they would be highly tolerant to UVB and would have efficient mechanism of protection such as dissipation of energy and screening substances. However, long term exposure to medium doses of UVB negatively affected sporophytes and consecutive exposures exacerbated the effect (Chapter 4). Also there was no evidence of a photoprotective role of phlorotannins in $U$. pinnatifida under these exposures. This is surprising because $U$. pinnatifida is an intertidal alga, and well developed mechanisms of protection against light were considered likely. Ample evidence suggests that intertidal seaweeds have mechanisms to cope with excess of light such as through the production of screening substances (Pavia et al. 1997, Cokcel \& Knowland 1999, de la Coba et al. 2009) and dissipation of energy via non-photochemical quenching (NPQ) (Müller et al. 2001, Szabó et al. 2005, Lavaud \& Clayton 2014). In brown seaweeds the screening capacity of phlorotannins against high light irradiances and UVB has been widely studied in several species (Pavia et al. 1997, Swanson \& Druehl 2002, AbdalaDiaz et al. 2006, Halm et al. 2011). However, for $U$. pinnatifida phlorotannin concentrations did not increase with UVB treatment and there was also a poor NPQ response. This finding suggests this species might have other strategies to survive in the intertidal. For example, it's success in the intertidal might be due to its ability to direct energy to growth and reproduction rather than protection as $U$. pinnatifida is an annual species and has a rapid growth rate and reach maturity very quickly ( 40 days) (Stuart et al.1999, Christian 2003, Chen 2012). Also, this species has a high fecundity rate producing millions of zoospores per individual (Stuart et 
al.1999, Christian 2003, Chen 2012). Moreover, synchronization of the life cycle to seasonal variation of the environmental conditions is another characteristic that may explain $U$. pinnatifida success. Thus, this species has its highest growth rate in late Winter and Spring where ambient UVB radiation is relatively low but increasing, decreasing the possibility of UVB damage.

In the experiments of Chapters 2, 3 and 4 there was a low impact of PAR and low impact of UVA in Chapters 3 and 4 on different life stages of $U$. pinnatifida. In Chapter 2 early life stages were able to germinate and growth in very low PAR irradiances PAR $(8 \mu$ mol photons $\left.\mathrm{m}^{-2} \mathrm{~s}^{-1}\right)$ and in Chapters 3 they develop to gametophytes under low PAR conditions $(35 \mu \mathrm{mol}$ photons $\mathrm{m}^{-2} \mathrm{~s}^{-1}$ ). Morelissen (2012) found an optimum development of gametophytes of this species between $\left(\sim 28-145 \mu \mathrm{mol}\right.$ photons $\left.\mathrm{m}^{-2} \mathrm{~s}^{-1}\right)$ and this is consistent with the finding of Chapter 3. The intertidal and low subtidal present much higher PAR irradiances (data from Chapter 5 and Morelissen et al. 2013) compared to the laboratory. This suggests that different life stages of $U$. pinnatifida have the potential to develop and grow in very low light conditions, and is consistent with the presence of subtidal populations of $U$. pinnatifida (Hay et al. 1987) and its wide vertical distribution (Curiel et al. 1998). Due to the low impact of UVA in the different life stages of $U$. pinnatifida observed in Chapter 3 and 4 the lack of UVA in Chapter 2 has little repercussion for the results. Moreover, Chapter 3 and 4 showed the different life stages of $U$. pinnatifida can tolerate moderate UVA irradiances that permit to this species inhabit well in the first meter of the water column where UVA irradiances are moderate due to attenuation of the solar radiation (Huovinen \& Gomez 2011).

Although change in UVB are not expected for the future due to the recovery of the ozone layer (Weatherhead \& Andersen. 2006, Hofmann \& Montzka 2009, IPCC 2013), still, UVB is an important stressor for intertidal organisms. The success of invasive species has been linked to a high physiological plasticity in response to environmental conditions (Yamashita et al. 2000, Raniello et al. 2004). Thus, the capacity of early life stages of $U$. pinnatifida to recover and repair damage from short exposure to UVB, the high plasticity of different life stages to cope with different light conditions, and the capacity to synchronize its life history to environmental cues suggest this species might succeed in a variety of scenarios. These characteristics permit this species to grow in a wide range of habitats from the intertidal to the subtidal, which could be linked to its invasive success. These characteristics could also favour this species in areas with high variability of light and changes in UVB irradiances. 


\section{Effect of light treatments with temperature}

Until relatively recently, most studies of environmental factors have focused on single stressors. It is now acknowledged, however, that interactive effects of multiple stressors are not only likely to occur in nature, but may have complex outcomes (Crain et al. 2008, Schiel 2009, Shears et al. 2010). In seaweeds, the interaction most studied is the effect of increasing temperature with UVB and responses are species specific showing a specie specific response (Altamirano et al. 2003, Rautenberger \& Bischof 2006, Steinhoff et al. 2008). For example, in some Phaeophyte species, increased temperature has an additive effect to UVB (Altamirano et al. 2003, Steinhoff et al. 2008), while for Ulvales species there is a compensatory effect of temperature on UVB (Rautenberger \& Bischof 2006). The compensatory effect may be due to high temperature being less damaging than lower temperatures, where the turnover and repair of D1, synthesis of pigments and enzymatic processes may be stimulated by increasing temperatures (Gómez et al. 2001, Cruces et al. 2013).

It is well known that the invasive $U$. pinnatifida has a wide range of thermotolerance (Skriptsova et al. 2004, Henkel \& Hofmann 2008); but there is a lack of knowledge of the effect of the interaction of this factor with other stressors. Therefore, this thesis evaluated the possible effect of UVB and temperature together on this invasive species for first time. As noted earlier, early life stages of $U$. pinnatifida are vulnerable to UVB. Therefore, due to it's the wide thermotolerance, I expected temperature would ameliorate the effect of UVB in early life stages of $U$. pinnatifida as described above for Ulva (Rauternberger et al. 2006). Surprisingly, there was no evidence of an interactive effect of light treatments and temperature on early life stages of $U$. pinnatifida. The photosynthetic capacity of zoospores was similar among temperatures at longer term recovery. Only settlement of $U$. pinnatifida was negatively affected by an increase of temperature in zoospores exposed to PA and PAB treatments (Chapter 3). An increase of water temperature might affect the potential of $U$. pinnatifida to spread to warmer areas in intertidal areas where UVA and UVB irradiances exists but it could lead introductions to happen in the subtidal where UV component of light is attenuated (Huovinen \& Gomez 2011). 
I also expected that temperature would reduce the effect of UVB on sporophytes of $U$. pinnatifida. Although, sporophytes of $U$. pinnatifida (Chapter 4) were affected by a complex interaction between light treatments, temperature and exposure, a beneficial effect of temperature after UVB exposure in sporophytes was not detected. This contrast with the results in early life stages (Chapter 3) that temperature lead similar recovery at the long term. This shows that the effect of environmental factors in $U$. pinnatifida is stage specific as it has been observed for other species (Fredersdorf et al. 2009). The physiological response of sporophytes to light treatments varied among temperatures and during exposures. Although there was no a clear pattern in the response of sporophytes to higher temperature, those individuals exposed to P and PA were little affected, while the addition of UVB had a strongly negative effect on the $F_{v} / F_{m}$, ETR and NQP of sporophytes. It has been suggested that the sensitivity of seaweeds to UVB increases as temperatures deviates from the optimum growth temperatures (Fredersdorf et al. 2009). In Chapter 4 the sensitivity of sporophytes of $U$. pinnatifida increases gradually as temperature recedes from the optimum temperature of $\sim 20$ ${ }^{\circ} \mathrm{C}$ (Morita et al. 2003) where the photosynthetic capacity was lower at the highest and lower temperature $\left(18\right.$ and $\left.22^{\circ} \mathrm{C}\right)$.

In Chapter 4, I showed that phlorotannins content was higher for sporophytes of $U$. pinnatifida incubated at higher water temperatures. It has been suggested that elevated temperature might affect the Golgi-ER membrane complex, which is likely to be responsible for the biosynthesis of SPs (Cruces et al. 2013) and phlorotannins production might be inhibited with temperatures over $20^{\circ} \mathrm{C}$ (Cruces et al. 2012). The higher phlorotannins content at higher temperature in $U$. pinnatifida suggests that physiological processes are not affected by the temperatures used in this thesis and even might stimulate phlorotannins production. Perhaps, phlorotannins production in $U$. pinnatifida might be stimulated by higher temperatures or the degradation of phlorotannins may be slower at higher temperatures contrasting with other Laminariales species (Cruces et al. 2012). Higher phlorotannins content at higher temperatures could be advantageous for this species since phlorotannins have multi protective roles such as wound healing and anti-grazer function (Lüder \& Clayton 2004, Halm et al. 2011).

The effect of rapid environmental changes on invasive species is unknown. Speculation regarding the possible outcomes is highly variable. Some authors suggest that invasive species might be favoured by climate change due to their plasticity leading to increased change in the structure and composition of native communities (Dukes \& Mooney 1999, Vilà, et al. 2007), 
while others are more sceptical and suggest invasive species might diminish under climate change (Hellmann et al 2008). For U. pinnatifida, an increase of water temperature due to climate change might have little effect due to its wide thermotolerance. This species grew well in temperatures $\sim 21{ }^{\circ} \mathrm{C}$ and it physiological response were not altered, thus $U$. pinnatifida would have the potential to maintain populations were already exist and even the potential to spread to lower latitudes with the expected increase of water temperatures due to global warming. $U$. pinnatifida is a very plastic species that can inhabit a wide range of environments (Wotton et al. 2004). If UVB remains stable in the future, the wide thermotolerance of $U$. pinnatifida could lead this species to respond favourably with the expected increase of water temperatures.

\section{Physiological seasonality}

Seasonal variability in the physiological performance of seaweeds from temperate and polar areas is well documented (Lüning 1993, Plouguerné et al 2006, Sampath-Wiley et al. 2008, Buschmann et al. 2014). Seaweeds have a seasonal development controlled by environmental signals e.g. photoperiod and temperature cycles (Lüning 1989, Müller et al. 2009). It has also been suggested that annual species have highly efficient abilities to physiologically adjust to seasonal variations of UVB, permitting them to acclimate rapidly (Huovinen et al. 2006, Buschmann et al. 2014). I expected that $U$. pinnatifida as an annual species would acclimates rapidly to variations of light. Chapter 5 showed that the photosynthetic capacity and phlorotannins content of $U$. pinnatifida vary seasonally. Photosynthetic capacity decreased as PAR and UVB increased in the field and this response was similar to other studies in the same species (Dean \& Hurd 2007). The seasonal response of the photosynthetic capacity of $U$. pinnatifida shows this species can rapidly acclimate to light conditions. U. pinnatifida has higher photosynthetic capacity than other Laminariales species in Winter when it is at its growth peak (Campbell et al. 1999). Although growth rates of $U$. pinnatifida were not quantified, I observed that the major period of growth of juveniles sporophytes occurs in the field between July and August (Chapter 5) and this is consistent with other studies in $U$. pinnatifida (Christian 2003,Yoshikawa et al. 2001, Dean \& Hurd 2007). Physiological adaptation of $U$. pinnatifida to low light and growth during winter are strategies that allow this species to compete effectively with other macroalgae (Campbell et al. 1999). 
Seasonality of phlorotannin content has been observed in brown seaweeds with increasing phlorotannins content as light irradiances increased (Abdala-Díaz et al 2006,Steingber 1995, Connan et al. 2004, Plouguerné et al. 2006, Celis-Plá et al. 2014). Also daily variation of phlorotannins content (Abdala-Díaz et al 2006, Connan et al. 2007, Rautenberger et al. 2013) and a rapid biosynthesis (within hours) after exposure to a stimulators (UVB or herbivory) has been documented (Arnold \& Targett 1998, Swanson \& Druehl 2002). I expected that the phlorotannin content of sporophytes of $U$. pinnatifida would change seasonally as a mechanism to protect themselves from the seasonal changes in UVB doses. The concentrations of SPs and CWPs varied thorough the year in sporophytes of $U$. pinnatifida (Chapter 5) and SPs presented interannual variation. The concentration of SPs increased toward Spring and Summer; while CWPs were higher in Winter and Spring. Although SPs show a seasonal response in $U$. pinatiffida, no correlation between phlorotannins and PAR or UVB level was detected (Chapter 5) contrasting with the possible photoprotective role observed in other brown seaweeds (Pavia et al. 1997, Henry \& Van Alstyne 2004, Swanson \& Druehl 2002, Halm et al. 2011, Schmidt et al. 2012, Figueroa et al. 2014). These results are consistent with those from Chapter 4 where light treatments also did not stimulate phlorotannins production; although in Chapter 4 only SPs were measured. Due to the minor variation of CWPs in Chapter 5 I would expect little variation of this phlorotannin in laboratory experiments similar to those in Chapter 4.

Variation of phlorotannins content throughout the year might be related to factors other than light. The lower difference between SPs and CWPs and the highest CWPs concentration was observed in Winter and Spring respectively when U. pinnatifida has its highest growth (Stuart et al.1999, Christian 2003). This differences and the higher CWPs in Spring might be due to SPs bind into the cell wall to thicken during growth (Arnold \& Targett 2000) as mechanism of protection from grazers, and the decrease of CWPs in Summer might be due to turnover to other cell wall compounds or degradation (Koivikko et al. 2005). Thus, U. pinnatifida allocates phlorotannins to their thick cell walls probably as a strategy of protection against grazing more than for photoprotection as has been described for other brown seaweeds (Steingber et al. 1995, Halm et al. 2011, Schmidt et al. 2012). 


\subsection{Conclusion and predictions}

The data presented in this thesis contribute to a better understanding of the tolerance of different life stages of $U$. pinnatifida to environmental stressors. It has given insights into the capacity and success of this species to grow in the intertidal where high variation of environmental conditions exists, for example light and temperature. Additionally, the results give a better understanding of the effect of two environmental factors on seaweeds and gives, in part, insights into the possible effect of global warming on this invasive kelp.

There are few studies of physiological acclimation and tolerance of invasive species in general to environmental changes. Greater physiological acclimation and tolerance to environmental changes might favour invasive species during climate change. However, as it was mentioned above controversial opinions exist in how invasive species would be affected by climate change. As far as I know this is the first attempt to determine the tolerance of UVB alone and combined with temperature in the invasive $U$. pinnatifida. In this thesis I observed sensitivity of $U$. pinnatifida to exposure to UVB, and tolerance to wide ranges of light and temperature. Early life stages can recover from UVB stress, while no recovery was observed in sporophytes. The capacity of recovery of early life stages and the tolerance to wide range of environmental conditions of this species makes this species to success in the areas where it has been introduced. These characteristics permit $U$. pinnatifida to grow from the intertidal where light conditions are intense but also in the subtidal where light conditions are low (Hay \& Luckens 1987, Casas \& Piriz 1996). If UVB increases again due to changes in the ozone layer $U$. pinnatifida, may still be able to grow viable populations by adjusting its vertical distributions to the light conditions. Under warming conditions, $U$. pinnatifida would be little affected by the expected increase of water temperatures. The little effect of increasing temperatures on $U$. pinnatifida showed in this study and its wide thermotolerance between 0 $27^{\circ} \mathrm{C}$ (Skriptsova et al. 2004) could lead this species to be successful under future global warming conditions and increase the potential of this species to invade other areas at higher latitudes but also to maintain populations where they already exists. The possible success of $U$. pinnatifida would agree with the supposition that climate change might favour introductions of invasive species (Dukes \& Mooney 1999, Vilà, et al. 2007, Schiel \& Thompson 2012).

U. pinnatifida is able to adjust its growth pattern to local environmental conditions, for example it is reproductive in Winter and Spring in its native environment (Campbell \& 
Burridge 1998, Yoshikawa et al. 2001), while in New Zealand, U. pinnatifida has year around successive generations (Hay 1990, Campbell \& Burridge 1998, Schiel et al. 2012, Gao et al. 2013). U. pinnatifida grows faster in Winter and early Spring than Autumn and Summer (Christian 2003) and maturity is rapidly reached due to its fast growth rate (Christian 2003); this species might release zoospores mainly in late Winter and Spring where light conditions are medium/low, decreasing the potential of light and UVB stress and increasing their capacity to survive and form viable populations. Although successive generations of sporophytes are observed in New Zealand throughout the year, I observed more viable zoospores in Winter/Spring than Summer (data not shown). Furthermore, their capacity for fast recovery after light stress could increase the survival of late recruits. Additionally, the seasonal physiological pattern shows this species can acclimate to the environmental conditions and allocate resources depending on its requirement for growth. Finally, the combination of all these characteristics makes $U$. pinnatifida a highly plastic species that might persist and even be favoured by environmental changes.

It is well known that $U$. pinnatifida is one if the world's 100 most invasive species (Lowe $e t$ al. 2000), and it is now present in many temperate coastal environments worldwide (Hay \& Luckens 1987, Floc'h et al. 1991, Piriz \& Casas 1994, Curiel et al. 1998, Silva et al. 2002, Aguilar-Rosas et al. 2004). This species has considerable commercial value and is cultivated in several countries including China, Japan, and Korea (Castric-Fey et al. 1999, Peteiro \& Freire 2012). Thus, aquaculture is likely to be an important avenue for dispersal and invasion (Floc'h et al. 1991). The success of $U$. pinnatifida in colonizing new environments is associated not only with its high physiological and morphological plasticity (Dean \& Hurd 2007), but also with its fast growth, high reproductive rate, and rapid maturation (Stuart 2004, Casas et al. 2004). Research on this species in New Zealand has focused mainly on its natural spread (Forrest et al. 2000), its physiology (Dean \& Hurd 2007, Richards et al. 2011) and its colonisation patterns (Hay \& Sanderson 1999, Forrest a\& Taylor 2002, Raffo et al. 2009, Schiel \& Thompson 2012). Prior to the present study, the tolerance of $U$. pinnatifida to environmental changes has been poorly explored, even though these may lead to further invasive success under climate change, as seen in other invasive species (Walther et al. 2009, Bellard et al. 2013, Ware et al. 2014).

There is lack of knowledge of the susceptibility of different life stages of $U$. pinnatifida to environmental stressors; moreover most of the studies have been centred on single life stages, 
particularly the sporophyte stage. This study shows for the first time, that the susceptibility of $U$. pinnatifida to environmental changes is life-stage specific and depends also on the type of stressor. Microscopic life stages such zoospores and gametophytes are more sensitive to UVB, tolerating lower UVB irradiances than sporophytes. However, both microscopic life stages and sporophytes tolerate a wide range of temperature. This tolerance might lead to the spread of this species to warmer areas, and under climate change to lower latitudes due to an increase of water temperature. Additionally, this study shows that there is not an interactive effect of both factors (UVB and temperature) on $U$. pinnatifida as observed in other Laminariales species. Therefore, the effect of UVB on $U$. pinnatifida is unlikely to be aggravated or mitigated by an increase of temperature due to climate change. The photoprotective role of phlorotannins has never been studied for $U$. pinnatifida; but it has been observed in several species of brown seaweeds. This study shows a lack of photoprotective capacity of phlorotannins in $U$. pinnatifida. Thus, $U$. pinnatifida might have different strategies to cope with stressors such as UVB. For example, early life stages might inhabit areas that are protected from direct natural light such as under other algae canopies, or in the subtidal and areas of the rocky intertidal; while sporophytes might direct their energy to growth and rapid reproduction instead to photoprotection. Thus, it is worth highlighting that the invasiveness of $U$. pinnatifida might be due to a suite of characteristics rather than one unique or individual characteristic. Its capacity to tolerate a wide range of temperature and a wide range of light conditions, its capacity to adjust its reproduction and physiology to the environmental conditions, and its different strategies to cope with stresses increases the capacity of this species to invade areas where it has been introduced. Under future climate change scenarios, These characteristics widen the range of possible areas where $U$. pinnatifida can develop, increasing its invasiveness capacity. Other critical stages of the U. pinnatifida life cycle that have not been addressed in this study, such zoospore settlement and sexual reproduction, should also be investigated to gain a better understanding of the success of this species under future climates.

\subsection{Limitations}

It is important to acknowledge the inevitable limitations of research. In this study, it was not possible to exactly replicate natural light conditions in the laboratory. For example, there were 
lower levels of PAR compared to those measured in the field at the water surface (Chapter 5), although they were similar to those found in the subtidal of Wellington coast (Morelissen et al. 2013). Low PAR level is a common problem in laboratory experiments and has often addressed by other researches (Karsten et al. 2003, Wiencke et al. 2004). PAR levels in laboratory experiments lead to higher UVR/PAR ratios than environmental light (Roleda et al. 2005). Higher ratios of UVB/PAR intensify the UVB effect on plants (Caldwell et al. 1998) and this may magnify the UVB effect on seaweeds (Dring et al. 1996, Roleda et al. 2005, Roleda et al. 2007). Despite this limitation, laboratory experiments give good insights into the possible effect of UVB on seaweeds. Moreover, field experiments are often difficult to manage due to the wide range of other factors involved that might interact or obscure the effect of interest on the focal organism.

Another limitation of this thesis was the lack of UVA in the experiments from Chapter 2. The lack of UVA in Chapter 2 might have little implication for those experiments since in Chapter 3 UVA has a minor effect on early life stages. In general, studies shows a minimum effect of UVA in seaweeds (Dring et al. 1996, Wiencke et al. 2000, Figueroa et al. 2003), and UVA might have compensatory effect for some seaweeds when PAR condition are low (PérezRodríguez et al. 1998, Ahamad 2010, Xu \& Gao 2010) or even have beneficial effects (Santas et al. 1998). In this thesis a minor effect of UVA on the different life stages of $U$. pinnatifida was detected and there was no evidence of a compensatory neither a negative effect of UVA for U. pinnatifida.

Another limitation of this study was the physiological variability from batch to batch of zoospores and sporophytes. The difference in the germination rate between Chapter 2 (late Winter and Spring) and Chapter 3 (early Winter) and differences in the physiological response of sporophytes between experiments in Chapter 4 are likely due to seasonal variation. Wiencke et al. $(2004,2007)$ also found differences in the rates of germination of Alaria esculenta and related this variation to different collection times. The variation between batches throughout suggests that the tolerance of $U$. pinnatifida also depends on the physiological stages of each the life stage and it is related to seasonality. By contrast, in the seasonal chapter (Chapter 5), the main limitation was the high variability of the light conditions in the field, which can affect sensitive physiological parameters such as photosynthesis. Even though I coordinated the sampling days to the same hour and same tide for each month and as far as possible maintained similar climatic conditions (clear sky), sometimes clear sky conditions did 
not occur for all the sampling days. This led to some variability that might mask some trends of this study.

\subsection{Future directions}

Further research is needed to understand the success of $U$. pinnatifida colonizing new environments and also to predict the possible impact of predicted environmental changes in this species. In this thesis I have investigated the tolerance of zoospores and sporophytes to UVB and the combination of UVB with temperature. However, there are still further questions to answer that have arisen in these experiments.

The tolerance of gametophytes, gamete formation and sexual reproduction under environmental stressors remain unstudied for $U$. pinnatifida. Since sensitivity to environmental factors is stage specific (Coelho et al. 2000), future research should consider these steps of the life cycle of $U$. pinnatifida to predict and understand more accurately the effect of environmental changes. Although in this thesis I tried to cover as much of the life cycle of $U$. pinnatifida as possible, some steps such as zoospores and gametes production and juvenile's sporophytes were not studied. The success of any species depends on the capacity of each life stage to acclimate and adapt to their environment. The failure of a single stage could have profound repercussions on the capacity of species to maintain viable populations.

The response of $U$. pinnatifida to environmental conditions in the field environment might vary from laboratory experiments as has been observed in other Laminariales species (Wiencke et al. 2004). Moreover, natural conditions are difficult to replicate in laboratories (Karsten et al. 2003, Wiencke et al. 2004). Therefore, to determine the tolerance of $U$. pinnatifida to environmental conditions more accurately, field experiments need to be considered.

Environmental changes occur simultaneously; therefore, future research should continue to focus on the effect of combined stressors. The interaction of more than two factors can have antagonist or synergistic effects as has been observed for other brown seaweeds (Altamirano et al. 2003, Rautenberger \& Bischof 2006, Steinhoff et al. 2008, Fredersdorf et al. 2009). Other factors are also expected to change due to climate change and anthropogenic activity such as 
$\mathrm{pH}$, nutrients and heavy metals. Therefore, the interaction of these factors should also be evaluated.

The length of experiments is generally short and addresses single life stages. For organisms with complex life cycles such as seaweeds, environmental effects at one life stage might have consequences for the subsequent development of later phases. Furthermore, the effect of environmental factors of one generation might influence the following generations. However, the maternal effect to the subsequent generations or life stages have not been evaluated in seaweeds as far as I know, although they have in other organisms (Pahkala et al. 2001, Burdge et al. 2007, Dunn \& Bale 2011). Therefore, research in the effect of stressor on successive generations should also be studied. 


\subsection{References}

Abdala-Díaz, R. T., Cabello-Pasini, A., Pérez-Rodríguez, E., Álvarez, R. C., \& Figueroa, F. L. (2006). Daily and seasonal variations of optimum quantum yield and phenolic compounds in Cystoseira tamariscifolia (Phaeophyta). Marine Biology, 148(3), 459-465

Aguilar-Rosas, R., L.E. Aguilar-Rosas, G. Ávila-Serrano, \& R. Marcos-Ramírez (2004) First record of Undaria pinnatifida (Harvey) Suringar (Laminariales, Phaeophyta) on the Pacific coast of Mexico. Botanica Marina 47:255-258.

Ahamad Z., H. (2010). Effects of PAR and high UVR on enzymes and other proteins involved in the function and protection of the photosynthetic apparatus of marine macroalgae.

Alongi, D. M. (2008). Mangrove forests: resilience, protection from tsunamis, and responses to global climate change. Estuarine, Coastal and Shelf Science. 76(1): 1-13.

Altamirano, M., Flores-Moya, A. \& Figueroa, F. (2003) Altamirano, M., Flores-Moya, A., \& Figueroa, F. L. (2003). Effects of UV radiation and temperature on growth of germlings of three species of Fucus (Phaeophyceae). Aquatic Botany. 75(1): 9-20

Arnold, T. M. \& Targett, N. M. (1998). Quantifying in situ rates of phlorotannin synthesis and polymerization in marine brown algae. Journal of Chemical Ecology. 24(3): 577-595.

Arnold, T. M. \& Targett, N. M. (2000). Evidence for metabolic turnover of polyphenolics in tropical brown algae. Journal of chemical ecology. 26(6): 1393-1410.

Bellard, C., W. Thuiller, B. Leroy, P. Genovesi, M. Bakkenes, \& F. Courchamp. (2013) Will climate change promote future invasions? Global Change Biology 19:3740-3748.

Bischof, K. \& Steinhoff, F. S. (2012). Impacts of stratospheric ozone depletion and solar UVB radiation on seaweeds. In Seaweed Biology (pp. 433-448). Springer Berlin Heidelberg.

Burdge, G. C., Slater-Jefferies, J., Torrens, C., Phillips, E. S., Hanson, M. A. \& Lillycrop, K. A. (2007). Dietary protein restriction of pregnant rats in the F0 generation induces altered methylation of hepatic gene promoters in the adult male offspring in the F1 and F2 generations. British Journal of Nutrition. 97(03): 435-439.

Buschmann, A. H., Pereda, S. V., Varela, D. A., Rodríguez-Maulén, J., López, A., González-Carvajal, L., ... \& Hernández-González, M. C. (2014). Ecophysiological plasticity of annual populations of giant kelp (Macrocystis pyrifera) in a seasonally variable coastal environment in the Northern Patagonian Inner Seas of Southern Chile. Journal of Applied Phycology. 26(2): 837-847. 
Cadet, J., Sage, E. \& Douki, T. (2005). Ultraviolet radiation-mediated damage to cellular DNA. Mutation Research/Fundamental and Molecular Mechanisms of Mutagenesis. 571(1): 3-17.

Campbell, S. J., Bite, J. S., \& Burridge, T. R. (1999). Seasonal patterns in the photosynthetic capacity, tissue pigment and nutrient content of different developmental stages of Undaria pinnatifida (Phaeophyta: Laminariales) in Port Phillip Bay, South-Eastern Australia. Botanica Marina, 42(3), 231-242.

Campbell, S. J. \& Burridge, T. R. (1998). Occurrence of Undaria pinnatifida (Phaeophyta: Laminariales) in Port Phillip Bay, Victoria, Australia. Marine and Freshwater Research. 49(5): 379-381.

Casas, G. N. \& Piriz, M. L. (1996). Surveys of Undaria pinnatifida (Laminariales, Phaeophyta) in Golfo Nuevo, Argentina. Hydrobiologia. 326(1): 213-215.

Casas, G., Scrosati, R. \& Piriz, M. L. (2004). The invasive kelp Undaria pinnatifida (Phaeophyceae, Laminariales) reduces native seaweed diversity in Nuevo Gulf (Patagonia, Argentina). Biological Invasions. 6(4): 411-416.

Castric-Fey, A., C. Beaupoil, J. Bouchain, E.Pradier, \&M.T. L'Hardy-Halos (1999) The introduced alga Undaria pinnatifida (Laminariales, Alariaceae) in the rocky shore ecosystem of the St Malo area: morphology and growth of the sporophyte. Botanica Marina 42:71-82.

Celis-Plá, P. S., Korbee, N., Gómez-Garreta, A. \& Figueroa, F. L. (2014). Seasonal photoacclimation patterns in the intertidal macroalga Cystoseira tamariscifolia (Ochrophyta). Scientia Marina. 78(3): 377-388.

Chen, W. W. (2012). Distribution, abundance and reproduction of Undaria pinnatifida (Harvey) Suringar from the Marlborough Sounds, New Zealand (Doctoral dissertation, Auckland University of Technology).

Christian S.J. (2003) Growth, Longevity and Density of the Adventive Asian Kelp Undaria Pinnatifida from the Intertidal Zone in Wellington Harbour and South Coast. Victoria University of Wellington.

Coelho, S.M., Rijstenbil, J. W. \& Brown, M. T. (2000) Impacts of anthropogenic stresses on the early development stages of seaweeds. Journal of Aquatic Ecosystem Stress and Recovery. 7(4): 317-333.

Cockel, C. \& Knowland, J. (1999) Ultraviolet radiation screening compounds. Biological Reviews, 94(3): 311-345. 
Connan, S., Deslandes, E. \& Gall, E. A. (2007). Influence of day-night and tidal cycles on phenol content and antioxidant capacity in three temperate intertidal brown seaweeds. Journal of experimental marine biology and ecology. 349(2): 359-369.

Connan, S., Goulard, F., Stiger, V., Deslandes, E., \& Ar Gall, E. (2004). Interspecific and temporal variation in phlorotannin levels in an assemblage of brown algae. Botanica Marina, 47(5), 410-416.

Crain, C. M., Kroeker, K. \& Halpern, B. S. (2008). Interactive and cumulative effects of multiple human stressors in marine systems. Ecology letters. 11(12): 1304-1315.

Cruces, E., Huovinen, P. \& Gomez, I. (2012) Interactive effects of UV radiation and enhanced temperature on photosynthesis, phlorotannin induction and antioxidant activities of two subAntarctic brown algae. Marine Biology. 160(1): 1-13.

Curiel, D., Bellemo, G., Marzocchi, M., Scattolin, M. \& Parisi, G. (1998). Distribution of introduced Japanese macroalgae Undaria pinnatifida, Sargassum muticum (Phaeophyta) and Antithamnion pectinatum (Rhodophyta) in the Lagoon of Venice. Hydrobiologia. 385(1-3): $17-22$.

Dean, P. R. \& Hurd, C. L. (2007). Seasonal growth, erosion rates, and nitrogen and photosynthetic ecophysiology of Undaria pinnatifida (Heterokontophyta) in southern New Zealand1. Journal of Phycology. 43(6):1138-1148.

de la Coba, F., Aguilera, J., Figueroa, F. L., De Gálvez, M. V., \& Herrera, E. (2009). Antioxidant activity of mycosporine-like amino acids isolated from three red macroalgae and one marine lichen. Journal of applied phycology. 21(2): 161-169.

Dinant, C, Houtsmuller, A. B. \& Vermeulen, W. (2008) Chromatin structure and DNA damage repair. Epigenetics \& Chromatin, 1(1): 9.

Dring, M. J., Wagner, A., Boeskov, J. \& Lüning, K. (1996). Sensitivity of intertidal and subtidal red algae to UVA and UVB radiation, as monitored by chlorophyll fluorescence measurements: influence of collection depth and season, and length of irradiation. European Journal of Phycology. 31(4): 293-302.

Dukes, J. \& Mooney, H. (1999) Does global change increase the success of biological success. Trends in Ecology and Evolution. 14(4):135-139.

Dunn, G. A. \& Bale, T. L. (2011). Maternal high-fat diet effects on third-generation female body size via the paternal lineage. Endocrinology. 152(6): 2228-2236. 
Figueroa, F. L., Nygård, C., Ekelund, N. \& Gómez, I. (2003). Photobiological characteristics and photosynthetic UV responses in two Ulva species (Chlorophyta) from southern Spain. Journal of Photochemistry and Photobiology B: Biology. 72(1): 35-44.

Figueroa, F. L., Domínguez-González, B. \& Korbee, N. (2014). Vulnerability and acclimation to increased UVB radiation in three intertidal macroalgae of different morpho-functional groups. Marine environmental research. 97: 30-38.

Floc'h, J.Y., R. Pajot, \& I. Wallentinus (1991) The Japanese brown alga Undaria pinnatifida on the coast of France and its possible establishment in European waters. Journal du Conseil International pour l'Exploration de la Mer 47:379-390.

Forrest, B.M., S.N. Brown, M.D. Taylor, \& C.L. Hurd (2000) The role of natural dispersal mechanisms in the spread of Undaria pinnatifida (Laminariales, Phaeophycea). Phycology 39:547-553.

Forrest, B.M., \& M.D. Taylor (2002) Assessing invasion impact : survey design considerations and implications for management of an invasive marine plant. Biological Invasions 4:375-386.

Fredersdorf, J., Müller, R., Becker, S., Wiencke, C. \& Bischof, K. (2009) Interactive effects of radiation, temperature and salinity on different life history stages of the Arctic kelp Alaria esculenta (Phaeophyceae). Oecologia. 160(3):483-492.

Gao, X., Endo, H., Taniguchi, K. \& Agatsuma, Y. (2013). Genetic differentiation of high-temperature tolerance in the kelp Undaria pinnatifida sporophytes from geographically separated populations along the Pacific coast of Japan. Journal of Applied Phycology. 25(2): 567-574.

Gómez, I., Figueroa, F. L., Sousa-Pinto, I., Viñegla, B., Pérez-Rodríguez, E., et al. (2001). Effects of UV radiation and temperature on photosynthesis as measured by PAM fluorescence in the red alga Gelidium pulchellum (Turner) Kützing. Botanica Marina. 44(1): 9-16.

Häder, D. P., Kumar, H. D., Smith, R. C., \& Worrest, R. C. (2007). Effects of solar UV radiation on aquatic ecosystems and interactions with climate change. Photochemical \& Photobiological Sciences. 6(3): 267-285.

Häder, D. P., Williamson, C. E., Wängberg, S. Å., Rautio, M., Rose, K. C., Gao, K., ... \& Worrest, R. (2015). Effects of UV radiation on aquatic ecosystems and interactions with other environmental factors. Photochemical \& Photobiological Sciences, 14(1), 108-126.

Halm, H., Lüder, U. H. \& Wiencke, C. (2011). Induction of phlorotannins through mechanical wounding and radiation conditions in the brown macroalga Laminaria hyperborea. European Journal of Phycology. 46(1):16-26. 
Harada, H., Vila-Costa, M., Cebrian, J. \& Kiene, R. P. (2009). Effects of UV radiation and nitrate limitation on the production of biogenic sulfur compounds by marine phytoplankton. Aquatic Botany. 90(1): 37-42.

Hay, C. H. \& Luckens, P. A. (1987). The Asian kelp Undaria pinnatifida (Phaeophyta: Laminariales) found in a New Zealand harbour. New Zealand journal of Botany. 25(2): 329-332.

Hay, C. H. (1990). The dispersal of sporophytes of Undaria pinnatifida by coastal shipping in New Zealand, and implications for further dispersal of Undaria in France. British phycological journal. 25(4): 301-313.

Hay, C. H. \& Villouta, E. (1993) Seasonality of the adventive Asian kelp Undaria pinnatifida in New Zealand. Botanica marina. 36(5):461-476.

Hay, C.H., \& J.C. Sanderson (1999) Dispersal of the Asian kelp Undaria in Australasia. In: Islands in the Pacific Century. Pacific Science Inter-Congress, 13-19 July 1998, The University of the South Pacific, Suva, Fiji Islands.

Hellmann, J. J., Byers, J. E., Bierwagen, B. G. \& Dukes, J. S. (2008). Five potential consequences of climate change for invasive species. Conservation Biology, 22(3), 534-543.

Henkel, S. \& Hofmann, G. (2008) Thermal ecophysiology of gametophytes cultured from invasive Undaria pinnatifida (Harvey) Suringar in coastal California harbours. Journal of Experimental Marine Biology and Ecology. 367(2): 164-173.

Henry, B. E., \& Van Alstyne, K. L. (2004). Effect of UV radiation on growth and phlorotannins in Fucus Gardneri (Phaeophyceae) juveniles and embryios1. Journal of Phycology, 40(3), 527533.

Hoegh-Guldberg, O., Mumby, P. J., Hooten, A. J., Steneck, R. S., Greenfield, P., et al. (2007). Coral reefs under rapid climate change and ocean acidification. Science. 318(5857): 1737-1742.

Hofmann, D. J. \& Montzka, S. A. (2009). Recovery of the ozone layer: The ozone depleting gas index. Eos, Transactions American Geophysical Union. 90(1): 1-2.

Hughes, T. P., Bellwood, D. R., Folke, C., Steneck, R. S. \& Wilson, J. (2005). New paradigms for supporting the resilience of marine ecosystems. Trends in ecology \& evolution. 20(7): 380386.

Huovinen, P., Gómez, I., \& Lovengreen, C. (2006). A Five-year Study of Solar Ultraviolet Radiation in Southern Chile (39 $\mathrm{S}$ ): Potential Impact on Physiology of Coastal Marine Algae?. Photochemistry and Photobiology, 82(2), 515-522. 
Huovinen, P. \& Gomez, I. (2011) Spectral attenuation of solar radiation in Patagonian fjord and coastal waters and implications for algal photobiology. Continental Shelf Research,. 31(3):254-259.

IPCC 2013 IPCC, 2013: Climate Change 2013: The Physical Science Basis. Contribution of Working Group I to the Fifth Assessment Report of the Intergovernmental Panel on Climate Change [Stocker, T. F., D. Qin, G.-K. Plattner, M. Tignor, S. K. Allen, J. Boschung, A. Nauels, Y. Xia, V. Bex and P. M. Midgley (eds.)]. Cambridge University Press, Cambridge, United Kingdom and New York, NY, USA. http://www.climatechange2013.org/images/report/WG1AR5_TS_FINAL.pdf

Kampa, M. \& Castanas, E. (2008). Human health effects of air pollution. Environmental pollution. 151(2): 362-367.

Karsten, U., Dummermuth, A., Hoyer, K. \& Wiencke, C. (2003). Interactive effects of ultraviolet radiation and salinity on the ecophysiology of two Arctic red algae from shallow waters. Polar Biology. 26(4): 249-258.

Key, T., McCarthy, A., Campbell, D. A., Six, C., Roy, S. \& Finkel, Z. V. (2010). Cell size trade-offs govern light exploitation strategies in marine phytoplankton. Environmental microbiology. 12(1): 95-104.

Koivikko, R., Loponen, J., Honkanen, T. \& Jormalainen, V. (2005). Contents of soluble, cell-wallbound and exuded phlorotannins in the brown alga Fucus vesiculosus, with implications on their ecological functions. Journal of chemical ecology. 31(1):195-212.

Kottuparambil, S., Shin, W., Brown, M. T. \& Han, T. (2012). UV-B affects photosynthesis, ROS production and motility of the freshwater flagellate, Euglena agilis Carter. Aquatic Toxicology. 122: 206-213.

Lavaud, J. \& Goss, R. (2014). The peculiar features of non-photochemical fluorescence quenching in diatoms and brown algae. In Non-Photochemical Quenching and Energy Dissipation in Plants, Algae and Cyanobacteria (pp. 421-443). Springer Netherlands.

Lowe, S., Browne, M., Boudjelas, S. \& De Poorter, M. (2000). 100 of the world's worst invasive alien species: a selection from the global invasive species database (p. 12). Species Survival Commission, World Conservation Union (IUCN), Auckland, New Zealand: Invasive Species Specialist Group.

Lüder, U. H., \& Clayton, M. N. (2004). Induction of phlorotannins in the brown macroalga Ecklonia radiata (Laminariales, Phaeophyta) in response to simulated herbivory - the first microscopic study. Planta, 218(6), 928-937.

Lüning, K. (1989). Environmental triggers in algal seasonality. Botanica marina. 32(5): 389-398. 
Lüning, K. (1993, January). Environmental and internal control of seasonal growth in seaweeds. In Fourteenth International Seaweed Symposium (pp. 1-14). Springer Netherlands.

Morelissen, B. (2012). Ecological effects of Undaria pinnatifida (Harvey) Suringar and nutrientenrichment on intertidal assemblages in the Wellington region of New Zealand. Victoria University of Wellington.

Morelissen, B., Dudley, B. D., Geange, S. W. \& Phillips, N. E. (2013). Gametophyte reproduction and development of Undaria pinnatifida under varied nutrient and irradiance conditions. Journal of Experimental Marine Biology and Ecology. 448: 197-206.

Morita, T., Kurashima, A. \& Maegawa, M. (2003). Temperature requirements for the growth of young sporophytes of Undaria pinnatifida and Undaria undarioides (Laminariales, Phaeophyceae). Phycological Research. 51(4): 266-270

Müller, P., Li, X. P. \& Niyogi, K. K. (2001). Non-photochemical quenching. A response to excess light energy. Plant Physiology. 125(4): 1558-1566.

Müller, R., Laepple, T., Bartsch, I. \& Wiencke, C. (2009). Impact of oceanic warming on the distribution of seaweeds in polar and cold-temperate waters. Botanica Marina. 52(6): 617638.

Navarro, N. P., Mansilla, A. \& Plastino, E. M. (2010). Iridaea cordata (Gigartinales, Rhodophyta): responses to artificial UVB radiation. Journal of applied phycology. 22(4): 385-394.

Occhipinti-Ambrogi, A. \& Savini, D. (2003). Biological invasions as a component of global change in stressed marine ecosystems. Marine pollution bulletin. 46(5):542-551.

Pahkala, M., Laurila, A. \& Merilä, J. (2001). Carry-over effects of ultraviolet-B radiation on larval fitness in Rana temporaria. Proceedings of the Royal Society of London. Series B: Biological Sciences. 268(1477): 1699-1706.

Parmesan, C. (2006). Ecological and evolutionary responses to recent climate change. Annual Review of Ecology, Evolution, and Systematics, 637-669.

Pavia, H., Cervin, G., Lindgren, A. \& Åberg, P. (1997). Effects of UV-B radiation and simulated herbivory on phlorotannins in the brown alga Ascophyllum nodosum. Marine Ecology Progress Series. 157:139-146.

Pérez-Rodríguez, E., Gómez, I., Karsten, U., \& Figueroa, F. L. (1998). Effects of UV radiation on photosynthesis and excretion of UV-absorbing compounds of Dasycladus vermicularis (Dasycladales, Chlorophyta) from southern Spain. Phycologia, 37(5), 379-387. 
Pfeifer, G. P. \& Besaratinia, A. (2011). UV wavelength-dependent DNA damage and human nonmelanoma and melanoma skin cancer. Photochem. Photobiol. Sci. 11(1): 90-97.

Peteiro, C., \& O. Freire (2013) Epiphytism on blades of the edible kelps Undaria pinnatifida and Saccharina latissima farmed under different abiotic conditions. Journal of the World Aquaculture Society 44:706-715.

Piriz, M.L., \& G. Casas (1994) Occurrence of Undaria pinnatifida in Golfo Nuevo, Argentina. Applied Phycology Forum 10: 4.

Plouguerné, E., Le Lann, K., Connan, S., Jechoux, G., Deslandes, E. \& Stiger-Pouvreau, V. (2006). Spatial and seasonal variation in density, reproductive status, length and phenolic content of the invasive brown macroalga Sargassum muticum (Yendo) Fensholt along the coast of Western Brittany (France). Aquatic Botany. 85(4): 337-344.

Raffo, M.P., M.C. Eyras, \& O.O. Iribarne (2009) The invasion of Undaria pinnatifida to a Macrocystis pyrifera kelp in Patagonia (Argentina, south-west Atlantic). Journal of the Marine Biological Association of the United Kingdom 89:1571-1580.

Raniello, R., Lorenti, M., Brunet, C. \& Buia, M. (2004) Photosynthetic plasticity of an invasive variety of Caulerpa racemosa in a coastal Mediterranean area: light harvesting capacity and seasonal acclimation. Marine Ecology Progress Series, 271:113-120.

Rautenberger, R. \& Bischof, K. (2006). Impact of temperature on UV-susceptibility of two Ulva (Chlorophyta) species from Antarctic and Subantarctic regions. Polar Biology. 29(11): 988996.

Rautenberger, R., Wiencke, C. \& Bischof, K. (2013). Acclimation to UV radiation and antioxidative defence in the endemic Antarctic brown macroalga Desmarestia anceps along a depth gradient. Polar biology. 36(12): 1779-1789.

Richards, D., C. Hurd, D. Pritchard, S. Wing, and C. Hepburn (2011) Photosynthetic response of monospecific macroalgal stands to density. Aquatic Biology 13:41-49.

Rockström, J., Falkenmark, M., Karlberg, L., Hoff, H., Rost, S., \& Gerten, D. (2009). Future water availability for global food production: the potential of green water for increasing resilience to global change. Water Resources Research, 45(7).

Roleda, M., Wiencke, C., Hanelt, D., van de Poll, W. \& Gruber, A. (2005) Sensitivity of Lamminariales zoospores fro Helgoland (North Sea) to ultraviolet and photosynthetically 
active radiation: implications for depth distribution and seasonal reproduction. Plant, Cell \& Environment. 28(4):466-479.

Roleda, M., Wiencke, C., Hanelt, D. \& Bischof, K. (2007) Sensitivity of the Early Life Stages of Macroalgae from the Northern Hemisphere to Ultraviolet Radiation. Photochemistry and Photobiology, 83:851-862.

Roleda, M., Lüder, U. \& Wiencke, C. (2010) UV-susceptibility of zoospores of the brown macroalga Laminaria digitata from Spitsbergen. Polar Biology. 33:577-588.

Santas, R., Korda, A., Lianou, Ch. \& Santas, Ph. (1998). Community responses to UV radiation. I. Enhanced UVB effects on biomass and community structure of filamentous algal assemblages growing in a coral reef- mesocosm. Marine Biology. 131:153-162.

Sampath-Wiley, P., Neefus, C. D. \& Jahnke, L. S. (2008). Seasonal effects of sun exposure and emersion on intertidal seaweed physiology: Fluctuations in antioxidant contents, photosynthetic pigments and photosynthetic efficiency in the red alga Porphyra umbilicalis Kützing (Rhodophyta, Bangiales). Journal of experimental marine biology and ecology. 361(2): 83-91.

Schiel, D. R. (2009). Multiple Stressors and Disturbances. In Marine Hard Bottom Communities (pp. 281-294). Springer Berlin Heidelberg.

Schiel, D. R., \& Thompson, G. A. (2012). Demography and population biology of the invasive kelp Undaria pinnatifida on shallow reefs in southern New Zealand. Journal of Experimental Marine Biology and Ecology, 434, 25-33.

Schmidt, É. C., Pereira, B., dos Santos, R. W., Gouveia, C., Costa, G. B., Faria, G. S., et al. (2012). Responses of the macroalgae Hypnea musciformis after in vitro exposure to UV-B. Aquatic Botany. 100: 8-17.

Sheras, N. T. \& Ross, P. M. (2010) Toxic cascades: multiple anthropogenic stressors have complex and unanticipated interactive effects on temperate reefs. Ecology letters. 13: 1149-1159.

Silva, P.C., R.A. Woodfield, A.N. Cohen, L.H. Harris, \& J.H.R. Goddard. (2002). First report of the Asian kelp Undaria pinnatifida in the northeastern Pacific Ocean. Biological Invasions 4:333338.

Skriptsova, A., Khomenko, V. \& Isakov, V. (2004). Seasonal changes in growth rate, morphology and alginate content in Undaria pinnatifida at the northern limit in the Sea of Japan (Russia). Journal of applied phycology. 16(1): 17-21 
Steinhoff, F., Wiencke, C., Müller, R. \& Bischof, K. (2008) Effects of ultraviolet radiation and temperature on the ultrastructure of zoospores of the brown macroalga Laminaria hyperborea. Plant Biology, 10(3):388-397.

Steinberg, P. D. (1995). Seasonal variation in the relationship between growth rate and phlorotannin production in the kelp Ecklonia radiata. Oecologia. 102(2): 169-173.

Stuart, M. D., Hurd, C. L. \& Brown, M. T. (1999). Effects of seasonal growth rate on morphological variation of Undaria pinnatifida (Alariaceae, Phaeophyceae). In Sixteenth International Seaweed Symposium (pp. 191-199). Springer Netherlands.

Stuart, M. D. (2004). Review of research on Undaria pinnatifida in New Zealand and its potential impacts on the eastern coast of the South Island (p. 40). Wellington, New Zealand: Department of Conservation.

Swanson, A. K., \& Druehl, L. D. (2002). Induction, exudation and the UV protective role of kelp phlorotannins. Aquatic Botany, 73(3), 241-253.

Szabó, I., Bergantino, E. \& Giacometti, G. M. (2005). Light and oxygenic photosynthesis: energy dissipation as a protection mechanism against photo-oxidation. EMBO reports. 6(7): 629-634.

Tala, F., Veliz K., Gomez, I. \& Edding, M. (2007) Early life stages of the South Pacific kelps Lessonia nigrescens and Lessonia trabeculata (Laminariales, Phaeophyceae) show recovery capacity following exposure to UV radiation. Phycologia, 46(4): 467-470.

Veliz, K., Edding, M., Tala, F. \& Gomez, I. (2006) Effects of ultraviolet radiation on different life cycle stages of the south Pacific kelps, Lessonia nigrescens and Lessonia trabeculata (Laminariales, Phaeophyceae). Marine Biology, 149(5):1015-1024.

Vilà, M., Corbin, J. D., Dukes, J. S., Pino, J., \& Smith, S. D. (2007). Linking plant invasions to global environmental change. In Terrestrial ecosystems in a changing world (pp. 93-102). Springer Berlin Heidelberg.

Weatherhead, E. C. \& Andersen, S. B. (2006). The search for signs of recovery of the ozone layer. Nature. 441(7089), 39-45.

Walther, G. R., Post, E., Convey, P., Menzel, A., Parmesan, C., Beebee, T. J., et al.. (2002). Ecological responses to recent climate change. Nature. 416(6879):389-395.

Walther, G.R., A. Roques, P.E. Hulme, M.T. Sykes, P. Pysek, I. Kühn, M. Zobel, S. Bacher, Z. BottaDukát, H. Bugmann, B. Czúcz, J. Dauber, T. Hickler, V. Jarosík, M. Kenis, S. Klotz, D. Minchin, M. Moora, W. Nentwig, J. Ott, V.E. Panov, B. Reineking, C. Robinet, V. Semenchenko, W. Solarz, W. Thuiller, M. Vilà, K. Vohland, and J. Settele. (2009). Alien 
species in a warmer world: risks and opportunities. Trends in Ecology and Evolution 24:68693.

Ware, C., J. Berge, J.H. Sundet, J.B. Kirkpatrick, A.D.M. Coutts, A. Jelmert, S.M. Olsen, O. Floerl, M.S. Wisz, and I.G. Alsos. (2014). Climate change, non-indigenous species and shipping: assessing the risk of species introduction to a high-Arctic archipelago. Diversity and Distributions 20:10-19.

Wiencke, C., Gómez, I., Pakker, H., Flores-Moya, A., Altamirano, M., Hanelt, D., Bischof K. \& Figueroa, F. L. (2000). Impact of UV-radiation on viability, photosynthetic characteristics and DNA of brown algal zoospores: implications for depth zonation. Marine ecology. Progress series, 197, 217-229.

Wiencke, C., Clayton, M. \& Schoenwaelder, M. (2004) Sensitivity and acclimation to UV radiation of zoospores from five species of Laminariales from the Arctic. Marine Biology, 145(1):31-39.

Wiencke, C., Lüder, U. \& Roleda, M. (2007) Impact of ultraviolet radiation on physiology and development of zoospores of the brown alga Alaria esculenta from Spitsbergen. Physiologia Plantarum, 130(4):601-612.

Wotton, D. M., O'Brien, C., Stuart, M. D. \& Fergus, D. J. (2004). Eradication success down under: heat treatment of a sunken trawler to kill the invasive seaweed Undaria pinnatifida. Marine Pollution Bulletin. 49(9): 844-849.

Xu, J. \& Gao, K. (2010). Use of UV-A Energy for Photosynthesis in the Red Macroalga Gracilaria lemaneiformis. Photochemistry and photobiology. 86(3): 580-585.

Yamashita, N., Ishida, A., Kushima, H. \& Tanaka, N. (2000) Acclimation to sudden increase in light favoring an invasive over native trees in subtropical islands, Japan. Oecologia. 125(3):412419.

Yoshikawa, T., Takeuchi, I. \& Furuya, K. (2001). Active erosion of Undaria pinnatifida. Suringar (Laminariales, Phaeophyceae) mass-cultured in Otsuchi Bay in northeastern Japan. Journal of experimental marine biology and ecology. 266(1): 51-65. 